Augusto Andrade Pereira

\title{
Projeções futuras do oceano Atlântico Sudoeste em dois cenários de aquecimento global (Versão Corrigida)
}

Dissertação apresentada ao Instituto Oceanográfico da Universidade de São Paulo, como parte dos requisitos para obtenção do título de Mestre em Ciências, área de Oceanografia Física

Orientadora:

Profa Dra Ilana Wainer

S ̃̃ O P A U L O

2011 


\author{
Universidade de São Paulo \\ Instituto Oceanográfico
}

\title{
Projeções futuras do oceano Atlântico Sudoeste em dois cenários de aquecimento global
}

\author{
Augusto Andrade Pereira
}

Dissertação apresentada ao Instituto Oceanográfico da Universidade de São Paulo (após as correções sugeridas pela banca), como parte dos requisitos para obtenção do título de Mestre em Ciências, área de Oceanografia Física

Julgado em $\_/ \ldots$ por

Conceito

Prof.(a.) Dr.(a.)

Conceito

Prof.(a.) Dr.(a.)

Conceito 


\section{Sumário}

Resumo xiii

Abstract $\quad$ xiv

Lista de Acrônimos $\quad$ Xv

\begin{tabular}{lll}
\hline & Introdução & 1
\end{tabular}

1.1 Preâmbulo . . . . . . . . . . . . . . . . . . . . . . . . . . . . . . . 1

1.2 Mudanças Climáticas no Antropoceno e a Importância dos Oceanos . . . . 3

$1.3 \quad$ O Atlântico Sul e sua importância . . . . . . . . . . . . . . . . . . . . . . . 8

1.4 Área de Estudo . . . . . . . . . . . . . . . . . . . . . . . . . 9 9

$1.4 .1 \quad$ A Corrente do Brasil . . . . . . . . . . . . . . . . . . 12

$1.4 .2 \quad$ A Corrente das Malvinas . . . . . . . . . . . . . . . . . . . . . . 13

1.4.3 A Confluência Brasil Malvinas . . . . . . . . . . . . . . . . . . . . 14

1.5 Motivação . . . . . . . . . . . . . . . . . . . . . . . . 18

1.6 Hipótese Científica $\ldots \ldots \ldots \ldots$

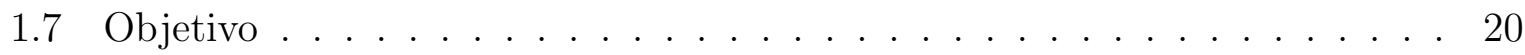

1.7.1 Objetivos Específicos . . . . . . . . . . . . . . . . 20

\begin{tabular}{lll}
\hline 2 & Materiais e Métodos & 21
\end{tabular}

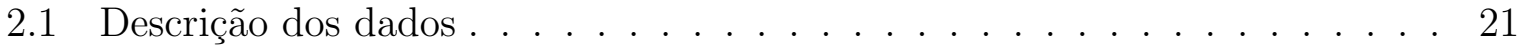

2.1 .1 As simulações numéricas do IPCC . . . . . . . . . . . . . . . 21

$2.1 .2 \quad$ Os dados de Reanálise do Simple Ocean Data Assimilation . . . . 24

2.2 Etapas de Trabalho . . . . . . . . . . . . . . . . . . . . . 25

2.2.1 Comparação dos Modelos no século XX e Determinação da melhor representação do Atlântico Sudoeste . . . . . . . . . . . . . . . . . 25

2.2 .2 Análise dos Resultados para as Projeções Climáticas . . . . . . . . 26

2.3 Descrição das Ferramentas Estatísticas Utilizadas . . . . . . . . . . . . . . 26

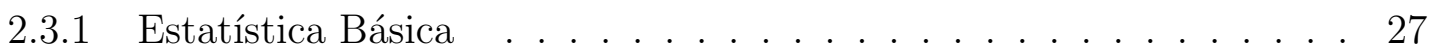

$2.3 .2 \quad$ Análise Espectral de Ondaletas . . . . . . . . . . . . . . . . . 28

$2.3 .3 \quad$ Definições e Cálculos Utilizados . . . . . . . . . . . . . . . . . . . . . . . 29

2.3 .4 Diagrama de Taylor . . . . . . . . . . . . . . . . . . . 30 
\begin{tabular}{lll}
\hline 3 & Resultados & 32
\end{tabular}

3.1 Escolha do modelo numérico mais adequado à região . . . . . . . . . . . . 32

$3.1 .1 \quad$ Padrão espacial médio . . . . . . . . . . . . . . . . . . . . 33

3.1.2 Diferença entre o padrão espacial médio do SODA e dos modelos. . 54

3.1 .3 Variabilidade Sazonal . . . . . . . . . . . . . . . . . . . . . 60

3.1 .4 Tendências . . . . . . . . . . . . . . . . . . . . . . . . . . 68

3.1 .5 Anomalias . . . . . . . . . . . . . . . . . . . 79

$3.1 .6 \quad$ Série Temporal $\ldots \ldots \ldots$. . . . . . . . . . . . . . . . . 81

3.1 .7 Síntese da escolha do modelo . . . . . . . . . . . . . . . . . . . . . 89

3.2 Comparação entre as saídas do MIROC para dois cenários climáticos de aquecimento global . . . . . . . . . . . . . . . . . . . . . . . . . 94

$3.2 .1 \quad$ O Padrão espacial médio . . . . . . . . . . . . . . . . . . . . 94

3.2 .2 O padrão climatológico e os cenários climáticos . . . . . . . . . 115

3.2 .3 Os cenários climáticos e as tendências . . . . . . . . . . . . . . . . . 121

3.2.4 A Corrente do Brasil e a Posição da Confluência Brasil Malvinas . . 125

3.2 .5 Padrões de Variabilidade no Atlântico Sudoeste . . . . . . . . . . . . 132

$\begin{array}{lll}4 & \text { Discussão } & 139\end{array}$

$\begin{array}{llr}5 & \text { Conclusões } & 142\end{array}$

\begin{tabular}{ll}
\hline Referências & 146
\end{tabular} 


\section{Lista de Figuras}

1 Diferença de temperatura $\left(\mathrm{em}^{\circ} \mathrm{C}\right)$ de 20 a 30 anos após o colapso da Circulação Termohalina no experimento. Retirado de Vellinga (2001). . . . . . 6

2 Circulação superficial do Atlântico Sul. Adaptado de Peterson \& Stramma (1991).

3 Representação esquemática da hipótese de Stommel(1965) a menor intensidade da Corrente do Brasil em relação à Corrente do Golfo. Adaptado de Silveira (2000). .

4 Circulação Superficial do Atlântico Sudoeste. Adaptado de Peterson \& Stramma (1991). . . . . . . . . . . . . . . . . . . 15

$5 \quad$ Tendência de aumento de TSM entre 1958 e 2000 em $10^{-1 \circ} \mathrm{C}$ segundo os dados do SODA. . . . . . . . . . . . . . . . . . . . . . . . . . . 19

$6 \quad$ Região de estudo. Em preto, as seções transversais latitudinal (1) em $40^{\circ}$

\begin{tabular}{|c|}
\hline W e longitudinal (2) em $39^{\circ} \mathrm{S}$. Em branco os pontos sobre a Corrente do \\
\hline
\end{tabular}

7 Temperatura média de superfície: (a) SODA, (b) GFDL, (c) MIROC e (d)

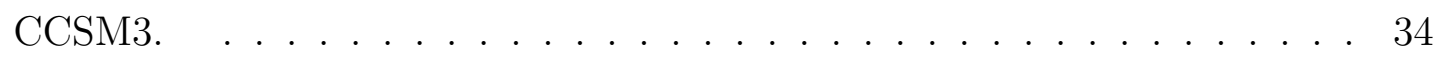

8 salinidade média de superfície: (a) SODA, (b) GFDL, (c) MIROC e (d) CCSM3. . . . . . . . . . . . . . . . . . . 42

$9 \quad$ Densidade média de superfície em $\mathrm{kg} / \mathrm{m}^{3}$ : (a) SODA, (b) GFDL, (c) MIROC e $(\mathrm{d})$ CCSM3. . . . . . . . . . . . . . . . . . . . . . . 43

10 Densidade média em subsuperfície $(50 \mathrm{~m}) \mathrm{em} \mathrm{kg} / \mathrm{m}^{3}$ : (a) SODA, (b) GFDL, (c) MIROC e (d) CCSM3. . . . . . . . . . . . . . . . . . . . . . . 44

11 Tensão média de tensão de cisalhamento do vento (vetores) sobre a superfície e seu módulo $\left(\mathrm{N} / \mathrm{m}^{2}\right)$ : (a) SODA, (b) GFDL, (c) MIROC e (d) CCSM3. . . . . . . . . . . . . . . . . . . . 45

12 Média de tensão de cisalhamento do vento (vetores) sobre seu respectivo rotacional $\left(\mathrm{N} / \mathrm{m}^{3}\right)$ : (a) SODA, (b) GFDL, (c) MIROC e (d) CCSM3. As linhas veremelhas representam o rotacional zero. . . . . . . . . . . . . . . 46

13 Média da altura do nível do mar $\left(10^{-1} \mathrm{~m}\right)$ : (a) SODA, (b) GFDL, (c) MIROC e $(\mathrm{d})$ CCSM3. $\ldots \ldots \ldots \ldots . \ldots . \ldots . \ldots 47$ 
14 Média da velocidade de corrente de superfície: (a) SODA, (b) MIROC e (c) CCSM3. . . . . . . . . . . . . . . . . . . . . . . . 48

15 Seção vertical média meridional de temperatura $\left({ }^{\circ} \mathrm{C}\right)$ na longitude de $40^{\circ} \mathrm{W}$ (Transecto 1): (a) SODA, (b) GFDL, (c) MIROC e (d) CCSM3. . . . . . 49

16 Seção vertical média meridional de salinidade na longitude de $40^{\circ} \mathrm{W}$ (Transecto 1): (a) SODA, (b) GFDL, (c) MIROC e (d) CCSM3. . . . . . . . . 50

17 Seção vertical média de temperatura na latitude de $39^{\circ} \mathrm{S}$ (Transecto 2): (a) SODA, (b) GFDL, (c) MIROC e (d) CCSM3. . . . . . . . . . . . . . . . . 51

$18 \quad$ Perfil médio zonal de salinidade na latitude de $39^{\circ} \mathrm{S}$ (Transecto 2): (a) SODA, (b) GFDL, (c) MIROC e (d) CCSM3. . . . . . . . . . . . . . . . . 52

19 Diagramas de estado para o conjunto (a) SODA e os modelos numéricos do IPCC no ponto $1\left(40^{\circ} \mathrm{W}, 30^{\circ} \mathrm{S}\right)$ : (b) GFDL, (c) MIROC e (d) CCSM3. Temperatura $\mathrm{em}{ }^{\circ} \mathrm{C}$ e salinidade em $\mathrm{psu}$. . . . . . . . . . . . . . 53

20 Diferença de temperatura de superfície entre os 3 modelos numéricos do IPCC ( (a) GFDL, (b) MIROC, (c) CCSM3) e os dados de Reanálise do SODA. . . . . . . . . . . . . . . . . 54

21 Diferença de salinidade média de superfície entre os 3 modelos numéricos do IPCC ( (a) GFDL, (b) MIROC, (c) CCSM3) e os dados de Reanálise do SODA. . . . . . . . . . . . . . . . . . . . 55

22 Diferença de tensão de cisalhamento médio do vento sobre a superfície do \begin{tabular}{|c|}
\hline oceano entre os 3 modelos numéricos do IPCC ( (a) GFDL, (b) MIROC, \\
\hline
\end{tabular} (c) CCSM3) e os dados de Reanálise do SODA. . . . . . . . . . . . . . 56

23 Diferença da altura média da superfície do oceano entre os 3 modelos \begin{tabular}{|c|}
\hline numéricos do IPCC ( (a) GFDL, (b) MIROC, (c) CCSM3) e os dados \\
\hline
\end{tabular} de Reanálise do SODA. . . . . . . . . . . . . . . . . . . 56

24 Transecto latitudinal em $50^{\circ} \mathrm{W}$ (Transecto 1) da diferença entre a temperatura média dos 3 modelos numéricos do IPCC ( (a) GFDL, (b) MIROC, (c) CCSM3) e os dados de Reanálise do SODA. . . . . . . . . . . . . . . . 57

25 Transecto longitudinal em $40^{\circ} \mathrm{S}$ (Transecto 2) da diferença entre a temperatura média dos 3 modelos numéricos do IPCC ( (a) GFDL, (b) MIROC, (c) CCSM3) e os dados de Reanálise do SODA. . . . . . . . . . . . . . . 58 
26 Transecto latitudinal em $50^{\circ} \mathrm{W}$ (Transecto 1) da diferença entre a salinidade média dos 3 modelos numéricos do IPCC ( (a) GFDL, (b) MIROC, (c) CCSM3) e os dados de Reanálise do SODA. . . . . . . . . . . . . . . . . . 59

27 Transecto longitudinal em $40^{\circ} \mathrm{S}$ (Transecto 2) da diferença entre a salinidade média dos 3 modelos numéricos do IPCC ( (a) GFDL, (b) MIROC, (c) CCSM3) e os dados de Reanálise do SODA. . . . . . . . . . . . . . . . 59

28 Diferença entre janeiro e julho de temperatura de superfície: (a) SODA, (b) GFDL, (c) MIROC e (d) CCSM3. . . . . . . . . . . . . . . . . . . . . 62

29 Diferença entre janeiro e julho de salinidade de superfície: (a) SODA, (b) GFDL, (c) MIROC e (d) CCSM3. . . . . . . . . . . . . . . . . . . . 63

30 Diferença entre janeiro e julho de densidade de superfície: (a) SODA, (b) GFDL, (c) MIROC e (d) CCSM3.

31 Diferença entre janeiro e julho da altura do nível do mar: (a) SODA, (b) GFDL, (c) MIROC e (d) CCSM3. . . . . . . . . . . . . . . . . . . 65

32 Diferença entre janeiro e julho da tensão do cisalhamento do vento sobre a superfície do mar: (a) SODA, (b) GFDL, (c) MIROC e (d) CCSM3. . . . 66

33 Média climatológica da latitude da posição da Confluência Brasil-Malvinas: (a) SODA, (b) GFDL, (c) MIROC e (d) CCSM3. . . . . . . . . . . . . . . 67

34 Tendência da temperatura de superfície: (a) SODA, (b) GFDL, (c) MIROC e $(\mathrm{d}) \mathrm{CCSM} 3 . \quad \ldots \ldots \ldots \ldots$

35 Tendência de salinidade de superfície: (a) SODA, (b) GFDL, (c) MIROC e $(\mathrm{d})$ CCSM3. $\ldots \ldots \ldots \ldots$

36 Tendência da altura do nível do mar: (a) SODA, (b) GFDL, (c) MIROC e (d) CCSM3. . . . . . . . . . . . . . . . . . . . . 71

37 Seção latitudinal em $40^{\circ} \mathrm{W}$ (Transecto 1) de tendência de temperatura: (a) SODA, (b) GFDL, (c) MIROC e (d) CCSM3. . . . . . . . . . . . . . . . . 72

38 Seção longitudinal em $39^{\circ} \mathrm{S}$ (Transecto 2) de tendência de temperatura: (a) SODA, (b) GFDL, (c) MIROC e (d) CCSM3. . . . . . . . . . . . . . . . . 73

39 Seção latitudinal em $40^{\circ} \mathrm{W}$ (Transecto 1) de tendência de salinidade: (a) SODA, (b) GFDL, (c) MIROC e (d) CCSM3. . . . . . . . . . . . . . . . . 74

$40 \quad$ Seção longitudinal em $39^{\circ} \mathrm{S}$ (Transecto 2) de tendência de salinidade: (a) SODA, (b) GFDL, (c) MIROC e (d) CCSM3. . . . . . . . . . . . . . . . . 75 
41 Seção latitudinal em $40^{\circ} \mathrm{W}$ (Transecto 1) de tendência de densidade: (a) SODA, (b) GFDL, (c) MIROC e (d) CCSM3. . . . . . . . . . . . . . . . . 76

42 Seção longitudinal em $39^{\circ} \mathrm{S}$ (Transecto 2) de tendência de densidade: (a) SODA, (b) GFDL, (c) MIROC e (d) CCSM3. . . . . . . . . . . . . . . . 77

43 Diagramas de Taylor comparando os dados de superfície de reanálise do SODA (linha vermelha) e os três modelos numéricos do $4^{\circ}$ Relatório do IPCC na Região $1\left(20-35^{\circ} \mathrm{W} ; 15-30^{\circ} \mathrm{S}\right)$ para (a) temperatura $\left({ }^{\circ} \mathrm{C}\right) ;(\mathrm{b})$ salinidade; (c) altura do nível do mar $\left(10^{-1} \mathrm{~m}\right)$; (d) tensão de cisalhamento do vento sobre a superfície $\left(\mathrm{N} / \mathrm{m}^{2}\right) . \ldots \ldots \ldots$. . . . . . . . . . . 81

44 Diagramas de Taylor comparando os dados de superfície de reanálise do SODA (linha vermelha) e os três modelos numéricos do $4^{\circ}$ Relatório do IPCC na Região $2\left(30-55^{\circ} \mathrm{W} ; 45-55^{\circ} \mathrm{S}\right)$ para (a) temperatura; (b) salinidade; (c) altura do nível do mar; (d) tensão de cisalhamento do vento sobre a superfície. . . . . . . . . . . . . . . . . . . . . 83

45 Erro quadrático médio das séries temporais de temperatura de superfície ( $\left.{ }^{\circ} \mathrm{C}\right)$ : (a) GFDL, (b) MIROC, (c) CCSM3 e os dados de Reanálise do SODA. 84

46 Erro quadrático médio das séries temporais de salinidade de superfície: (a) GFDL, (b) MIROC, (c) CCSM3 e os dados de Reanálise do SODA. . . . . 85

47 Erro quadrático médio das séries temporais da tensão de cisalhamento do \begin{tabular}{|c|}
\hline vento sobre a superfície $\left(\mathrm{N} / \mathrm{m}^{2}\right):$ (a) GFDL, (b) MIROC, (c) CCSM3 e os \\
\hline
\end{tabular} dados de Reanálise do SODA. . . . . . . . . . . . . . . . . . . . 86

48 Erro quadrático médio das séries temporais da elevação do nível do mar \begin{tabular}{|c|}
\hline$\left(10^{-1} \mathrm{~m}\right)$ : (a) GFDL, (b) MIROC, (c) CCSM3 e os dados de Reanálise do \\
\hline
\end{tabular}

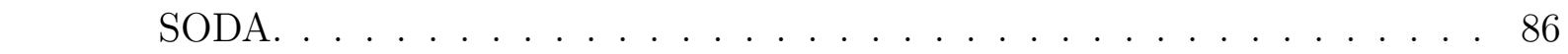

49 Transecto latitudinal em $50^{\circ} \mathrm{W}$ (Transecto 1 ) do erro quadrático médio \begin{tabular}{|l}
\hline entre a temperatura dos 3 modelos numéricos do IPCC ( (a) GFDL, (b) \\
\hline MIROC, (c) CCSM3) e os dados de Reanálise do SODA. . . . . . . . . . . \\
\hline $50 \quad$ Transecto longitudinal em $40^{\circ}$ S (Transecto 2) do erro quadrático médio \\
\hline entre a temperatura dos 3 modelos numéricos do IPCC ( (a) GFDL, (b) \\
\hline MIROC, (c) CCSM3) e os dados de Reanálise do SODA. . . . . . . . . . 87 \\
\hline
\end{tabular} 
51 Transecto latitudinal em $50^{\circ} \mathrm{W}$ (Transecto 1) do erro quadrático médio entre a salinidade dos 3 modelos numéricos do IPCC ( (a) GFDL, (b) MIROC, (c) CCSM3) e os dados de Reanálise do SODA. . . . . . . . . . . . 88

52 Transecto longitudinal em $40^{\circ} \mathrm{S}$ (Transecto 2) do erro quadrático médio entre a salinidade dos 3 modelos numéricos do IPCC ( (a) GFDL, (b) MIROC, (c) CCSM3) e os dados de Reanálise do SODA. . . . . . . . . . . 88

53 Diferença de TSM $\left({ }^{\circ} \mathrm{C}\right)$ entre três períodos dos experimentos para o século XXI e a média do século XX- cenários A1b: (a), (b) e (c) e B2 (c), (d) e (e). 98

54 Diferença de temperatura em $1000 \mathrm{~m}\left({ }^{\circ} \mathrm{C}\right)$ entre três períodos dos experimentos para o século XXI e a média do século XX- cenários A1b: (a), (b)

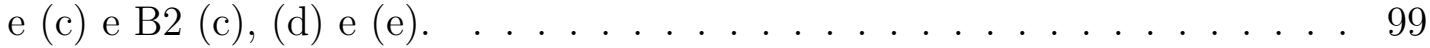

55 Diferença de temperatura em $1700 \mathrm{~m}\left({ }^{\circ} \mathrm{C}\right)$ entre três períodos dos experimentos para o século XXI e a média do século XX- cenários A1b: (a), (b) e $(\mathrm{c})$ e B2 $(\mathrm{c}),(\mathrm{d})$ e $(\mathrm{e}) . \ldots \ldots 100$

56 Diferença de SSM entre três períodos dos experimentos para o século XXI e a média do século XX- cenários A1b: (a), (b) e (c) e B2 (c), (d) e (e). . 101

57 Diferença de salinidade em $1000 \mathrm{~m}$ entre três períodos dos experimentos para o século XXI e a média do século XX- cenários A1b: (a), (b) e (c) e B2 $(\mathrm{c}),(\mathrm{d}) \mathrm{e}(\mathrm{e}) . \ldots \ldots \ldots \ldots 1$

58 Diferença de salinidade em $1700 \mathrm{~m}$ entre três períodos dos experimentos \begin{tabular}{|c|}
\hline para o século XXI e a média do século XX- cenários A1b: (a), (b) e (c) e \\
\hline
\end{tabular} B2 (c), (d) e (e). . . . . . . . . . . . . . . . . . . 102

59 Diferença de densidade de superfície $\left(\mathrm{kg} / \mathrm{m}^{3}\right)$ entre três períodos dos experimentos para o século XXI e a média do século XX- cenários A1b: (a), (b)

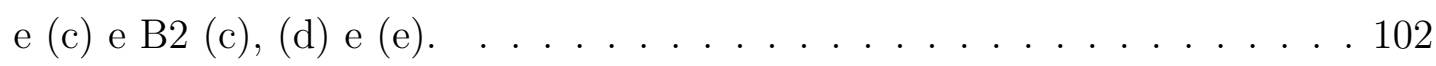

60 Diferença de densidade em $1000 \mathrm{~m}\left(\mathrm{~kg} / \mathrm{m}^{3}\right)$ entre três períodos dos experimentos para o século XXI e a média do século XX- cenários A1b: (a), (b) e $(\mathrm{c})$ e B2 (c), (d) e (e). . . . . . . . . . . . . . . . . . 103

61 Diferença de densidade em $1700 \mathrm{~m}\left(\mathrm{~kg} / \mathrm{m}^{3}\right)$ entre três períodos dos experimentos para o século XXI e a média do século XX- cenários A1b: (a), (b) e (c) e B2 (c), (d) e (e). . 
62 Diferença média de tensão de cisalhamento do vento sobre o mar $\left(\mathrm{N} / \mathrm{m}^{3}\right)$ entre três períodos dos experimentos para o século XXI e a média do século XX- cenários A1b: (a), (b) e (c) e B2 (c), (d) e (e). . . . . . . . . . . . . . 104

63 Perfis verticais no ponto $1\left(40^{\circ} \mathrm{W}, 30^{\circ} \mathrm{S}\right)$ da diferença entre as variáveis (temperatura -(a) e (e), salinidade - (b) e (f), densidade - (c) e (g) e velocidade - (d) e (h)) em dois cenários climáticos A1b (a,b e c) e B2 (d, e, e f) normalizados pelos desvio padrão das variáveis durante o Século XX. As linhas azuis representam o primeiro período (2000-2033), as verdes o segundo (2033-2066) e as vermelhas o terceiro (2066-2100). . . . . . . . . 106

64 Perfis verticais no Ponto $2\left(55^{\circ} \mathrm{W}, 45^{\circ} \mathrm{S}\right)$ da diferença entre as variáveis (temperatura -(a) e (e), salinidade - (b) e (f), densidade - (c) e (g) e velocidade - (d) e (h)) em dois cenários climáticos A1b (a,b e c) e B2 (d, e, e f) normalizados pelos desvio padrão das variáveis durante o Século XX. As linhas azuis representam o primeiro período (2000-2033), as verdes o segundo (2033-2066) e as vermelhas o terceiro (2066-2100). . . . . . . . . 107

65 Seção latitudinal em $40^{\circ} \mathrm{W}$ de diferença de temperatura $\left({ }^{\circ} \mathrm{C}\right)$ entre três períodos dos experimentos para o século XXI e a média do século XXcenários A1b: (a), (b) e (c) e B2 (c), (d) e (e). . . . . . . . . . . . . . . 108

66 Seção longitudinal em $40^{\circ} \mathrm{S}$ de diferença de temperatura $\left({ }^{\circ} \mathrm{C}\right)$ entre três períodos dos experimentos para o século XXI e a média do século XXcenários A1b: (a), (b) e (c) e B2 (c), (d) e (e).

67 Seção latitudinal em $40^{\circ} \mathrm{W}$ de diferença de salinidade entre três períodos dos experimentos para o século XXI e a média do século XX- cenários A1b: (a), (b) e (c) e B2 (c), (d) e (e).

68 Seção longitudinal em $40^{\circ} \mathrm{S}$ de diferença de salinidade entre três períodos dos experimentos para o século XXI e a média do século XX- cenários A1b: (a), (b) e (c) e B2 (c), (d) e (e).

69 Seção latitudinal em $40^{\circ} \mathrm{W}$ de diferença de densidade $\left(\mathrm{kg} / \mathrm{m}^{3}\right)$ entre três períodos dos experimentos para o século XXI e a média do século XXcenários A1b: (a), (b) e (c) e B2 (c), (d) e (e). . . . . . . . . . . . . . . . 112 
70 Seção longitudinal em $40^{\circ} \mathrm{S}$ de diferença de densidade $\left(\mathrm{kg} / \mathrm{m}^{3}\right)$ entre três períodos dos experimentos para o século XXI e a média do século XXcenários A1b: (a), (b) e (c) e B2 (c), (d) e (e). . . . . . . . . . . . . . . 113

71 Diagramas de estado (médio) em $30^{\circ} \mathrm{S}, 40^{\circ} \mathrm{W}$ : (a) século XX, (b) cenário A1b e (c) B2. As linhas azuis representam o período entre 2000 e 2033, as verdes entre 2033 e 2066 e as vermelhas entre 2066 e 2100. . . . . . . . . . 113

72 Padrão climatológico de temperatura $\left({ }^{\circ} \mathrm{C}\right)$ em superfície em três períodos distintos (entre 2000 e 2033 (a), entre 2033 e 2066 (b) e e entre 2066 e 2100 (c)). Média do Século XX em preto, cenários A1b em vermelho e B2 em verde. Ponto $1-\left(40^{\circ} \mathrm{W}, 30^{\circ} \mathrm{S}\right)$. . . . . . . . . . . . . . . 115

73 Padrão climatológico de temperatura $\left({ }^{\circ} \mathrm{C}\right)$ em superfície em três períodos distintos (entre 2000 e 2033 (a), entre 2033 e 2066 (b) e e entre 2066 e 2100 (c)). Média do Século XX em preto, cenários A1b em vermelho e B2 em verde. Ponto $2-\left(55^{\circ} \mathrm{W}, 45^{\circ} \mathrm{S}\right)$.

74 Diferença entre a média de janeiro e julho de salinidade de superfície: (a) século XX, (b) entre 2000 e 2033. (c) entre 2033 e 2066, (d) entre 2066 e 2100 no cenário A1b e (e) entre 2000 e 2033. (f) entre 2033 e 2066, (g) entre 2066 e 2100 no cenário B2. . . . . . . . . . . . . . . . . . . . . . . . . 118

75 Padrão climatológico de salinidade $\left({ }^{\circ} \mathrm{C}\right)$ em superfície em três períodos distintos (entre 2000 e 2033 (a), entre 2033 e 2066 (b) e e entre 2066 e 2100 (c)). Média do Século XX em preto, cenários A1b em vermelho e B2 em verde. Ponto $1-\left(40^{\circ} \mathrm{W}, 30^{\circ} \mathrm{S}\right)$.

76 Padrão climatológico de salinidade $\left({ }^{\circ} \mathrm{C}\right)$ em superfície em três períodos distintos (entre 2000 e 2033 (a), entre 2033 e 2066 (b) e e entre 2066 e 2100 (c)). Média do Século XX em preto, cenários A1b em vermelho e B2 em verde. Ponto $2-\left(55^{\circ} \mathrm{W}, 45^{\circ} \mathrm{S}\right)$.

77 Padrão climatológico da posição da frente da Confluência Brasil-Malvinas $\mathrm{em}^{\circ}$ de latitude (a, b e c), do módulo do transporte da Corrente do Brasil (d, e e f) e da Corrente das Malvinas (g, h e i) em Sv, durante três períodos distintos (entre 2000 e 2033. entre 2033 e 2066 e entre 2066 e 2100) - Século XX, cenários A1b e B2. . 
78 Tendência de temperatura $\left({ }^{\circ} \mathrm{C} / \mathrm{ano}\right)$ entre 2000 e 2100 nos cenários climáticos A1b (a- superfície, c- em 1000m e e- em 1700) e B2 (b- superfície, d- em 1000m e f-em 1700). . . . . . . . . . . . . . . . . . . . 122

79 Tendência de salinidade $\left(10^{-2} \mathrm{ano}^{-1}\right)$ entre 2000 e 2100 nos cenários climáticos A1b (a- superfície, c- em 1000m e e- em 1700) e B2 (b- superfície, d- em $1000 \mathrm{~m} \mathrm{e} \mathrm{f-em} \mathrm{1700).} \mathrm{.} \mathrm{.} \mathrm{.} \mathrm{.} \mathrm{.} \mathrm{.} \mathrm{.} \mathrm{.} \mathrm{.} \mathrm{.} \mathrm{.} \mathrm{.} \mathrm{.} \mathrm{.} \mathrm{.} \mathrm{.} \mathrm{.} \mathrm{.} 123$

80 Espectro de Potência de Ondaletas da posição da CBM $\left({ }^{\circ 2}\right)$ : (a) Século XX, (b) Cenário A1b e (c) Cenário B2. . . . . . . . . . . . . . . . . . . 126

81 Espectro de Potência de Ondaletas do transporte da CB $\left(\mathrm{Sv}^{2}\right)$ : (a) Século XX, (b) Cenário A1b e (c) Cenário B2. . . . . . . . . . . . . . . . . . . . . 126

82 Espectro de Potência de Ondaletas do transporte da $\mathrm{CM}\left(\mathrm{Sv}^{2}\right)$ : (a) Século XX, (b) Cenário A1b e (c) Cenário B2. . . . . . . . . . . . . . . . . . . . . 127

83 Coerência de ondaletas cruzadas entre a posição da CBM e o transporte da CB: (a) Século XX, (b) A1b e (c) B2. . . . . . . . . . . . . . . . . . . 129

84 Coerência de ondaletas cruzadas entre a posição da CBM e o transporte da CM: (a) Século XX, (b) A1b e (c) B2. . . . . . . . . . . . . . . . . . . 131

85 Espectro de Potência de Ondaletas de TSM $\left({ }^{\circ} \mathrm{C}\right)^{2}$ no ponto $1\left(40^{\circ} \mathrm{W}, 30^{\circ} \mathrm{S}\right)$ :

(a) Século XX, (b) Cenário A1b e (c) Cenário B2. . . . . . . . . . . . . . . 132

86 Espectro de Potência de Ondaletas de TSM $\left({ }^{\circ} \mathrm{C}\right)^{2}$ no ponto $2\left(55^{\circ} \mathrm{W}, 45^{\circ} \mathrm{S}\right)$ :

(a) Século XX, (b) Cenário A1b e (c) Cenário B2. . . . . . . . . . . . . . . 133

87 Espectro de Potência de Ondaletas da temperatura em $1000 \mathrm{~m}\left({ }^{\circ} \mathrm{C}\right)^{2}$ no ponto $1\left(40^{\circ} \mathrm{W}, 30^{\circ} \mathrm{S}\right)$ : (a) Século XX, (b) Cenário A1b e (c) Cenário B2. . 133

88 Espectro de Potência de Ondaletas de temperatura em $1700 \mathrm{~m}\left({ }^{\circ} \mathrm{C}\right)^{2}$ no ponto $1\left(40^{\circ} \mathrm{W}, 30^{\circ} \mathrm{S}\right)$ : (a) Século XX, (b) Cenário A1b e (c) Cenário B2. 134

89 Espectro de Potência de Ondaletas de SSM no ponto $1\left(40^{\circ} \mathrm{W}, 30^{\circ} \mathrm{S}\right):$ (a) Século XX, (b) Cenário A1b e (c) Cenário B2. . . . . . . . . . . . . . . . . 136

90 Espectro de Potência de Ondaletas de SSM no ponto $2\left(55^{\circ} \mathrm{W}, 45^{\circ} \mathrm{S}\right)$ : (a) Século XX, (b) Cenário A1b e (c) Cenário B2. . . . . . . . . . . . . . . 137

91 Espectro de Potência de Ondaletas de salinidade em 1000m no ponto 1 $\left(40^{\circ} \mathrm{W}, 30^{\circ} \mathrm{S}\right)$ : (a) Século XX, (b) Cenário A1b e (c) Cenário B2. . . . . . . 137

92 Espectro de Potência de Ondaletas de salinidade em $1700 \mathrm{~m}$ no ponto 1 $\left(40^{\circ} \mathrm{W}, 30^{\circ} \mathrm{S}\right)$ : (a) Século XX, (b) Cenário A1b e (c) Cenário B2. . . . . . . 138 


\section{Lista de Tabelas}

$1 \quad$ Síntese das principais diferenças das médias anuais dos experimentos pré e

pós industriais de Wainer (2004). . . . . . . . . . . . . . . . . . . 7

$2 \quad$ Massas d'águas que compõem a Corrente das Malvinas. . . . . . . . . . . . 9

3 Massas d'águas que compõem a Corrente das Malvinas. . . . . . . . . . . . 14

$4 \quad$ Temperatura $\left({ }^{\circ} \mathrm{C}\right)$ e densidade $\left(\mathrm{kgm}^{-3}\right)$ das três corpos d'água identificadas

na superfície da confluência Brasil-Malvinas, descrita por Provost (1996). . 16

5 Tabela de emissão de gases estufa no contexto de dois cenários climáticos

propostos pelo IPCC (Adaptado de IPCC Special Report and Scenario Fa-

mily). . . . . . . . . . . . . . . . . . . . 22

6 Resolução dos modelos oceânicos e atmosféricos utilizados pelo GFDL para

o $4^{\circ}$ Relatório de Avaliação do IPCC . . . . . . . . . . . . . . . . . . 24

7 Índices termohalinos das massas d'água na região da Confluência Brasil-

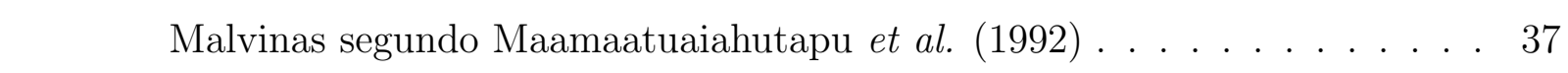

$8 \quad$ Índices termohalinos encontrados através dos diagramas de estado SODA e dos modelos numéricos do IPCC no ponto $1\left(40^{\circ} \mathrm{W}, 30^{\circ} \mathrm{S}\right)$. . . . . . . . . 39

9 Profundidades dos núcleos e interfaces das massas d'água encontradas através dos diagramas de estado SODA e dos modelos numéricos do IPCC no ponto

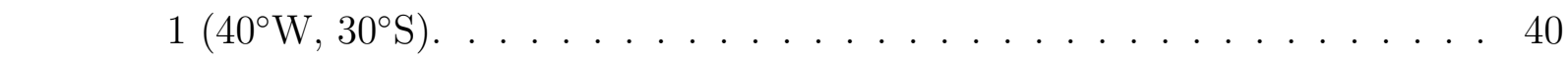

10 Módulos dos transportes (Sv) das Correntes do Brasil e das Malvinas \begin{tabular}{|c|}
\hline (média entre 1958 e 2000) calculados através do SODA e dos modelos \\
\hline
\end{tabular} numéricos do IPCC. . . . . . . . . . . . . . . . . . . 40

11 Posição da CBM (média entre 1958 e 2000) calculada através do SODA e

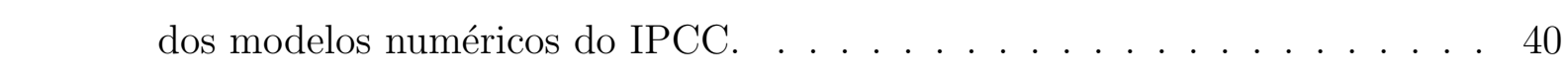

12 Correlação entre as médias climatológicas das variáveis de superfícies do SODA e dos 3 modelos do $4^{\circ}$ Relatório de Avaliação do IPCC: (a) SODA, (b) GFDL, (c) MIROC e (d) CCSM3. . . . . . . . . . . . . . . . . 61

13 Tendências da posição da CBM e dos transportes das Correntes do Brasil e das Malvinas. . . . . . . . . . . . . . . . . . . . . . . . . . . . . 78 
14 Desvio padrão das anomalias das variáveis em relação à média climatológica nos Pontos $1\left(40^{\circ} \mathrm{W}, 30^{\circ} \mathrm{S}\right)$ e $2\left(55^{\circ} \mathrm{W}, 45^{\circ} \mathrm{S}\right)$ do SODA e dos 3 modelos do $4^{\circ}$ Relatório de Avaliação do IPCC em 3 profundidades - 5m (superfície), 1000m (associada a AIA) e 1700 (associada a APAN). . . . . . . . . . . . 79

15 Síntese dos critérios de escolha do modelo numérico adequado para a região. 93

16 Diferença entre a média de superfície nos cenários A1b e B2 e a média do século XX e o respectivo desvio padrão da variável durante o século XX. . 94

17 Diferença entre a média em 1000m nos cenários A1b e B2 e a média do século XX e o respectivo desvio padrão da variável durante o século XX. . 96

18 Diferença entre a média em 1700m nos cenários A1b e B2 e a média do século XX e o respectivo desvio padrão da variável durante o século XX. . 97

19 Média dos módulos dos transportes das correntes do Brasil e das Malvinas (Sv) segundo o modelo MIROC em dois cenários de aquecimento global (A1b e B2) e a posição média da confluência das duas correntes ( $\left.{ }^{\circ} \mathrm{S}\right)$. . . . . 111

20 Índices termohalinos de 3 massas d'águas em três períodos do século XXI segundo o MIROC. . . . . . . . . . . . . . . . . . . . . . . . . . 114

21 Profundidades $(\mathrm{m})$ dos núcleos e interfaces de 3 massas d'águas em três períodos do século XXI segundo o MIROC. . . . . . . . . . . . . . . . . . 114

22 Tendências da Posição da CBM (\%/ano) e dos transportes daB e da CM (Sv/ano). . . . . . . . . . . . . . . . . . . . . 124

23 Correlação entre a posição da CBM, o transporte da CB e da CM. . . . 125 


\section{Resumo}

O Atlântico Sudoeste comporta uma das regiões oceânicas mais energéticas do planeta: a Confluência Brasil-Malvinas (CBM). Essa região encerra o giro subtropical do Atlântico Sul e possui fundamental importância para a dinâmica desse oceano bem como para o clima regional. Através de saídas de modelos numéricos acoplados do $4^{\circ}$ Relatório do IPCC, descreve-se o comportamento dessa região em dois cenários futuros de aquecimento global: um de elevada emissão de gases estufa (A1b) e o outro mais ameno em termos de impactos antrópicos (B2). Ambos os cenários apresentaram fortes tendências de aumento de temperatura sobretudo na superfície (chegando a $0,065^{\circ} \mathrm{C}$ /ano no cenário A1b e $0,055^{\circ} \mathrm{C} /$ ano no B2). A salinidade de superfície mostrou forte tendência positiva do Equador até a região da CBM, e negativa em maiores latitudes. A posição média da CBM desloca-se em aproximadamente $1,1^{\circ}$ para sul no cenário A1b (entre 2066 e 2100) e 0,9 no cenário B2. O padrão espectral dessa posição (dominado pelo ciclo anual no século XX) é dominado pela variabilidade de baixa frequência no cenário A1b. Tais modificações na média e no espectro da posição da CBM estão associados à intensificação e mudança da Corrente do Brasil. 


\section{Abstract}

Southwestern Atlantic comprises one of the most energetic region of the world: BrazilMalvinas Confluence (BMC). This region lies within the Southern Atlantic Subtropical Gyre and holds fundamental importance for this oceanic dynamics as well as for the regional climate. Through numerical modeling output coupled to IPCC's $4^{t} h$ Report, it is sunk to describe this region behavior for two distinct future scenarios: high greenhouse gases emission (A1b) and a milder one in terms of anthropic impacts (B2). Both scenarios have shown strong temperature increasing tendencies, especially on the surface (reaching up to $0,065^{\circ} \mathrm{C} /$ year in $\mathrm{A} 1 \mathrm{~b}$ and $0,055^{\circ} \mathrm{C} /$ year in $\mathrm{B} 2$ ). Surface salinity have also shown strong positive tendency from the Equator to the BMC region, and negative in higher latitudes. BMC medium position is shifted around $1,1^{\circ} \mathrm{S}$ in $\mathrm{A} 1 \mathrm{~b}$ scenario (between 2066 and 2010) and $0,9^{\circ}$ in B2. Spectral pattern on this position (dominated for XX century annual cycle) is controlled by low-frequency variabilities in A1b scenario. These modifications in average and spectral patterns of BMC position are linked to the intensification and changing of Brazil current. 


\section{Lista de Acrônimos}

ACAS - Água Central do Atlântico Sul

ACP - Água Circumpolar Profunda

ACS - Água Circumpolar Superior

AIA - Água Intermediária Antártica

APAN - Água Profunda do Atlântico Norte

APW - Água Profunda do Mar de Weddell

AT - Água Tropical

CCSM - Climate System Model

CB - Corrente do Brasil

CBM - Confluência Brasil-Malvinas

CCA - Corrente Circumpolar Antártica

CM - Corrente das Malvinas

CNB - Corrente do Norte do Brasil

FCB - Frente da Corrente do Brasil

FSA - Frente Subantártica

FST - Frente Subtropical

GFDL - Geophysical Fluid Dynamics Laboratory

IPCC - Intergovernmental Panel on Climate Change

MIROC - Model for Interdisciplinary Research on Climate

SSM - Salinidade de Superfície do Mar

SODA - Simple Ocean Data Assimilation

TSM - Temperatura de Superfície do Mar 


\section{Introdução}

\subsection{Preâmbulo}

A capacidade humana de interferir no ambiente é um fator crescente desde os primórdios da humanidade. Diversos autores já identificam essa intervenção como o principal fator atuante no sistema Terra, determinando o término do Holoceno e o início de uma nova era, o Antropoceno. Steffen et al. (2007) dividem o Antropoceno em três períodos principais. O primeiro, inicia-se por volta de 1800 quando a Revolução Industrial potencializou os impactos antropogênicos no planeta e terminou com a chamada "Grande Aceleração" (por volta de 1945), quando esse processo é subitamente intensificado. Nos dias atuais, o Antropoceno encontra-se no terceiro período, marcado pelo manejo dos impactos humanos na natureza e seus possíveis efeitos maléficos. Vive-se uma época marcada pela grande concentração de esforços para a melhor compreensão dos processos envolvidos, bem como pela busca de novas estratégias para mitigar e desacelerar os ônus do "desenvolvimento" humano.

A emissão de gases estufa, sobretudo de dióxido de carbono $\left(\mathrm{CO}_{2}\right)$, é considerado um traçador da evolução do Antropoceno (Steffen et al. 2007). Nesse cenário, as mudanças climáticas globais e suas possíveis origens antrópicas são um assunto de amplo interesse político-científico, embora sua compreensão não seja nada trivial. O aumento das taxas de emissões de gases estufa e seus efeitos protagonizam os debates sobre o assunto. Durante o primeiro período do Antropoceno, o que representa 145 anos, a concentração de dióxido de carbono atmosférico superou a variabilidade natural de todo o Holoceno (últimos 11,5 mil anos). Aproximadamente 3/4 do carbono antropogênico foi emitido depois dos anos 1950 e metade nos últimos 30 anos (Broecker \& Stocker 2006).

Os impactos desses gases no clima terrestre e suas consequências são alvos de grandes esforços avaliativos por parte da comunidade internacional. A contribuição humana nas mudanças globais frente à variabilidade climática natural já observada em outros períodos da história da Terra é uma questão chave para discussões científicas e políticas contemporâneas.

O Intergovernamental Panel on Climate Changes (IPCC ) é um órgão que reúne pesquisadores dos maiores centros de pesquisas do planeta com o intuito de estimar cenários futuros de mudanças climáticas baseados na emissão de gases estufa na atmosfera. Através 
de 21 modelos numéricos globais acoplados, o $4^{\circ}$ Relatório do IPCC fornece as previsões das variáveis físicas em diferentes cenários.

Sabe-se que, embora a média da temperatura da superfície terrestre esteja aumentando, tal aumento não é uniforme e difere regionalmente (Levitus et al. 2000). Como exemplo, podemos citar o continente Antártico, onde tanto o resfriamento quanto o aquecimento coexistem nos cenários de aquecimento global. Nos oceanos, tais contrastes podem ter impactos de difícil compreensão, já que a própria circulação oceânica global depende da temperatura, das taxas de derretimento de gelo, da pluviosidade e tensão de cisalhamento do vento dentre outros fatores também relacionados ao clima (Levitus 1984; Bigg et al. 2003). Por outro lado, os oceanos desempenham um papel decisivo para o clima, sendo responsáveis pela distribuição e armazenamento de grande parte do calor na Terra devido ao alto calor específico da água. Dessa forma, os oceanos são grandes agentes reguladores do clima, suavizando variações drásticas da temperatura global.

Grande parte do excesso de calor fornecido pelo Sol em baixas latitudes é redistribuído pelas correntes marinhas. Embora, as velocidades associadas aos movimentos oceânicos sejam muito baixas em relação à atmosfera, as correntes transportam grandes quantidades de calor para altas latitudes, diminuindo o gradiente latitudinal de temperatura. Um importante mecanismo de distribuição de calor é a Corrente Termohalina Global, sistema que integra os oceanos por meio das correntes superficiais e profundas (Gordon 1986). A principal extensão latitudinal desse cinturão encontra-se no Atlântico. Esse oceano transporta águas superficiais para o Norte, enquanto carrega águas profundas para o Hemisfério Sul resultando em troca de calor inter-hemisférica. No setor austral do oceano Atlântico Sul, ocorrem praticamente todas as trocas de massas d'água e de calor com outros oceanos. Além disso, a região Sudoeste desse oceano abriga uma das feições oceânicas mais energéticas do planeta: A Confluência Brasil-Malvinas (CBM) (Chelton et al. 1990; Provost \& Traon 1993; Ferreira 2010).

A Confluência Brasil-Malvinas é a região onde as correntes do Brasil e das Malvinas se encontram. Essa estrutura oceânica encerra o giro subtropical do Atlântico Sul e possui dinâmica muito complexa (Peterson \& Stramma 1991). Sua posição varia latitudinalmente ao longo do ano e a formação de vórtices é um importante fator de exportação de massas de água quentes e salinas para a Corrente Circumpolar Antártica (Legeckis \& Gordon 1982). 
Embora de extrema importância para a oceanografia em meso-grande escala, o complexo comportamento da Confluência Brasil-Malvinas, ainda não foi suficientemente descrito e compreendido. O entendimento do Antropoceno e as influências das mudanças climáticas globais na CBM são desafios a serem superados. A dinâmica da região em cenários futuros, além de pouco explorada, também apresenta-se como tema de relevância científica. A análise dos padrões espaço-temporais dessa região através de cenários prognósticos propostos pelo IPCC poderia então indicar respostas a alterações globais, além de auxiliar a compreensão dessa complexa dinâmica.

\subsection{Mudanças Climáticas no Antropoceno e a Importância dos Oceanos}

Etheridge et al. (1996), através de análises de amostras de ar atmosférico aprisionado em testemunhos de gelo, concluíram que a concentração de dióxido de carbono permaneceu relativamente baixa entre 1550 e 1800. Apesar da variabilidade natural a concentração atmosférica desse gás pouco oscilou durante esse período permanecendo entre 275 e 284 ppm. Após a Revolução Industrial ( 1830) a taxa de crescimento dessa concentração acentuou-se consideravelmente atingido quase 350ppm no início desse século. Em nenhum período conhecido do planeta a variabilidade natural desse gás foi tão intensa e acredita-se que a grande parte desse acréscimo seja antropogênico.

A queima de combustíveis fósseis, bem como grandes queimadas e a pecuária são responsáveis pela liberação de toneladas de dióxido de carbono, bem como outros gases estufa (como o metano, o óxido nitroso e o ozônio). Esses gases intensificam o processo natural de aprisionamento de calor emitida pela Terra através do infravermelho, chamado de efeito estufa.

Esse efeito ocorre porque esses gases não absorvem as ondas curtas solares, mas absorvem radiação infravermelha emitida pela Terra, mantendo a temperatura do planeta maior e mais estável. Embora o principal gás estufa seja o vapor d'água - responsável por 80\% da absorção atmosférica de radiação infra-vermelha - o dióxido de carbono lidera as discussões a respeito de mudanças climáticas, já que acredita-se que a concentração atmosférica desse gás aumentou sensivelmente no último século.

O clima terrestre sempre oscilou em escalas de tempo geológicas, porém, devido a vários fatores, acredita-se que a ação humana seja a causa das acentuadas alterações do 
clima desde a Revolução Industrial. Embora o discernimento entre os agentes antrópicos das mudanças climáticas ante à variabilidade natural seja complicado, atualmente observamse diversos indícios de alterações do clima regional e global no planeta (IPCC 2007).

Diversos autores descrevem curvas de temperatura média da superfície terrestre e em praticamente todas observamos um tendência clara de aumento (por volta de $0,5^{\circ} \mathrm{C}$ nos últimos 50 anos)(Cane et al. 1997; Houghton 1995; IPCC 2007). Levitus (2000) descreve uma elevação da temperatura da água do mar em aproximadamente $0,06^{\circ} \mathrm{C}$ entre as décadas de 50 e 90. Os dados de reanálise do SODA (Carton et al. 2000), mostram uma elevação de mais de $0,1^{\circ} \mathrm{C}$ para o Atlântico Sudoeste e por volta de $0,17^{\circ} \mathrm{C}$ no Oceano Austral (Gille 2002).

Outras evidências já indicam a ocorrência de alterações climáticas em grande escala. Segundo o último relatório do IPCC (2007), podemos citar o aumento da quantidade de vapor d'água na atmosfera, a diminuição da cobertura de gelo em ambos os hemisférios, o aumento do nível do mar global, aumento da temperatura de camadas de gelo permanentes, alterações drásticas do ciclo pluvial em grandes regiões e períodos mais intensos e longos de seca em áreas cada vez maiores (IPCC 2007). Peltier e Tushingham (1989) estimaram que nas últimas 7 décadas o nível do mar aumentou em uma taxa de $24 \mathrm{~mm}$ por década enquanto que Bakun (1990) observou a intensificação das correntes costeiras durante o século XX. McCabe et al. (2001) verificaram o aumento de ciclones de altas latitudes e de tempestades nas médias e altas latitudes durante o inverno das últimas décadas, provavelmente ligados a elevação da temperatura na superfície do planeta.

Embora muitas evidências sejam observadas, não é possível distinguir as mudanças antropogênicas das naturais. Diversos modelos numéricos tentam estimar os impactos da emissão antrópica de gases estufa em contrapartida a variabilidade natural do clima terrestre e exploram as possibilidades futuras nesse sentido. Crowley (2000) conclui que 41 a $65 \%$ das variações de temperatura anteriores a 1850 devem-se ao vulcanismos e anomalias na irradiância solar, porém durante o século XX a maior forçante da variabilidade do clima terrestre é a emissão de gases estufa devido a atividade humana. Segundo Delworth e Knutson (2000), o aquecimento global entre 1925 e 1944 deve-se à combinação entre a variabilidade climática multidecadal e a ação do homem.

Estima-se que as maiores taxas de aumento de temperatura ocorrem nos pólos durante o inverno (Gates 1993). Por outro lado, algumas regiões do continente Antártico podem 
resfriar em cenários de aquecimento global. Além disso, em um planeta mais quente, o sistema hidrológico pode ser drasticamente alterado. Modelos acoplados de circulação indicam o aumento da pluviosidade nas margens dos continentes e diminuição nas regiões centrais (Houghton 1995).

Os oceanos protagonizam boa parte das discussões a respeito das mudanças globais do clima, pois representam a componente do sistema Terra que armazena e transporta a maior quantidade de calor, além de ser um sorvedouro de gases estufa como o dióxido de carbono. Mais de 1/3 do carbono liberado é absorvido pelo oceano (Sarmiento \& Gruber 2002).

A circulação termohalina global pode enfraquecer em cenários de aquecimento superficial do planeta (Manabe \& Stouffer 1994) acarretando em um menor transporte de carbono para águas profundas, menor distribuição latitudinal de calor e alterações dos padrões de distribuições de grandes massas d'águas em todos os oceanos. Diversos autores descrevem a possibilidade do enfraquecimento da Circulação Termohalina no Atlântico e suas consequências sobre o clima global (Broecker 1997; Vellinga \& Wood 2002), enquanto outros acreditam que esse processo já está ocorrendo (Hansen et al. 2001; Bryden et al. 2005).

As estimativas de enfraquecimento da Circulação Termohalina Global em cenários de aumento dos gases estufa, variam entre 0 e $50 \%$ em diferentes modelos numéricos acoplados (Schmittner et al. 2005; Gregory 2005). Tal enfraquecimento pode estar relacionado a redução da densidade em regiões de convecção oceânica devido ao resfriamento de água de superfície (Bryan et al. 2006) e a diminuição da densidade de superfície devido ao aumento da precipitação em altas latitudes (Dixon et al. 1999). Thorpe et al. (2001) atribuiram $60 \%$ do enfraquecimento da Circulação Termohalina Global aos efeitos térmicos e $40 \%$ às alterações halinas. Alguns autores discordam dessa estimativa e afirmam que o efeito da temperatura seria compensado por mudanças na salinidade (Latif et al. 2000; Guemas \& Salas-Mélia 2007).

Vellinga \& Wood (2002), em um estudo numérico, simularam o colapso da Circulação Termohalina no Atlântico através da diminuição da salinidade nas camadas superficiais do Atlântico Norte. Nas primeiras cinco décadas do experimento, foram observados fortes impactos atmosféricos e oceânicos na superfície do planeta. Ao cessar o transporte interhemisférico de calor, característico da Circulação Termohalina Atlântica o Hemisfério 
Norte é resfriado (de 1 a $2^{\circ} \mathrm{C}$ na média) enquanto o Sul sofre um ligeiro aquecimento. Nos continentes, observam-se a diminuição da pluviosidade em relação à evaporação na Europa e Ásia e o deslocamento da Zona de Convergência Intertropical (ZCIT) para Sul gerando fortes alterações do regime pluviométrico na América do Sul e África. Como consequência do resfriamento e diminuição da umidade no Hemisfério Norte, a produção primária global da vegetação é reduzida em 5\% o que representa uma redução de aproximadamente 3GtonC/ano. Nesse estudo, a circulação termohalina se restabeleceu em aproximadamente 1 século.

A Figura 1 representa as anomalias de temperatura do ar na superfície do planeta no experimento citado.

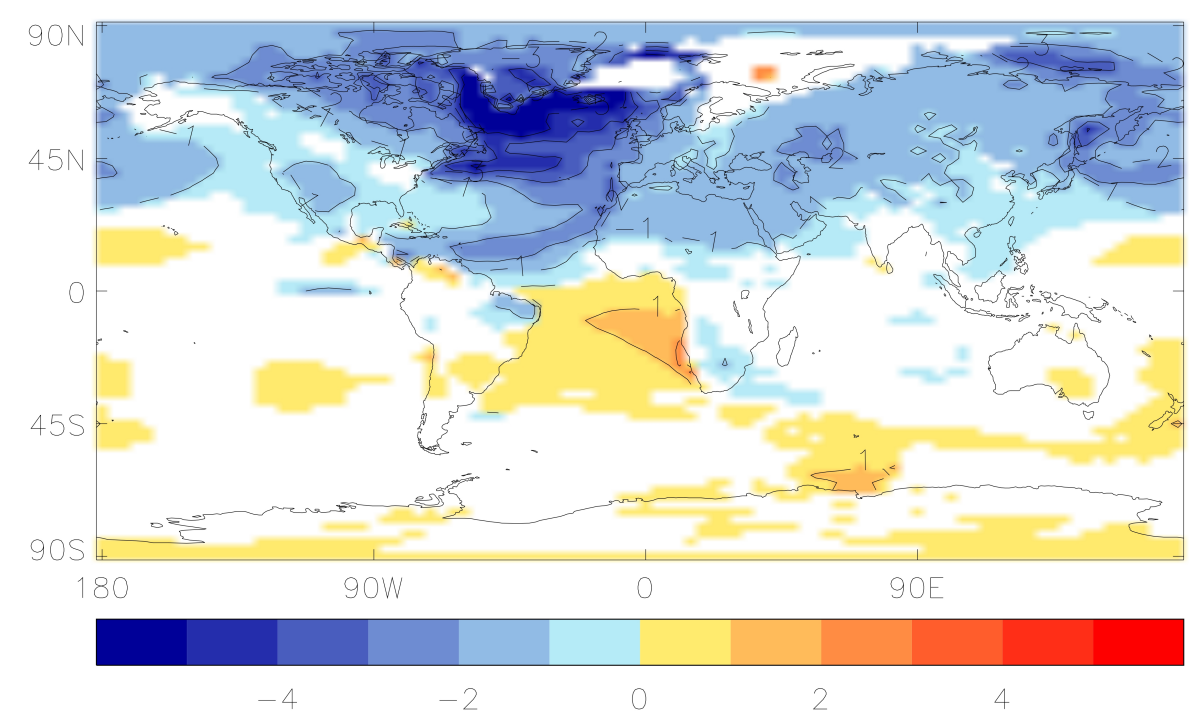

Figura 1: Diferença de temperatura $\left(\mathrm{em}^{\circ} \mathrm{C}\right)$ de 20 a 30 anos após o colapso da Circulação Termohalina no experimento. Retirado de Vellinga (2001).

Além de alterar a distribuição global de calor, o enfraquecimento da Circulação Termohalina, e consequentemente a formação de massas d'água profundas, reduz a capacidade dos oceanos de extrair gases estufa liberados na atmosfera. Além disso, outros fatores dificultariam a remoção oceânica de gases estufa em um mundo mais quente como a redução de processos de ressurgência (que diminuem a produção primária superficial) e o aquecimento da água do mar (que reduz a solubilidade de gases). Crueger et al. (2008) aponta que a maior redução na capacidade de absorção do dióxido de carbono encontrar-se-ia no Oceano Austral (45\%) e no Atlântico Norte (30\%). Este estudo numérico demonstra 
que mesmo que as emissões futuras de dióxido de Carbono antropogênico se reduza às da atualidade, os oceanos só seriam capazes de assimilar uma quantidade muito menor.

Outro efeito notável do aquecimento global é o aumento do nível do mar médio global. Em um cenário onde a temperatura média de superfície aumentasse $0,5^{\circ} \mathrm{C}$, seria observada a elevação do nível do mar de 2 a $7 \mathrm{~cm}$ devido ao derretimento de geleiras e entre 2 e $5 \mathrm{~cm}$ devido a expansão térmica da água (Wigley e Raper, 1987).

No Atlântico Sul, os impactos das mudanças climáticas globais ainda foram pouco explorados. Wainer (2004) et al. através de um estudo numérico, descreve diferenças climatológicas sensíveis entre os períodos pré e pós industriais. Para representar o período pré industrial, o modelo numérico adotou a concentração de $\mathrm{CO}_{2}$ encontrada em testemunhos de gelo referentes ao início do século XIX (240ppm), enquanto que para o pós industrial utilizou-se a média do ano de 1990 (304ppm). Nesse estudo, concluiu-se que o impacto dos gases estufas no armazenamento de calor no oceano, e consequentemente da emissão de ondas longas, é muito maior do que o efeito da variação da constante solar nos dois períodos. Além disso, esse estudo concluiu que as alterações em altas latitudes são mais intensas sobretudo em relação à função de corrente barotrópica responsável pela intensificação da Corrente Circumpolar Antártica. Esse processo pode impactar na intensidade e conformação da Circulação Termohalina e a distribuição do calor através do oceano (Manabe \& Stouffer 1994). Na região tropical, as maiores alterações referem-se à mudança do regime pluviométrico sobretudo durante o verão e o outono austral.

A Tabela 1 resume as principais diferenças entre a climatologia pré e pós industriais encontradas por Wainer (2004):

\begin{tabular}{cccc}
\hline Região & $\mathrm{TSM}\left({ }^{\circ} \mathbf{C}\right)$ & FCB $(\mathbf{m b})$ & PPT(mm/ano) \\
\hline \hline Atlântico Sul & 0.64 & 3.35 & -8.00 \\
$\mathbf{0 - 2 5}^{\circ} \mathbf{S}$ & 0.41 & 0.49 & -24.53 \\
$\mathbf{2 5 - 4 5}^{\circ} \mathbf{S}$ & 0.67 & 1.87 & -9.31 \\
$\mathbf{4 5 - 6 0}^{\circ} \mathbf{S}$ & 0.92 & 11.25 & 25.25 \\
\hline
\end{tabular}

Tabela 1: Síntese das principais diferenças das médias anuais dos experimentos pré e pós industriais de Wainer (2004). Experimentos com 240 e 304ppmv respectivamente.

Além desses impactos previstos no Atlântico Sul, Pereira (2007) ainda descreve a importância da alteração do gelo marinho no Atlântico Sudoeste e na CBM. Segundo 
a autora, a redução do montante de gelo marinho no oceano austral poderia acarretar no deslocamento da CBM para o Sul, bem como aumento de TSM e SSM na região. Este estudo detectou alterações de salinidade e temperatura além da superfície: Na Água Profunda do mar de Weddell (APW), na Água Intermediária Antártica (AIA) e na Água Central do Atlântico Sul (ACAS).

\subsection{O Atlântico Sul e sua importância}

O Oceano Atlântico, um importante reservatório de calor para o sistema climático Levitus 1984), abriga o ramo de maior extensão meridional da circulação termohalina global (Gordon \& Greengrove 1986) que, por transportar grandes quantidades de calor, regula o clima terrestre. A conexão entre este oceano e a circulação termohalina global ocorre através da sua porção austral.

Praticamente toda exportação e importação significativas de volumes d'água no oceano Atlântico ocorrem no Hemisfério Sul (Peterson \& Stramma 1991). Na região Sudoeste, a Corrente do Brasil (CB), através de vórtices, é capaz de introduzir água quente e salina na Corrente Circumpolar Antártica (CCA) e, indiretamente, em outros oceanos, como o Índico (Gordon 1989). Também nessa região, um ramo da Corrente Circumpolar Antártica se desprende e forma a Corrente das Malvinas (CM). Essa corrente transporta águas frias e pouco salinas para o interior do Atlântico Sul (Legeckis \& Gordon 1982). Parte da água injetada, provém do mar de Weddell sendo particularmente densa Reid et al. 1977). Na porção Sudeste, parte da Corrente do Atlântico Sul que não incorpora a Corrente de Benguela, transporta águas para o Índico (Peterson \& Stramma 1991) enquanto que a Corrente das Agulhas insere águas quentes e salinas na corrente de Benguela através do fenômeno Vazamento das Agulhas e, principalmente, da formação de vórtices anticiclônicos e anéis (De Ruijter et al. 1999).

Além desse importante papel na troca de massas d'águas entre as bacias oceânicas, o Atlântico Sul desempenha um papel fundamental na transferência inter-hemisférica de calor. Ao encontrar a costa do Brasil, a Corrente Sul Equatorial se divide em Corrente do Brasil, e Corrente Norte do Brasil. Esta última, não retorna ao giro anticiclônico e segue para o Norte contribuindo à Corrente do Golfo com aproximadamente 10Sv Roemmich 1983). O fluxo exportado para o Hemisfério Norte é compensado por um fluxo, de aproximadamente mesma magnitude, de Água Profunda do Atlântico Norte que segue para 


\begin{tabular}{|c|c|c|c|c|}
\hline & Temperatura & Salinidade & Profundidade & Referência \\
\hline Água Subantártica de Superfície (ASA) & $10^{\circ} \mathrm{C}$ & $<34.3$ & $0-500 \mathrm{~m}$ & Bianchi et al. (1993) \\
\hline Agua Intermediária Antártica (AIA) & $3-5^{\circ} \mathrm{C}$ & 34.2 & $600-1000 \mathrm{~m}$ & Piola \& Gordon (1989) \\
\hline Água Circumpolar Porfunda (ACP) & $2.5^{\circ} \mathrm{C}$ & 34.5 & $1000-3500 m$ & Maаmaаtuaiahutanu (1092) \\
\hline Água Profunda do Mar de Weddel (APMW) & $-0.2^{\circ} \mathrm{C}$ & 34.7 & $>3500 \mathrm{~m}$ & \\
\hline
\end{tabular}

Tabela 2: Massas d'águas que compõem a Corrente das Malvinas.

o Sul. Essa água densa, formada em altas latitudes do Hemisfério Norte, é caracterizada por temperaturas baixas, e flui abaixo da corrente do Brasil até encontrar a Corrente Circumpolar Antártica. Dessa forma, essa troca de águas de temperaturas tão distintas acarreta numa transferência de calor entre os hemisférios (do sul para o norte). A incerteza em quantificar essa transferência é muito elevada devido às limitações físicas e a escassez de dados (Peterson \& Stramma 1991). A formação de correntes profundas no oceano Austral desempenha um papel fundamental no sequestro de Carbono atmosférico. A região das altas latitudes do Oceano Atlântico Sul é conhecida como um dos maiores sorvedouros de gás caobônico entre todos os oceanos (Takahashi et al. 2009; Bianchi et al. 2009).

Além disso, o Atlântico Sul possui forte impacto no clima da América do Sul. Pezzi \& Cavalcanti (2001) descrevem a importância de fenômenos de Dipolo do Atlântico, associados às fases do El Niño resultantdo no deslocamento da Zona de Convergência Intertropical e consequentes anomalias positivas e negativas de pluviosidade na América do Sul e sobretudo no Nordeste brasileiro. Esta região mostrou-se particularmente sensível ao gradiente interhemirférico de temperatura da superfície do mar nesse oceano (Wagner 1996).

No Atlântico Sudoeste, observamos uma das regiões oceânicas mais energéticas do mundo: A Confluência Brasil-Malvinas. Essa região é uma peça chave para o entendimento do Atlântico Sul como um todo, impactando os processos acima descritos.

\section{4 Área de Estudo}

A circulação superficial do Atlântico Sul, é dominada por um sistema de giros e pelas correntes Sul Equatorial e Circumpolar Antártica, forçados principalmente pelo cisalhamento do vento na superfície, induzidos por um centro semi-permanente de alta pressão atmosférica no centro da bacia (Peterson \& Stramma 1991) . Esses ventos, induzem uma 
circulação preferencial anticiclônica e uma intensificação da corrente de borda oeste: a Corrente do Brasil (Stommel 1957). A Figura 2 representa a circulação superficial do Atlântico Sul, adaptado de Peterson \& Stramma (1991).

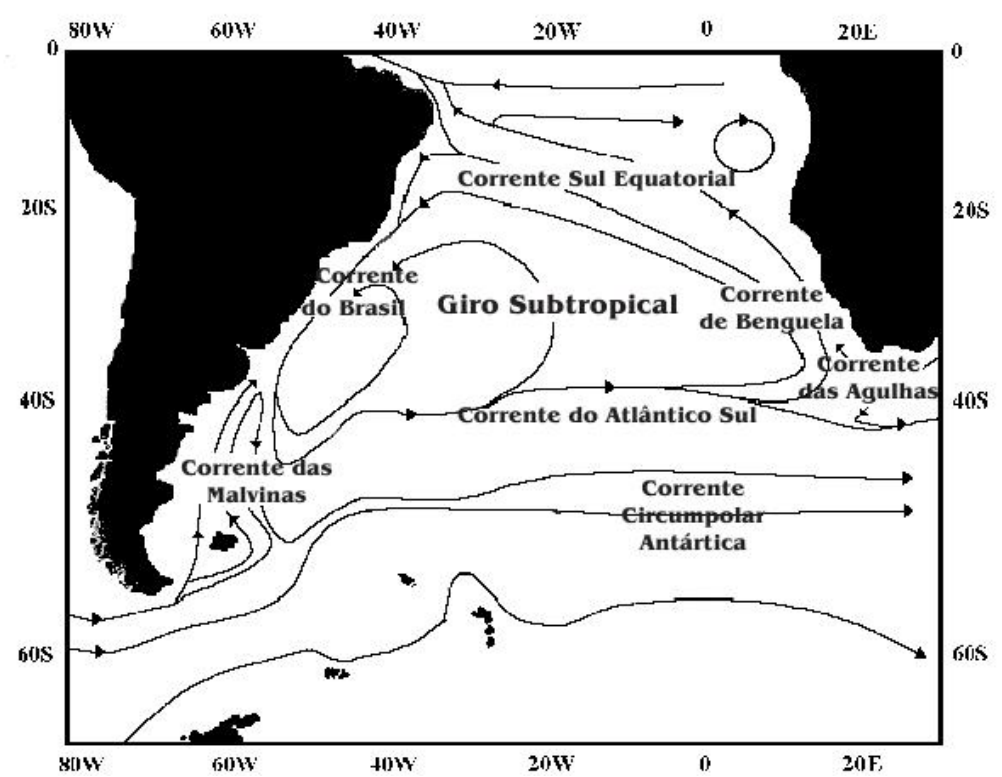

Figura 2: Circulação superficial do Atlântico Sul. Adaptado de Peterson \& Stramma (1991).

O giro anticiclônico é composto por quatro correntes principais:

1. A Corrente do Atlântico Sul: determina o limite Sul do giro anticiclônico e flui por volta de $40^{\circ} \mathrm{S}$. Se origina do encontro da Corrente das Malvinas e da Corrente do Brasil. Segundo Stramma \& Peterson (1990), essa corrente, basicamente zonal, é separada da Corrente Circumpolar Antártica pela Frente Subtropical (fronteira hidrográfica entre a água subtropical e a água subpolar) e começa na região da Confluência Brasil-Malvinas, por volta de $55^{\circ} \mathrm{W}$. Essa corrente pode ser identificada em profundidades maiores que 1000m e transporta em média 30Sv Stramma \& Peterson 1990).

2. A Corrente de Benguela: na região Sudoeste da costa africana, a Corrente do Atlântico Sul passa a fluir para Norte, e com alguma contribuição da Corrente das Agulhas (aproximadamente 8Sv) (Peterson \& Stramma 1991), forma a Corrente de Benguela. Essa corrente determina o extremo leste do giro subtropical sendo mais fraca que a Corrente do Brasil, flui pela costa Sudoeste da África antes de formar a 
Corrente Sul Equatorial. A magnitude máxima de transporte encontrada na camada superficial foi em $32^{\circ} \mathrm{S}$ equivalente a $21 \mathrm{~Sv}$ (Stramma 1989).

3. A Corrente Sul Equatorial: Essa corrente determina o limite Norte do giro subtropical do Atlântico Sul estendendo-se não só zonalmente, mas também meridionalmente. Sua velocidade é marcada por uma forte variabilidade temporal e espacial (Stramma et al. 1991). Essa corrente dá origem às Correntes do Brasil e do Norte do Brasil, sendo a última mais intensa.

4. A Corrente do Brasil: fortemente baroclínica (da Silveira et al. 1999), flui para Sul contornando a plataforma continental leste da América do sul carregando águas quentes e salinas de baixas latitudes. Essa corrente, estende-se da superfície até 400 a 700m de profundidade, e transporta Água Tropical (AT) e Água Central do Atlântico Sul (ACAS) (Wüst 1935 apud da Silveira et al. 2000).Como grande parte da água da Corrente Sul Equatorial é desviada para o Norte, essa corrente não possui grande força (Peterson \& Stramma 1991), atingindo um máximo de superfície de $72 \mathrm{~cm} / \mathrm{s}$ (Miranda \& Castro Filho 1982) em $19^{\circ} \mathrm{S}$ e transporte de $6,5 \mathrm{~Sv}$ (nível de referência de 500m). Mais que 50\% desse transporte se limita aos primeiros $200 \mathrm{~m}$ aumentando a partir de $24^{\circ} \mathrm{S}$ a uma taxa de $5 \%$ a cada $100 \mathrm{~km}$ Gordon \& Greengrove 1986). Através de imagens de infravermelho de satélite, Garfield (1988) demonstrou que boa parte da corrente do Brasil flui na plataforma continental nunca se desprendendo muito da costa.

O limite sul dessa Corrente é determinado por seu encontro com a Corrente das Malvinas, podendo variar entre 35 e $40^{\circ} \mathrm{S}$ (Wainer et al. 2000).

A Corrente das Malvinas, é uma ramificação da Corrente Circumpolar Antártica que permeia o Atlântico Sul através da Passagem de Drake e flui sobre a plataforma continental. Como a Corrente Circumpolar Antártica, a Corrente das Malvinas é essencialmente fria e pouco salina. Seu transporte é fortemente barotrópico (Garzoli 1993). Através de dados históricos de campos de densidade e um modelo numérico multi-camadas, Zyryanov \& Severov (1979) estimaram um transporte verticalmente integrado de 32Sv durante o inverno e de 40Sv no verão. Essa corrente é extremamente sensível à variabilidade dos ventos de oeste que forçam os movimentos oceânicos austrais. 


\subsubsection{A Corrente do Brasil}

Stommel (1948) descreveu os giros anticiclônicos oceânicos e observou que a vorticidade relativa fornecida pelo rotacional dos ventos sinóticos para a superfície oceânica gerava uma intensificação das Correntes de Contorno Oeste. No Atlântico Sul, a Corrente do Brasil (que estabelece o limite oeste do giro subtropical) possui intensidade muito inferior à sua equivalente no Atlântico Norte - A Corrente do Golfo. Essa diferença pode ser explicada pela estrutura termohalina dos dois compartimentos oceânicos que no Norte é favorável a essa corrente e no Sul é contrário (Stommel 1965). A Figura 3 representa a hipótese de Stommel para a assimetria das estruturas dinâmicas entre os dois hemisférios, apesar da similaridade de intensidade e conformação dos ventos.

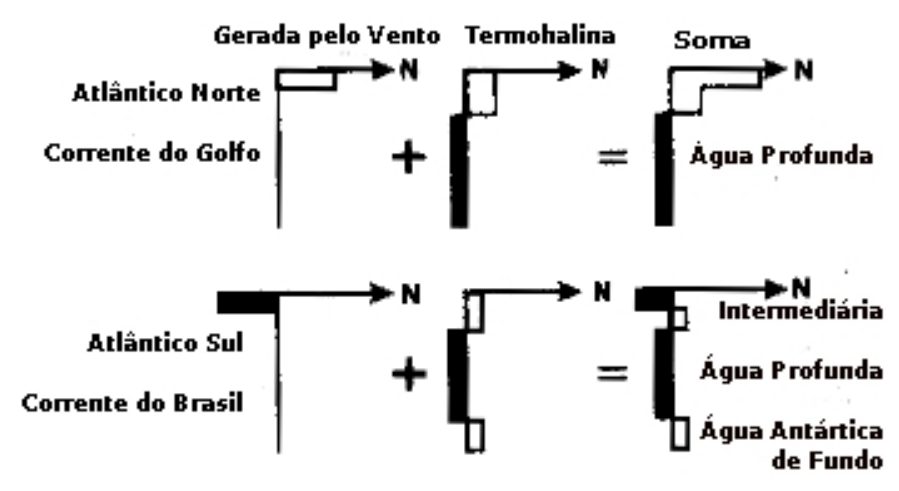

Figura 3: Representação esquemática da hipótese de Stommel(1965) a menor intensidade da Corrente do Brasil em relação à Corrente do Golfo. Adaptado de Silveira (2000).

No Atlântico Norte, observamos um modelo de duas camadas na estrutura termohalina (para norte em superfície e para o sul nas águas profundas). Assim, a Corrente do Golfo conta com as duas componentes para norte (a termohalina e a forçada pelos ventos). Por outro lado, a Corrente do Brasil possui componentes contrárias (termohalina para sul e para norte descrita por Sverdrup) justificando a diferença de intensidade das duas correntes e a inversão das velocidades entre 400 e 700m. Além disso, a circulação termohalina da região ainda conta com a Água Antártica de Fundo (a partir dos 4000m) para norte.

A corrente do Brasil, origina-se da bifurcação da Corrente Sul Equatorial e percorre a costa do Brasil e do Uruguai até se separar da costa abruptamente quando encontra outra corrente de composição termohalina muito diferente - A Corrente das Malvinas (entre 33 
e $38^{\circ} \mathrm{S}$ ) onde as correntes se separam da costa e fluem sentido leste (Peterson \& Stramma 1991).

A Corrente do Brasil é definida como a corrente de contorno oeste superficial em direção ao sul, que encerra o giro subtropical do Atlântico Sul. Embora a massas d'água da região sejam as características desse oceano: Água Tropical (AT), Água Central do Atlântico Sul (ACAS), Água Intermediária Antártica (AIA), Água Circumpolar Superior (ACS) e Água Profunda do Atlântico Norte (APAN) (da Silveira \& Brown 2000), por ser uma corrente superficial a CB transporta apenas as duas primeiras.

O transporte da Corrente do Brasil varia muito com a latitude e com o nível de referência adotado. Em $22^{\circ} \mathrm{S}$ o transporte da Corrente do Brasil com o nível de referência em $500 \mathrm{~m}$ foi calculado em $6 \mathrm{~Sv}$ (da Silveira et al. 2004), enquanto que em $38^{\circ} \mathrm{S}$ foi de 19Sv (Gordon \& Greengrove 1986). Essa corrente essencialmente baroclínica é dominada por uma variabilidade de períodos entre 130 a 300 dias associada à variação de tensão de cisalhamento do vento sobre o Atlântico Sul (Olson et al. 1988).

\subsubsection{A Corrente das Malvinas}

Olson (1988) definiu a Corrente das Malvinas como aquela que é originada de um ramo da frente mais boreal (Subantártica) associada à Corrente Circumpolar Antártica no Estreito de Drake após a bifurcação das águas subantárticas ao passarem pelo Arquipélago das Malvinas. Essa corrente, após contornar o Platô das Malvinas segue para oeste até a quebra da plataforma onde passa a fluir para Norte até encontrar a Corrente do Brasil.

Ao contrário da Corrente do Brasil, a Corrente das Malvinas possui um fluxo homogêneo (sempre para o Norte) da superfície até o fundo, caracterizando uma corrente barotrópica. Vivier \& Provost (1999) sugerem que o transporte barotrópico corresponde a mais da metade do transporte total.

As estimativas de transporte dessa corrente variam muito. Enquanto Peterson (1992) estima o transporte em 88Sv, Vivier e Provost (1999) estimaram em 41,5Sv.

Diversas massas d'água compõem a Corrente das Malvinas. A Tabela 3 representa tais massas d'águas, sua propriedades termohalinas e sua respectiva profundidade.

Embora a Corrente das Malvinas aparente ter uma variabilidade basicamente inter anual, Vivier \& Provost (1999) idear="2010" entificaram a presença de ciclos de períodos de cerca de 135 dias associados à interação com a Corrente Circumpolar Antártica. 


\begin{tabular}{|c|c|c|c|c|}
\hline & Temperatura & Salinidade & Profundidade & Referência \\
\hline Água Subantártica de Superfície (ASA) & $10^{\circ} \mathrm{C}$ & $<34.3$ & $0-500 \mathrm{~m}$ & Bianchi et al. (1993) \\
\hline Agua Intermediária Antártica (AIA) & $3-5^{\circ} \mathrm{C}$ & 34.2 & $600-1000 \mathrm{~m}$ & Piola \& Gordon (1989) \\
\hline Água Circumpolar Porfunda (ACP) & $2.5^{\circ} \mathrm{C}$ & 34.5 & $1000-3500 m$ & Maаmaаtuaiahutanu (1092) \\
\hline Água Profunda do Mar de Weddel (APMW) & $-0.2^{\circ} \mathrm{C}$ & 34.7 & $>3500 \mathrm{~m}$ & \\
\hline
\end{tabular}

Tabela 3: Massas d'águas que compõem a Corrente das Malvinas.

\subsubsection{A Confluência Brasil Malvinas}

O encontro entre essas duas correntes gera processos dinâmicos particularmente complexos, sendo uma das regiões oceânicas mais energéticas do planeta (Chelton et al. 1990). É conhecida como a região da Confluência Brasil-Malvinas. O contraste entre as características termohalinas das correntes, torna-a intensamente complexa marcada por fortes gradientes horizontais de propriedades físicas, alta variabilidade temporal e consequentemente intensa atividade de instabilidades geofísicas e formação de meandros e vórtices (Legeckis \& Gordon 1982).

As medições do transporte meridional líquido médio de volume na região da CBM oscilam entre 10Sv (Garzoli \& Bianchi 1987) e 11Sv (Garzoli 1993) - sempre para Sul. As velocidades máximas foram encontradas por volta de $38^{\circ} \mathrm{S}(0,55 \mathrm{~m} / \mathrm{s})$ e a velocidade média de $0,35 \mathrm{~m} / \mathrm{s}$.

A Figura 4 (Adaptada de Peterson \& Stramma, 1991), representa a circulação superficial do Atlântico Sudoeste incluindo a Corrente do Brasil e a Confluência Brasil Malvinas.

Além disso, há a descarga do Rio da Prata de cerca de $153 \mathrm{~km}^{3}$ de água doce de alta temperatura ao ano (Depetris \& Paolini 1991). Na região, foram detectadas variações superficiais de temperatura de 7 a $18^{\circ} \mathrm{C}$ e de salinidade entre 33,6 e 36,0 (Gordon 1989).

Em um estudo observacional a bordo do primeiro cruzeiro de alta resolução espacial (22km entre cada estação) na região da Confluência Brasil-Malvinas (Confluence 3) durante o verão de 1990, Provost (1996) descreveu as principais feições hidrográficas superficiais utilizando dados de CTD, concentração de oxigênio e clorofila, além de dados de Infra-vermelho (satélite), fluxo de calor e volume de descarga fluvial da bacia do Prata. O estudo descreveu frentes demarcadas por fortes contrastes de propriedades das massas d'águas, identificando o encontro de águas de origens distintas. Foram encontradas 4 frentes principais:

1. Frente Leste-Oeste: Gradientes meridionais intensos de temperatura e oxigênio as- 


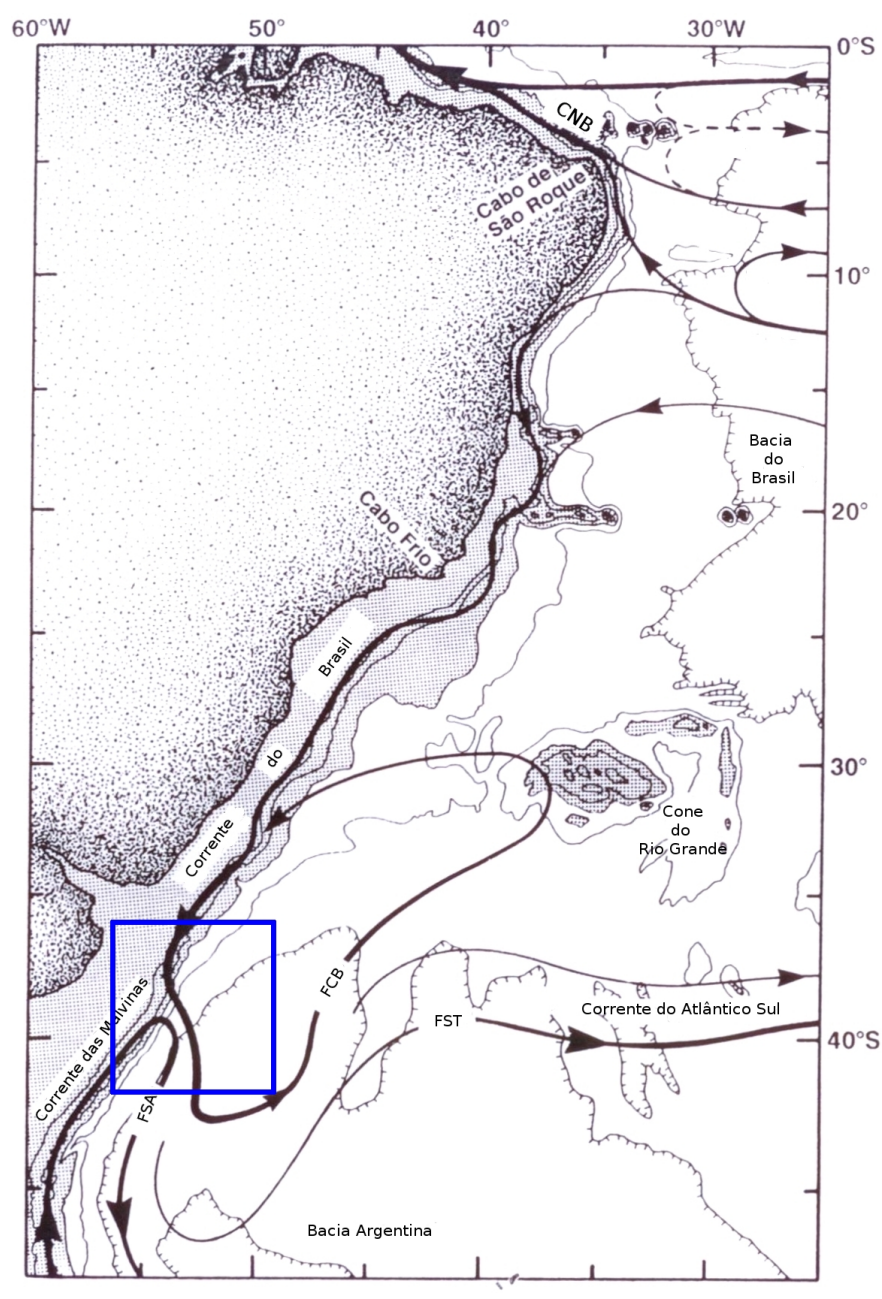

Figura 4: Circulação superficial do Atlântico Sudoeste e a Confluência Brasil Malvinas. Termos abreviados: Corrente Norte do Brasil (CNB), Frente Subantártica (FSA), Frente da Corrente do Brasil (FCB) e Frente Subtropical (FST). Adaptado de Peterson \& Stramma (1991).

sociadas à termoclina sazonal (água mais gelada, doce e supersaturada em oxigênio ao sul).

2. Frente Norte-sul: Forte gradiente zonal de salinidade devido às águas da Bacia do Prata.

3. Frente da Quebra da plataforma: Caracterizada pelo contraste da alta concentração de Clorofila a ao encontrar as águas de plataforma.

4. Frente entre a Corrente das Malvinas e a retroflexão associada à Confluência.

Além disso, esse estudo detectou a presença de três corpos d'água distintas descritas na 
Tabela 4. Uma massa d'água leve, proveniente do Rio da Prata, outra muito densa, proveniente da Corrente das Malvinas e por fim uma massa d'água intermediária proveniente da Corrente do Brasil.

\begin{tabular}{ccc}
\hline \hline Origem & Temperatura & Densidade \\
\hline \hline Corrente do Brasil & $>23^{\circ} \mathrm{C}$ & 24.70 \\
Corrente das Malvinas & $<11^{\circ} \mathrm{C}$ & 25.00 \\
Rio da Prata & $>24^{\circ} \mathrm{C}$ & 24.00 \\
\hline
\end{tabular}

Tabela 4: Temperatura $\left({ }^{\circ} \mathrm{C}\right)$ e densidade $\left(\mathrm{kg} / \mathrm{m}^{-3}\right)$ das três corpos d'água identificadas na superfície da confluência Brasil-Malvinas, descrita por Provost (1996).

Embora as águas subantárticas carregadas pela Corrente das Malvinas e a ACAS, presentes na termoclina da Corrente do Brasil ocupem a mesma amplitude no limite de densidade $\left(\sigma=25,5-27 \mathrm{kgm}^{-3}\right)$, elas têm características termohalinas muito diferentes e a convergência dessas massas d'água permite a formação de camadas alternadas de águas subantárticas e subtropical conhecidas como "estruturas intercaladas" (Piola et al. 2000).

Outro estudo de Provost (1993) utilizando dados do Geosat de altimetria entre Novembro de 1986 e Dezembro de 1988 encontrou uma forte anisotropia na região com relação à velocidade, que pode estar associada ao movimento frontal. Na região de máxima variabilidade, as variações meridionais de velocidade são três vezes mais significativas que as zonais. Ainda nesse estudo, o autor detectou sinais de períodos e escalas espaciais consistentes com ondas de Rossby nesta latitude.

Essa região não homogênea espacialmente, também é marcada por uma forte variabilidade temporal.

A posição típica média da CBM é $38^{\circ} \mathrm{S}$ (Gordon \& Greengrove 1986). Diversos autores descreveram a oscilação da posição da Confluência Brasil-Malvinas e determinaram que esta se desloca para o Norte durante o inverno austral (Gordon 1989; Matano et al. 1993 Provost \& Traon 1993; Wainer et al. 2000), porém suas forçantes não foram completamente descritas. A variação da posição da CBM possui amplitude média de 1 a $6^{\circ} \mathrm{e}$ velocidade média de $0,14 \mathrm{~ms}^{-1}$ (Goni \& Wainer 2001).

A presença de meandros pode fazer com que a CBM atinja regiões mais austrais (até $\left.44^{\circ} \mathrm{S}\right)$. As componentes anual e inter anual respondem por mais de $75 \%$ da variabilidade das oscilações da frente (Goni \& Wainer 2001). Diversos estudos indicam a influência da variabilidade anual da Corrente do Brasil na Confluência Brasil Malvinas (Legeckis 
\& Gordon 1982, Matano et al. 1993; Wainer et al. 2000), porém Legeckis \& Gordon (1982) mostraram que o efeito sazonal não é capaz de explicar completamente a oscilação da CBM, sendo necessário também considerar os processos turbulentos. Giarolla (1999) em um experimento numérico forçado somente pelo cisalhamento do vento, verificou uma oscilação de até $5^{\circ}$ de latitude na posição da CBM sem considerar a variação sazonal dessa variável. Nesse mesmo estudo, constatou que a região abriga mais de $40 \%$ da energia cinética não turbulenta do Atlântico Sul e a intensa atividade da instabilidade baroclínica na região.

A interação oceano-atmosfera na região ainda foi pouco estudada. Pezzi et al. (2005) sugere que o limite da camada atmosférica sobre a região é fortemente modulada pelo intenso gradiente termal entre a CB e a CM. A velocidade do vento em superfície mostrou-se muito correlacionada às anomalias de TSM na região. Processos turbulentos de pequenas escalas espaço-temporais gerados na interação oceano-atmosfera podem induzir a variabilidades na evolução de processos de grande escala tanto no oceano quanto na atmosfera (Acevedo et al. 2010).

A posição da CBM varia entre 40 e $46^{\circ} \mathrm{S}$ durante o verão (Legeckis \& Gordon 1982) e de 35 a $30^{\circ} \mathrm{S}$ no inverno (Ciotti et al. 1995). Diversos estudos demonstram que a CBM possui variabilidade sazonal e inter anual (Provost et al. 1992, Garzoli \& Giulini 1994; Ciotti et al. 1995). Tais oscilações podem estar relacionados tanto a variabilidades na Corrente do Brasil quanto na corrente das Malvinas (Garzoli \& Giulini 1994; Smith et al. 1994). Wainer et al. (2000) encontraram uma forte correlação entre a variação da posição da CBM e a tensão de cisalhamento do vento em $40^{\circ} \mathrm{S}$.

Por determinar a fronteira entre águas quentes do giro tropical e frias da Corrente Circumpolar Antártica, essa oscilação da Confluência Brasil-Malvinas possui forte impacto tanto no clima local quanto na biota marinha (Matano et al. 1993).

Outro fenômeno peculiar à essa região é a alta taxa de emissão de vórtices (Legeckis \& Gordon 1982). Na região da retroflexão, a Corrente do Brasil desprende 7 a 9 vórtices anticiclônicos ao ano (Lentini et al. 2002).

Devido a sua complexidade dinâmica, a região é de difícil compreensão e previsão de cenários futuros. Um estudo utilizando o Climate System Model (CSM), realizado por Wainer et al. (2000), mostrou que um modelo de baixa resolução não é capaz de resolver processos dinâmicos de meso-escala como livre-circulação e meandros, mas é capaz de 
reproduzir as características sazonais da Confluência Brasil-Malvinas.

Em um estudo com altímetros dos satélites TOPEX/Poseidon e Jason, Polito \& Sato (2008) constataram uma tendência fortemente positiva de anomalia da altura da superfície do mar e consequentemente mais energia potencial disponível. Além disso, o gradiente horizontal dessa grandeza também aumentou, intensificando as correntes geostróficas, a quantidade de energia cinética disponível e a possibilidade de instabilidades geostróficas. Foi observado aumento de amplitude de ondas de Rossby e vórtices.

Ferreira (2010) observou através de dados de altímetros entre 1993 e 2008 que a região da CBM apresentou maior energia associada a ondas de Rossby, maior variabilidade da Frente (que não mostrou-se relacionado a fenômenos de El Niño ou La Niña) e o deslocamento para o sul dessa feição. O entendimento desses processos em um cenário climático distinto é um desafio.

Além da extrema importância da CBM na oceanografia de meso-grande escala, a região mostrou-se muito sensível às mudanças climáticas do Antropoceno. A Figura 5 mostra a tendência de aumento de temperatura de superfície entre 1958 e 2000 segundo o conjunto de dados de reanálise do Simple Ocean Data Assimilation System (SODA).

A Figura 5 mostra que no século XX, a região da Confluência é significativamente impactada pelas mudanças do clima. A descrição de seu comportamento em cenários de aquecimento ainda mais extremos é de fundamental importância para o entendimento da resposta do Atlântico Sul às mudanças climáticas globais.

\subsection{Motivação}

A região da Confluência Brasil-Malvinas desempenha um importante papel na circulação do Atlântico Sul, na troca de massa d'água entre os oceanos e no clima local. Sua enorme complexidade torna difícil sua compreensão e principalmente sua previsão sob cenários climáticos futuros, sobretudo em modelos de escalas globais. A região mostra-se muito sensível às mudanças climáticas atuais. A necessidade de compreender as respostas da região de estudo às mudanças climáticas globais é a principal motivação desse trabalho.

\subsection{Hipótese Científica}

A hipótese desse trabalho é que sob um cenário de aquecimento global o Atlântico Sudoeste sofrerá alterações maiores neste século em relação ao século passado. O padrão 


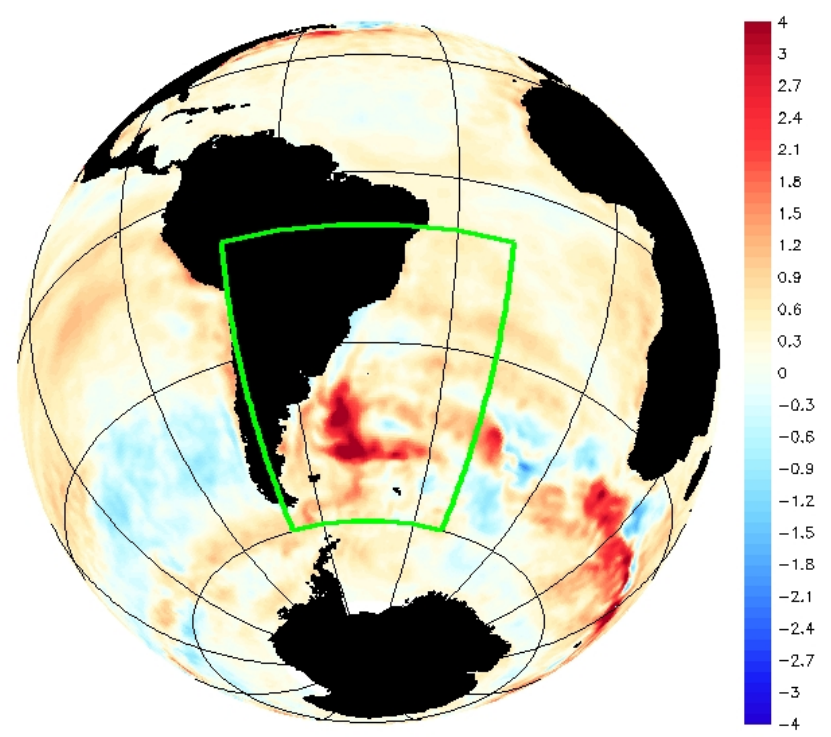

Regiao de Estudo

Figura 5: Tendência de aumento de TSM entre 1958 e 2000 em $10^{-1}{ }^{\circ} \mathrm{C}$ segundo os dados do dados de reanálise do Simple Ocean Data Assimilation System (SODA). 
climatológico, médio e espectral da posição da CBM, bem como das variáveis físicas são alterados na região. A posição média da CBM será deslocada para sul e sua amplitude anual média aumentada como resposta à introdução de energia no sistema.

\subsection{Objetivo}

Esse trabalho objetiva descrever o comportamento do Atlântico Sudoeste em cenários futuros de aquecimento global e compará-los com o século XX, através do modelo numérico do $4^{\circ}$ Relatório do IPCC mais adequado para a região. Descrever o padrão climatológico e espectral de salinidade, temperatura e tensão de cisalhamento do vento, bem como da posição da CBM.

\subsubsection{Objetivos Específicos}

1. Determinar qual dos modelos representa melhor a região da Confluência BrasilMalvinas.

2. Determinar a posição média da Confluência Brasil Malvinas e sua variabilidade (amplitude e frequência) temporal para os dois cenários de aquecimento e para o século XX e sua tendência.

3. Comparar os padrões e formas de variabilidades dos parâmetros oceanográficos e suas principais tendências nos dois cenários.

4. Comparar os índices termohalinos de três massas d'águas principais: Água Tropical (AT), Água Intermediária Antártica (AIA) e Água Profunda do Atlântico Norte (APAN) no século XX e nos cenários A1b e B2. 


\section{Materiais e Métodos}

\subsection{Descrição dos dados}

Neste trabalho serão utilizados dados dos modelos numéricos do Intergovernmental Panel on Climate Change (IPCC) e de Reanálise do Simple Ocean Data Assimilation (SODA).

\subsubsection{As simulações numéricas do IPCC}

As previsões climáticas do IPCC utilizam modelos numéricos para sintetizar o efeito de emissões hipotéticas de gases estufa no oceano e na atmosfera. Para isso, foram utilizados diferentes cenários prognósticos de emissão de gases estufa e diferentes modelos numéricos desenvolvidos por diversos centros de pesquisa em clima ao redor do globo.

\section{Os cenários de desenvolvimentos globais do IPCC}

Os cenários de emissão de carbono do IPCC (Special Report on Emissions Scenarios - SRES) são agrupados em quatro famílias: A1, A2, B1 e B2, que exploram maneiras diversas de desenvolvimento, abrangendo uma grande variedade de evoluções demográficas, econômicas e tecnológicas, resultando em diferentes quantidades de emissões de gases estufa (IPCC 2001). As projeções de emissões são amplamente utilizadas na estimativa de futuras mudanças climáticas. As estimativas de desenvolvimentos socioeconômico, demográfico e tecnológico subsidiam as previsões atuais de mudanças climáticas e seus impactos.

Cada cenário futuro é caracterizado por diferentes taxas de emissões dos principais gases estufas e precursores de ozônio (IPCC 2001) (eg. Gás Carbônico, Metano, Óxido Nítrico, Óxidos de Nitrogênio em Geral, Clorofluorcarbonos).

\section{Descrição dos Cenários}

O cenário A1, assume um planeta caracterizado pelo rápido crescimento econômico, uma população que aumenta intensamente até a metade do século e uma rápida introdução de tecnologias mais novas e eficientes.

O cenário de um planeta marcado pela heterogeneidade, grande crescimento populacional e econômico e um desenvolvimento tecnológico letárgico é descrito pelo cenário $\mathrm{A} 2$.

O cenário B1 descreve um mundo mais convergente com mesma população mundial 


\begin{tabular}{|c|c|c|c|c|c|c|c|c|}
\hline $\begin{array}{l}\text { Gases / } \\
\text { Cenários }\end{array}$ & $\begin{array}{c}\text { CO } \\
\text { (Gigatons } \\
\text { de Carbono) }\end{array}$ & $\begin{array}{c}\text { CH } \\
\text { (Megatons } \\
\text { de Metano) }\end{array}$ & $\begin{array}{c}\text { NO } \\
\text { Megatons } \\
\text { de } \\
\text { Nitrogênio }\end{array}$ & $\begin{array}{c}\text { HPFC, PFC, SF } \\
\text { (Megatons de } \\
\text { Carbono } \\
\text { Equivalente) }\end{array}$ & $\begin{array}{c}\text { CO } \\
\text { (Megatons) }\end{array}$ & $\begin{array}{l}\text { NMVOCs } \\
\text { (Megatons) }\end{array}$ & $\begin{array}{c}\text { NO } \\
\text { (Megatons } \\
\text { de } \\
\text { Nitrogênio) }\end{array}$ & $\begin{array}{c}\text { SO } \\
\text { (Megatons } \\
\text { de Enxofre) }\end{array}$ \\
\hline$A 1 b$ & $\begin{array}{c}29,1(19,6- \\
34,5)\end{array}$ & $\begin{array}{c}889(549- \\
1069)\end{array}$ & $\begin{array}{c}16,5(8,1- \\
19,3)\end{array}$ & 1096 & $\begin{array}{c}2325(776- \\
2646)\end{array}$ & $\begin{array}{c}342(169 \\
-342)\end{array}$ & $\begin{array}{c}192(70,9- \\
110,0)\end{array}$ & $\begin{array}{c}60,3(60,3- \\
92,9)\end{array}$ \\
\hline B2 & $\begin{array}{c}13,3(10,8- \\
21,8)\end{array}$ & $\begin{array}{c}597(465- \\
613)\end{array}$ & $\begin{array}{c}6,9(6,9- \\
18,1)\end{array}$ & 839 & $\begin{array}{c}2002(661- \\
2002)\end{array}$ & $\begin{array}{c}170(130- \\
304)\end{array}$ & $\begin{array}{c}61,2(34,5- \\
76,5)\end{array}$ & $\begin{array}{c}47,9(33,3- \\
47,9)\end{array}$ \\
\hline
\end{tabular}

Tabela 5: Tabela de emissão de gases estufa no contexto de dois cenários climáticos propostos pelo IPCC (Adaptado de IPCC Special Report and Scenario Family).

que os cenários A1, mas caracterizado por mudanças econômicas mais rápidas e intensas. O cenário B2, estima um mundo de crescimentos populacional e econômico moderados, enfatizando soluções locais para a sustentabilidade econômica, social e ambiental.

Neste trabalho foram escolhidos dois cenários contrastantes como objeto de estudo.

1. O cenário A1b, caracterizado por elevadas taxas de emissões de gases estufa.

2. No outro extremo escolhemos o cenário B2.

As emissões no cenário XXI previstas para cada cenário estão expressas na Tabela 5. O cenário $A 1$

A1 é o cenário que descreve um mundo futuro em que a globalização é dominante. Nesse cenário os crescimentos econômico e populacional são rápidos e o desenvolvimento tecnológico é mais eficiente. Algumas questões paralelas são a convergência econômica e cultural, com uma redução significativa em diferenças regionais e renda per capita. A família de cenários A1 se divide em três grupos que descrevem direções alternativas da mudança tecnológica no sistema energético. Os três grupos de A1 distinguem-se por sua ênfase tecnológica: intensiva no uso de combustíveis fósseis (A1F1), fontes energéticas não-fósseis $(\mathrm{A} 1 \mathrm{~T})$ ou um equilíbrio entre todas as fontes (A1B) (não dependendo exclusivamente de uma determinada fonte de energia);

O cenário B2 
Este cenário é marcado pelo regionalismo. Temos um cenário bem mais brando no sentido de emissão de gases estufas. Nesse caso, o desenvolvimento é marcado por grande preocupação regional com sustentabilidade e muitos esforços se intensificam no sentido de desenvolver formas de energia alternativas e limpas. A sociedade mais instruída e com maior acesso à informação, intensifica o desenvolvimento social, tecnológico e econômico de forma sustentável. Além disso, nesse contexto, a população cresce de forma muito mais controlada. Em 2100 a população prevista é de 10 bilhões de habitantes, contra 15 bilhões do cenário A1b. Dessa forma, a expansão agropecuária é contida.

\section{Os modelos numéricos}

O $4^{\circ}$ Relatório de Avaliação do IPCC utilizou dados de saída de 23 modelos numéricos acoplados. Todos eles consideram o acoplamento entre o oceano e atmosfera como principais forçantes do clima terrestre. Foram utilizados desde modelos de apenas duas componentes (oceânica e atmosférica), como o modelo alemão ECHAM5/MPI-OM, desenvolvido pelo Max-Planck Institute, até modelos de cinco componentes, no caso do modelo japonês Model for Interdisciplinary Research on Climate - MIROC - que considera também descarga de rios, a interação com o gelo marinho e os fluxos de água e temperatura com as superfícies continentais no seu processamento.

Neste trabalho, pretende-se utilizar as saídas de três desses modelos: MIROC, GFDL e CCSM3. Para o Atlântico Sul, esses modelos obtiveram bons desempenhos quando comparados com o século XX e com a climatologia (Russell et al. 2007; Ferrero 2009).

O MIROC, desenvolvido e mantido pelo Center for Climate System Research (CCSR - Tóquio), pelo National Institute for Environmental Studies (NIES) e pelo Frontier Research Center for Global Change (FRCGC), utiliza um acoplador de fluxos, sendo que a atmosfera somente interage com o oceano (modelado pelo CCSR Ocean Component Model - COCO) através da criosfera (Hasumi \& Emori 2004). Esse modelo utiliza a equação geral do movimento geofísico e as aproximações hidrostática e de Boussinesq. Sua resolução espacial é de $0,2815^{\circ}$ de latitude por $0,1875^{\circ}$ de longitude e 47 níveis verticais no oceano.

O modelo climático americano GFDL-CM2.1, desenvolvido pelo NOAA's Geophysical Fluid Dynamics Laboratory acopla terra/biosfera, criosfera, atmosfera e oceano. O acoplamento oceano-atmosfera, ocorre a cada duas horas e o modelo não corrige os fluxos. Embora a resolução temporal seja equivalente nos modelos oceânicos e atmosféricos descritos, a resolução espacial é diferente para cada um deles. 
O modelo climático acoplado Community Climate System Model, desenvolvido pelo National Center for Atmospheric Research - NCAR conta com 4 componentes: atmosfera, oceano, gelo marinho e continentes. Há representação na atmosfera de alguns processos químicos de modificação da concentração de gases estufas por reações químicas e a formação de aerossóis a partir de dióxido de enxofre e Sulfeto de Dimetila. Nesse modelo, as resoluções espaciais são distintas para cada componente. O modelo atmosférico varia sua resolução com a latitude, sendo no Equador de 1,4 . Por outro lado, o modelo oceânico possui 320 x 384 pontos de grade horizontal e 40 níveis verticais.

Em relação ao $3^{\circ}$ Relatório de Avaliação do IPCC, os modelos descritos foram aprimorados sobretudo no que diz respeito a três critérios: aumento da resolução horizontal e vertical dos modelos (bem como de componentes dinâmicas), maior número de processos incorporados (particularmante a modelagem de aerossóis e de processos de superfícies continental e de gelo) e a aprimoramento das parametrizações dos modelos. Nenhum dos três modelos escolhidos nesse trabalho possui correção de fluxos (para evitar a "deriva" do modelo) e todos trabalham com processos dinâmicos de cisalhamento de gelo marinho, bem como com a formação de fissuras nas camadas de gelos.

As características principais das componentes oceânicas e atmosféricas dos três modelos esstão expressas na Tabela 6 .

\begin{tabular}{|c|c|c|c|}
\hline & Patrocinadores & Atmosfera & Oceano \\
\hline & País & $\begin{array}{l}\text { Pressāo no topo } \\
\text { Resoluçāo }\end{array}$ & $\begin{array}{c}\text { Resoluçāo } \\
\text { Coordenadas Z } \\
\text { Tipo de Superficie }\end{array}$ \\
\hline cсsм3 & $\begin{array}{l}\text { National Center for Atmospheric Research (NCAR) } \\
\text { USA }\end{array}$ & $\begin{array}{c}2,2 \mathrm{hPa} \\
1.4 \times 1.4^{\circ}\end{array}$ & $\begin{array}{l}0,3-1 \times 1^{\circ} \\
\text { Isobáricas } \\
\text { Livre }\end{array}$ \\
\hline GFDL CM 2.1 & $\begin{array}{l}\text { U. S. Department of Commerce/ National Oceanic and Atomspheric Administratio } \\
\text { (NOAA)/ Geophysical Fluid Dynamics Laboratory } \\
\text { USA }\end{array}$ & $\begin{array}{l}3 \mathrm{hPa} \\
2 \times 2,5^{\circ}\end{array}$ & $\begin{array}{c}0,3-1 \times 1^{\circ} \\
\text { Isobáricas } \\
\text { Livre }\end{array}$ \\
\hline MIROC 3.2 (hires) & $\begin{array}{c}\text { Center for Climate System Research (University of Tokyo) / National Institute for } \\
\text { Environmental Studies/ Frontier Research Center for Global Change (JAMSTEC) } \\
\text { Japan }\end{array}$ & $\begin{array}{c}3 \mathrm{hPa} \\
1,1^{\circ} \times 1,1^{\circ}\end{array}$ & $\begin{array}{c}0,2 \times 0,3^{\circ} \\
\text { Sigma } \\
\text { Livre }\end{array}$ \\
\hline
\end{tabular}

Tabela 6: Resolução dos modelos oceânicos e atmosféricos utilizados pelo GFDL para o $4^{\circ}$ Relatório de Avaliação do IPCC

\subsubsection{Os dados de Reanálise do Simple Ocean Data Assimilation}

O SODA (Simple Ocean Data Assimilation) utiliza assimilações de dados em um modelo numérico oceânico baseado no Parallel Ocean Program 1.3 (POP). Este modelo possui 900 X 600 pontos de grade com uma resolução horizontal média de $0,255^{\circ}$ x $0,405^{\circ}$. Sua 
resolução vertical é de 10 metros nas regiões superficiais, com um total de 40 níveis verticais. Para as assimilações de dados, o SODA utiliza um esquema em que os dados observados de temperatura e salinidade são utilizados para atualizar o modelo numérico. Esse esquema de assimilação é descrito detalhadamente por Carton et al. (2000a); Carton et al. (2000b) . A avaliação deste conjunto de dados e a comparações com observações independentes podem ser encontradas em Carton \& Geise (2007) .

As reanálises do SODA utilizam os dados do European Center for Medium Range Weather Forecasts (ERA-40) para tensão de cisalhamento do vento entre 1958 e 2001 e do escaterômetro QuickSCAT de 2000 a 2004.

\subsection{Etapas de Trabalho}

Este trabalho é constituído de duas etapas principais:

1. Comparação entre os resultados dos modelos numéricos e os dados de reanálise global do SODA (Simple Ocean Data Assimilation) para o século XX.

2. Comparação entre as saídas dos diferentes cenários climáticos para o século XXI.

\subsubsection{Comparação dos Modelos no século XX e Determinação da melhor representação do Atlântico Sudoeste}

A região Brasil-Malvinas comporta um sistema de massas d'água de origens muito distintas (Reid et al. 1977; Gordon 1989). Dessa forma, os processos oceânicos são demarcados por fortes contrastes de salinidade e temperatura, o que torna essas duas propriedades eficientes traçadores da dinâmica local. Dessa forma, pretende-se comparar a evolução temporal da distribuição horizontal e vertical dessas variáveis da saída do modelo numérico e os dados de Reanálise através das seguintes etapas:

- Comparação dos padrões médios de superfície e perfis verticais entre o SODA e os três modelos das seguintes variáveis: Temperatura potencial, salinidade, velocidade de corrente, tensão de cisalhamento do vento sobre o mar e densidade além da posição média da CBM e transportes das Correntes das Malvinas e do Brasil.

- Determinação e comparação entre os modelos dos Índices Termohalinos e as profundidades das seguintes massas d'água: AT, AIA e APAN. 
- Comparação do ciclo sazonal das variáveis acima descritas.

- Comparação entre as tendências das variáveis na superfície e no fundo.

- Mapas de erro quadrático médio e diagramas de Taylor.

Assim, o modelo que apresentar os menores valores de erro quadrático médio, mapas climatológicos e médios representativos das principais feições da Confluência e diagramas de estado que representem de forma geral as massas d'água da região será escolhido para prosseguir com a análise prognóstica dos cenários climáticos.

\subsubsection{Análise dos Resultados para as Projeções Climáticas}

Nesta etapa do trabalho pretendem-se comparar os resultados do modelo numérico que melhor representa a região de estudo em dois cenários climáticos do IPCC: A1b e B2. Através das seguintes ferramentas estatísticas:

- Comparação de mapas das diferenças dos parâmetros físicos em superfície, 1000m e 1700m entre os cenários A1b e B2 e a média do Século XX, bem como de seções meridional e zonal.

- Comparação do ciclo sazonal em um ponto referente à $\mathrm{CB}$ e outro à CM, bem como da posição da CBM e dos transportes dessas correntes.

- Análise espectral de ondaletas das anomalias das variáveis em relação ao ciclo sazonal.

- Comparação dos mapas tendências das variáveis (em 0, 1000m, 1700m) e seções verticais.

- Diagramas de Estado e determinação dos Índices termohalinos da AT, AIA e APAN através de triângulos de mistura (Mamayev 1975).

Os resultados dos cenários do século XXI foram divididos em três períodos (20002033, 2033-2066,2066-2100) com o objetivo de melhor representar a diferença entre eles (sobretudo no último período) e ao mesmo tempo gerar médias climatológicas consistentes.

\subsection{Descrição das Ferramentas Estatísticas Utilizadas}

Nesta seção, serão descritas as ferramentas estatísticas utilizadas. 


\subsubsection{Estatística Básica}

A medida utilizada para estimar as diferenças entre as séries temporais dos modelos e os dados de reanálise será o Erro Quadrático Médio (EQM) e é dado por:

$$
E Q M=\sqrt{\frac{\sum_{i=1}^{n}\left(F_{i}-R\right)^{2}}{n}} .
$$

Sendo $F_{i}$ os dados do modelo, $R$ os dados da reanálise e $n$ o comprimento da série temporal.

Para descrever o padrão anual das saídas dos modelos e da reanálise, utilizaremos as climatologias anuais e sazonais. Na climatologia mensal calcula-se a média aritmética dos parâmetros para cada mês do ano, descrevendo um "ano médio" que estima a variabilidade sazonal da região. Como a śerie temporal abrange 100 anos, essa climatologia é representativa do período. A climatologia de uma variável $x$ é dada por:

$$
\bar{x}(i)=\frac{1}{n} \sum_{j=0}^{n-1} x_{i+12 j} .
$$

Sendo $n$ o número de anos da série temporal, $x$ o valor da grandeza utilizada no cálculo, $i$ o número relativo ao mês e $j$ o número do ano (inciando no zero).

A climatologia sazonal será calculada através das médias dos meses climatológicos em que predomina cada estação. Como o estudo refere-se somente ao hemisfério Sul temos que o verão corresponde a dezembro, janeiro e fevereiro; o outono a março, abril e maio; o inverno a junho, julho e agosto; e a primavera a setembro, outubro e novembro.

A partir dessa climatologia, calcularemos as anomalias das variáveis definida como a diferença entre a série temporal e seu respectivo mês médio:

$$
d_{i}=x_{i}-\bar{x}
$$

Sendo $d_{i}$ a anomalia no iésimo ponto da série temporal dada por $x_{i}$ e $\bar{x}$ a média aritmética do mês correspondente.

As tendências serão estimadas a partir do método dos mínimos quadrados. Esse método pode aproximar os dados a um polinômio qualquer. No caso da regressão linear, que será utilizada, uma função do primeiro grau. Para se obter a reta dos mínimos quadrados basta resolver o sistema de equações: 


$$
\left[\begin{array}{cc}
n & \sum_{i=1}^{n} x_{i} \\
\sum_{i=1}^{n} x_{i} & \sum_{i=1}^{n} x_{i}^{2}
\end{array}\right] \cdot\left[\begin{array}{l}
a \\
b
\end{array}\right]=\left[\begin{array}{c}
\sum_{i=1}^{n} y_{i} \\
\sum_{i=1}^{n} x_{i} y_{i}
\end{array}\right] .
$$

Sendo $y_{i}$ os valores da série correspondentes a $x_{i}, a$ o coeficiente linear da reta e $b$ o coeficiente angular. Utilizando a regra de Cramer, temos que:

$$
b=\frac{n \cdot \sum_{i=1}^{n} x_{i} y_{i}-\sum_{i=1}^{n} x_{i} \sum_{i=1}^{n} y_{i}}{n \cdot \sum_{i=1}^{n} x_{i}^{2}-\left(\sum_{i=1}^{n} x_{1}\right)^{2}} .
$$

Para estimar a correlação linear, dividimos a covariância entre a reta e a série temporal pela multiplicação de seus desvios padrão. Sendo o desvio padrão da série $x_{i}$ dado por:

$$
\sigma_{x}=\sqrt{\frac{\sum_{i=1}^{n}\left(x_{i}-\bar{x}\right)^{2}}{n-1}} .
$$

E a covariância entre $x_{i}$ e $y_{i}$ dada por:

$$
\sigma_{x y}=\sqrt{\frac{\sum_{i=1}^{n}(x-\bar{x})^{2}-\left(y_{i}-\bar{y}\right)}{n}} .
$$

Dessa forma, dados o desvio padrão da série $x_{i}\left(\sigma_{x}\right)$ e $y_{i}\left(\sigma_{y}\right)$ e a covariância entre as duas $\left(\sigma_{x y}\right)$, podemos encontrar o coeficiente de correlação:

$$
r_{x y}=\frac{\sigma_{x y}}{\sigma_{x} \sigma_{y}}
$$

No caso de uma das séries ser a reta encontrada na regressão linear, chamamos de correlação linear. Esse coeficiente de correlação também será calculado entre as saídas dos modelos para estimar a semelhança entre eles.

\subsubsection{Análise Espectral de Ondaletas}

Com o intuito de reconhecer nas séries temporais os principais padrões de variabilidade, bem como a intensidade em que cada modo de variação ocorreu ao longo do tempo, foi utilizada a Análise Espectral de ondaletas. Essa transformação trata-se de uma transformação da função inicial em ondas de diferente periodicidade, nos fornecendo informações a respeito da frequência e potência de suas componentes.

Tanto a Transformada Rápida de Fourier quanto a análise espectral de ondaletas decompõem séries temporais em ondas de diferentes períodos e amplitudes (funções de 
senos e cossenos), porém a transformada de ondaletas nos permite observar como essa variabilidade periódica do espectro se comporta ao longo da série temporal. Segundo Adreoli $\&$ Kayano (2004), as ondaletas são apropriadas para analisar no tempo e no espaço os modos dominantes de variabilidade nas séries temporais. Assim, é possível não só verificar o período dos modos de variabilidade (como El Niño), mas também quando eles foram mais intensos ou sutis.

A transformada de Ondaletas decompõe o sinal em algumas funções elementares derivadas do processo de dilatação e translação de uma ondaleta-mãe (Lau e Weng, 1995). A função da transformada de ondaletas $(W)$ é dada por:

$$
W_{l, t^{\prime}}(f)=f, \psi_{l t^{\prime}}^{*}=\int f(t) \psi_{l, t^{\prime}}^{*}(t) d t
$$

onde $l$ é o parâmetro de escala, $t^{\prime}$ é o parâmetro de translação e $\psi_{l, t^{\prime}} *$ é o complexo conjugado das ondaletas $\psi_{l, t^{\prime}}$ e $\psi$ é a ondaleta-mãe. O parâmetro $l$ de escala permite dilatar ou comprimir um sinal. Se o valor de $l>1$, a função é comprimida, se $l<1$ a função é expandida. A escolha da ondaleta-mãe é arbitrária, mas deve ser semelhante à série de dados tratada. Tratando-se de séries temporais de dados climátológicos e oceanográficos, normalmente utiliza-se a ondaleta de Morlet, dada por (Torrence e Campo, 1998):

$$
\psi_{0}=\pi^{-1 / 4} e^{i w_{0} \eta} e^{-\eta^{2} / 2}
$$

Sendo $\eta$ um fator de tempo adimensional e $w_{0}$ a frequência.

Neste trabalho, todas as transformadas de ondaletas foram feitas utilizando a ondamãe de Morlet. Para a identificação de fenômenos climáticos através das variáveis físicas, foi utilizado o ruído vermelho com auto correlação de 0,72 .

\subsubsection{Definições e Cálculos Utilizados}

Para fins comparativos, foram calculados alguns parâmetros relevantes para a região de estudo. Matano et al. (1993) utilizaram dados de altura do nível do mar para determinar a posição da frente da $C B M$ que nesse estudo foi definido como a maior latitude da posição da altura 0 do nível do mar entre $55^{\circ} \mathrm{W}$ e $50^{\circ} \mathrm{W}$.

O cálculo do transporte de volume da Corrente do Brasil e da Corrente das Malvinas foi realizado através das velocidades de correntes fornecidas pelos modelos e dados de 
Reanálises. Sabe-se que o transporte de volume transportado através de uma área é dado pelo produto da velocidade desse fluxo pela área transversal ao escoamento. Assim temos, para um fluxo que varia espacialmente:

$$
T v=\iint_{A} \vec{v} \cdot \vec{n} d A
$$

sendo $T v$ o transporte de volume através de $A, \vec{v}$ a velocidade do fluxo e $\vec{n}$ o vetor unitário normal à área $A$.

Para dados discretizados, podemos utilizar a aproximação a seguir:

$$
T v=\sum_{j} \sum_{i} \vec{v}_{i j} \cdot \Delta z_{i j} \cdot \Delta x_{i j}
$$

Sendo $v$ a velocidade média que atravessa a região de altura $z$ e largura $x$ na posição $i, j$.

Os transportes da Corrente do Brasil foram calculados em $30^{\circ} \mathrm{S}$ e foi definido como o fluxo para sul de velocidades superiores a $0,02 \mathrm{~m} / \mathrm{s}$ entre a costa e $45^{\circ} \mathrm{W}$. Os transportes relativos à Corrente das Malvinas foram calculados em $45^{\circ} \mathrm{S}$ através das velocidades sentido norte de magnitudes superiores a $0,05 \mathrm{~m} / \mathrm{s}$ entre $55^{\circ} \mathrm{W}$ e $70^{\circ} \mathrm{W}$.

\subsubsection{Diagrama de Taylor}

O Diagrama de Taylor é uma forma prática e rápida de comparar resultados de modelos numéricos. Nesse diagrama, é possível visualizar três parâmetros estatísticos essenciais na comparação entre saídas de modelos e os dados: correlação entre as duas séries, erro quadrático médio e os respectivos desvios padrão. Dessa forma, em uma única figura bidimensional, obtemos ferramentas importantes na discussão da validação de modelos numéricos.

Nesse digrama, plotamos os dados em coordenadas polares sendo o ângulo $\Theta$ dado pelo arcseno(correl) (sendo correl a correlação entre a saída do modelo e os dados) e o raio $r$ dado pelo desvio padrão da série temporal. Taylor (2001) mostrou que a distância entre o pontos plotados (da saída do modelo e dos dados) é dado pelo EQM entre eles (desprezando desvios da média). Dessa forma, quanto mais próximo os pontos estiverem, mais próximo o modelo se encontra dos dados medidos. É importante ressaltar que esse método não leva em consideração os desvios em relação à média. Dessa forma, 
ao comparar dois resultados de modelos, além dos Diagramas de Taylor, deve-se observar as médias representadas por eles, isoladamente. 


\section{Resultados}

A primeira parte dos resultados descreve o desempenho dos três modelos numéricos na região de estudo para escolha do modelo a ser utilizado neste trabalho em relação aos dados de Reanálise do SODA durante o período entre 1958 e 2000.

\subsection{Escolha do modelo numérico mais adequado à região}

O modelo numérico eleito, deve não só descrever o padrão espacial esperado para região, como também descrever a variabilidade temporal. Assim os modelos foram comparados com o SODA segundo 6 aspectos:

1. Padrões médios gerais;

2. Diferenças entre os padrões médios dos modelos e do SODA;

3. Padrões sazonais;

4. Tendências;

5. Anomalias em relação à climatologia e

6. Análises de Erro quadrático médio entre a série dos modelos e os dados do SODA e Diagramas de Taylor.

Todas as análises abrangem o período comum às saídas dos modelos para o século XX e os dados do SODA (de Janeiro de 1958 a Dezembro de 2000).

A região de estudo é o Atlântico Sudoeste (entre 20 e $65^{\circ} \mathrm{W}$ e entre 10 e $60^{\circ} \mathrm{S}$ ) que comporta a Confluência Brasil-Malvinas. Foram escolhidos 2 pontos e 2 radiais como referências. O Ponto $1\left(40^{\circ} \mathrm{W}, 30^{\circ} \mathrm{S}\right)$ representa o domínio da Corrente do Brasil enquanto o Ponto $2\left(55^{\circ} \mathrm{W}, 45^{\circ} \mathrm{S}\right)$ representa o domínio da Corrente das Malvinas. A radial longitudinal foi escolhida em $40^{\circ} \mathrm{S}$ para descrever o comportamento da $\mathrm{CBM}$, e a latitudinal em 50 W - Figura 6. Todas as análises foram feitas entre 1958 e 2000 (período comum a todos os modelos e ao SODA). Definiu-se também a Região 1 (entre 20 e $35^{\circ} \mathrm{W}$, e entre 15 e $30^{\circ} \mathrm{S}$ ) que representa o giro subtropical e suas massa d'água características e a Região 2 (entre 30 e $55^{\circ} \mathrm{W}$ e entre 45 e $55^{\circ} \mathrm{S}$ ). 


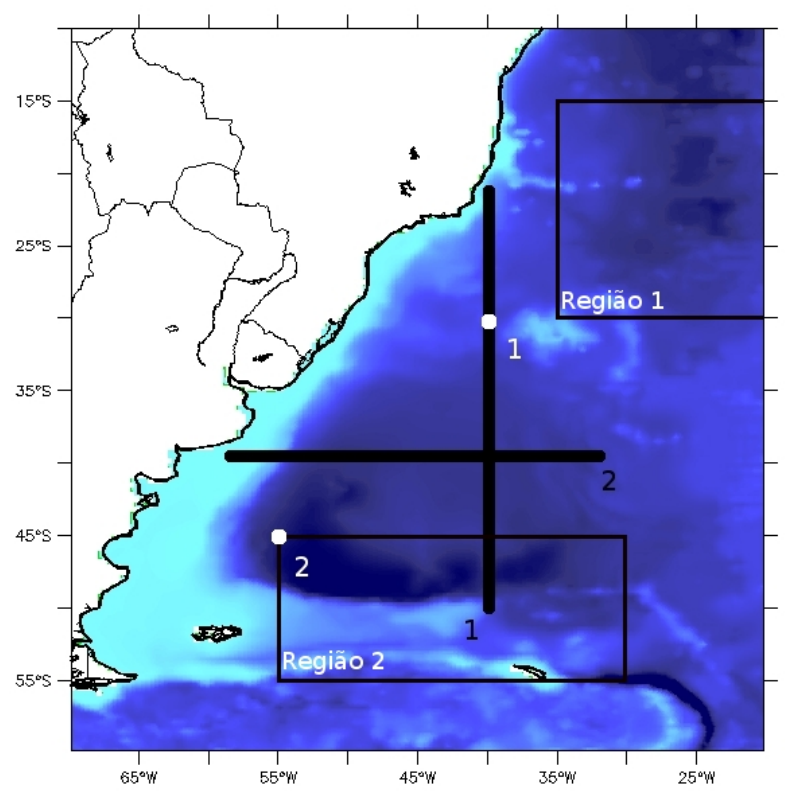

Figura 6: Região de estudo. Em preto, as seções transversais latitudinal (1) em $40^{\circ} \mathrm{W}$ e longitudinal (2) em $39^{\circ} \mathrm{S}$. Em branco os pontos sobre a Corrente do Brasil (1) e sobre a Corrente das Malvinas (2).

\subsubsection{Padrão espacial médio}

As Figuras 7 e 8 representam os mapas médios de temperatura e salinidade dos dados de reanálise global do SODA e dos 3 modelos do $4^{\circ}$ Relatório do IPCC. Observamos que todos os modelos numéricos superestimam a temperatura de superfície, com exceção do CCSM3 que subestima em quase $1^{\circ} \mathrm{C}$. O MIROC foi o que melhor representou a temperatura, tanto no que concerne a valores absolutos e posições das isotermas quanto a feições. As intrusões das Correntes do Brasil e das Malvinas aparecem mais nitidamente na saída desse modelo, bem como no SODA.

Todos os modelos subestimaram a salinidade de superfície da região (Figura 8), principalmente o CCSM3, apesar de não considerar o aporte de água doce do Rio da Prata. Foi possível observar, em todos os modelos e nos dados de reanálise, a intrusão das águas salinas da Corrente do Brasil, mas não da Corrente das Malvinas. O padrão encontrado nos três modelos reflete o encontrado pelo SODA, mas nenhum conseguiu descrevê-lo com precisão.

Os padrões de salinidade e temperatura do MIROC, mais próximos aos do SODA determinam um padrão de densidade também satisfatório, tanto em valores absolutos 
(a)

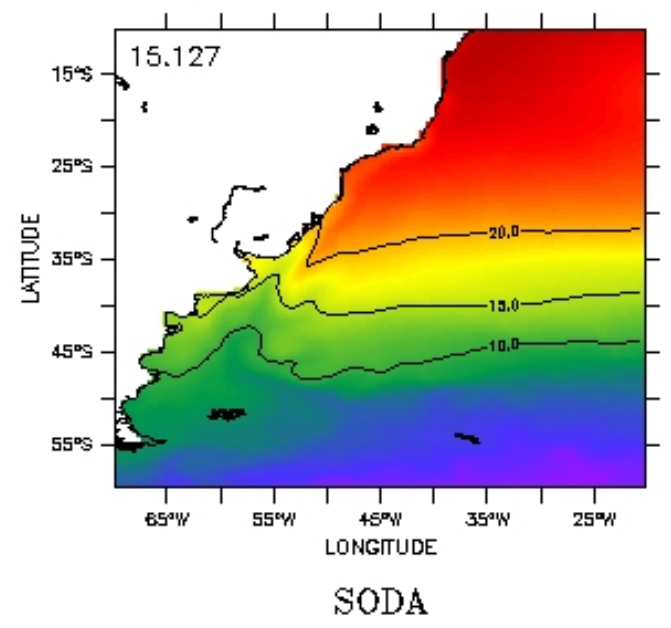

(c)

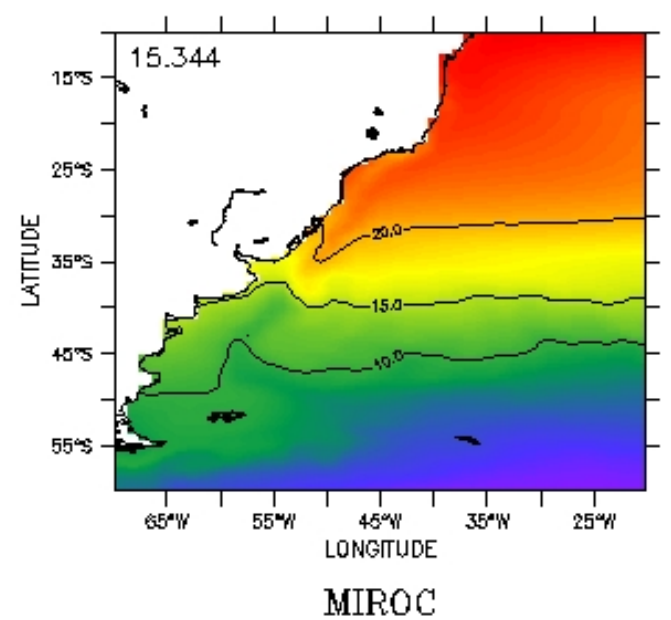

(b)

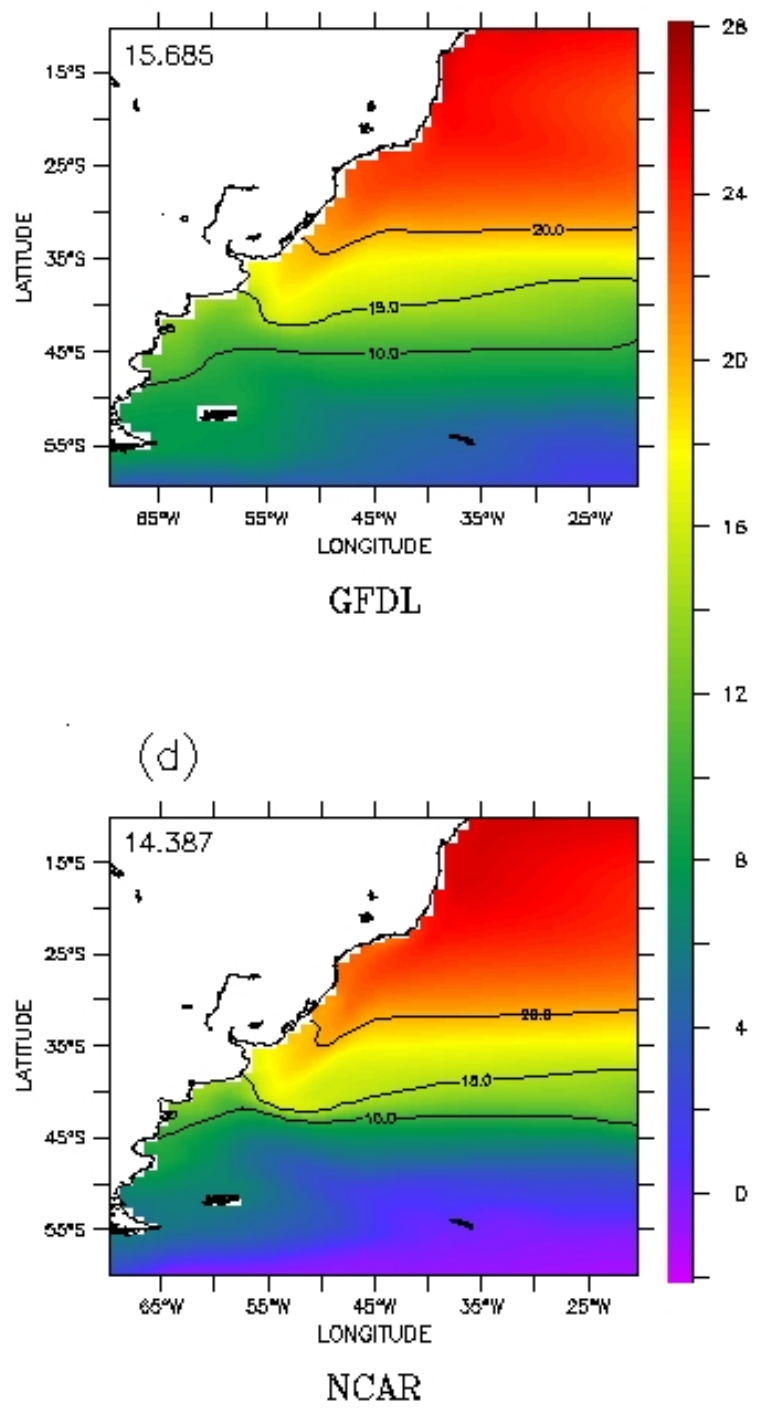

Figura 7: Temperatura média de superfície $\left(\mathrm{em}^{\circ} \mathrm{C}\right)$ : (a) SODA, (b) GFDL, (c) MIROC e (d) CCSM3. Acima e à esquerda encontramos a média na região.

quanto em relação as feições, como visto na Figura 9. Esse modelo (o único dos 3 que considera o aporte fluvial como uma de suas componentes) é o que melhor representa a intrusão de águas mais densas da Corrente da Malvinas na região da Confluência, embora seja o que mais subestime o gradiente dessa variável e deprecie a densidade na região mais austral. O CCSM3 é o que mais se aproximou dos valores de densidade do SODA, embora as feições não estejam bem representadas (sobretudo na região da Confluência onde a densidade é muito exagerada em relação ao SODA). O GFDL subestima os efeitos 
da Corrente das Malvinas e sua densidade.

Provost et al. (1996) definiram, através das densidades, 4 tipos de água na superfície do Atlântico Sudoeste. As definições de densidades citadas em superfície, segundo os autores, não compõem o melhor padrão para distinguir os tipos de água da região. Ao invés disso, os autores sugerem a densidade de subsuperfície $(50 \mathrm{~m})$, para separar as massas d'água da região. A Figura 10 compara as densidades que definem as águas da Corrente do Brasil $\left(26,4 \mathrm{~kg} / \mathrm{m}^{3}\right)$ das proveniente da Corrente das Malvinas $\left(25,6 \mathrm{~kg} / \mathrm{m}^{3}\right)$ nessa profundidade (Provost et al. 1996). Nessa figura, as isopicnais marcam o domínio da Corrente do Brasil e da Corrente das Malvinas. Novamente o MIROC obteve mais êxito em determinar a latitude de alcance dessas densidades e sua distribuição. O CCSM3 e o GFDL apresentaram um gradiente meridional muito mais suave do que o previsto pelo SODA na região de encontro entre as duas correntes.

Em linhas gerais, o padrão médio da tensão do cisalhamento do vento foi satisfatoriamente representado por todos os modelos e superestimado em relação ao conjunto de dados utilizado pelo SODA (ERA), sobretudo em altas latitudes representado na Figura 11. A intensificação dos ventos de oeste pode justificar a intensificação da Corrente Circumpolar Antártica, e consequente a Corrente das Malvinas ocasionando o deslocamento das iso-halinas para norte em todos os modelos. Esses efeitos, foram mais intensamente verificados no CCSM3. O modelo que melhor representou o padrão espacial médio de tensão de cisalhamento do vento, tanto em valores absolutos como nas feições gerais foi o MIROC, apesar da componente meridional parecer superestimada em altas latitudes, enquanto que no SODA é praticamente zero.

Embora a componente meridional da tensão de cisalhamento do vento não seja bem representada no MIROC (sobretudo na parte mais austral), este é o que melhor delimita a região de rotacional zero da tensão do cisalhamento do vento, expresso pela isolinha vermelha na Figura 12, Este modelo foi o único que representou uma anomalia positiva do rotacional próximo à região da CBM, e a anomalia negativa próxima a a costa por volta de $25^{\circ} \mathrm{S}$. O rotacional do vento está intimamente ligado ao transporte da Corrente do Brasil (Sverdrup et al. 1942). A superestimativa dos modelos em relação a essa grandeza física, pode acarretar em uma contribuição exagerada da Corrente do Brasil para a região da Confluência. O modelo que possui valores médios mais próximos em relação ao SODA é o MIROC. 
A anomalia da altura do nível do mar, embora seja um parâmetro relativo somente à superfície, reflete a dinâmica de toda a estrutura da coluna d'água. Observamos um claro contraste dessa variável sobre a Corrente do Brasil em relação à região da Corrente das Malvinas (Figura 13). A interface entre esses regimes (demarcado pela isolinha de altura 0, com exceção do GFDL) está representada na Figura 13. No GFDL, a isolinha de 0m não foi bem representada. Esse modelo, não representou as alturas positivas no padrão médio, embora apresente bons resultados para a tensão de cisalhamento do vento. Novamente o MIROC obteve uma representação mais coerente em relação ao SODA.

A velocidade de corrente, foi comparada apenas entre o SODA e os modelos MIROC e CCSM3, devido à indisponibilidade dos dados de corrente do modelo do GFDL. Na Figura 14, observamos que ambos os modelos representam bem as correntes superficiais do Atlântico Sudoeste, apesar das intensidades das correntes nesses modelos serem menores que no SODA (sobretudo no CCSM3).

A resolução mais baixa dos modelos impede a representação de estruturas complexas de velocidades associadas à CBM. A Corrente do Brasil é mais enfraquecida nos modelos e a Corrente das Malvinas é melhor contemplada no MIROC.

O melhor desempenho do MIROC nos parâmetros de superfície, não se faz tão claro na estrutura vertical. As Figuras 15 e 16 representam seções verticais meridionais de temperatura e salinidade, respectivamente, na longitude de $40^{\circ} \mathrm{W}$. Todos os modelos representaram bem a estrutura vertical de temperatura, em contraponto com a salinidade.

Em todos os dados, observamos um núcleo de água quente em superfície e subsuperfície, relacionado à intrusão da Corrente do Brasil. Essa temperatura é subestimada em todos os modelos, principalmente no MIROC. Esse núcleo torna-se mais raso e menos quente nesse modelo. A redução do erro relacionado ao GFDL e ao CCSM3 pode estar associado ao fato desses modelos exagerarem (mais do que o MIROC) o efeito do cisalhamento do vento. Isso faz com que as duas correntes (do Brasil e das Malvinas) sejam superestimadas. Dessa forma, o MIROC é o modelo que apresenta menores gradientes meridionais de temperatura.

Abaixo de 3500 metros o MIROC é o que mais superestima a temperatura de fundo. Sendo o CCSM3 o que melhor representa o núcleo de água gelada próxima ao fundo (abaixo de $0^{\circ} \mathrm{C}$ ). Como acontece na temperatura, a influência da Corrente do Brasil na salinidade parece estar subestimada no MIROC. O núcleo salino entre a superfície e os 200 
metros visto nos dados de reanálise do SODA é superestimado no GFDL e subestimado tanto no MIROC, quanto no CCSM3. As águas pouco salinas de altas latitudes possuem excessiva influência no CCSM3. Em regiões mais profundas, o MIROC representou melhor a salinidade intermediária, levemente depreciada nos outros modelos.

Observamos que nem mesmo o SODA representou corretamente os índices termohalinos verificados na literatura. A Tabela 7 representa os índices termohalinos das possíveis massas d'águas encontradas na região (Maamaatuaiahutapu et al. 1992).

\begin{tabular}{ccccccc} 
& AT & AIA & ACP(Sup) & APAN & ACP(lnf) & APW \\
\hline Temperatura $\left({ }^{\circ} \mathbf{C}\right)$ & 16 & 4 & 2.5 & 3 & 1.5 & -0.2 \\
Salinidade & 35.58 & 34.2 & 34.6 & 34.92 & 34.76 & 34.68 \\
Densidade (kg.m $\left.{ }^{-3}\right)$ & 26.36 & 31.76 & 32.26 & 36.99 & 45.62 & 46.14 \\
\hline
\end{tabular}

Tabela 7: Índices termohalinos das massas d'água na região da Confluência BrasilMalvinas segundo Maamaatuaiahutapu et al. (1992)

Nas Figuras 15 e 16, foram plotadas as referidas temperaturas e salinidades como referência de comparação entre os modelos. Embora esses índices isolados não sejam suficientes para identificar as massas d'águas, foram úteis para caracterizar a estrutura geral dos perfis. As ACPs são massas d'água de difícil identificação e portanto não foram consideradas. Dessa forma, utilizamos para comparar os índices termohalinos referentes a AT, AIA e APAN. A profundidade não foi suficiente para representar a APW.

Na Figura 15 observamos que os modelos representaram de forma similar a isolinha de $16^{\circ} \mathrm{C}$, representando a Água Tropical, porém o único modelo que não superestimou a profundidade máxima dessa isolinha $(250 \mathrm{~m})$ foi o CCSM3. A salinidade de 35.8 se restringiu às latitudes inferiores a $32^{\circ} \mathrm{S}$ (Figura 16), enquanto a densidade característica mostrou influência desse corpo d'água até latitudes maiores que $46^{\circ} \mathrm{S}$. Os perfis de densidade se mostraram muito semelhantes ao SODA em todos os modelos.

Por outro lado, a isolinha de $4{ }^{\circ} \mathrm{C}$ ao longo da seção em $40^{\circ} \mathrm{W}$ foi muito bem representada pelo CCSM3 e pelo MIROC, mas não pelo GFDL. Essa isoterma, referente à AIA pareceu representar bem essa massa d'água (entre 850 e 1100m). Por outro lado, a iso-halina de 34.2 não foi representativa, ao contrário do mínimo local de salinidade, típico da AIA (Maamaatuaiahutapu et al. 1992) inclusive no GFDL.

A isoterma referente à $\operatorname{APAN}\left(3^{\circ} \mathrm{C}\right)$, foi melhor representada no MIROC. Porém, a iso-halina de 34.92, só foi observada no CCSM3, não sendo observada nem mesmo no 
SODA, possivelmente por conta da influência da ACP Inferior. A iso-halina referente à APW não foi observada em nenhum dos dados.

Por outro lado, a isoterma de zero graus, que define a influência dessa massa d'água profunda, densa e salina foi detectada pelo SODA e pelo CCSM3.

Nas seções zonais de temperatura e salinidade em $39^{\circ} \mathrm{S}$ - Transecto 2 - (Figuras 17 e 18), observamos que a influência da Corrente do Brasil é superestimada tanto no GFDL quanto no CCSM3. Esses modelos representaram salinidade muito elevada, em relação ao SODA, sobretudo em subsuperfície. Por outro lado, todos os modelos representaram bem os valores absolutos de salinidade na média. Enquanto os modelos GFDL e CCSM3 exageram os gradientes horizontais e verticais de salinidade, o MIROC os subestimam levemente.

Os transectos zonais de temperatura estão melhores representados, sobretudo no MIROC. As feições gerais encontradas no SODA estão bem representadas nesse modelo. Os valores absolutos também parecem satisfatoriamente próximos. O CCSM3 também apresentou bons resultados, sobretudo em regiões profundas (acima dos 4000 metros) onde os outros modelos representaram águas mais quentes. O GFDL apresentou as feições menos próximas ao SODA e os piores valores absolutos.

No perfil zonal em $39^{\circ} \mathrm{S}$, a isoterma de $16^{\circ} \mathrm{C}$ não se mostrou eficiente para delimitar a AT nem a iso-halina de 35.8. Por outro lado, a densidade mostrou uma interface semelhante em todos os modelos (por volta dos 50 metros).

Nessa radial, as isotermas de $4^{\circ} \mathrm{C}$ também representam bem a AIA, bem como o mínimo de salinidade. O que não ocorre com a iso-halina de 34.2, situada mais ao fundo.

As iso-halinas características da APAN e da APW foram capturadas pelo GFDL e pelo CCSM3 apenas. Nem mesmo o SODA representou essas iso-halinas mais profundas.

Embora o MIROC pareça representar melhor as massas d'água em geral, novamente ele não representa as águas de temperaturas inferiores a $0^{\circ} \mathrm{C}$ da $\mathrm{APW}$, presente em toda a seção.

Foram escolhidos os pontos $1\left(40^{\circ} \mathrm{W}, 30^{\circ} \mathrm{S}\right)$ e $2\left(55^{\circ} \mathrm{W}, 45^{\circ} \mathrm{S}\right)$ para representarem as estruturas verticais médias sobre a Corrente do Brasil e das Malvinas. Todos os modelos apresentaram praticamente todas as correlações acima de $90 \%$ tanto nos perfis de salinidade quanto no de temperatura.

Todos os modelos, apresentaram maiores correlações verticais nos perfis de tempera- 


\begin{tabular}{|c|c|c|c|c|c|c|c|c|c|c|c|c|}
\hline \multirow{4}{*}{$\begin{array}{c}\text { Temperatura }\left({ }^{\circ} \mathrm{C}\right) \\
\text { Salinidade }\end{array}$} & \multicolumn{4}{|c|}{ AT } & \multicolumn{4}{|c|}{ AIA } & \multicolumn{4}{|c|}{ APAN } \\
\hline & $\overline{\text { SODA }}$ & GFDL & MIROC & CCSM3 & SODA & GFDL & MIROC & CCSM3 & $\overline{\text { SODA }}$ & GFDL & MIROC & $\overline{\mathrm{CCSM} 3}$ \\
\hline & 18.5 & $\begin{array}{l}17.8 \\
\end{array}$ & 17.7 & 17.8 & 2.0 & 4.5 & 4.3 & 1.8 & 3.0 & 5.0 & 2.8 & 3.9 \\
\hline & 35.9 & 36.0 & 35.5 & 36.0 & 34.1 & 34.0 & 34.1 & 33.6 & 34.8 & 35.2 & 34.9 & 35.2 \\
\hline
\end{tabular}

Tabela 8: Índices termohalinos encontrados através dos diagramas de estado SODA e dos modelos numéricos do IPCC no ponto $1\left(40^{\circ} \mathrm{W}, 30^{\circ} \mathrm{S}\right)$.

tura do que nos perfis de salinidade, sobretudo no ponto 1. O único modelo que apresentou correlação inferior a 95\% de temperatura, foi o MIROC no ponto $2(83,7 \%)$. Esse modelo apresentou correlações muito superiores no ponto 1 (relacionado à Corrente do Brasil) às encontradas no ponto 2 (relacionado à Corrente das Malvinas) e foi o único que obteve uma correlação significativa de salinidade no ponto 1 .

A Figura 19 representa o diagrama de estado referente ao ponto 1 para todos os modelos e para os dados de Reanálise. Foram escolhidas 3 massas d'águas de referência para a comparação de seus respectivos índices termohalinos: Água Tropical (AT), Água Intermediária Antártica (AIA) e a Água Profunda do Atlântico Norte (APAN). A Tabela 8 refere-se aos índices termohalinos encontrados a partir dos diagramas de estado de cada modelo no ponto 1 em comparação com os dados de Reanálise do SODA.

A Água Tropical (AT), na literatura, apresenta índices termohalinos $16^{\circ} \mathrm{C}$ e 35.58 (Maamaatuaiahutapu et al. 1992) - Tabela 7. Através dos dados do SODA, encontramos índices significativamente maiores $\left(18.5^{\circ} \mathrm{C}\right.$ e 35.9$)$. Todos os modelos convergiram para uma temperatura $\left(17.8^{\circ} \mathrm{C}\right)$ intermediária. O MIROC obteve o índice halino próximo ao da literatura enquanto o GFDL e o CCSM3 assemelharam-se ao SODA.

No caso da Água Intermediária Antártica (AIA) o SODA subestimou a temperatura do índice termohalino $\left(2^{\circ} \mathrm{C}\right)$ em relação à literatura $\left(4^{\circ} \mathrm{C}\right)$. Tanto o GFDL, quanto o MIROC obtiveram resultados semelhantes à literatura na temperatura e na salinidade $\left(4,5^{\circ} \mathrm{C}\right.$, e 34.0). Por outro lado, o CCSM3 obteve o índice térmico mais próximo ao $\operatorname{SODA}\left(1,8^{\circ} \mathrm{C}\right)$ e halino consideravelmente inferior ao SODA e à literatura.

O SODA, o MIROC e a literatura (Maamaatuaiahutapu et al. 1992) concordam na determinação dos índices termohalinos para a Água Profunda do Atlântico Norte (APAN). Por outro lado o GFDL e o CCSM3 não obtiveram semelhante êxito.

Dessa forma, o MIROC representou melhor a APAN, mas em relação às outras massas d'águas nenhum modelo se destacou especificamente na determinação do índice termoha- 


\begin{tabular}{|c|c|c|c|c|}
\hline \multicolumn{5}{|c|}{ Núcleos (m) } \\
\hline & SODA & GFDL & MIROC & CCSM3 \\
\hline AT & 98.5 & 140 & 150 & 105.6 \\
\hline AIA & 963 & 750 & 900 & 750 \\
\hline \multicolumn{5}{|c|}{ Interfaces (m) } \\
\hline & SODA & GFDL & MIROC & CCSM3 \\
\hline AT x AIA & 520 & 380 & 550 & 500 \\
\hline AIA $\times$ APAN & 1350 & 1400 & 1440 & 950 \\
\hline
\end{tabular}

Tabela 9: Profundidades dos núcleos e interfaces das massas d'água encontradas através dos diagramas de estado SODA e dos modelos numéricos do IPCC no ponto $1\left(40^{\circ} \mathrm{W}\right.$, $\left.30^{\circ} \mathrm{S}\right)$.

\begin{tabular}{cccc}
\multicolumn{4}{c}{ Transporte (Sv) } \\
\hline & SODA & MIROC & CCSM3 \\
\hline Corrente do Brasil & 12.8 & 12.2 & 10.5 \\
Corrente das Malvinas & 55.5 & 82.5 & 34.3 \\
\hline
\end{tabular}

Tabela 10: Módulos dos transportes (Sv) das Correntes do Brasil e das Malvinas (média entre 1958 e 2000) calculados através do SODA e dos modelos numéricos do IPCC.

lino.

A Tabela 9 fornece as profundidades dos núcleos das interfaces e suas respectivas interfaces.

Com exceção do núcleo da AT, o MIROC representou bem todas as profundidades de núcleos e interfaces ao contrário do CCSM3. O GFDL, por sua vez, representou de forma satisfatória somente a interface AIA x AT.

Outras variáveis que embasarão o estudo são os transportes da Corrente do Brasil, da Corrente das Malvinas e a posição da Confluência Brasil-Malvinas. As tabelas 10 e 11 contém os valores calculados para cada modelo e para o SODA. Não foi possível calcular os fluxos para o GFDL, já que esse não possui valores de correntes.

Fisher (1964) estimou o transporte da Corrente do Brasil em 28-30 S em aproxima-

\begin{tabular}{cccc}
\multicolumn{4}{c}{ Posição da CBM $\left({ }^{\circ} \mathrm{S}\right)$} \\
\hline SODA & GFDL & MIROC & CCSM3 \\
\hline 41.2 & 35.8 & 39.7 & 42.3 \\
\hline
\end{tabular}

Tabela 11: Posição da CBM (média entre 1958 e 2000) calculada através do SODA e dos modelos numéricos do IPCC. 
damente 11,4 Sv, enquanto Garfield (1990) em $18 \mathrm{~Sv}$ em $31^{\circ} \mathrm{S}$. O cálculo de transporte da $\mathrm{CB}$ em $30^{\circ} \mathrm{S}$ do SODA foi coerente $(12,8 \mathrm{~Sv})$ e de acordo com o MIROC (12,2 Sv). O GFDL apresentou um transporte menor $(10,5 \mathrm{~Sv})$. Por outro lado, o transporte da Corrente das Malvinas apresentou maiores divergências. Spadone (2006) (Spadone et al. 1992) estimou um transporte médio em $46^{\circ} \mathrm{S}$ de $41,5 \mathrm{~Sv}$ para a Corrente das Malvinas. O SODA superestimou esse transporte (55,5 Sv) e o MIROC ainda mais (82,5 Sv) enquanto o CCSM3 subestimou (34,3 Sv).

As diferenças entre os transportes pode ser a causa do deslocamento da posição média da CBM demonstrado na Tabela 11. O MIROC e o CCSM3 apresentaram posições da CBM mais próximas ao SODA. A altura do nível do mar não representou bem a posição da CBM no GFDL.

De forma geral, o MIROC representou melhor as estruturas de superfície (TSM, SSM, densidade, tensão de cisalhamento do vento e altura do nível do mar) em relação ao SODA. Embora esse sucesso não seja tão claro na estrutura vertical, esse modelo ainda assim se sobressaiu perante aos outros, embora não tenha representado a APW (temperaturas inferiores a $0^{\circ} \mathrm{C}$ ). O CCSM3 foi o que mais subestimou TSM e SSM, mas obteve melhores valores absolutos de densidade (embora as feições de distribuição de densidade não estejam bem representados). Por outro lado, o GFDL não representou a elevação do nível do mar e sua representação do padrão médio foi a que mais diferiu dos dados do SODA. 
(a)

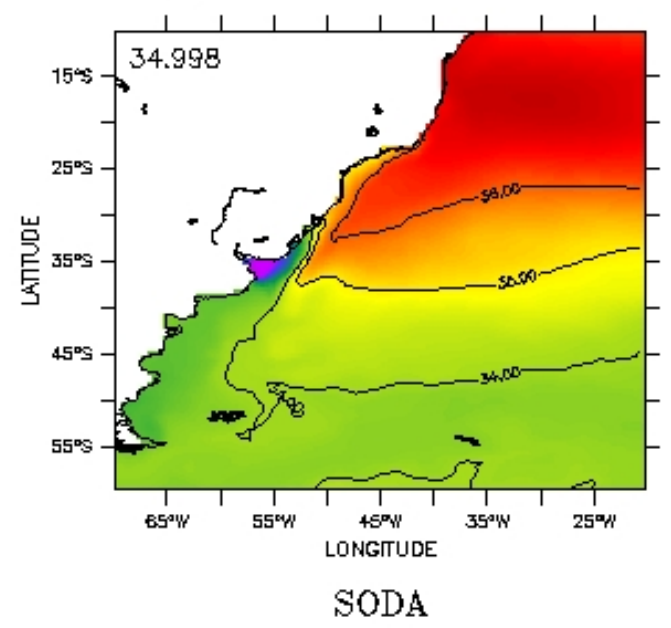

(c)

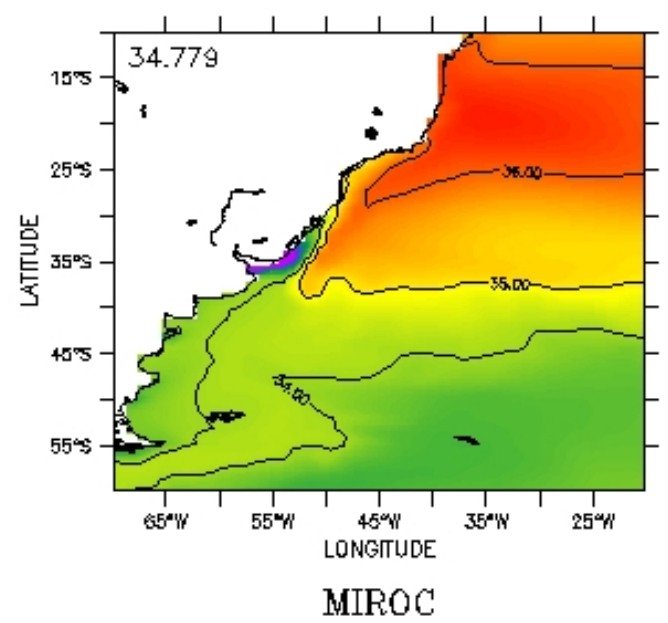

(b)

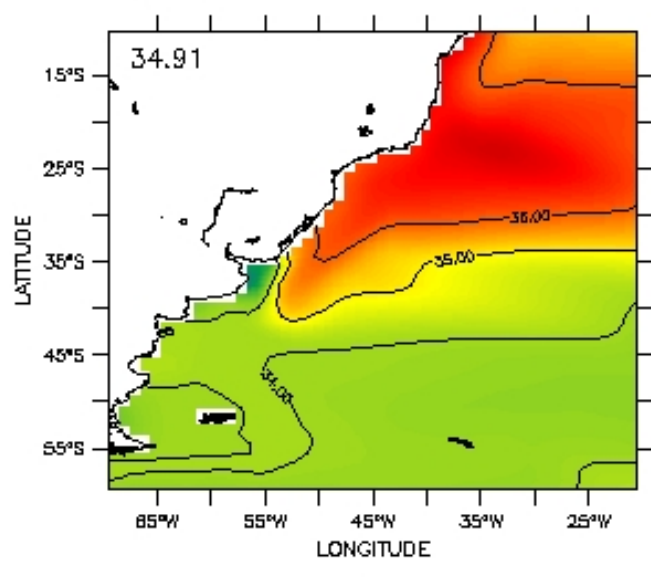

GFDL

(d)

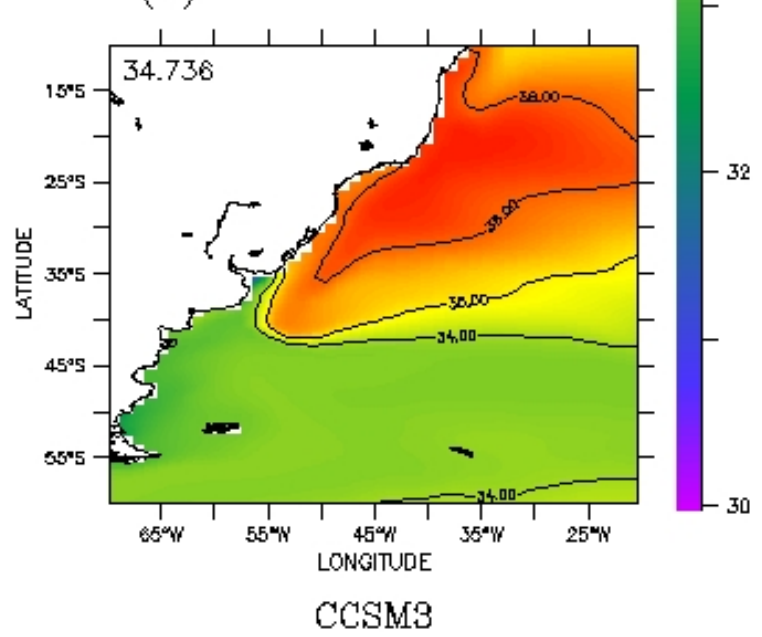

Figura 8: Salinidade de superfície média: (a) SODA, (b) GFDL, (c) MIROC e (d) CCSM3. Acima e à esquerda encontramos a média na região. 
(a)

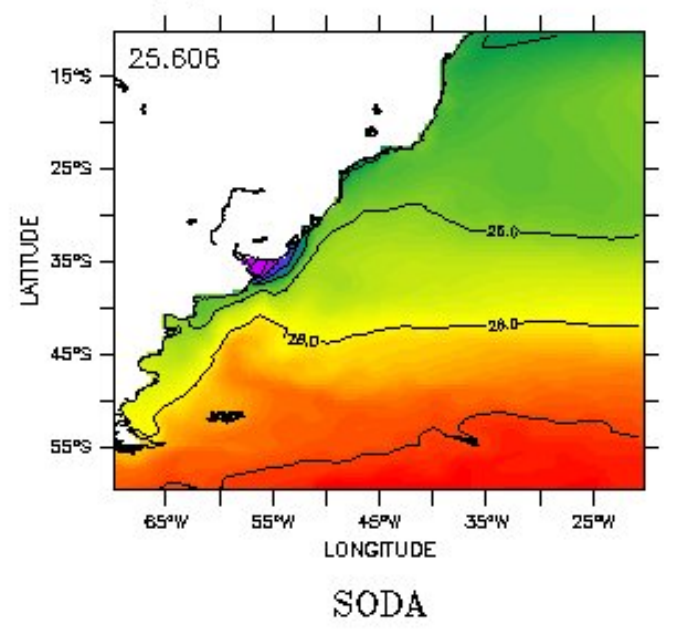

(c)

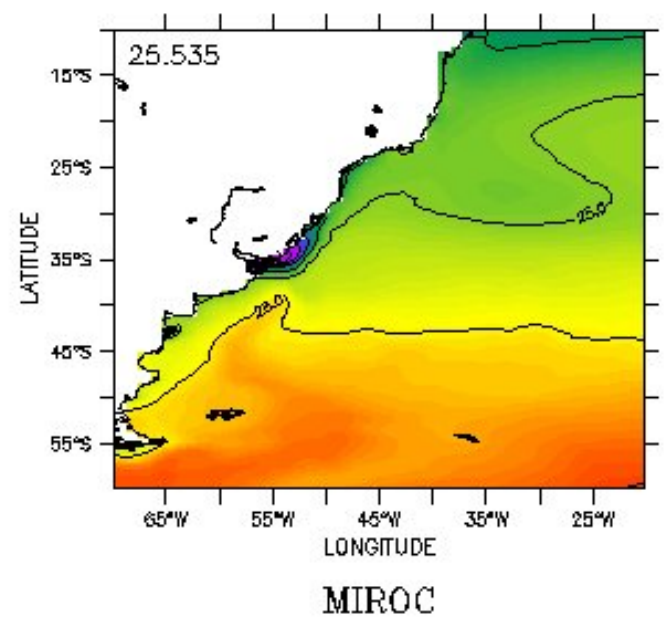

(b)

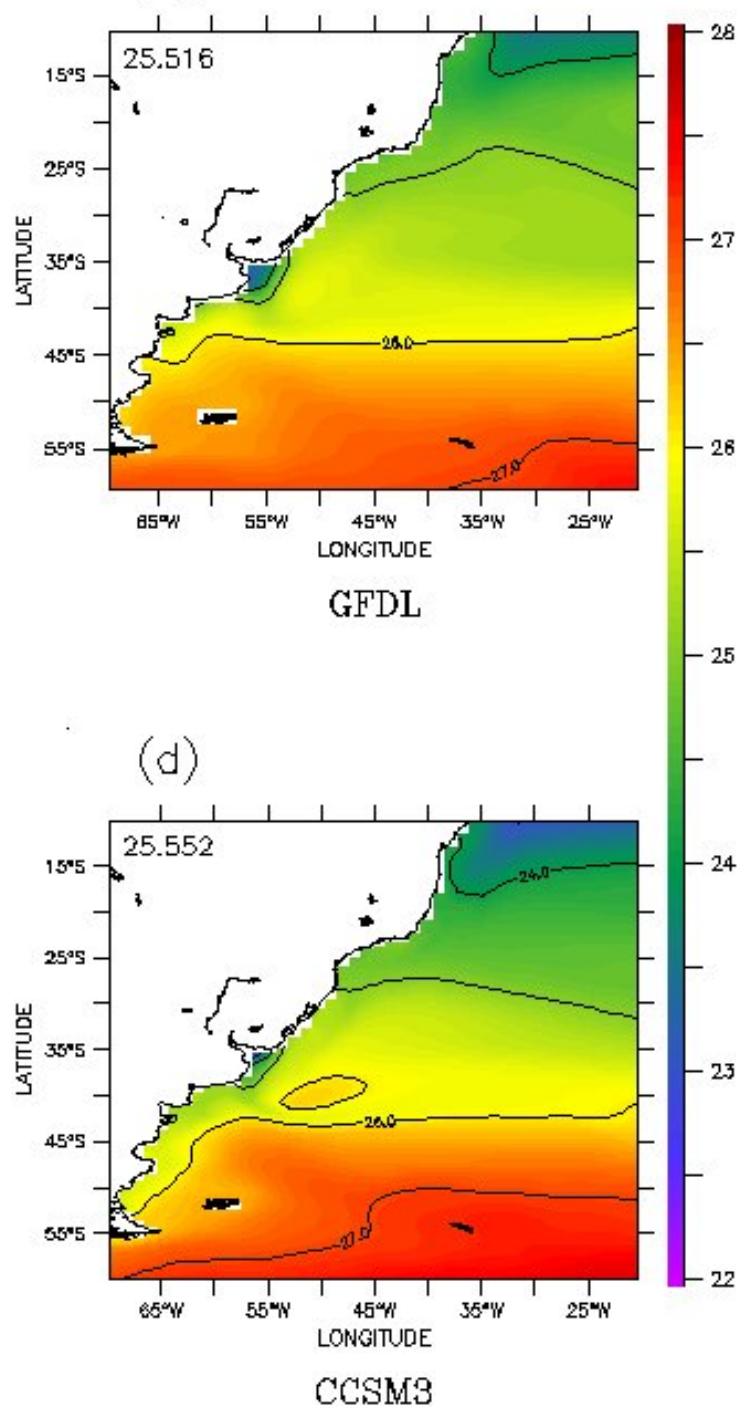

Figura 9: Densidade média de superfície em $\mathrm{kg} / \mathrm{m}^{3}$ : (a) SODA, (b) GFDL, (c) MIROC e (d) CCSM3. 
(a)

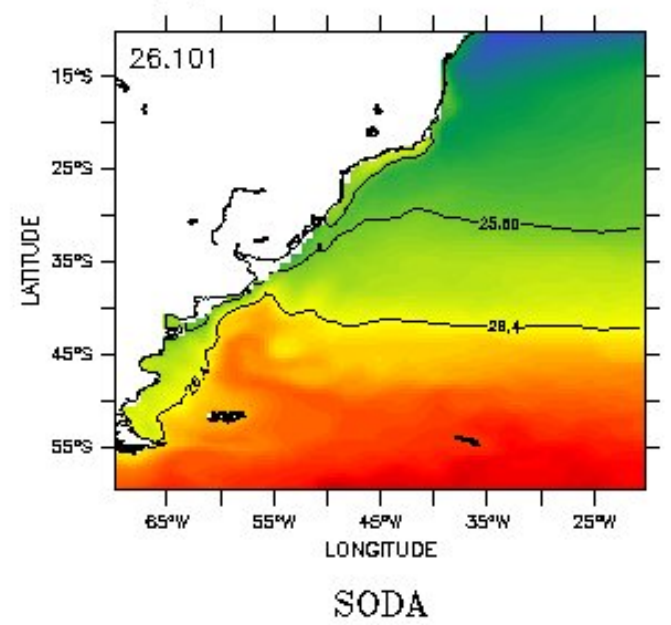

(c)

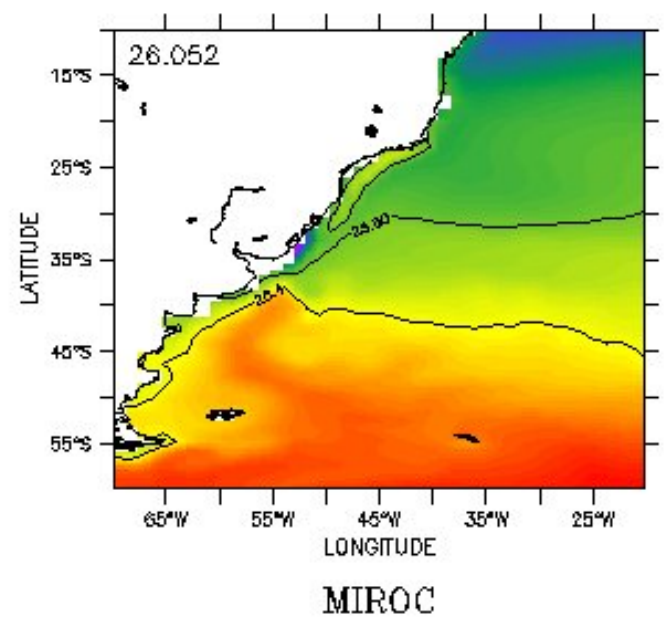

(b)

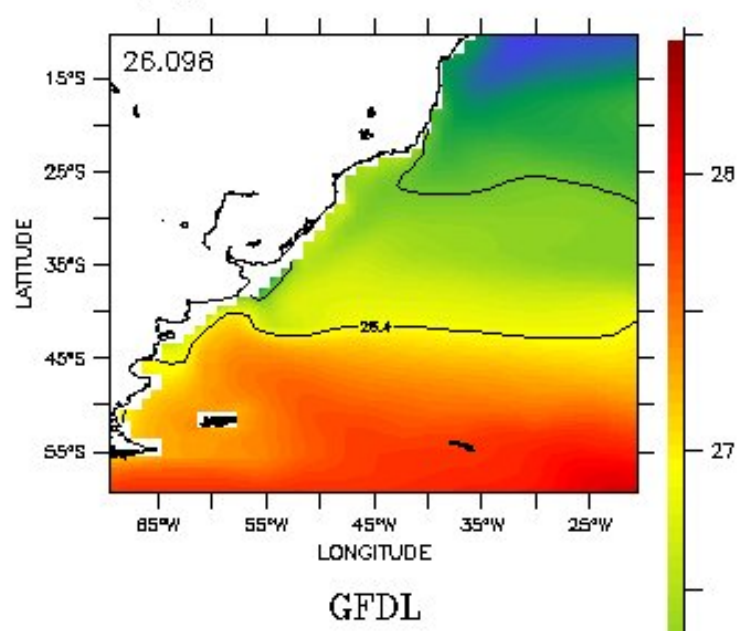

(d)

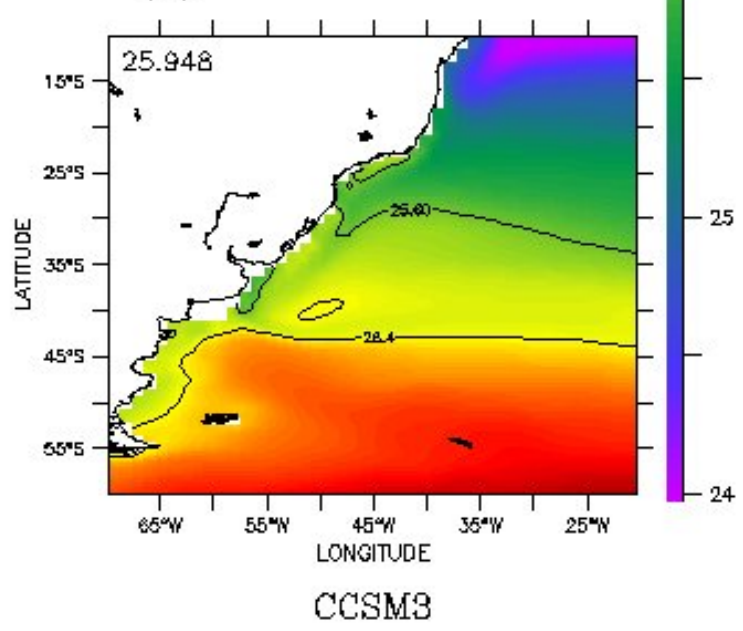

Figura 10: Densidade média em subsuperfície (50m) em $\mathrm{kg} / \mathrm{m}^{3}$ : (a) SODA, (b) GFDL, (c) MIROC e (d) CCSM3. Acima e à esquerda encontramos a média na região. 
(a)

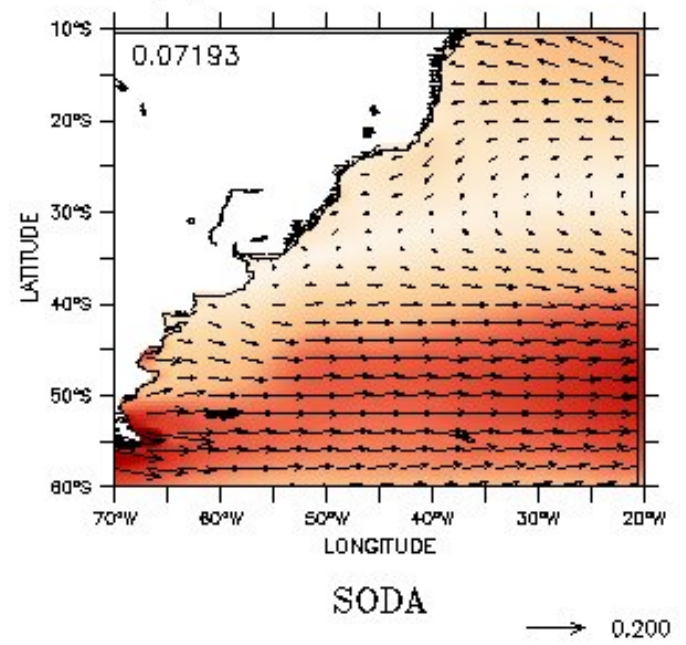

(c)

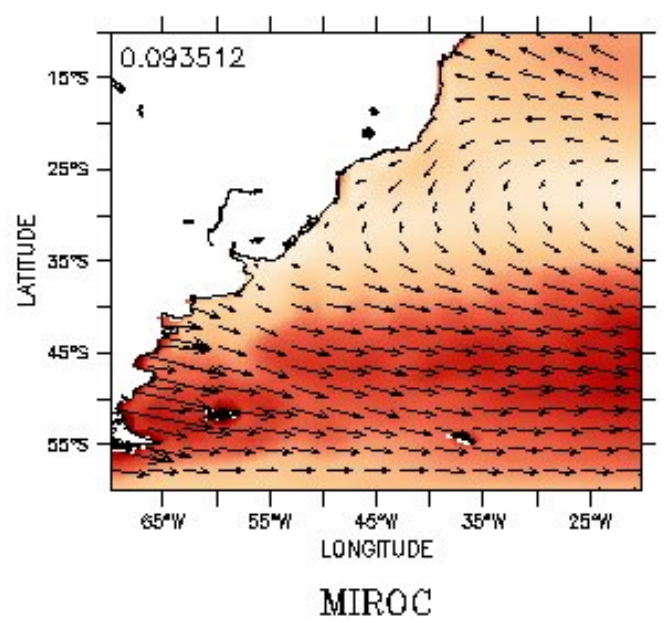

(b)

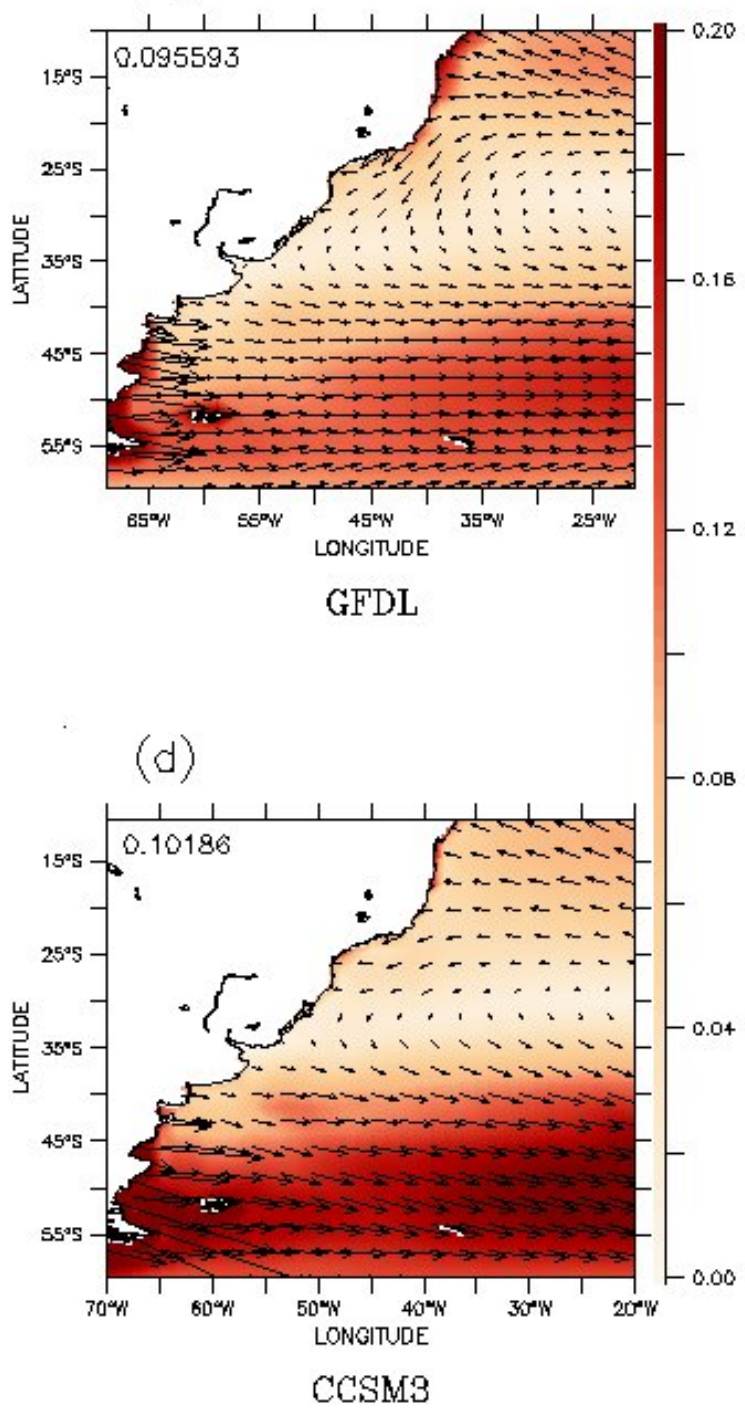

Figura 11: Tensão média de tensão de cisalhamento do vento (vetores) sobre a superfície e seu módulo $\left(\mathrm{N} / \mathrm{m}^{2}\right)$ : (a) SODA, (b) GFDL, (c) MIROC e (d) CCSM3. Acima e à esquerda encontramos a média na região. 
(a)

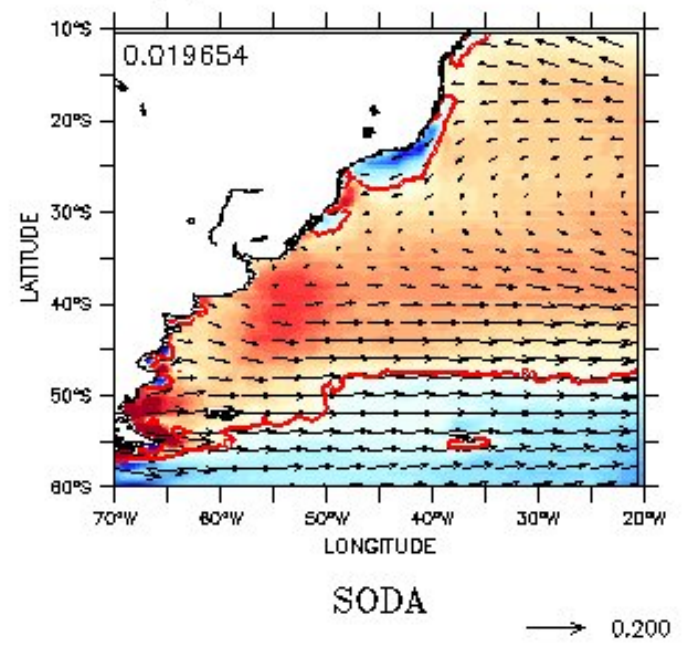

(c)

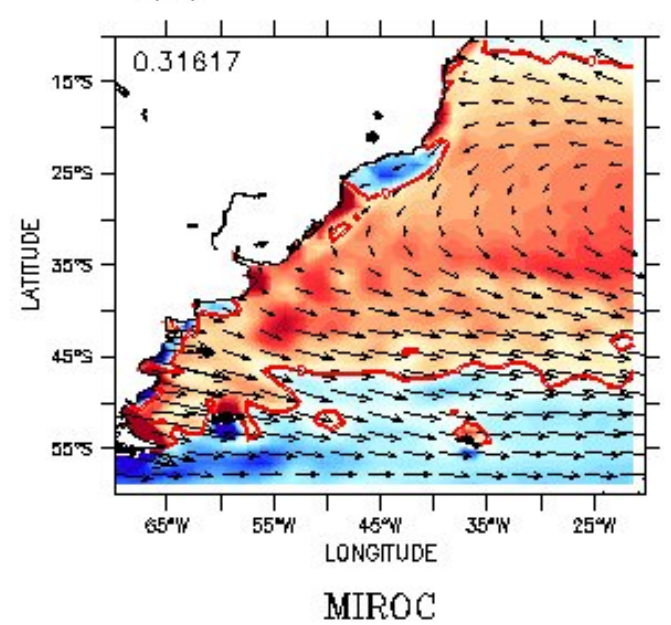

(b)

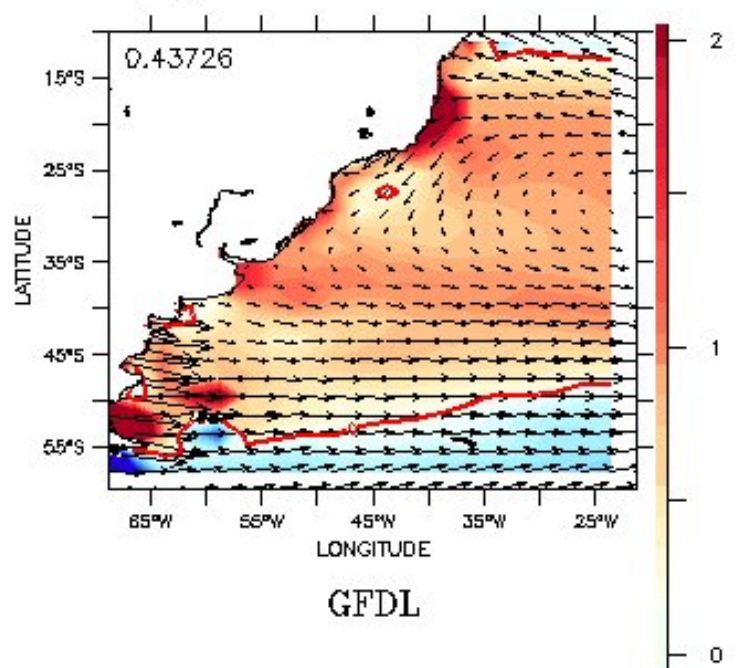

(d)

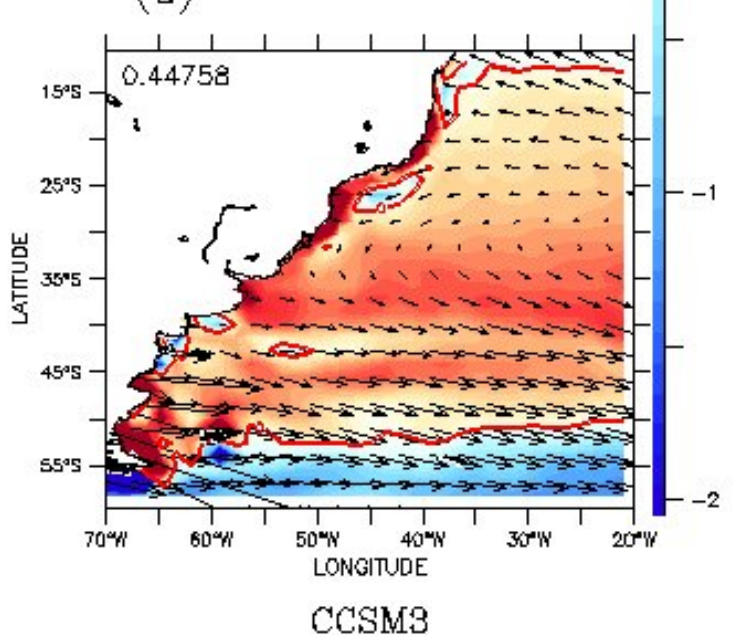

Figura 12: Média de tensão de cisalhamento do vento (vetores) sobre seu respectivo rotacional $\left(\mathrm{N} / \mathrm{m}^{3}\right)$ : (a) SODA, (b) GFDL, (c) MIROC e (d) CCSM3. Acima e à esquerda encontramos a média na região. As linhas veremelhas representam o rotacional zero. 
(a)

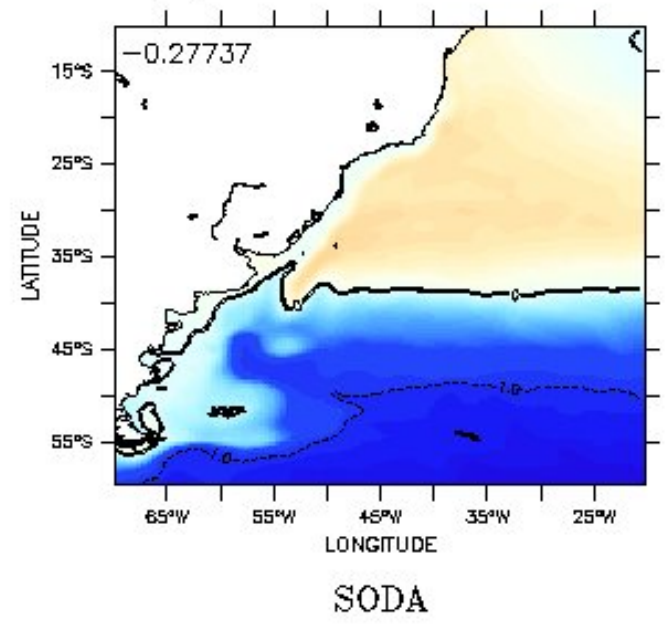

(c)

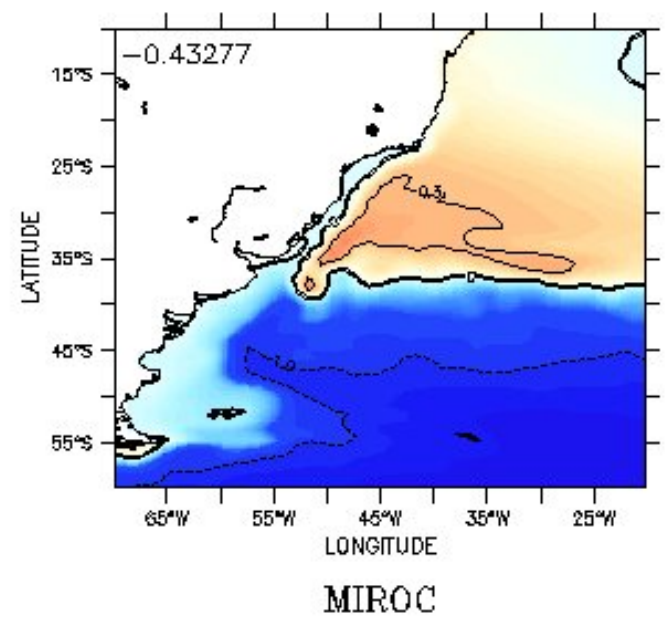

(b)

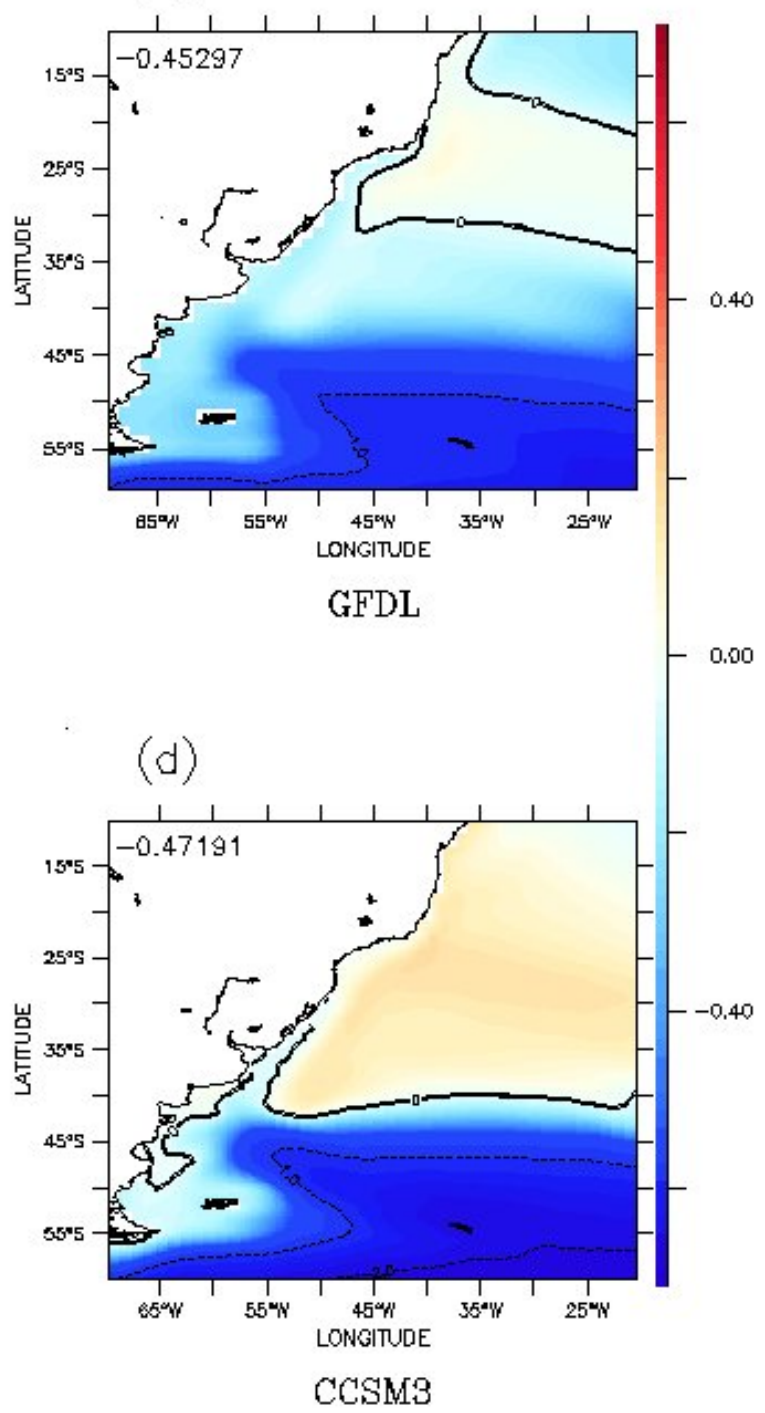

Figura 13: Média da altura do nível do mar $\left(10^{-1} \mathrm{~m}\right)$ : (a) SODA, (b) GFDL, (c) MIROC e (d) CCSM3. Acima e à esquerda encontramos a média na região. 


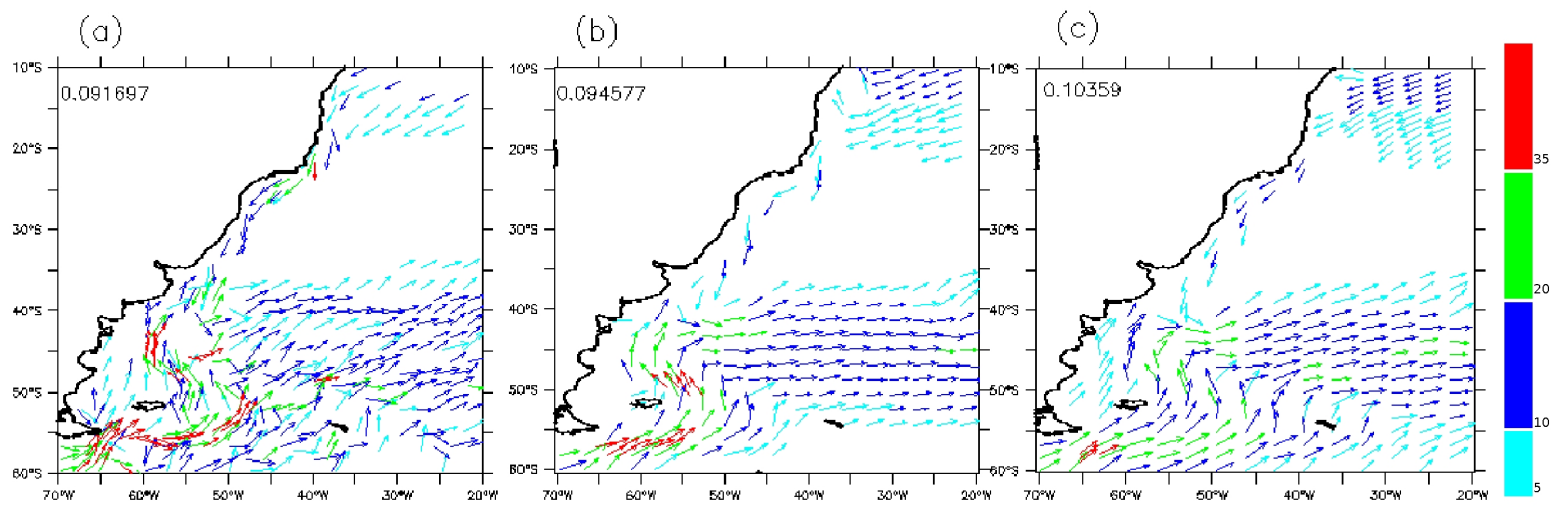

Figura 14: Média da Velocidade de corrente $(\mathrm{cm} / \mathrm{s})$ de superfície segundo o SODA e 2 modelos do $4^{\circ}$ Relatório de Avaliação do IPCC: (a) SODA, (b) MIROC e (c) CCSM3. Acima e à esquerda encontramos a média do módulo na região e os vetores inferios a $5 \mathrm{~cm} / \mathrm{s}$ não foram plotados. 
(a)

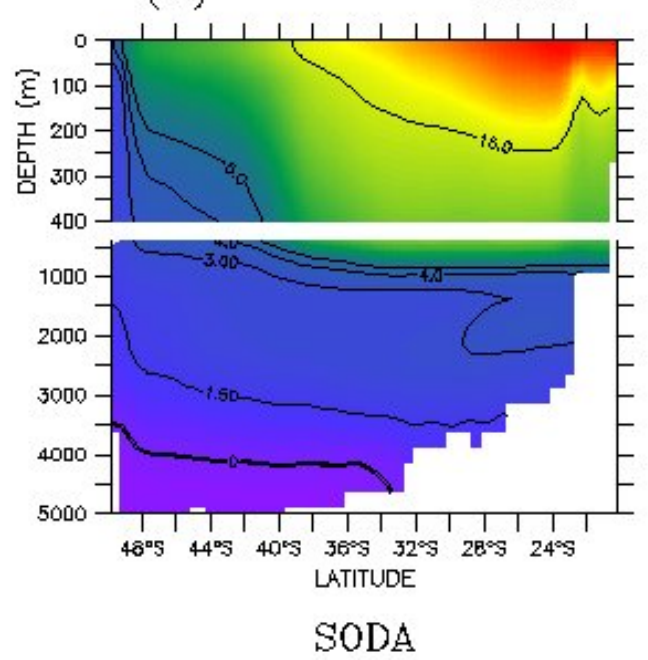

(c)

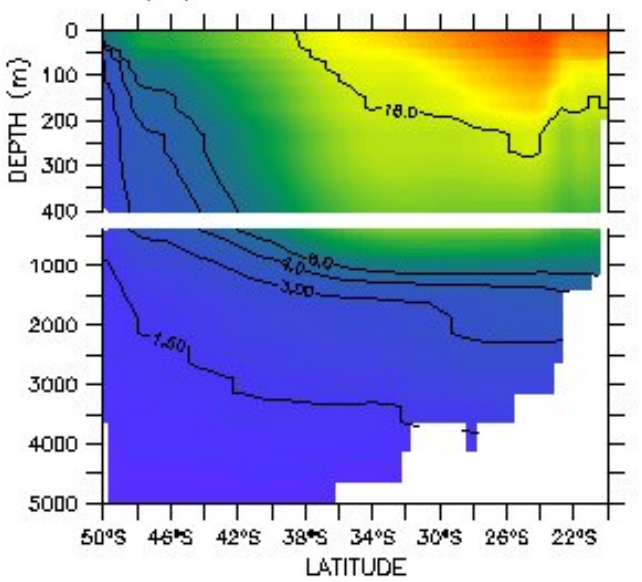

MIROC (b)

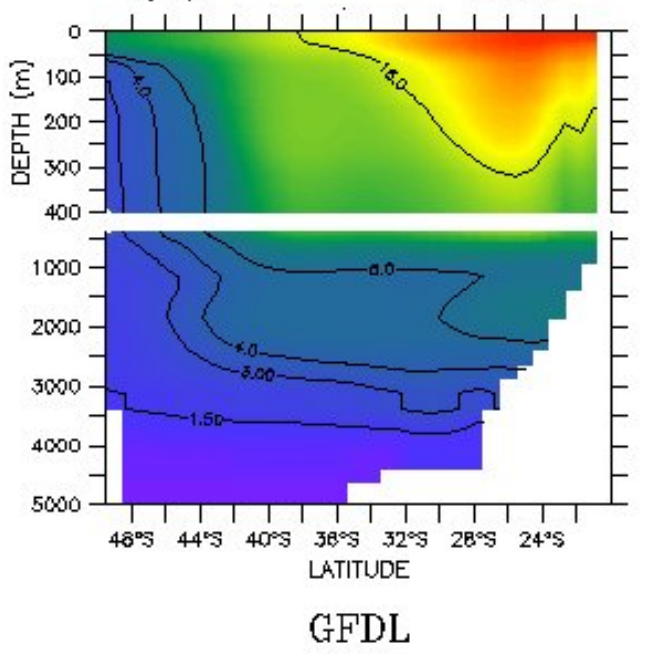

(d) 14.387

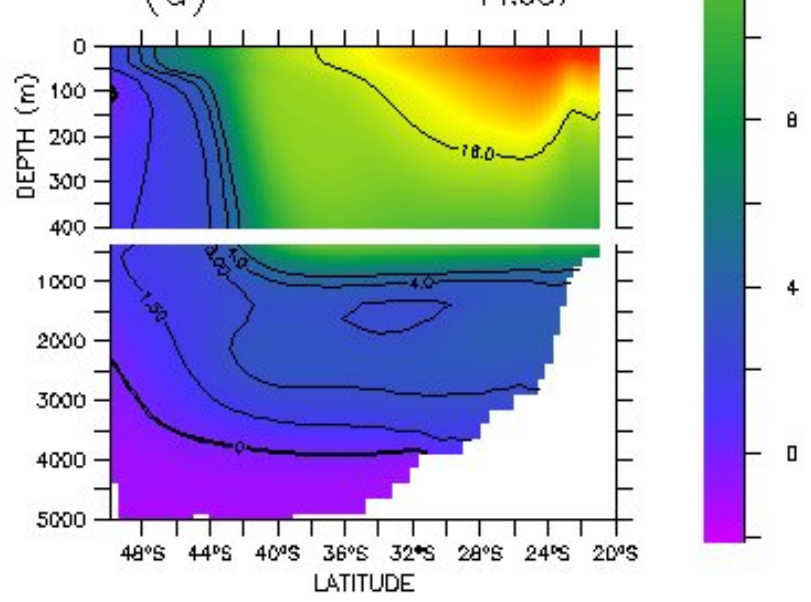

CCSM3

Figura 15: Seção vertical média meridional de temperatura $\left({ }^{\circ} \mathrm{C}\right)$ na longitude de $40^{\circ} \mathrm{W}$ (Transecto 1): (a) SODA, (b) GFDL, (c) MIROC e (d) CCSM3. Acima e à direita encontramos a média na seção. 
(a)

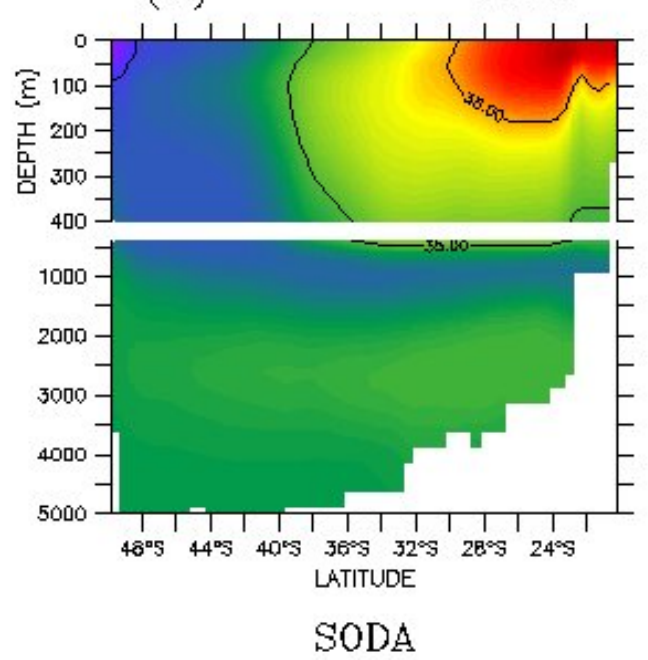

(c)

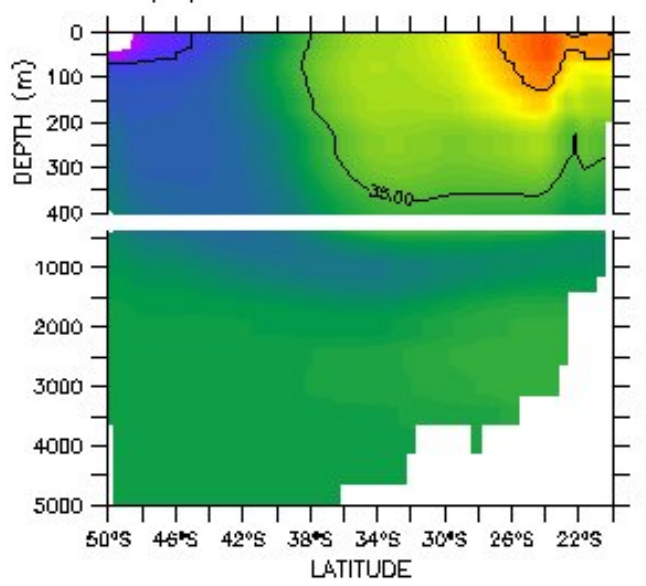

MIROC (b)

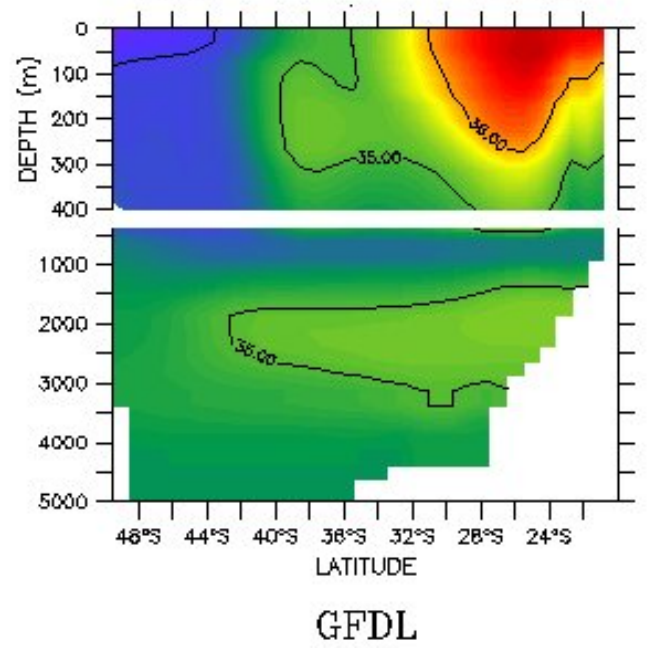

(d)

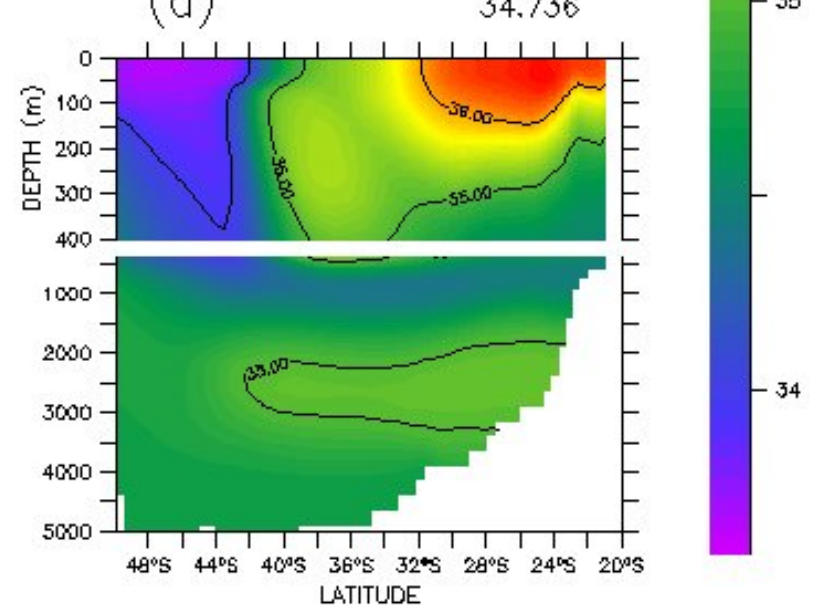

CCSM3

Figura 16: Seção vertical média meridional de salinidade na longitude de $40^{\circ} \mathrm{W}$ (Transecto 1): (a) SODA, (b) GFDL, (c) MIROC e (d) CCSM3. Acima e à direita encontramos a média na seção. 
(a)

15.127

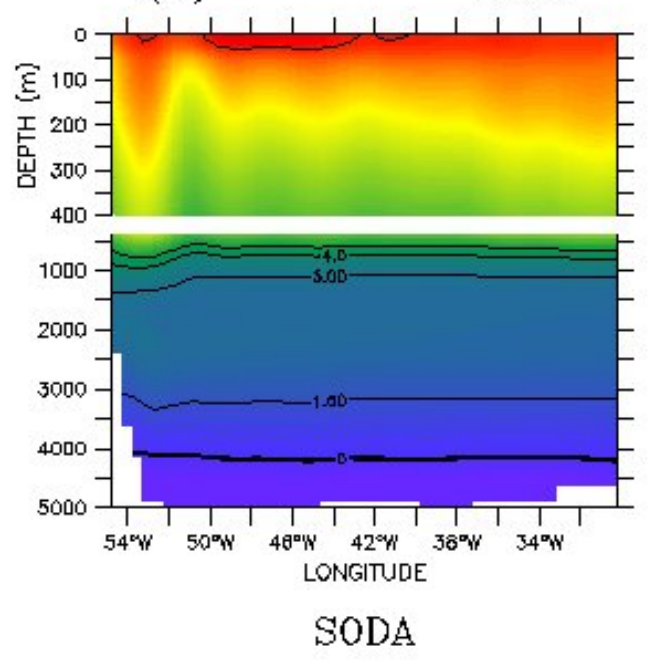

(c)

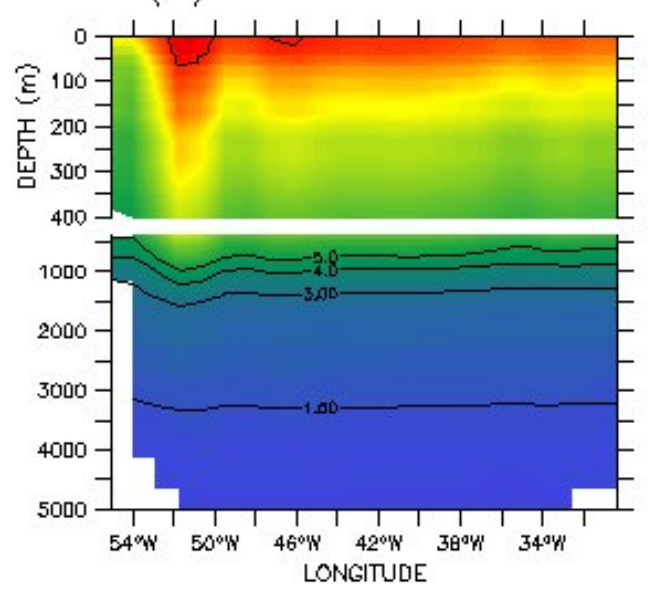

MIROC (b)

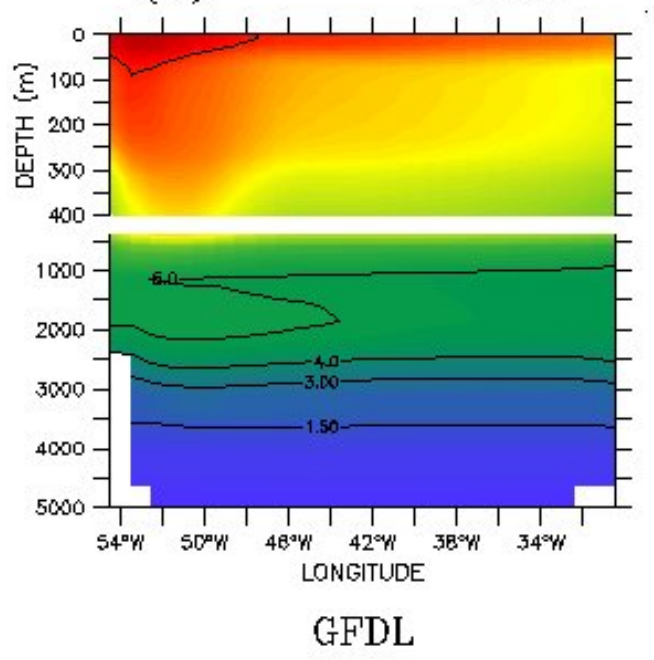

(d)

14.387

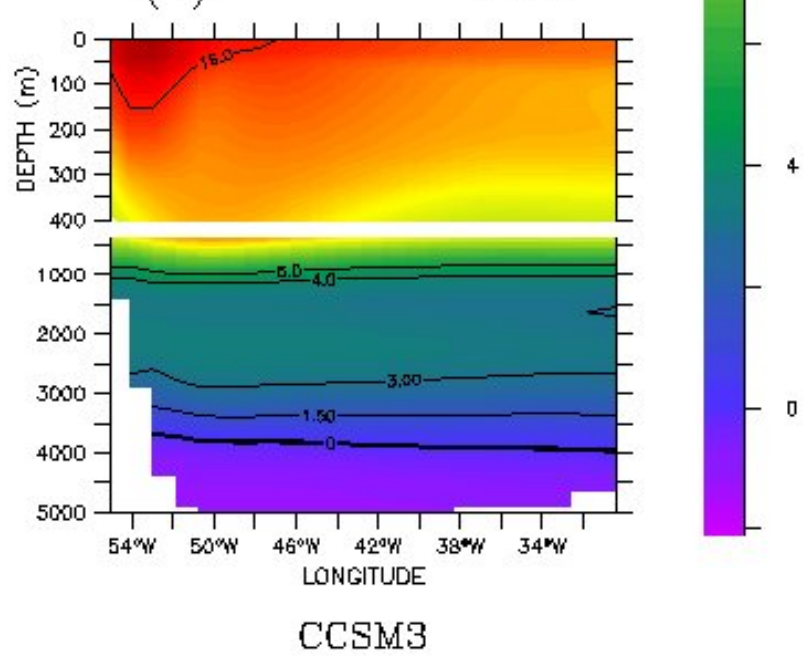

Figura 17: Seção vertical média zonal de temperatura $\left({ }^{\circ} \mathrm{C}\right)$ na latitude de $39^{\circ}$ Ṣ (Transecto 2): (a) SODA, (b) GFDL, (c) MIROC e (d) CCSM3. Acima e à direita encontramos a média na seção. 
(a)

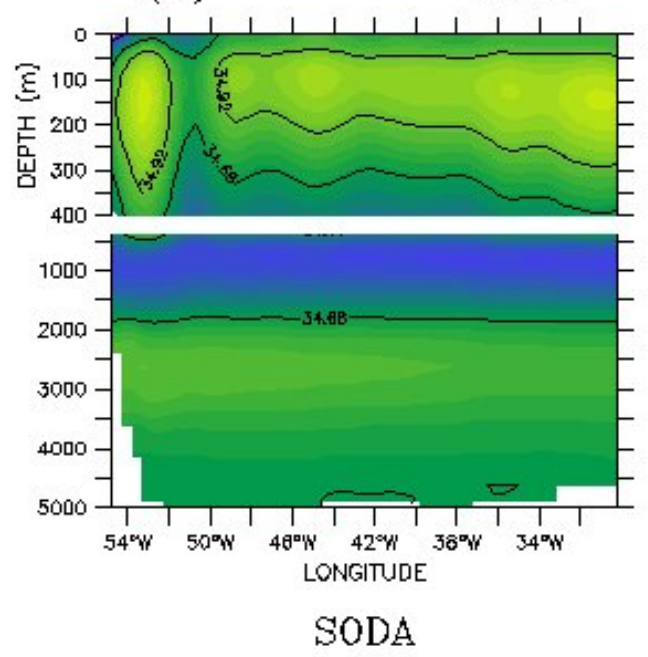

(c)

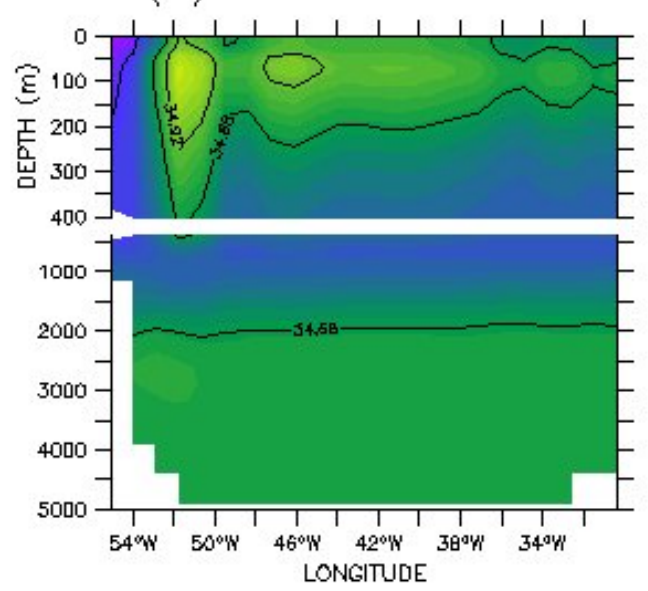

MIROC (b)

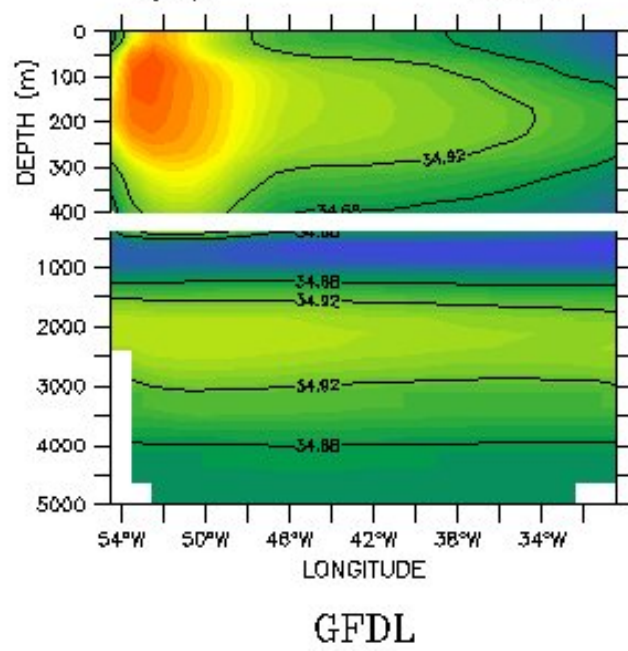

(d)

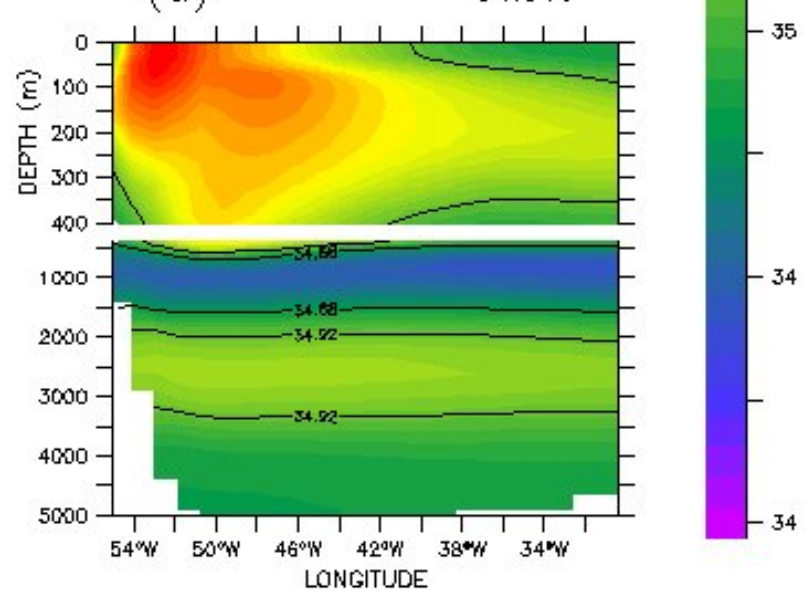

$\operatorname{CCSM} 3$

Figura 18: Perfil médio zonal de salinidade na latitude de $39^{\circ} \mathrm{S}$ (Transecto 2): (a) SODA, (b) GFDL, (c) MIROC e (d) CCSM3. Acima e à direita encontramos a média na seção. 
(a)

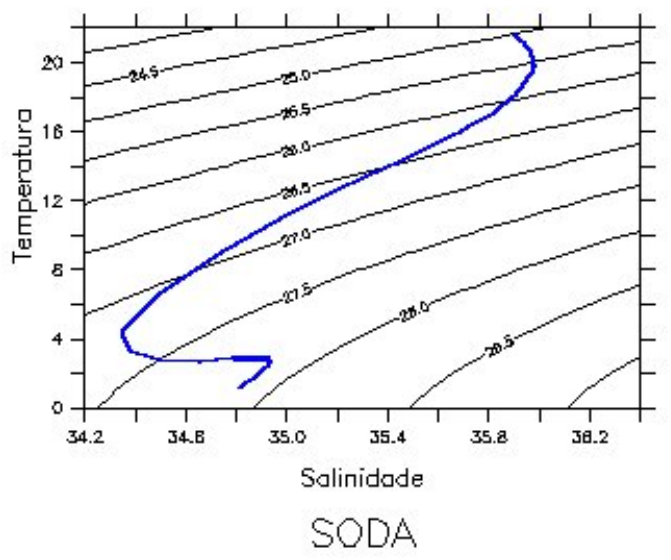

(c)

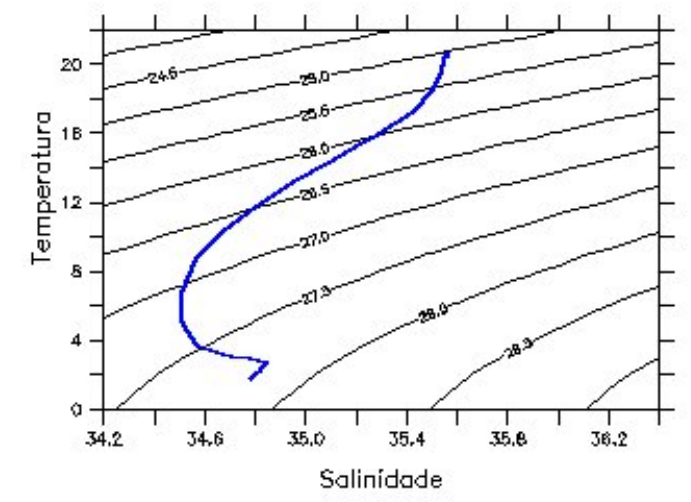

PONTO $1 \quad$ MIROC (b)

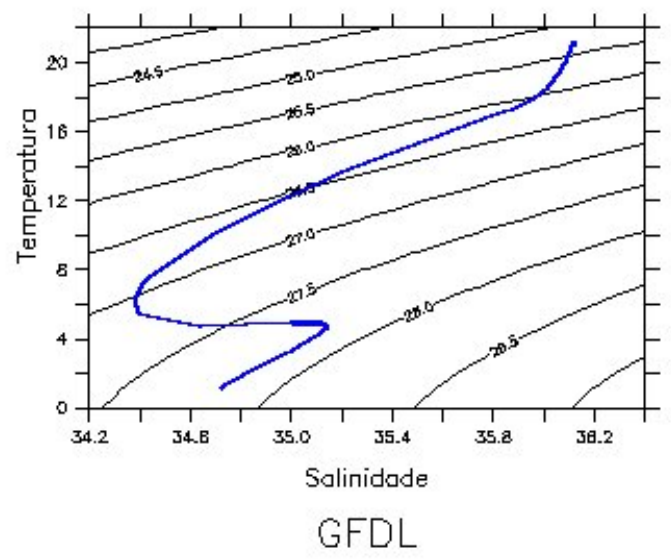

(d)

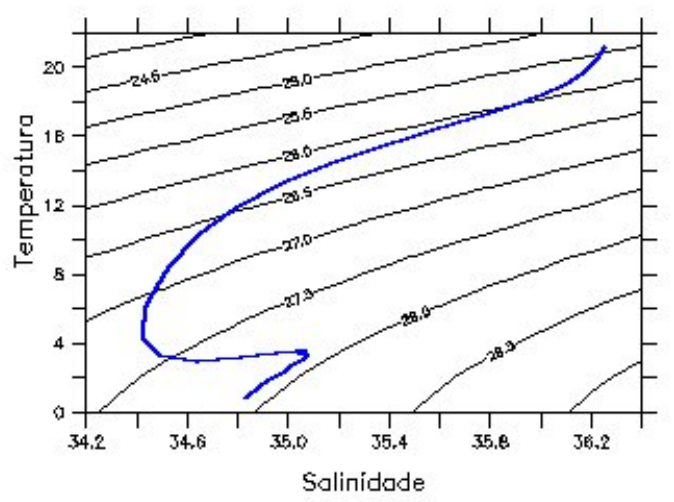

$\cos 33$

Figura 19: Diagramas de estado para o conjunto (a) SODA e os modelos numéricos do IPCC no ponto $1\left(40^{\circ} \mathrm{W}, 30^{\circ} \mathrm{S}\right)$ : (b) GFDL, (c) MIROC e (d) CCSM3. Temperatura em ${ }^{\circ} \mathrm{C}$ e salinidade em psu. 


\subsubsection{Diferença entre o padrão espacial médio do SODA e dos modelos}

Esta parte dos resultados, descreve as diferenças encontradas entre o padrão médio dos modelos e do SODA.

A partir da Figura 20, concluímos que os modelos numéricos resolvem a temperatura de superfície muito melhor no domínio da Corrente do Brasil do que no da Corrente das Malvinas. Ao sul de $35^{\circ} \mathrm{S}$, o MIROC e o GFDL superestimam a temperatura de superfície da Corrente das Malvinas em mais de $2^{\circ} \mathrm{C}$, ao contrário do CCSM3. Com exceção do MIROC, todos os modelos apresentam águas mais quentes na CBM do que o SODA. Embora seja o modelo que mais superestima a temperatura em altas latitudes, o GFDL foi o que apresentou a menor média da diferença em relação ao $\operatorname{SODA}\left(0,15^{\circ} \mathrm{C}\right)$. O CCSM3, embora apresente menor desvio da temperatura na maior parte da região, apresentou as diferenças pontuais mais intensas de temperatura, no padrão médio e superfície. O MIROC, como meio termo, apresenta uma distribuição mediana de desvios de temperatura de superfície que se estende por quase toda a região, mas raramente ultrapassa os $2^{\circ} \mathrm{C}$.

(a)

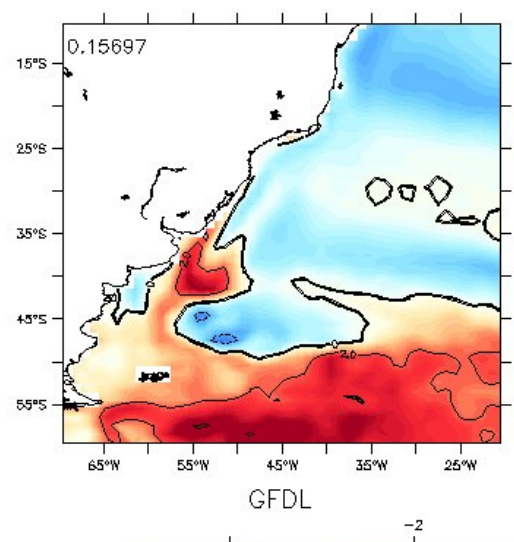

(b)

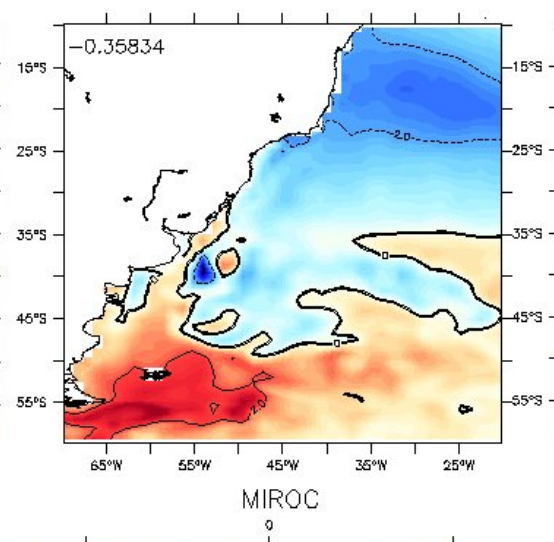

(c)

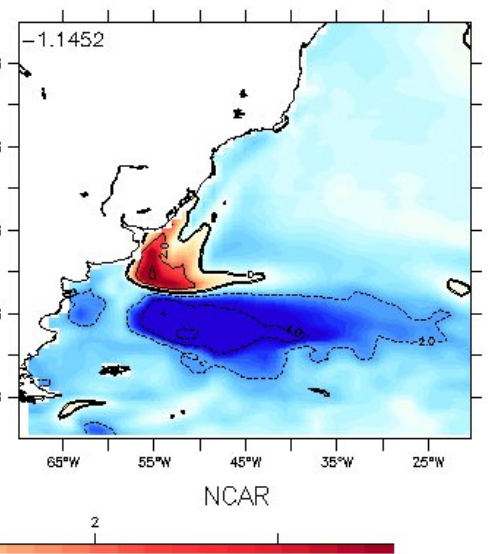

Figura 20: Diferença de temperatura média de superfície $\left({ }^{\circ} \mathrm{C}\right)$ entre os 3 modelos numéricos do IPCC ( (a) GFDL, (b) MIROC, (c) CCSM3) e os dados de Reanálise do SODA. Média da diferença acima e à esquerda.

Por outro lado, as salinidades médias de superfície de todos os modelos diferem do SODA com um padrão bem menos claro (Figura 21). Todos os modelos apresentaram salinidade média acima da do SODA próximo ao Rio da Prata, até mesmo o MIROC (que considera o aporte fluvial). O GFDL apresenta menor salinidade na região da Confluência. 
Todos os modelos subestimaram a salinidade de superfície no domínio da corrente do Brasil (sobretudo o CCSM3).

(a)

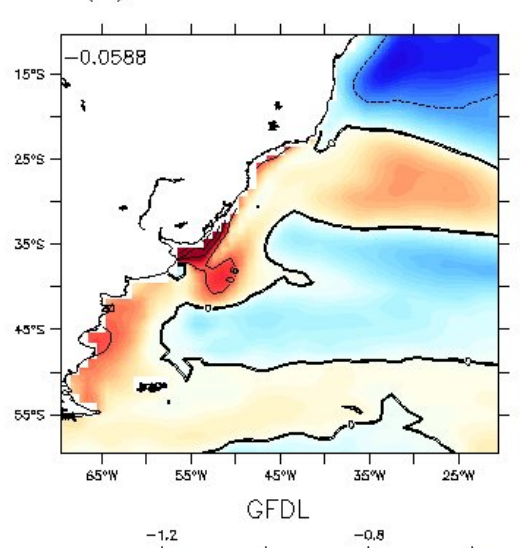

(b)

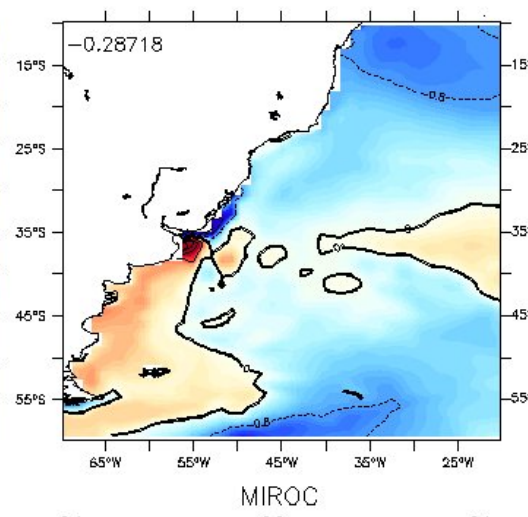

(c)

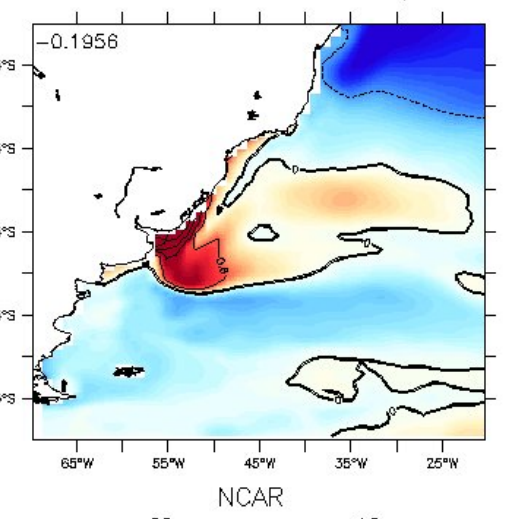

Figura 21: Diferença de salinidade média de superfície entre os 3 modelos numéricos do IPCC ( (a) GFDL, (b) MIROC, (c) CCSM3) e os dados de Reanálise do SODA. Média da diferença acima e à esquerda.

De forma geral, os modelos representam o módulo da tensão do cisalhamento do vento sobre a superfície do mar mais intenso. O GFDL obteve os piores resultados perto da costa (Figura 22). O MIROC representou uma tensão de cisalhamento do vento exagerado em quase toda a região (com exceção das latitudes maiores que $50^{\circ} \mathrm{S}$ ) e representou a menor diferença média dessa variável $\left(0.014 \mathrm{~N} / \mathrm{m}^{2}\right)$. Já o CCSM3 apresenta a tensão de cisalhamento do vento consideravelmente exagerado em grandes latitudes. A estimativa exagerada da tensão do cisalhamento no oceano austral pode representar, erroneamente, a intensificação da Corrente Circumpolar Antártica.

A elevação do nível do mar, foi subestimada (em geral) no domínio da Corrente do Brasil, ao contrário do que ocorreu em grandes latitudes. O MIROC, por sua vez, subestimou a elevação do nível do mar na região da Confluência. No CCSM3 encontramos diferenças significativas sobretudo em altas latitudes, possivelmente por conta da intensificação da tensão do cisalhamento do vento nesse modelo. A maior diferença média foi representada pelo MIROC $\left(-0,072 \mathrm{~N} / \mathrm{m}^{2}\right)$.

As Figuras de 24 a 27 mostram as diferenças entre as seções verticais médias de temperatura e salinidade nos transectos 1 e 2 . 
(a)

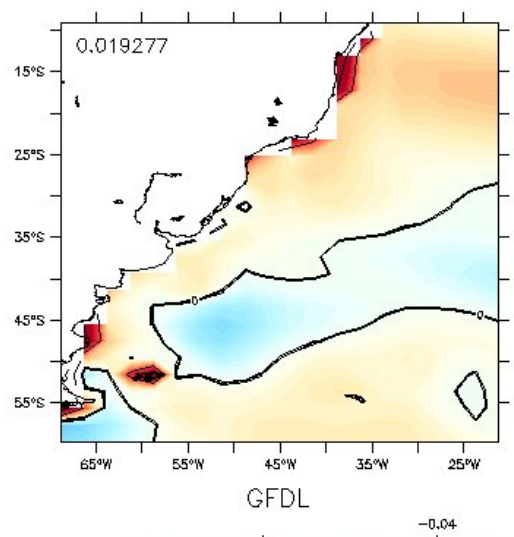

(b)

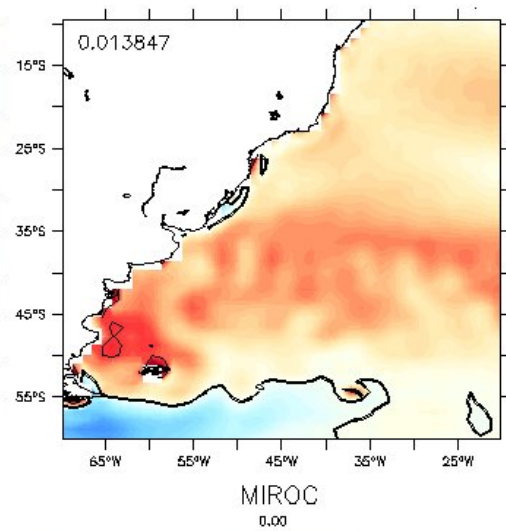

(c)

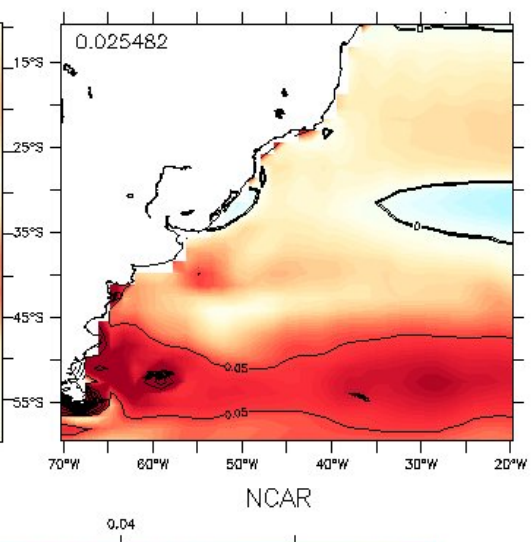

Figura 22: Diferença de tensão de cisalhamento médio do vento $\left(\mathrm{N} / \mathrm{m}^{2}\right)$ sobre a superfície do oceano entre os 3 modelos numéricos do IPCC ( (a) GFDL, (b) MIROC, (c) CCSM3) e os dados de Reanálise do SODA e média da diferença acima e à esquerda.

(a)

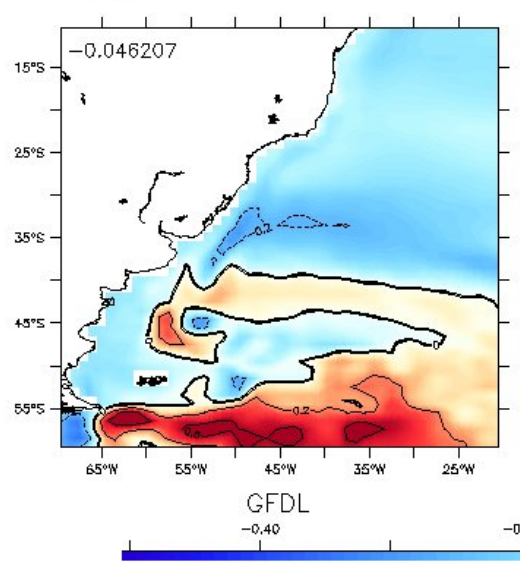

(b)

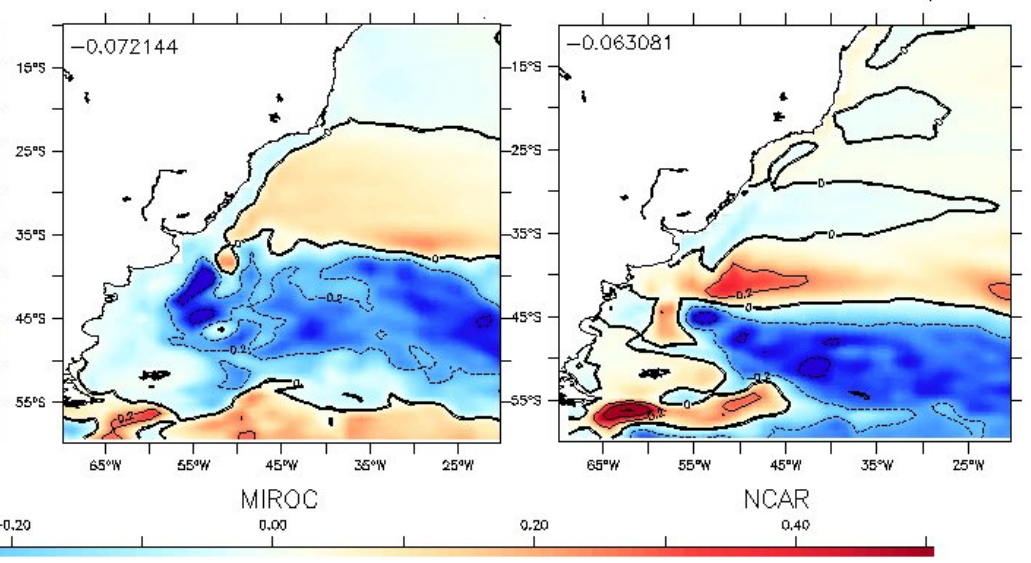

Figura 23: Diferença da altura média da superfície do oceano $\left(10^{-1} \mathrm{~m}\right)$ entre os 3 modelos numéricos do IPCC ( (a) GFDL, (b) MIROC, (c) CCSM3) e os dados de Reanálise do SODA. Média da diferença acima e à esquerda. 
(a)

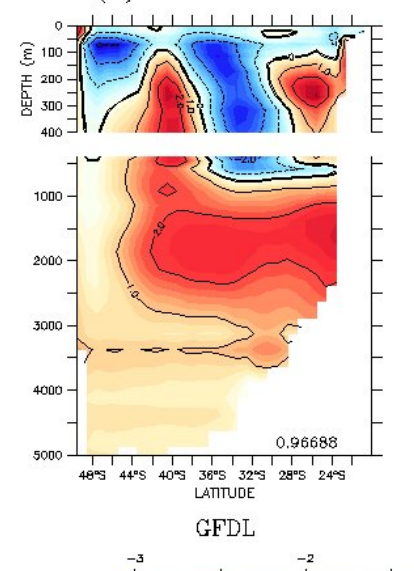

(b)

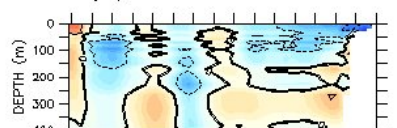

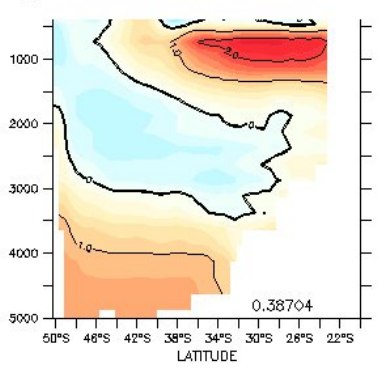

MIROC

(c)
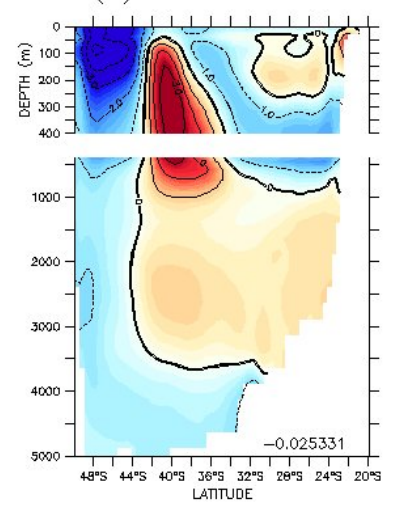

CCSM3

Figura 24: Transecto latitudinal em 50W (Transecto 1) da diferença entre a temperatura média $\left({ }^{\circ} \mathrm{C}\right)$ dos 3 modelos numéricos do IPCC ( (a) GFDL, (b) MIROC, (c) CCSM3) e os dados de Reanálise do SODA. Média da diferença abaixo e à esquerda.

Como visto nas figuras 24 e 25 a temperatura por volta de $40^{\circ} \mathrm{S}$ é superior no GFDL nos primeiros 400m, sobretudo próximo a costa (possivelmente devido ao aporte do Rio da Prata). Nas latitudes próximas, observamos águas mais frias do que as representadas pelo SODA. Abaixo dos 1000 metros o GFDL representou águas mais quentes que o SODA, sobretudo entre 1000 e $2000 \mathrm{~m}$, onde a diferença superou os $2^{\circ} \mathrm{C}$.

Nos outros dois modelos, as maiores diferenças concentram-se na superfície. A distribuição meridional da temperatura média foi melhor representada no MIROC que apresentou difeneças inferiores a $0.5^{\circ} \mathrm{C}$ em quase todo o transecto. Por outro lado, em $40^{\circ} \mathrm{S}$, o padrão de temperatura diferiu significativamente do SODA nos primeiros 400m. O CCSM3 superestimou muito a temperatura em $40^{\circ} \mathrm{S}$. Entre 400 e $500 \mathrm{~m}$ esse desvio superou os $6^{\circ} \mathrm{C}$.

Observamos na Figura 26 que o GFDL representa salinidade muito inferior na região da CBM entre 0 e 400m (relacionadas à AT) e entre 1000 e 2000 (AIA e APAN). Por outro lado, em todo o transecto latitudinal a salinidade abaixo de 4000m desse modelo é mais baixa que a do SODA. Na Figura 27, o transecto longitudinal em $40^{\circ} \mathrm{S}$ mostra que até os 400 metros, a salinidade do GFDL supera em até 1 unidade a salinidade do SODA, possivelmente devido ao aporte do Rio da Prata. Por outro lado, a superestimação da salinidade entre 1000 e 2000 metros (superior a 0.2) também é vista em toda extensão 
(a)

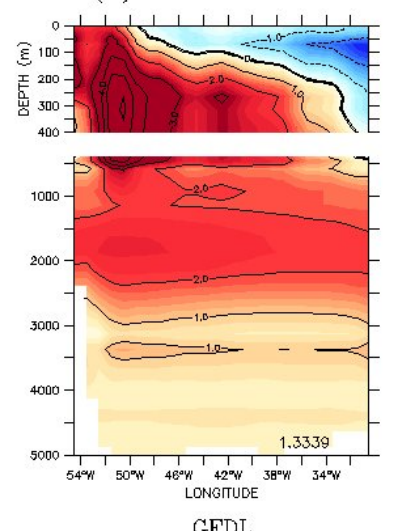

GFDL (b)
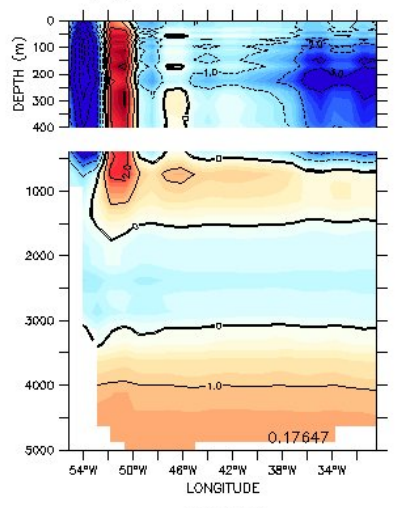

MIROC (c)
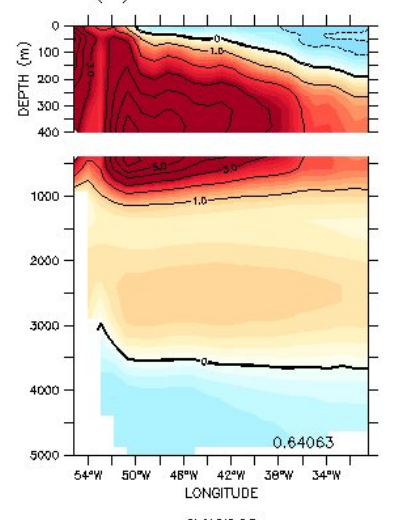

CCSM3

Figura 25: Transecto longitudinal em $40^{\circ} \mathrm{S}$ (Transecto 2) da diferença entre a temperatura média $\left({ }^{\circ} \mathrm{C}\right)$ dos 3 modelos numéricos do IPCC ( (a) GFDL, (b) MIROC, (c) CCSM3) e os dados de Reanálise do SODA. Média da diferença abaixo e à esquerda.

longitudinal.

A salinidade do MIROC, por outro lado, é muito inferior na superfície (em até 0.5), mas ao contrário dos outros modelos não concentra a maior parte dos erros na região da Confluência. Entre 1000 e 2000m, assim como o GFDL, esse modelo também superestima a salinidade em ambos os transectos mas em menor intensidade (abaixo de 0.1). Abaixo dessa profundidade a salinidade é subestimada, até os $4000 \mathrm{~m}$, onde é praticamente igual ao do SODA.

O CCSM3 concentrou quase todo seu erro na superfície. Com exceção da região próxima a $40^{\circ} \mathrm{S}$, o CCSM3 subestimou bastante a salinidade até os $400 \mathrm{~m}$, porém nessa região ela foi superestimada em quase todas as longitudes. Abaixo dos 400m a salinidade do CCSM3 superou ligeiramente a do SODA até o fundo.

Assim, todos os modelos apresentaram desvios consideráveis no padrão médio em todas as variáveis. Nenhum modelo se destacou de forma clara em relação à diferença do padrão médio, sendo que cada um deles apresentou bons resultados em algumas das análises. 
(a)

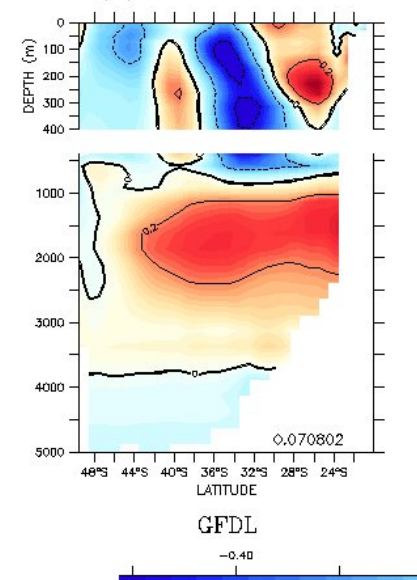

(b)

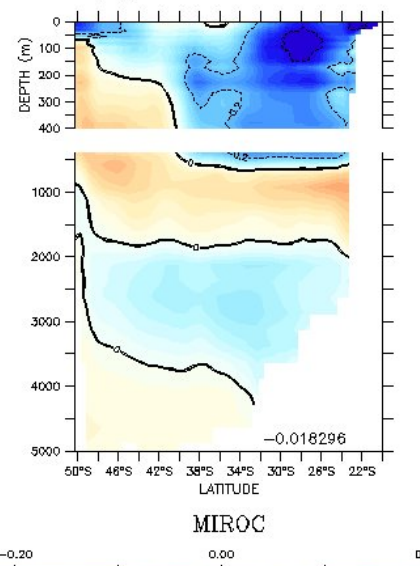

(c)
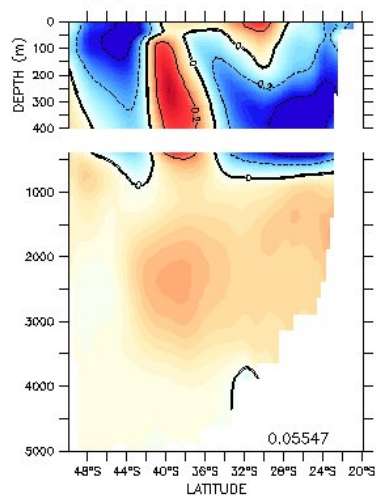

CCSM3

Figura 26: Transecto latitudinal em $50^{\circ} \mathrm{W}$ (Transecto 1) da diferença entre a salinidade média dos 3 modelos numéricos do IPCC ( (a) GFDL, (b) MIROC, (c) CCSM3) e os dados de Reanálise do SODA. Média da diferença acima e à esquerda.

(a)

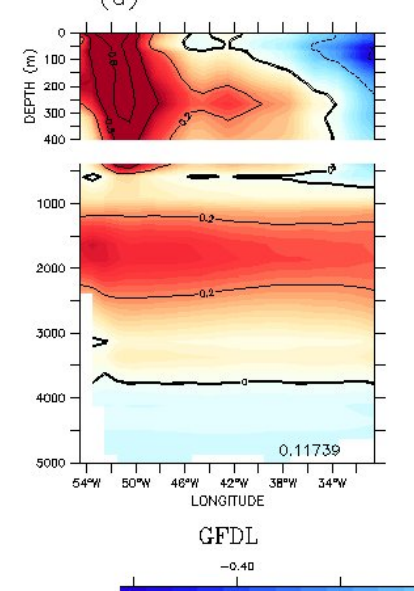

(b)

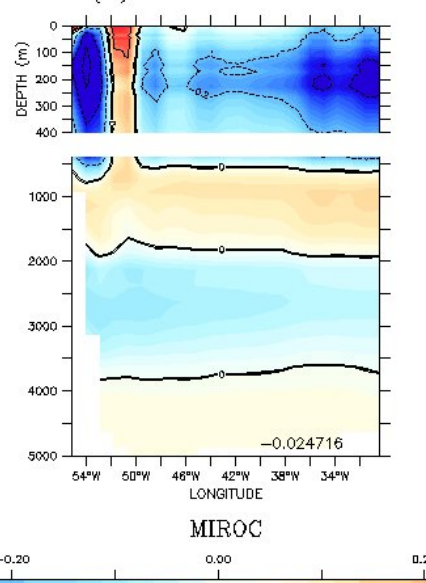

(c)
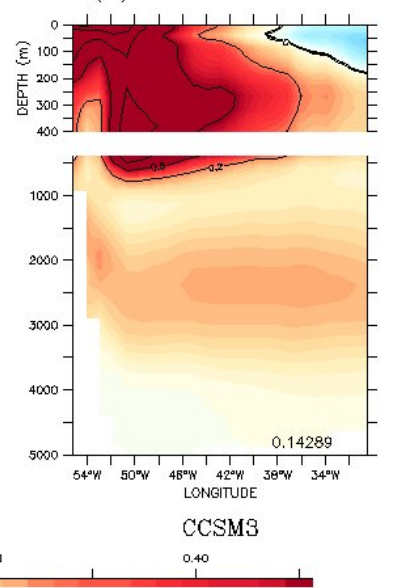

Figura 27: Transecto longitudinal em $40^{\circ} \mathrm{S}$ (Transecto 2) da diferença entre a salinidade média dos 3 modelos numéricos do IPCC ( (a) GFDL, (b) MIROC, (c) CCSM3) e os dados de Reanálise do SODA. Média da diferença acima e à esquerda. Média da diferença acima e à esquerda. 


\subsubsection{Variabilidade Sazonal}

Nessa seção, pretende-se comparar o padrão climatológico da região de estudos.

As Figuras 28 a 32 representam a média da diferença das grandezas físicas de superfície entre janeiro e julho. Observamos na Figura 28 que o GFDL exagerou na amplitude do ciclo sazonal, obtendo diferenças entre os meses maiores que $5^{\circ} \mathrm{C}$ na maior parte da região.

Embora o CCSM3 possua a menor média da diferença na região, o MIROC foi o que melhor representou a distribuição horizontal de superfície. De forma geral, esse modelo representou bem as amplitudes do ciclo sazonal de superfície, porém superestimou-a na região da Corrente das Malvinas.

A representação dos modelos da variabilidade sazonal da salinidade é mais problemática do que da temperatura. Observamos na Figura 29 que o CCSM3 não representou bem as amplitudes, enquanto o MIROC e o GFDL assemelham-se mais ao SODA. O MIROC obteve a média mais próxima do SODA na região.

Como consequência, a densidade de superfície é melhor representada no MIROC na distribuição e nos valores (Figura 30). O CCSM3 apresentou o pior padrão de amplitude sazonal. Com exceção desse modelo, todos os dados representaram maior variabilidade sazonal da densidade (acima de $1 \mathrm{~kg} / \mathrm{m}^{3}$ ) próxima a região da CBM.

A variabilidade da altura do nível do mar é muito mais intensa na região da CBM (como observamos no SODA - Figura 31). O único modelo que representou bem essa amplitude foi o MIROC. Na Figura 32 observamos que todos os modelos superestimaram a amplitude do ciclo sazonal de tensão de cisalhamento do vento, sobretudo na CBM.

No ponto $1\left(40^{\circ} \mathrm{W}, 30^{\circ} \mathrm{S}\right)$, ocorrem as maiores correlações entre as séries climatológicas do SODA e dos modelos (sobretudo na climatologia de temperatura). Na superfície, todos os modelos obtiveram correlações superiores a 98\% com o SODA. Porém, por volta dos $2000 \mathrm{~m}$ e $130 \mathrm{~m}$ de profundidade todos os modelos obtiveram correlações negativas também observadas na salinidade. Em superfície a salinidade obteve correlação entre $68 \%$ (MIROC) e 82\% (GFDL). A série climatológica de elevação do nível do mar possui correlação entre $80 \%$ e $90 \%$.

No ponto $2\left(55^{\circ} \mathrm{W}, 45^{\circ} \mathrm{S}\right)$ a correlação entre a climatologia de temperatura dos modelos e do SODA também foi bem alta (acima dos 98\%), porém a salinidade de superfície não obteve uma climatologia semelhante (correlações negativas). A altura do nível do mar obteve boas correlações, sobretudo no MIROC e no GFDL (90 e 91\%, respectivamente). 
A Tabela 12 apresenta as correlações entre as climatologias das variáveis em superfície.

Ponto 1

\begin{tabular}{|c|c|c|c|}
\hline & Temperatura & Salinidade & Altura do Nível do Mar \\
\hline GFDL & 0.99 & 0.82 & 0.88 \\
\hline MIROC & 0.99 & 0.68 & 0.89 \\
\hline CCSM3 & 0.98 & 0.74 & 0.86 \\
\hline \multicolumn{4}{|c|}{ Ponto 2} \\
\hline & Temperatura & Salinidade & Altura do Nível do Mar \\
\hline GFDL & 0.99 & -0.53 & 0.91 \\
\hline MIROC & 1 & -0.37 & 0.9 \\
\hline CCSM3 & 0.98 & -0.55 & 0.82 \\
\hline
\end{tabular}

Tabela 12: Correlação entre as médias climatológicas das variáveis de superfícies do SODA e dos 3 modelos do $4^{\circ}$ Relatório de Avaliação do IPCC: (a) SODA, (b) GFDL, (c) MIROC e (d) CCSM3.

A Figura 33 representa a média climatolológica da posição da Confluência Brasil Malvinas segundo o SODA e os modelos numéricos. O MIROC foi o modelo que melhor representou a posição da CBM obtendo correlação de $92 \%$ com o SODA ante a $88 \%$ do GFDL e 79\% do CCSM3. Além disso esse modelo obteve a amplitude de variação próxima ao do SODA. O CCSM3, embora obtenha a menor correlação obteve as posições mais próximas ao esperado.

De forma geral, o MIROC representou bem as amplitudes da variabilidade climatológica da região. Além disso, esse modelo obteve a melhor correlação em relação à posição da Confluência Brasil-Malvinas. 
(a)

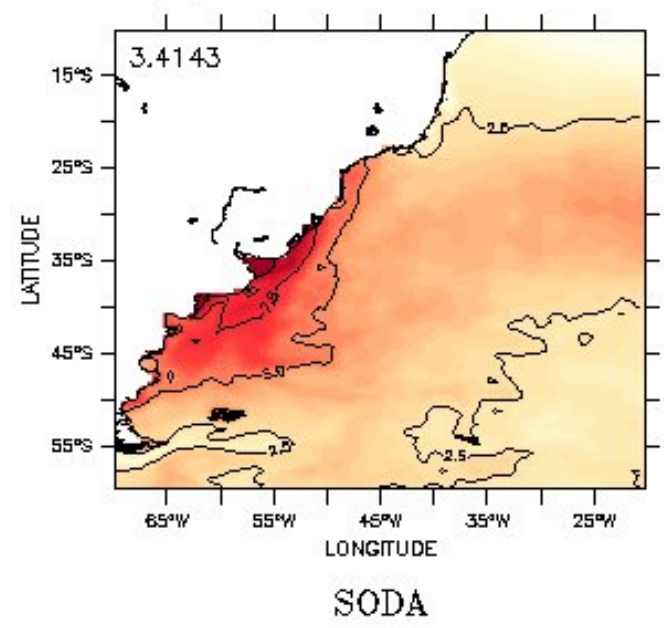

(c)

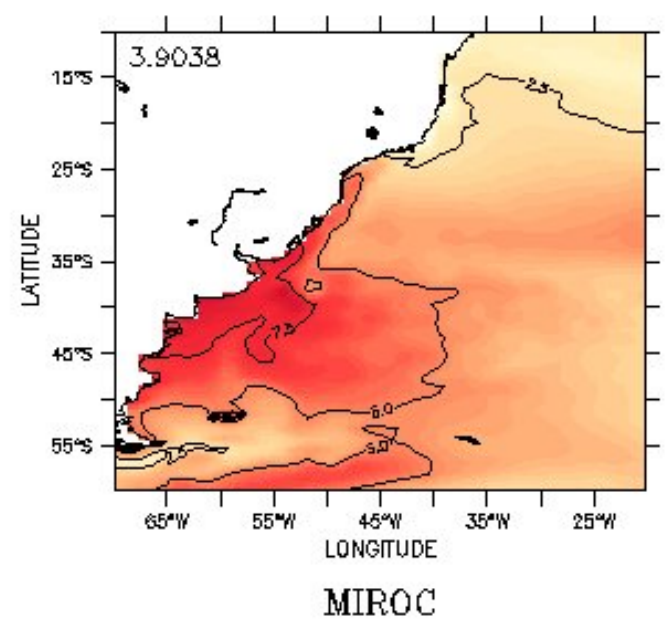

(b)

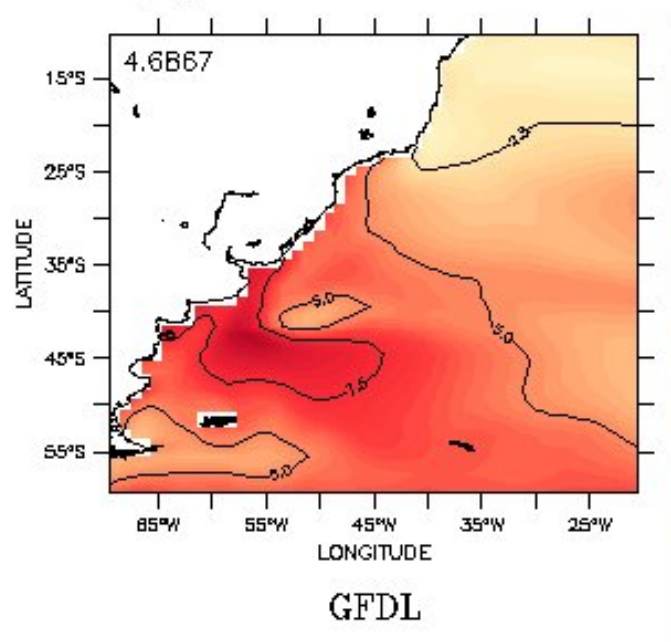

(d)

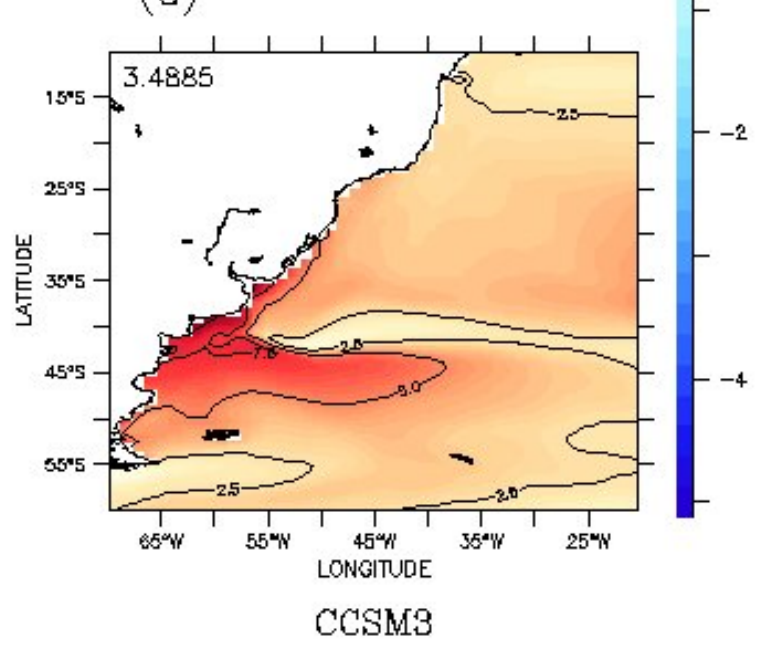

Figura 28: Diferença entre janeiro e julho de temperatura de superfície $\left({ }^{\circ} \mathrm{C}\right)$ : (a) SODA, (b) GFDL, (c) MIROC e (d) CCSM3. Média da diferença acima e à esquerda. 
(a)

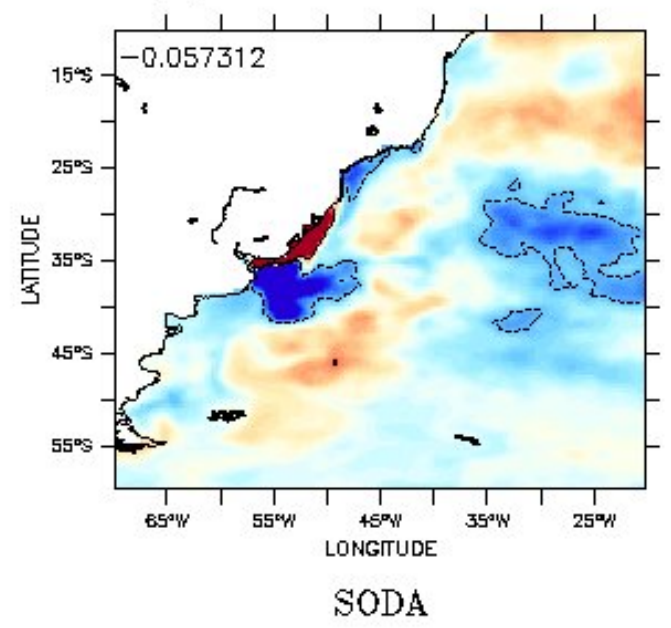

(c)

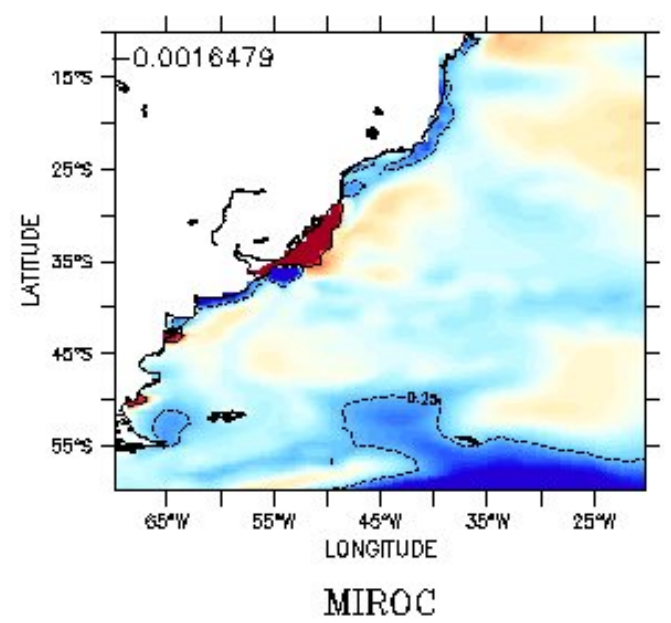

(b)

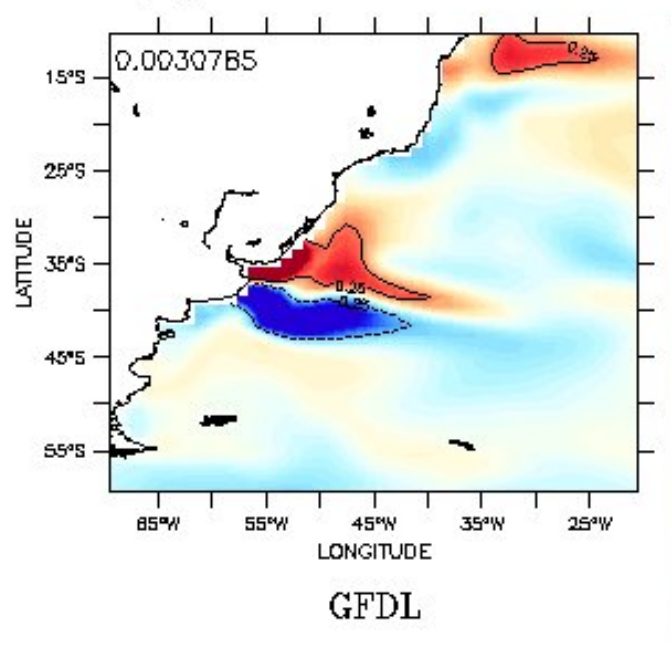

(d)

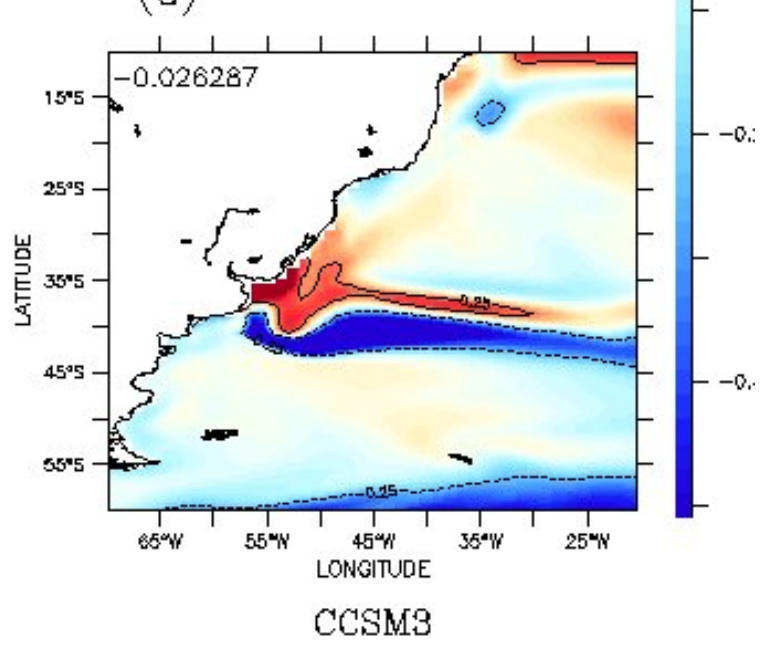

Figura 29: Diferença entre janeiro e julho de salinidade de superfície: (a) SODA, (b) GFDL, (c) MIROC e (d) CCSM3. Média da diferença acima e à esquerda. 
(a)

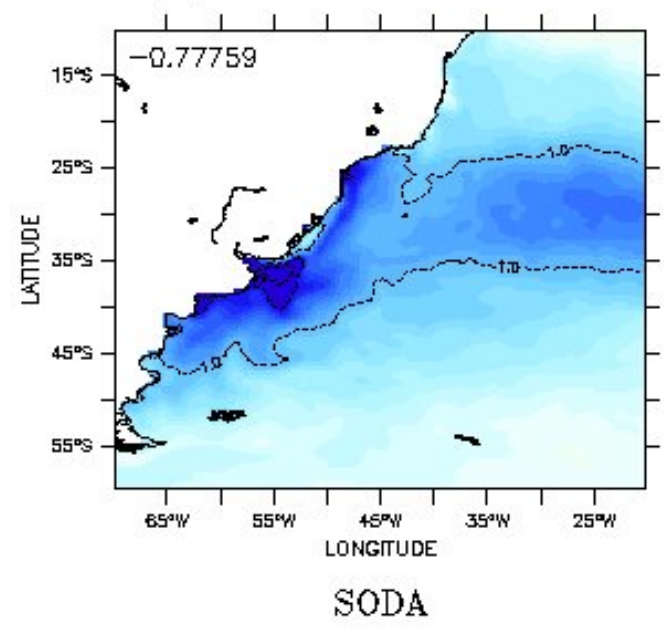

(c)

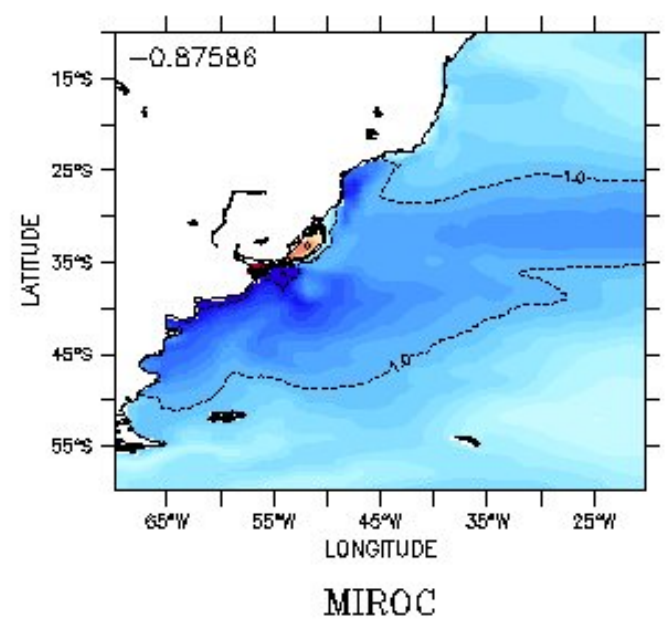

(b)

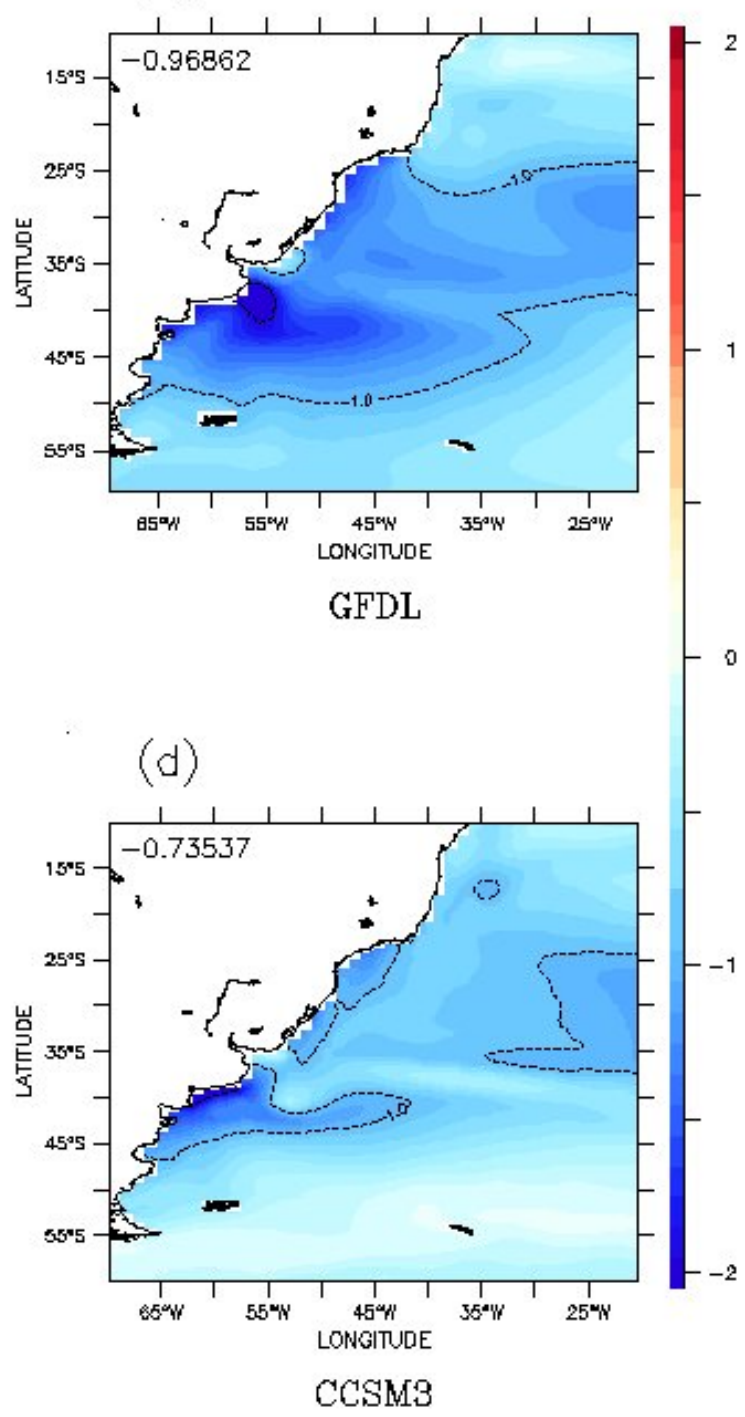

Figura 30: Diferença entre janeiro e julho de densidade de superfície $\left(\mathrm{kg} / \mathrm{m}^{3}\right)$ : (a) SODA, (b) GFDL, (c) MIROC e (d) CCSM3. Média da diferença acima e à esquerda. 
(a)

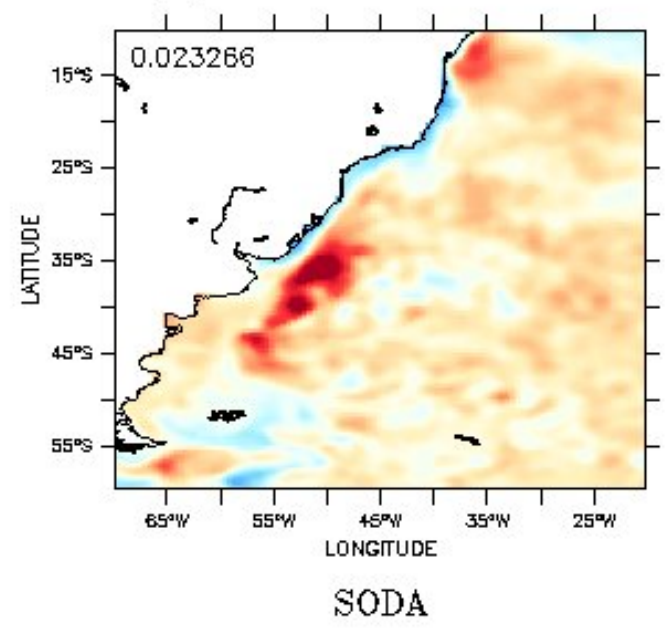

(c)

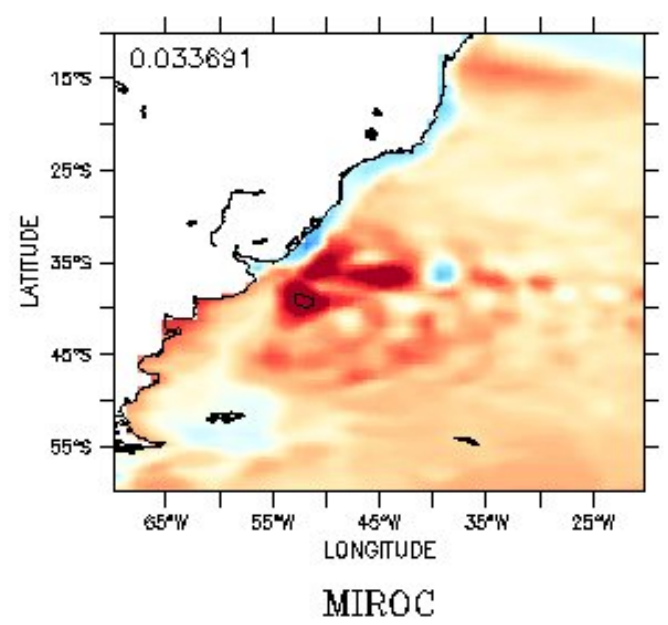

(b)

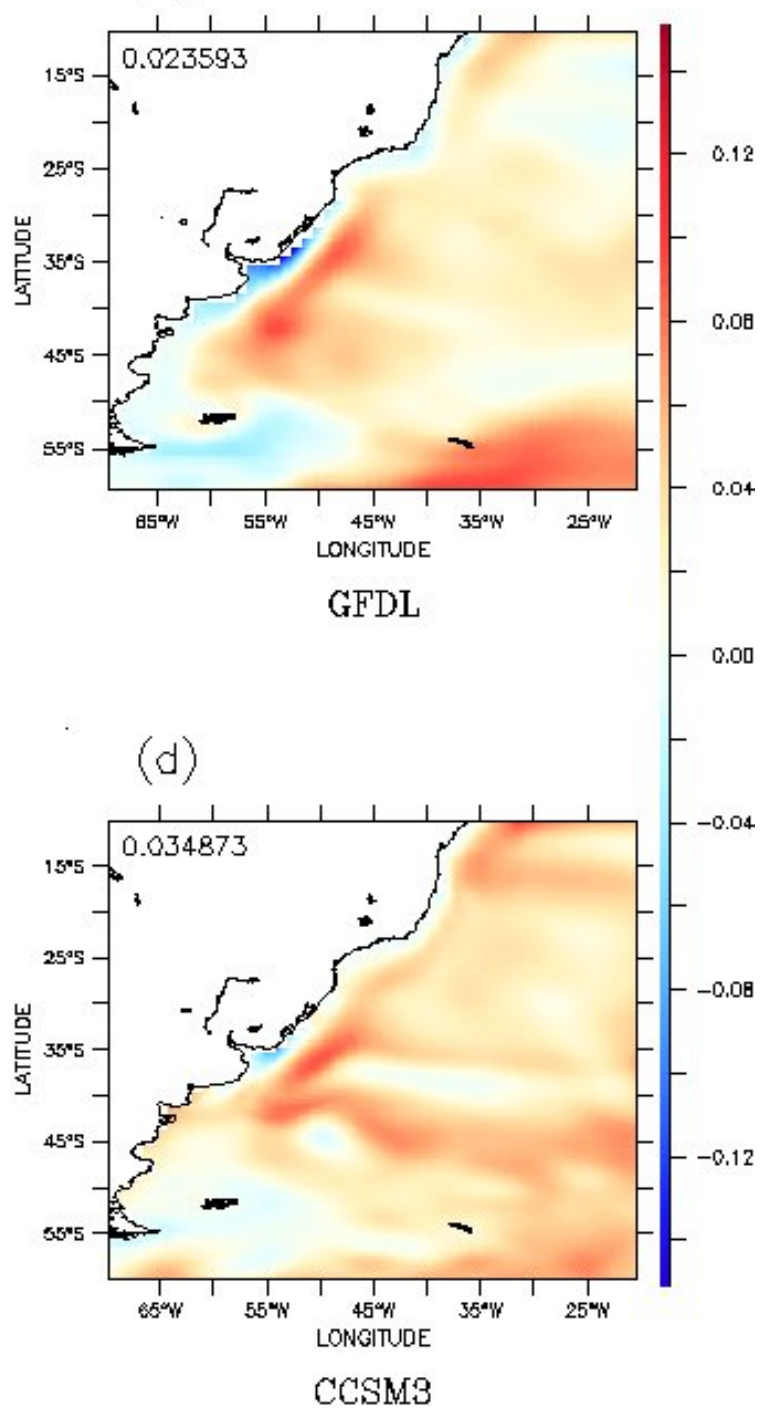

Figura 31: Diferença entre janeiro e julho da altura do nível do mar (dcm): (a) SODA, (b) GFDL, (c) MIROC e (d) CCSM3. Média da diferença acima e à esquerda. 
(a)

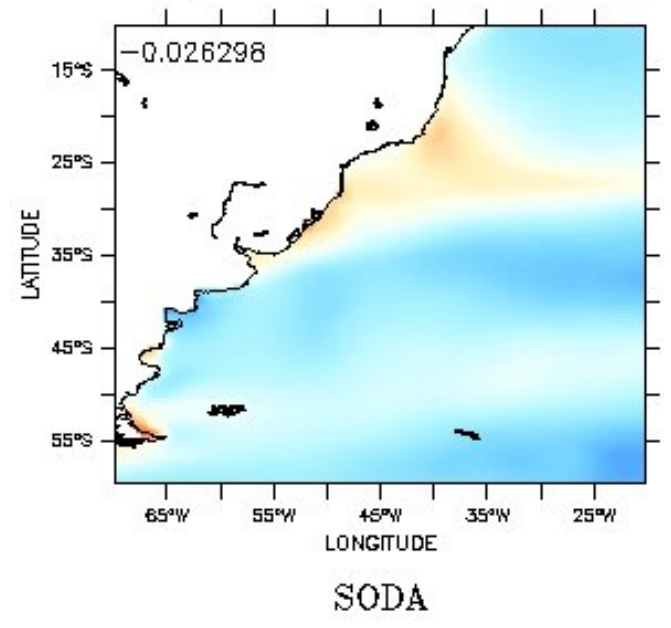

(c)

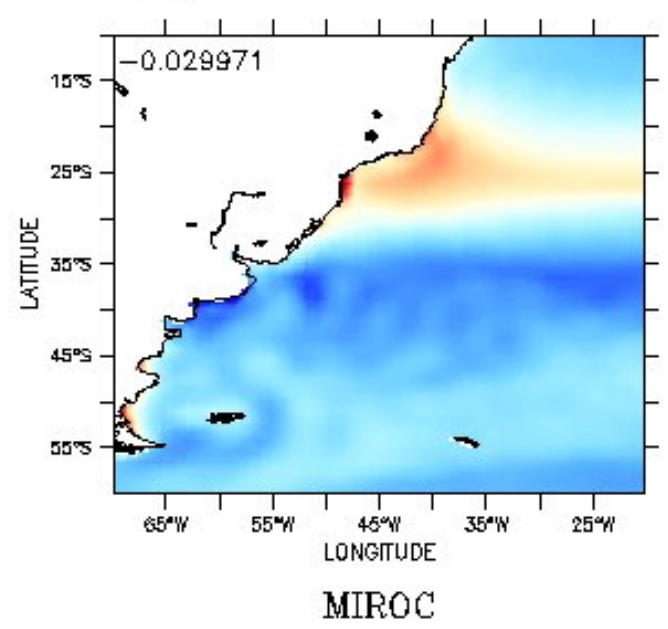

(b)

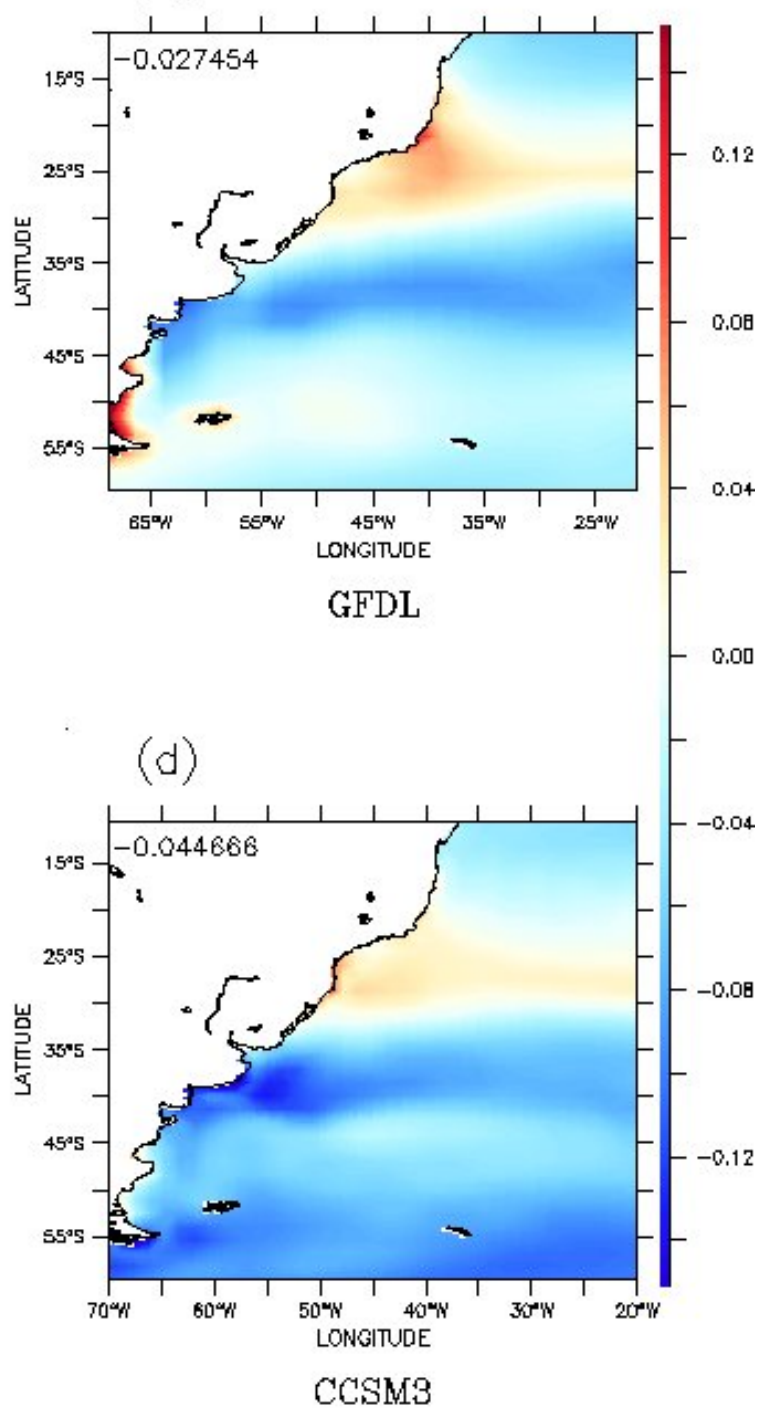

Figura 32: Diferença entre janeiro e julho da tensão do cisalhamento do vento $\left(\mathrm{N} / \mathrm{m}^{2}\right)$ sobre a superfície do mar: (a) SODA, (b) GFDL, (c) MIROC e (d) CCSM3. Média da diferença acima e à esquerda. 
(a)

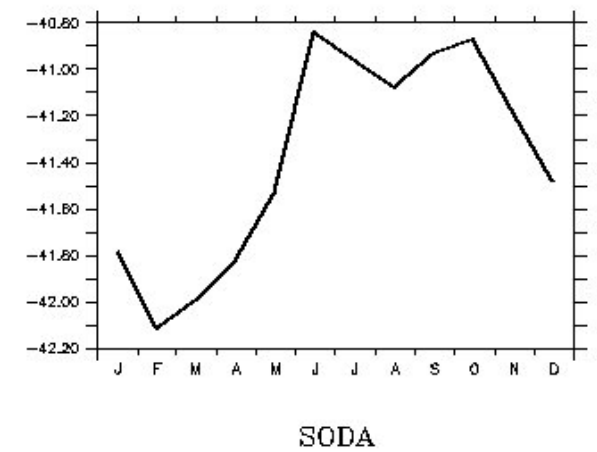

(c)

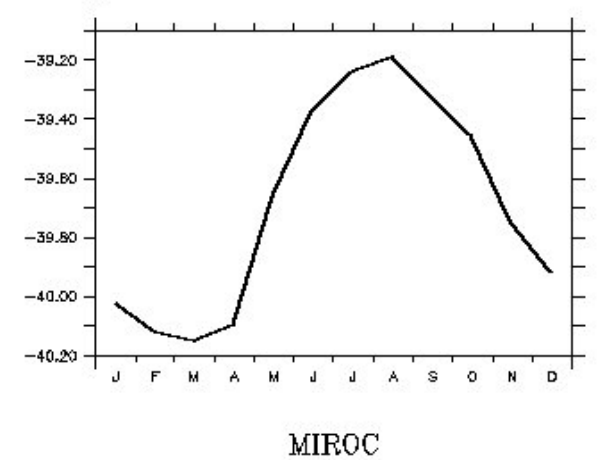

(b)

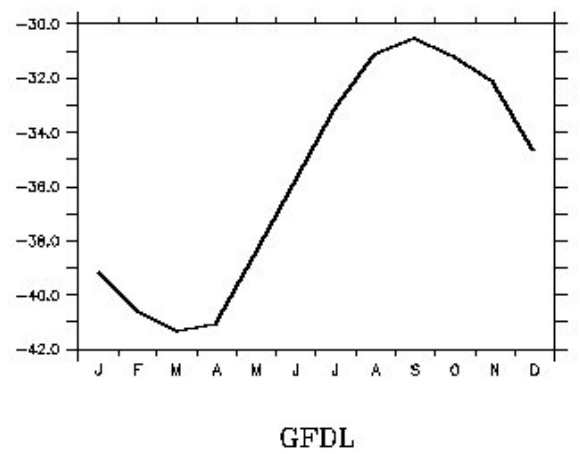

(d)

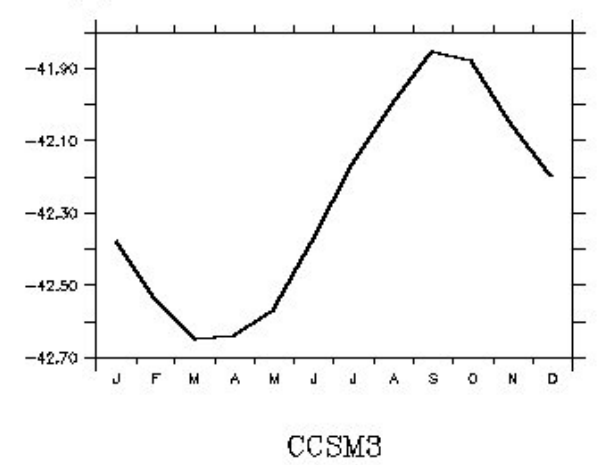

Figura 33: Média Climatológica da Latitude da Posição da Confluência Brasil-Malvinas:

(a) SODA, (b) GFDL, (c) MIROC e (d) CCSM3. 


\subsubsection{Tendências}

Nesta seção, serão analisadas as tendências dos parâmetros físicos. Definiu-se como tendência o coeficiente angular da reta da regressão linear dos dados no tempo (entre 1958 e 2000).

Na Figura 34 observamos que a tendência de temperatura de superfície é subestimada em todos os modelos. Sobretudo na região da CBM e regiões adjacentes, observamos uma tendência do SODA superior a $0.015^{\circ} \mathrm{C} /$ ano enquanto que nos modelos essa tendência não superou $0.007^{\circ} \mathrm{C} /$ ano. Entre os modelos, o que menos subestimou essa tendência foi o MIROC.

O mesmo ocorreu com a tendência de salinidade (Figura 35). E novamente o modelo que mais se aproximou foi o MIROC, ao contrário dos outros dois modelos.

O MIROC novamente se destacou em relação à elevação do nível do mar. Com exceção a região de tendência negativa entre 25 e $35^{\circ} \mathrm{S}$, o MIROC representou bem toda a região. Além disso, esse modelo foi o que menos subestimou o aumento da altura do nível do mar em quase toda a região. O CCSM3 foi o que obteve pior desempenho.

Nenhum modelo foi capaz de representar a intensa tendência positiva da tensão de cisalhamento do vento.

Os perfis longitudinais de temperatura da Figura 38 mostram que os primeiros 400 metros concentram a principal região de aumento de temperatura. O MIROC concentra a maior parte dessa tendência por volta dos $52^{\circ} \mathrm{W}$. Abaixo dessa profundidade, não ultrapassa os $0.005^{\circ} \mathrm{C} /$ ano.

A tendência de salinidade, novamente foi subestimada em todos os modelos - Figuras 39 e 40. Observamos que na seção latitudinal (em 40 W), os valores são negativos em todas as profundidades maiores que $400 \mathrm{~m}$. O MIROC superestima a tendência positiva próxima a costa. No Transecto $2\left(\mathrm{em} 39^{\circ} \mathrm{S}\right)$, observamos no SODA e em todos os modelos, uma forte taxa de aumento de salinidade na região da CBM. Todos os modelos subestimaram essa tendência, sobretudo o CCSM3.

Praticamente os transectos inteiros são dominados por tendências negativas de densidade (Figuras 41 e 42). O MIROC representa uma tendência muito acentuada nas proximidades da costa. Por outro lado, a tendência positiva em superfície (até $50 \mathrm{~m}$ ) só é representada no GFDL. A forte tendência negativa representada no Transecto latitudinal (1) próxima a Confluência $\left(39^{\circ} \mathrm{S}\right)$ pelo SODA, não apareceu em nenhum modelo. 
(a)

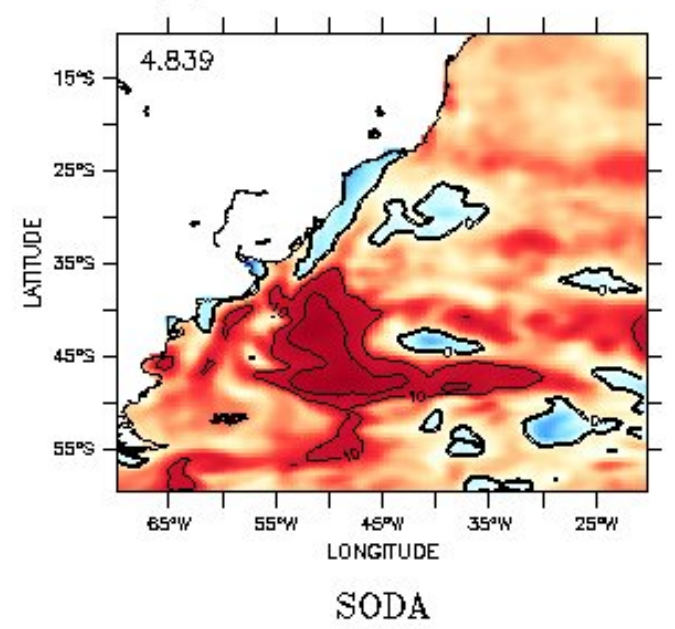

(c)

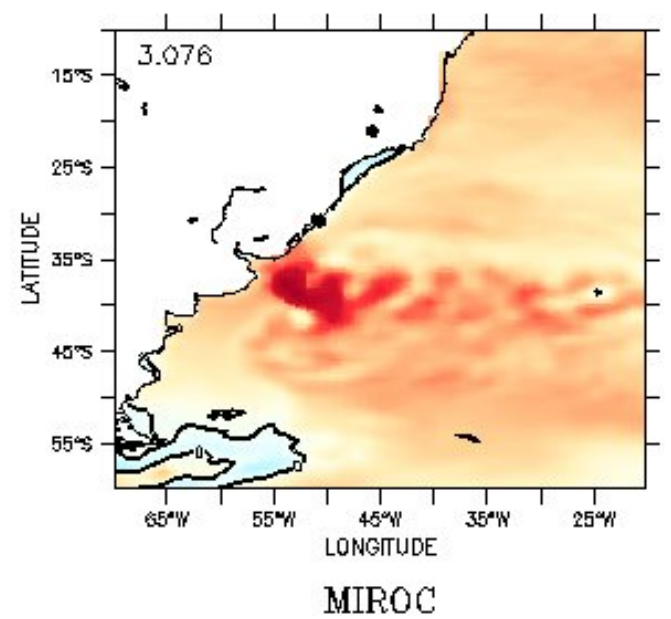

(b)

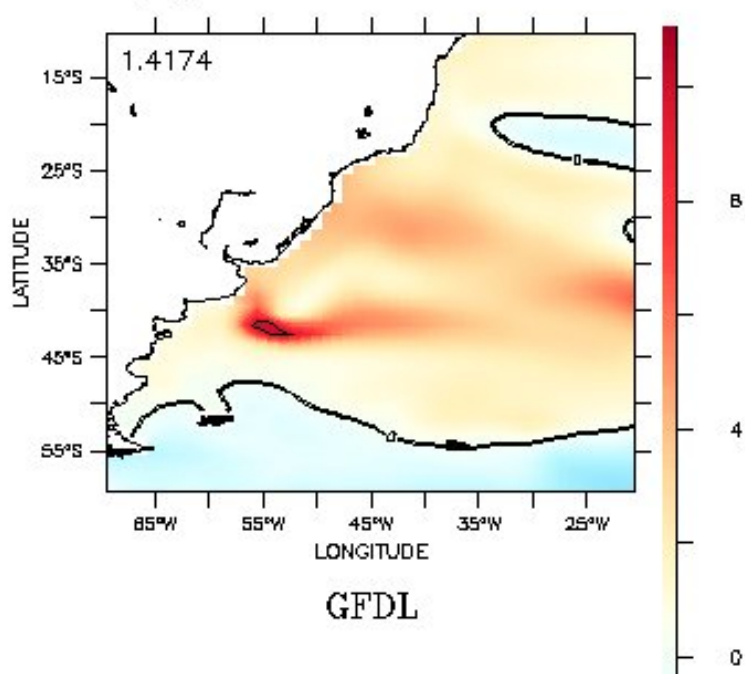

(d)

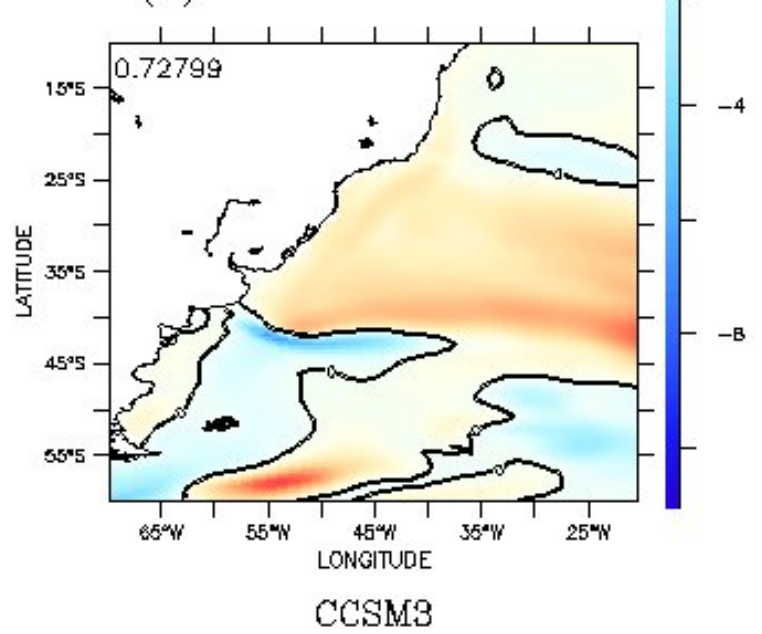

Figura 34: Tendência de temperatura $\left(10^{-4 \circ} \mathrm{C} / \mathrm{ano}\right)$ de superfície: (a) SODA, (b) GFDL, (c) MIROC e (d) CCSM3. Média da tendência acima e à esquerda. 
(a)

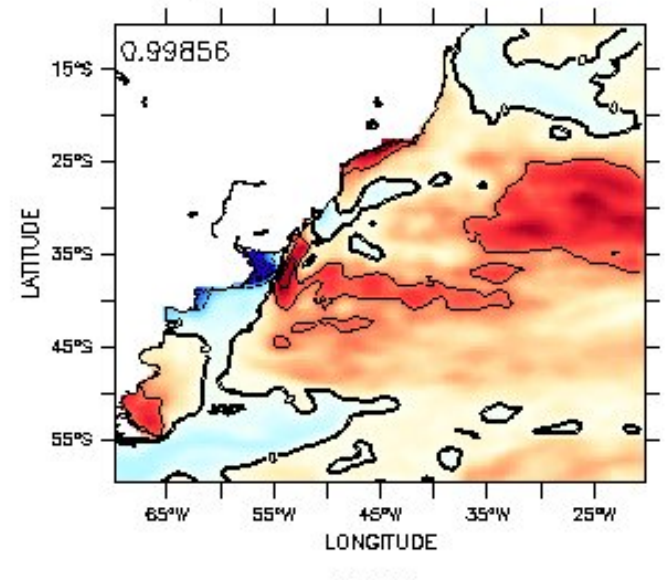

SODA

(c)

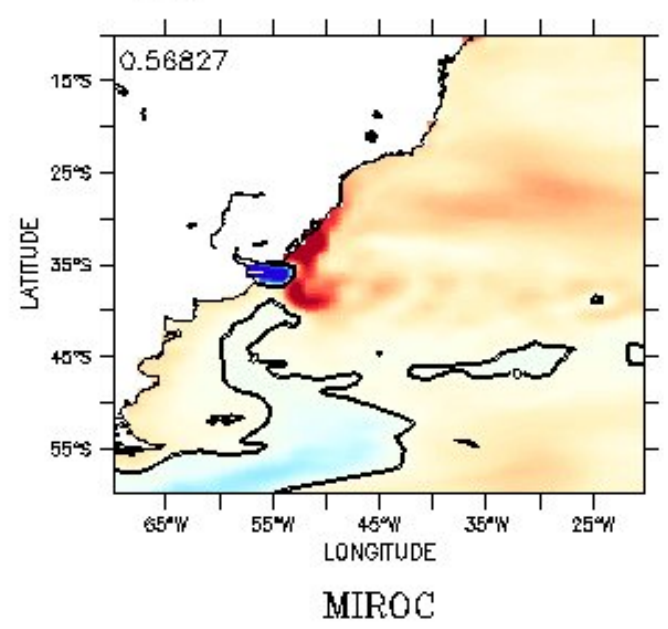

(b)

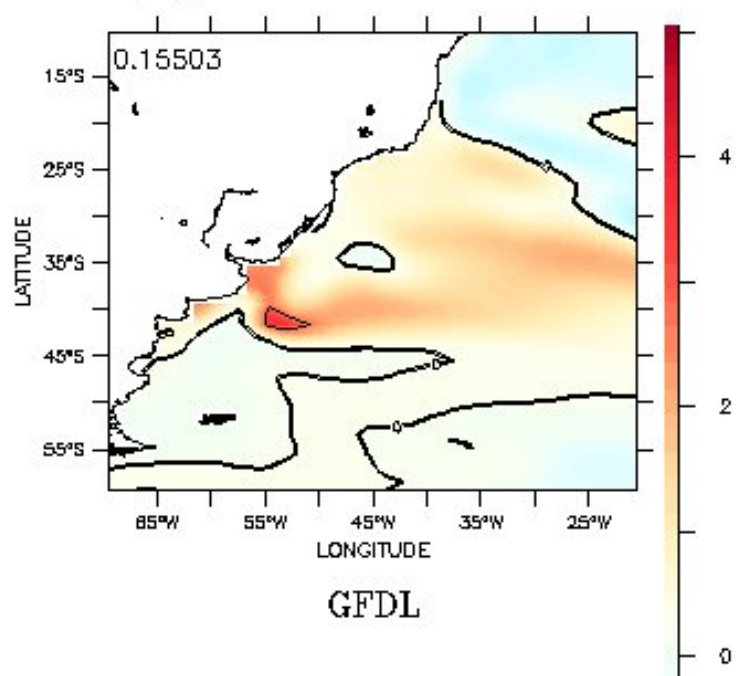

(d)

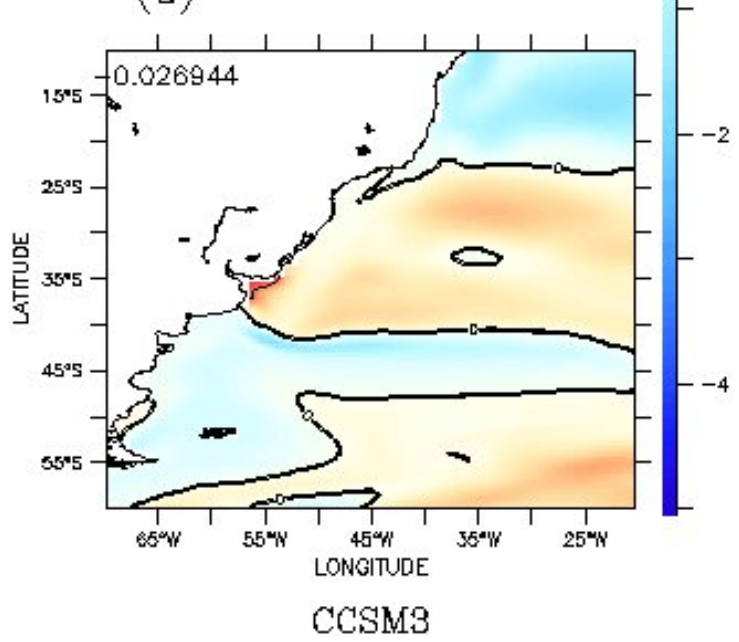

Figura 35: Tendência de salinidade de superfície $\left(10^{-4} \mathrm{ano}^{-1}\right)$ segundo o SODA e 3 modelos do $4^{\circ}$ Relatório de Avaliação do IPCC: (a) SODA, (b) GFDL, (c) MIROC e (d) CCSM3. Média da tendência acima e à esquerda. 
(a)

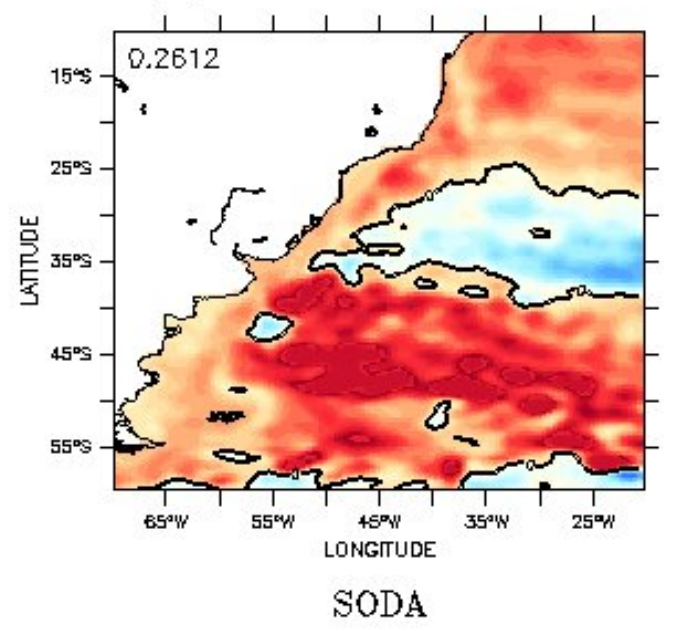

(c)

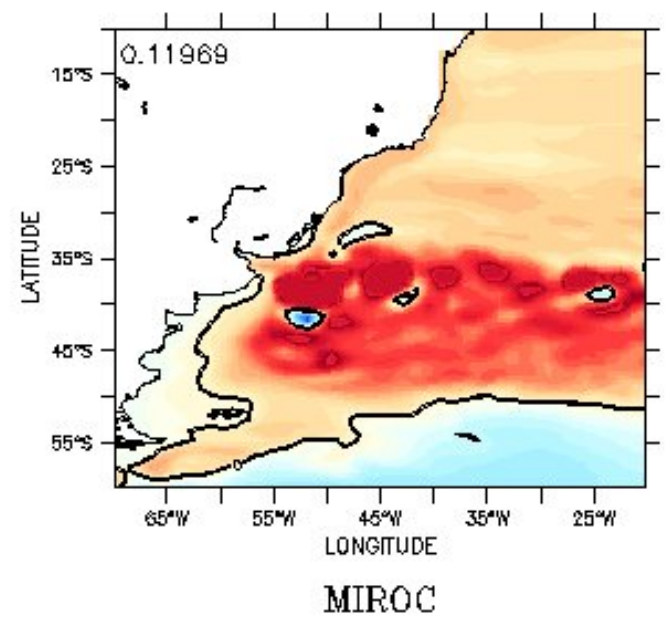

(b)

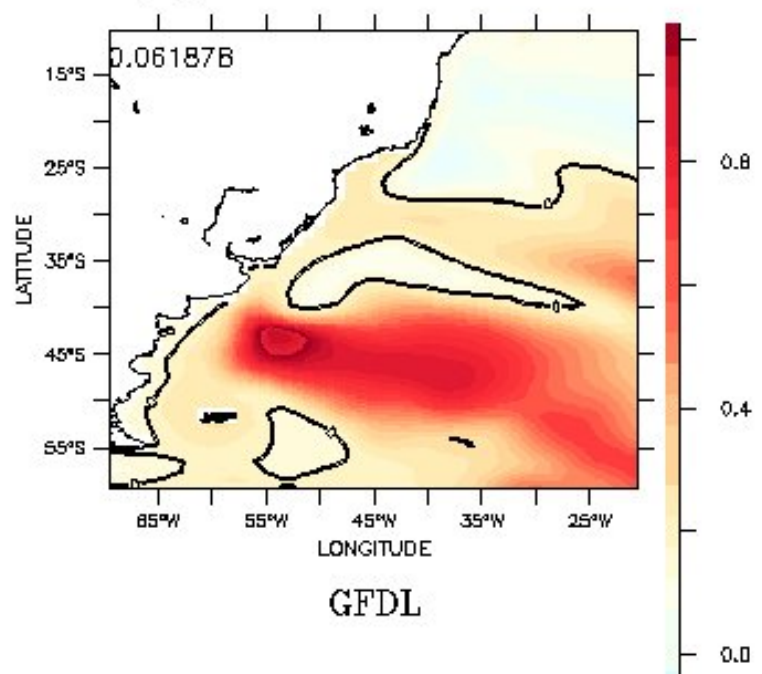

(d)

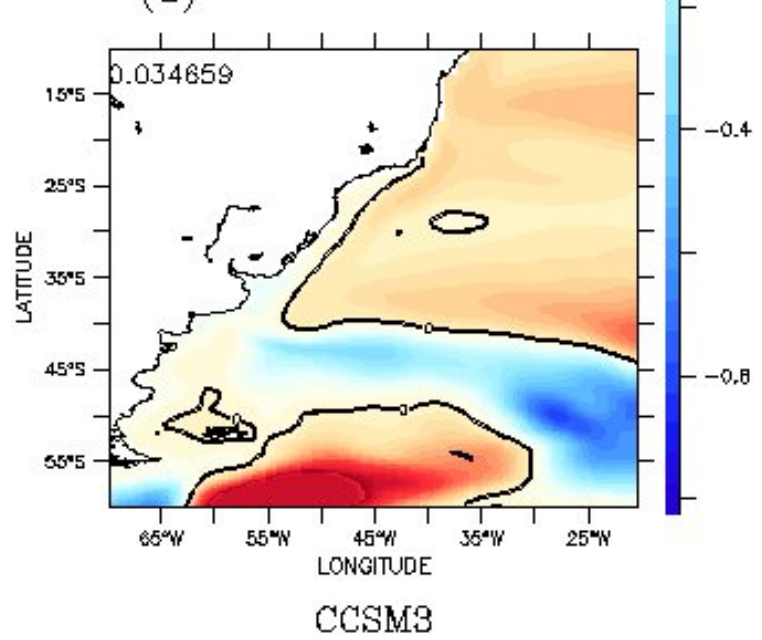

Figura 36: Tendência da altura do nível do mar $\left(10^{-4} \mathrm{dcm} / \mathrm{ano}\right)$ : (a) SODA, (b) GFDL, (c) MIROC e (d) CCSM3. Média da tendência acima e à esquerda. 
(a)

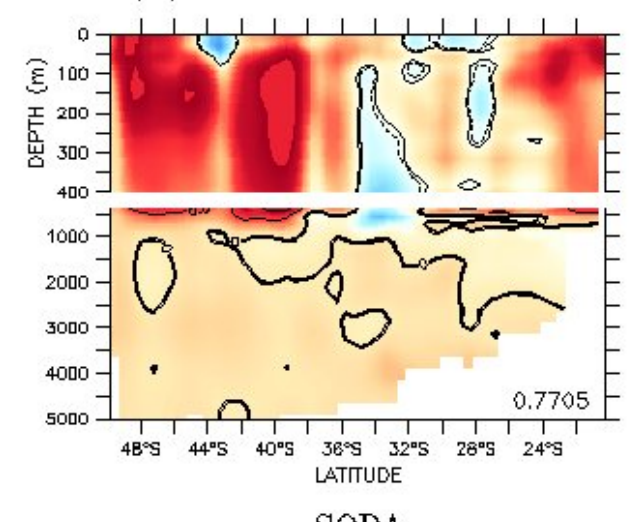

(c)

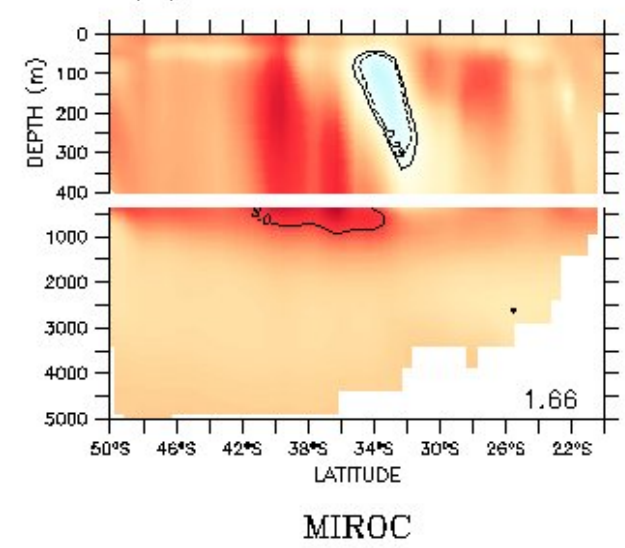

(b)

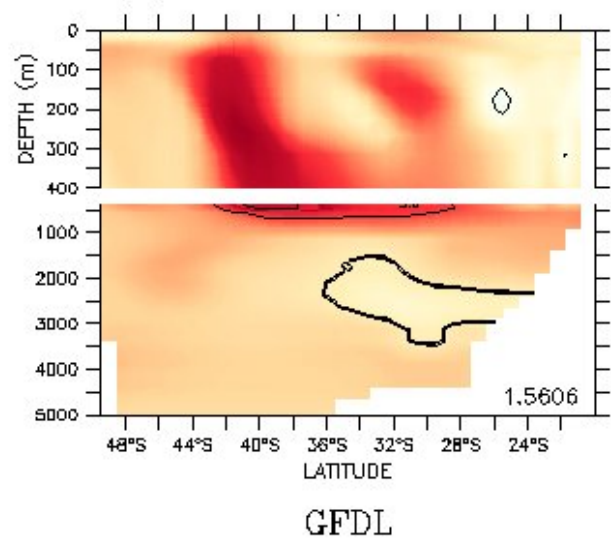

(d)

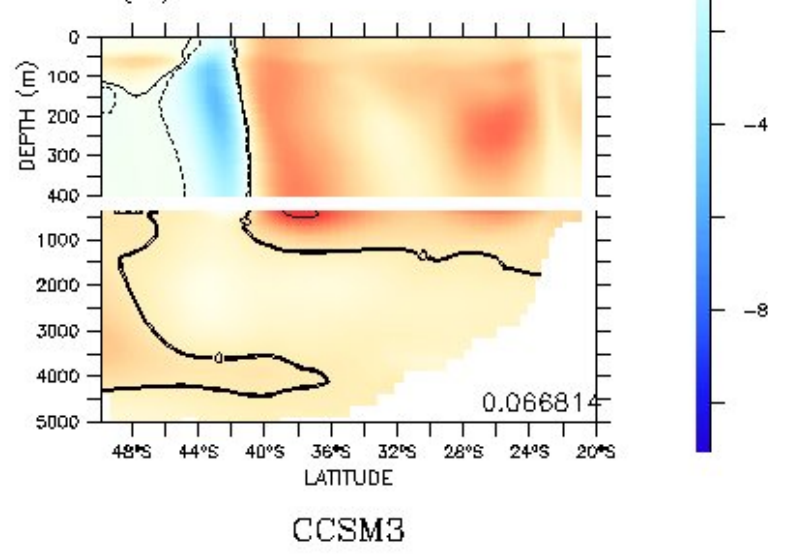

Figura 37: Seção latitudinal $\mathrm{em} 40^{\circ} \mathrm{W}$ (Transecto 1) de tendência de temperatura $\left(10^{-4 \circ} \mathrm{C} / \mathrm{ano}\right)$ : (a) SODA, (b) GFDL, (c) MIROC e (d) CCSM3. Média da tendência acima e à esquerda. 
(a)

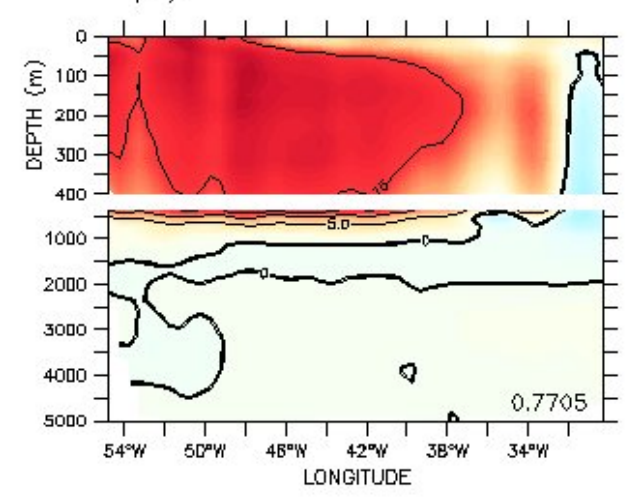

SODA

(c)

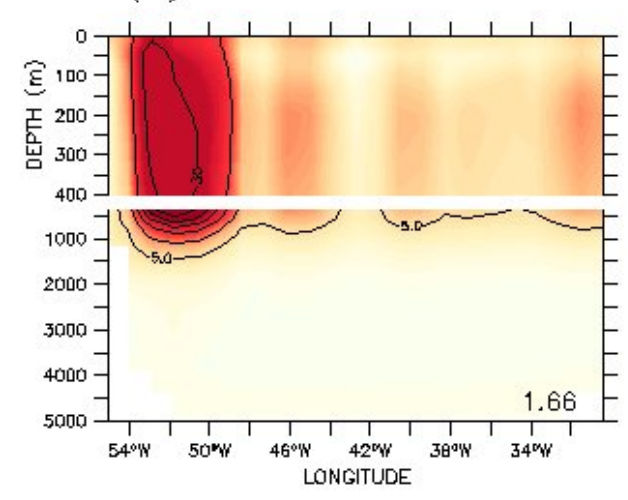

MIROC (b)

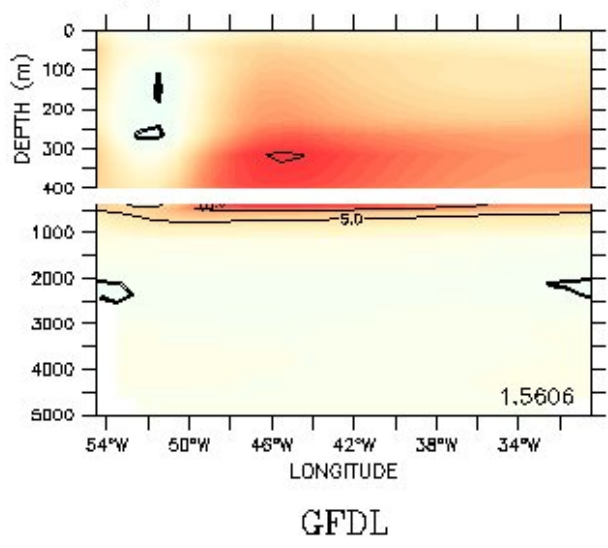

(d)

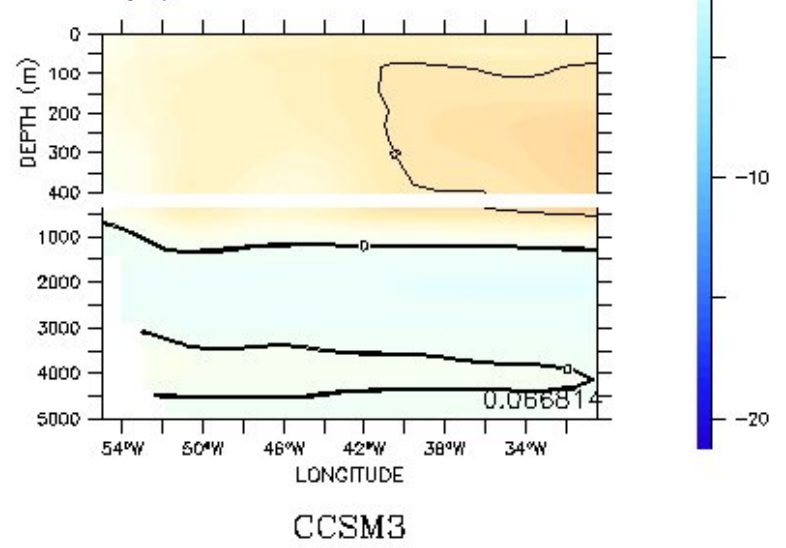

Figura 38: Seção longitudinal em $39^{\circ} \mathrm{S}$ (Transecto 2) de tendência de temperatura $\left(10^{-4 \circ} \mathrm{C} / \mathrm{ano}\right)$ : (a) SODA, (b) GFDL, (c) MIROC e (d) CCSM3. Média da tendência acima e à esquerda. 
(a)

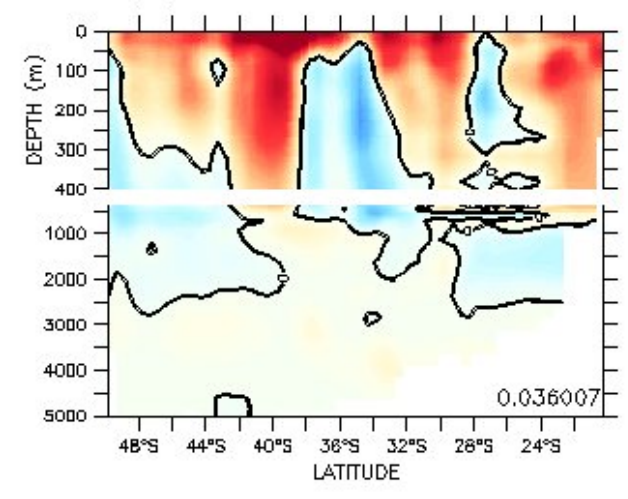

SODA

(c)

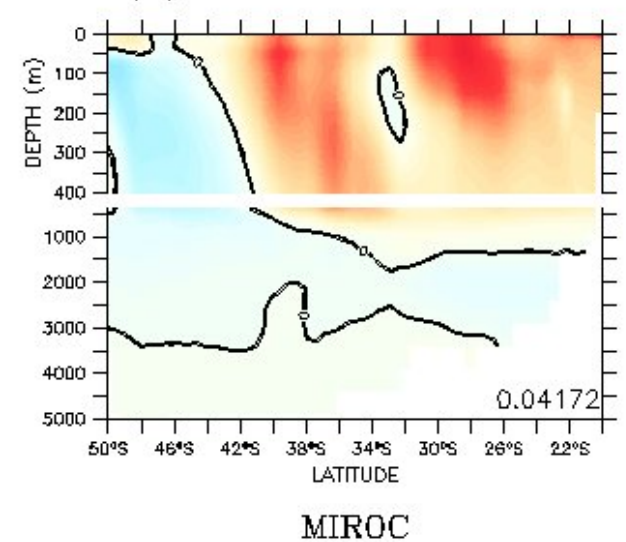

(b)

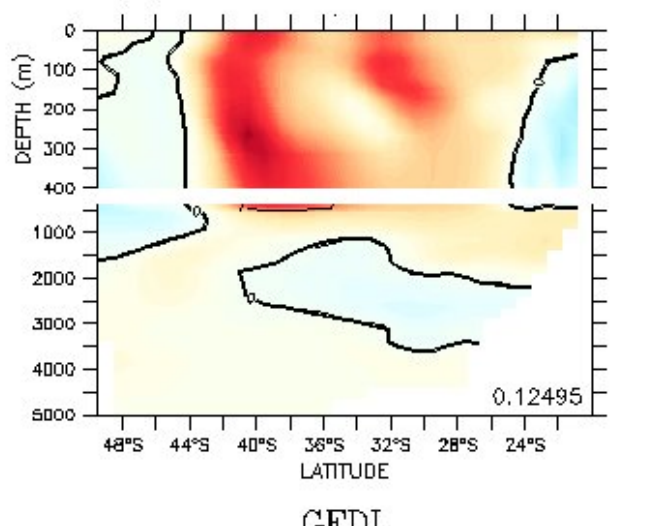

(d)

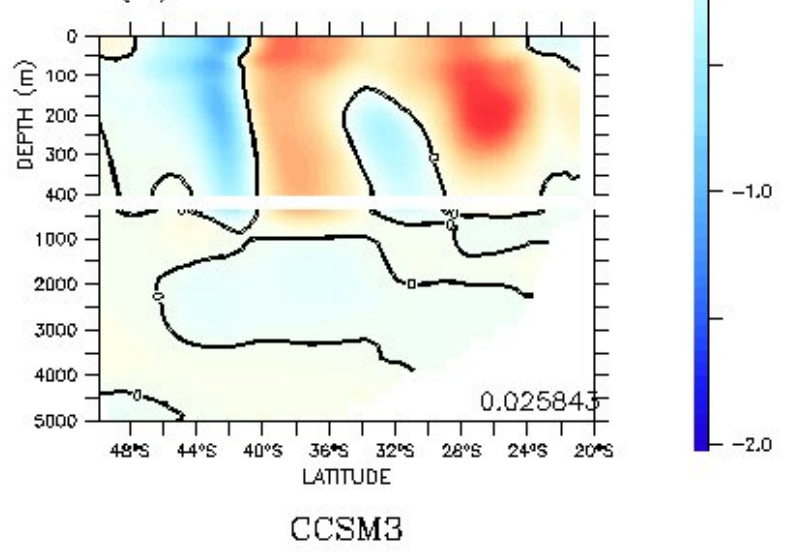

Figura 39: Seção latitudinal em $40^{\circ} \mathrm{W}$ (Transecto 1) de tendência de salinidade $\left(10^{-4} \mathrm{ano}^{-1}\right)$ : (a) SODA, (b) GFDL, (c) MIROC e (d) CCSM3. 
(a)

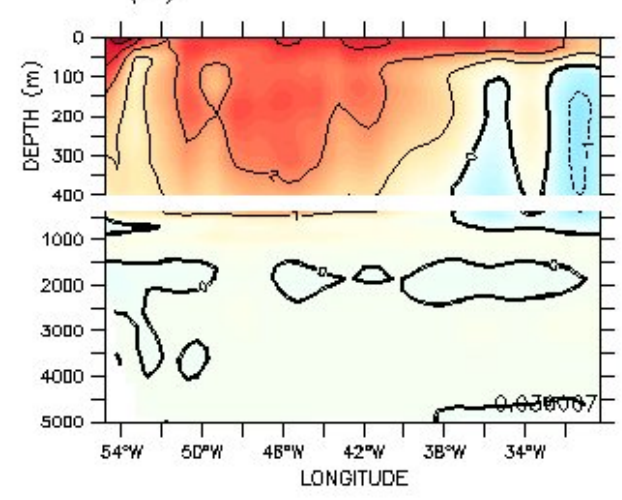

SODA

(c)

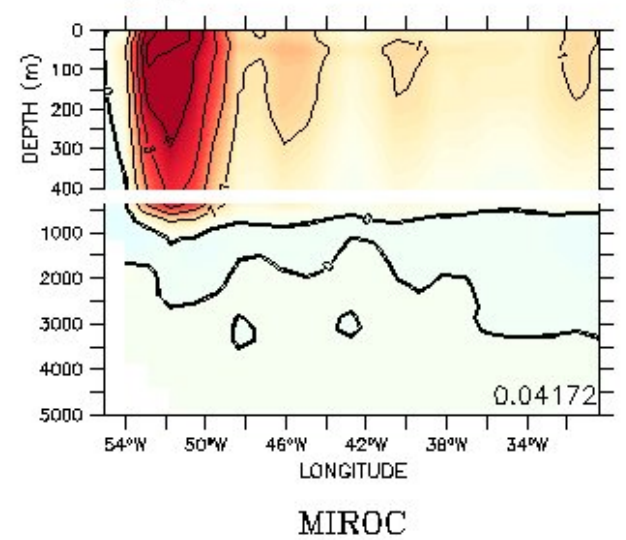

(b)

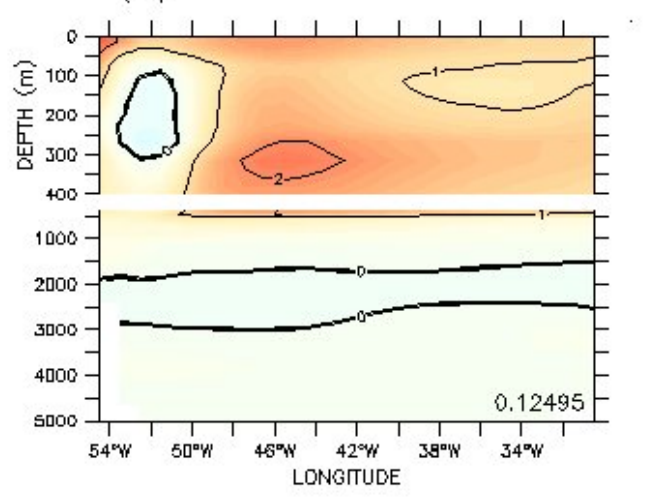

GFDL

(d)

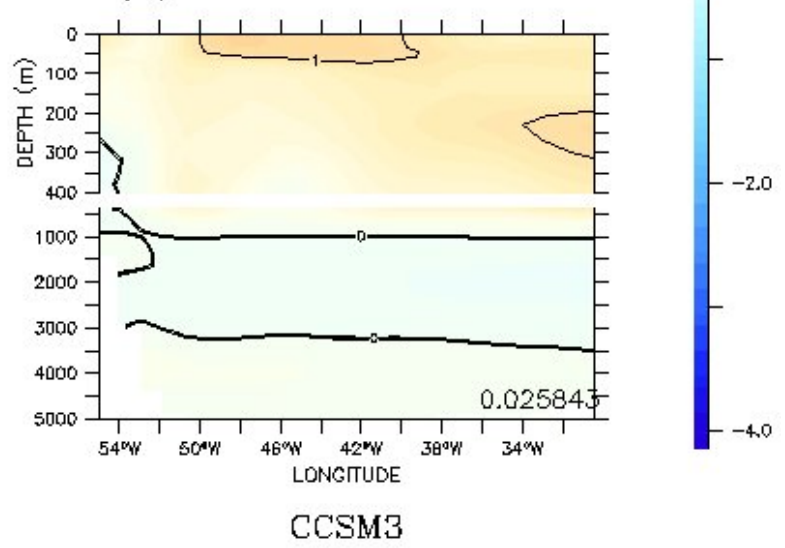

Figura 40: Seção longitudinal em $39^{\circ} \mathrm{S}$ (Transecto 2) de tendência de salinidade $\left(10^{-4} \mathrm{ano}^{-1}\right)$ : (a) SODA, (b) GFDL, (c) MIROC e (d) CCSM3. 
(a)

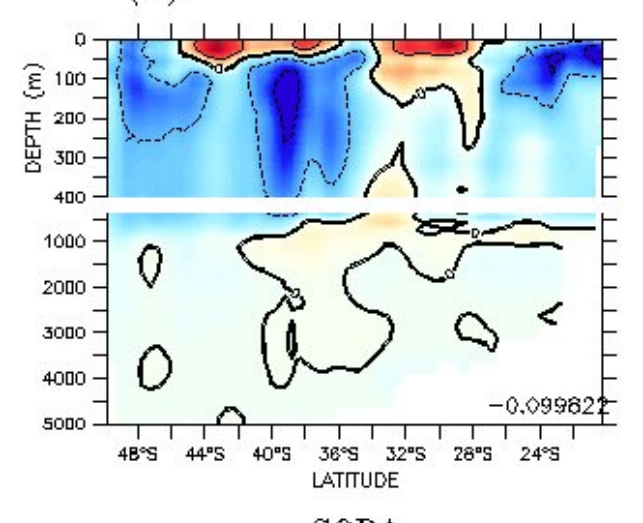

SODA

(c)

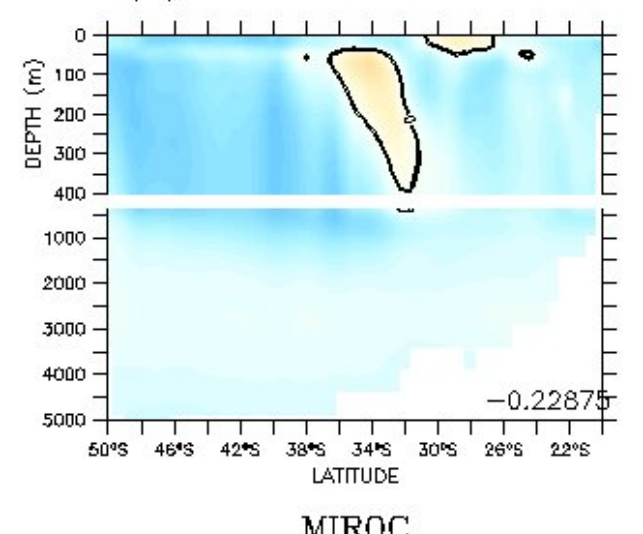

(b)

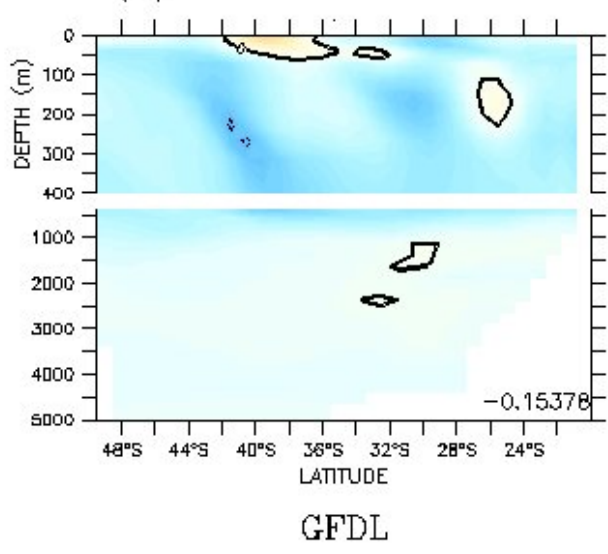

(d)

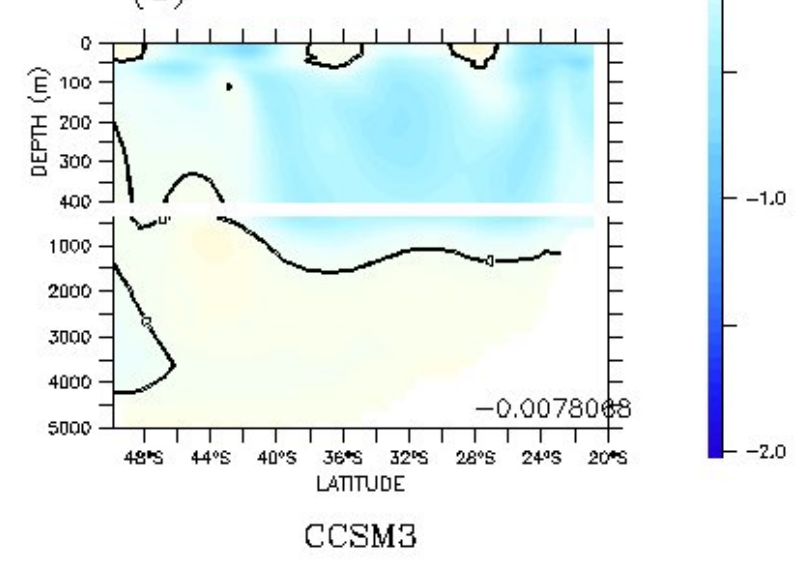

Figura 41: Seção latitudinal em $40^{\circ} \mathrm{W}$ (Transecto 1) de tendência de densidade $\left(10^{-4} \mathrm{~kg} /\left(\mathrm{m}^{3}\right.\right.$.ano) $)$ do SODA e 3 modelos do $4^{\circ}$ Relatório de Avaliação do IPCC: (a) SODA, (b) GFDL, (c) MIROC e (d) CCSM3. 
(a)

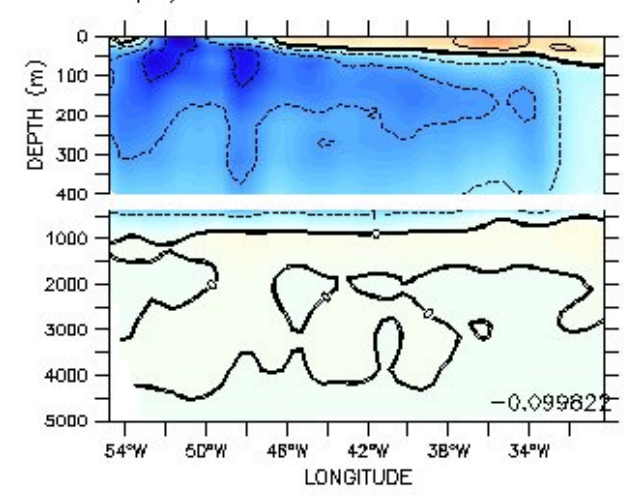

SODA

(c)

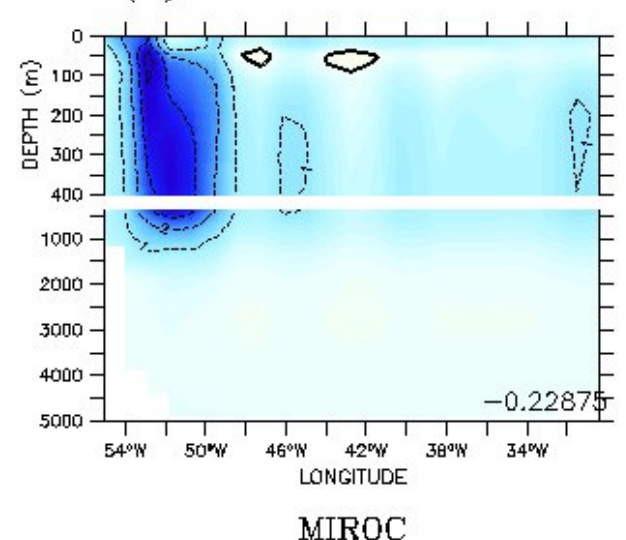

(b)

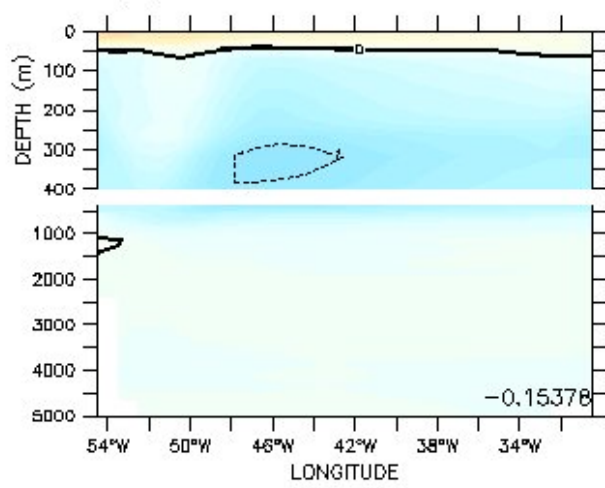

GFDL

\section{(d)}

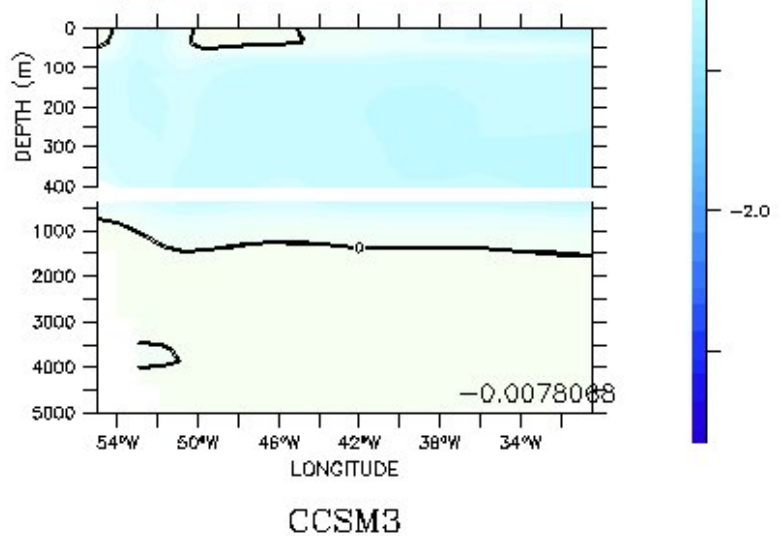

Figura 42: Seção longitudinal em $39^{\circ} \mathrm{S}$ (Transecto 2) de tendência de densidade $\left(10^{-4} \mathrm{~kg} /\left(\mathrm{m}^{3}\right.\right.$.ano) ): (a) SODA, (b) GFDL, (c) MIROC e (d) CCSM3. 
Na Tabela 13 estão representadas as tendências (entre 1958 e 2000) da posição da Confluência Brasil-Malvinas e dos transportes das duas Correntes envolvidas. Observamos que todos os modelos e os dados de reanálise indicam uma tendência negativa da posição da CBM, ou seja, um deslocamento para sul. Essa tendência é subestimada pelo GFDL e pelo CCSM3, enquanto é mais sutilmente superestimada pelo MIROC. O GFDL não possui dados disponíveis de velocidade e por isso, não foi possível calcular os transportes das correntes. Quanto aos outros dois modelos, nenhum conseguiu representar o aumento expressivo do transporte da Corrente do Brasil representado no SODA. Por outro lado, o enfraquecimento da Corrente das Malvinas é representado somente pelo MIROC, mesmo que subestimada.

\begin{tabular}{ccccc}
\hline \multicolumn{5}{c}{ Tendências } \\
\hline & SODA & GFDL & MIROC & CCSM3 \\
\hline Posição da CBM $\left(10^{-2} \%\right.$ ano $)$ & -6.5 & -3.9 & -7.5 & -1.3 \\
Transporte da CB $\left(10^{-2}\right.$ Sv/ano) & 2.2 & 0.1 & 0.0 \\
Transporte da CM $\left(10^{-2}\right.$ Sv/ano) & -5.5 & -2.1 & -0.1 \\
\hline
\end{tabular}

Tabela 13: Tendências da posição da CBM e dos transportes das Correntes do Brasil e das Malvinas.

Dessa forma, embora nenhum modelo tenha sido capaz de representar as feições das tendências das variáveis, o MIROC foi o que menos as subestimou, mostrando estar menos condicionado ao padrão climatológico. 


\subsubsection{Anomalias}

A análise das anomalias é importante no confronto dos modelos numéricos sobretudo para a compreensão de quanto a saída do modelo é capaz de descrever as variabilidades físicas além das climatologias. Certos modelos apresentam excelentes resultados relativos aos padrões médios ou variabilidade climatológica por estarem extremamente atrelados à climatologia fornecida. Por outro lado, um modelo numérico de grande escala não intenta descrever perfeitamente as anomalias ao longo da séries temporais, mas sim as tendências e panoramas gerais. Assim, a Tabela 14 descreve os desvios padrões associados às series temporais de anomalias (sem tendência) nos pontos 1 e $2-40^{\circ} \mathrm{W}, 30^{\circ} \mathrm{S}$ e $55^{\circ} \mathrm{W}, 45^{\circ} \mathrm{S}$ respectivamente.

\begin{tabular}{|c|c|c|c|c|c|c|c|c|c|c|c|c|}
\hline \multicolumn{13}{|c|}{ Ponto 1} \\
\hline & \multicolumn{4}{|c|}{$5 \mathrm{~m}$} & \multicolumn{4}{|c|}{ AIA $(1000 \mathrm{~m})$} & \multicolumn{4}{|c|}{ APAN (1700m ) } \\
\hline & SODA & GFDL & MIROC & CCSM3 & SODA & GFDL & MIROC & CCSM3 & SODA & GFDL & MIROC & CCSM3 \\
\hline Temperatura $\left({ }^{\circ} \mathrm{C}\right)$ & 0.838 & 0.650 & 0.509 & 0.474 & 0.350 & 0.113 & 0.151 & 0.069 & 0.103 & 0.028 & 0.053 & 0.031 \\
\hline Salinidade & 0.320 & 0.127 & 0.140 & 0.077 & 0.070 & 0.014 & 0.008 & 0.006 & 0.026 & 0.008 & 0.007 & 0.006 \\
\hline Nivel do Mar (dcm) & 0.068 & 0.024 & 0.328 & 0.020 & $\star \star * * \star * * * * \star * * * * *$ & $\star \star \star \star \star \star \star \star \star \star \star * *$ & 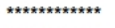 & 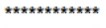 & $* * * * * * * * * * * *$ & $* * * * * * * * * * * *$ & $* * * * * * * * * * *$ & $* * * * * * * * * * *$ \\
\hline Cisalhamento $\left(\mathrm{N} / \mathrm{m}^{2}\right)$ & 0.175 & 0.006 & 0.020 & 0.017 & $\star * * * * * * * * * * * * * *$ & $\star \star \star \star * \star * \star * * \star * *$ & $* \star * * * * * * * * * * *$ & $* * * * * * * * * * * *$ & $* \star * * * * * * * * * * *$ & $\star * * * * * * * * * * * *$ & $\star * * * * * * * * * *$ & $* * * * * * * * * * *$ \\
\hline Densidade $\left(\mathrm{kg} / \mathrm{m}^{3}\right)$ & 0.289 & 0.166 & 0.140 & 0.132 & 0.038 & 0.008 & 0.018 & 0.009 & 0.012 & 0.004 & 0.010 & 0.004 \\
\hline Velocidade $(\mathrm{cm} / \mathrm{s})$ & 0.053 & $\star * * * * * * * * * * * *$ & 0.008 & 0.012 & 0.020 & $* * * * * * * * * * *$ & 0.001 & 0.002 & 0.012 & $* * * * * * * * * * * * *$ & 0.001 & 0.001 \\
\hline \multicolumn{13}{|c|}{ Ponto 2} \\
\hline & \multicolumn{4}{|c|}{$5 \mathrm{~m}$} & \multicolumn{4}{|c|}{ AIA $(1000 \mathrm{~m})$} & \multicolumn{4}{|c|}{ APAN $(1700 \mathrm{~m})$} \\
\hline & SODA & GFDL & MIROC & cCSM3 & SODA & GFDL & MIROC & ccsm3 & SODA & GFDL & MIROC & CCSM3 \\
\hline Temperatura $\left({ }^{\circ} \mathrm{C}\right)$ & 1.558 & 0.516 & 0.742 & 0.481 & 0.343 & 0.087 & 0.186 & 0.040 & 0.138 & 0.058 & 0.118 & 0.024 \\
\hline Salinidade & 0.267 & 0.031 & 0.060 & 0.069 & 0.047 & 0.012 & 0.022 & 0.010 & 0.032 & 0.003 & 0.009 & 0.007 \\
\hline Nivel do Mar (dcm) & 0.012 & 0.037 & 0.098 & 0.030 & $\star * * * * * * * * * * * * * *$ & $* * * * * * * * * *$ & $* * * * * * * * * * * *$ & $* * * * * * * * * * * *$ & $* * * * * * * * * * * *$ & $* * * * * * * * * * * *$ & $* * * * * * * * * * *$ & $* * * * * * * * * * *$ \\
\hline Cisalhamento $\left(\mathrm{N} / \mathrm{m}^{2}\right)$ & 0.032 & 0.031 & 0.039 & 0.033 & $\star \star * * * * * * * * * * * *$ & $\star \star * \star * * * * * * *$ & $\star \star \star * * * \star * * * * * *$ & $\star \star \star * \star * * * * \star * * * *$ & $* * * * * * * * * * * * *$ & $\star * \star \star * \star * \star * \star * * \star * *$ & $\star \star * * * * * * * * * *$ & $* * * * * * * * * * * *$ \\
\hline Densidade $\left(\mathrm{kg} / \mathrm{m}^{3}\right)$ & 0.223 & 0.102 & 0.132 & 0.079 & 0.061 & 0.195 & 0.037 & 0.012 & 0.037 & 0.008 & 0.020 & 0.008 \\
\hline Velocidade $(\mathrm{cm} / \mathrm{s})$ & 0.150 & $\star * \star * * * * * * * * * *$ & 0.008 & 0.013 & 0.095 & $* \star * * * * * * * *$ & 0.003 & 0.003 & 0.049 & $\star * \star * * * * * * * * * *$ & 0.003 & 0.003 \\
\hline
\end{tabular}

Tabela 14: Desvio padrão das anomalias das variáveis em relação à média climatológica nos Pontos $1\left(40^{\circ} \mathrm{W}, 30^{\circ} \mathrm{S}\right)$ e $2\left(55^{\circ} \mathrm{W}, 45^{\circ} \mathrm{S}\right)$ do SODA e dos 3 modelos do $4^{\circ}$ Relatório de Avaliação do IPCC em 3 profundidades - 5m (superfície), 1000m (associada a AIA) e 1700 (associada a APAN).

De forma geral, todos os modelos subestimaram a variabilidade não associada à climatologia. A temperatura, foi a grandeza que chegou mais próxima ao desvio padrão esperado. Embora na camada superficial todos os modelos obtenham um resultado parecido, na camadas mais profundas o MIROC foi o que chegou mais próximo do desvio padrão da anomalia do SODA.

A anomalia de salinidade apresentou ainda menor variabilidade. Embora o MIROC obtenha um desvio padrão da anomalia acima dos outros, na maior parte das análises, este ainda não supera nem 50\% do esperado do SODA em nenhum caso, chegando a menos de $20 \%$. Por outro lado, a anomalia da altura do nível do mar obteve desvios padrões 
superiores e no ponto 2. O MIROC representou bem o desvio padrão de anomalias de tensão de cisalhamento do vento.

Em resposta a temperatura e salinidade, a anomalia de densidade do MIROC foi a que menos subestimou a variabilidade, sobretudo abaixo da superfície. A variabilidade da anomalia de velocidade foi muito subestimada também em todos os modelos.

Dessa forma, assim como visto nas tendências, o MIROC é o modelo que menos subestima a variabilidade além do ciclo anual sobretudo nas profundidades da AIA e da APAN. Por outro lado, o GFDL obtém um resultado melhor do que o CCSM3 em superfície, mas não em 1000 e 1700m. 


\subsubsection{Série Temporal}

Nesta seção, as séries temporais dos modelos serão confrontadas com o SODA. O Diagrama de Taylor é uma ferramenta que permite uma comparação de saídas de modelos numéricos rápida e prática. As Figuras 43 e 44 representam os Diagramas de Taylor referentes à série temporal da média de superfície da Região 1 do domínio da Corrente do Brasil (entre 20 e $35^{\circ} \mathrm{W}$ e entre 15 e $30^{\circ} \mathrm{S}$ ) e outro referente à média da Região 2 no domínio da Corrente das Malvinas (entre 30 e $55^{\circ} \mathrm{W}$ e entre 45 e $55^{\circ} \mathrm{S}$ ) respectivamente.

(a)

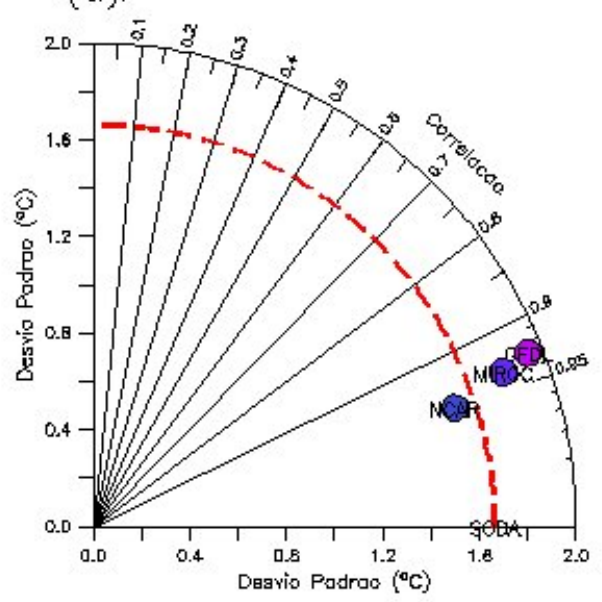

(c).

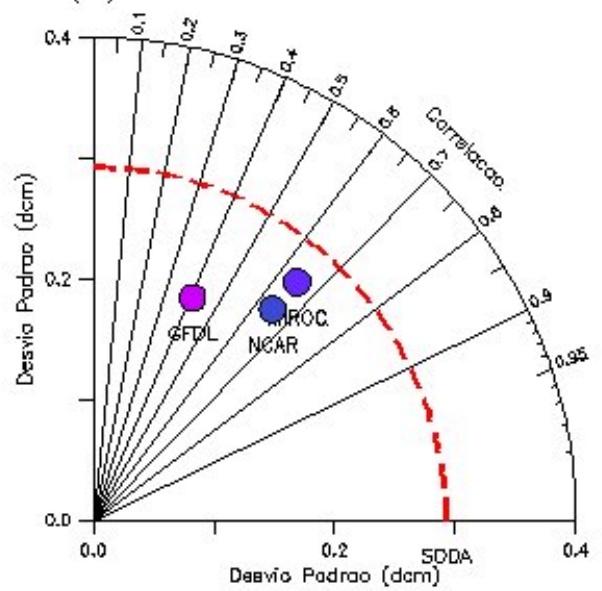

(b)

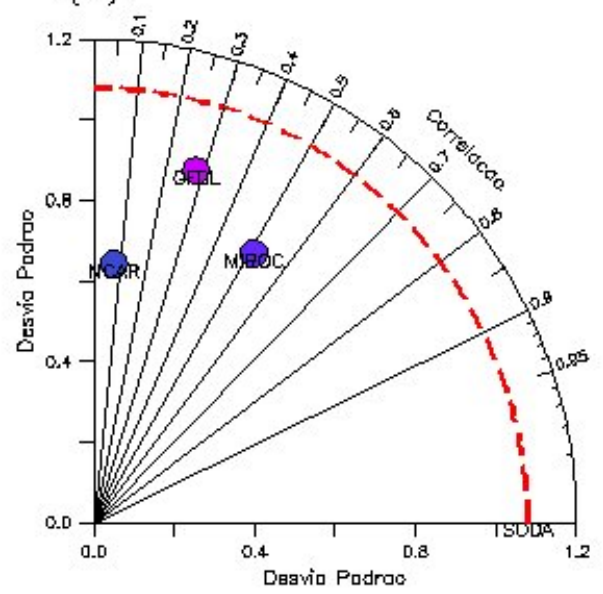

(d)

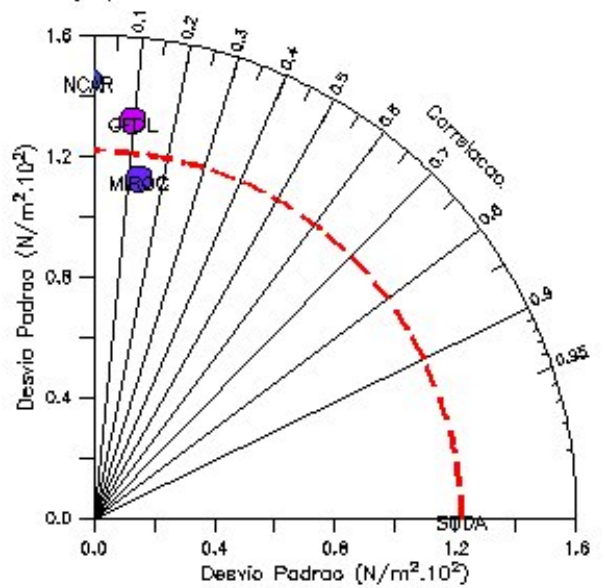

Figura 43: Diagramas de Taylor comparando os dados de superfície de reanálise do SODA (linha vermelha) e os três modelos numéricos do $4^{\circ}$ Relatório do IPCC na Região 1 (20$35^{\circ} \mathrm{W} ; 15-30^{\circ} \mathrm{S}$ ) para (a) temperatura $\left({ }^{\circ} \mathrm{C}\right)$; (b) salinidade; (c) altura do nível do mar $\left(10^{-1} \mathrm{~m}\right) ;(\mathrm{d})$ tensão de cisalhamento do vento sobre a superfície $\left(\mathrm{N} / \mathrm{m}^{2}\right)$. 
Observamos nos Diagramas de Taylor que todos os modelos obtiveram melhores resultados em superfície no domínio da Corrente do Brasil (Região 1) em relação ao domínio da Corrente das Malvinas (Região 2). Os resultados de temperatura se aproximam em todos os modelos dos dados do SODA. O CCSM3 representa o menor erro quadrático médio (dado pela distância entre o ponto do SODA no diagrama e o modelo) apresentando a melhor correlação e desvio padrão.

Por outro lado, esse modelo representa o pior resultado na análise de salinidade na Região 1, enquanto o MIROC apresenta o melhor resultado. Na Região 2 nenhum modelo obteve uma boa correlação com os dados do SODA. Ao contrário da altura do nível do mar, destacando-se na Região 1 o MIROC e o CCSM3 e na Região 2 o GFDL e o MIROC (a correlação do CCSM3 nessa região foi quase nula).

A tensão de cisalhamento do vento obteve o pior resultado em ambas as regiões. Embora o desvio padrão das séries sejam próximos, a correlação não ultrapassou 10\% o que elevou significativamente o erro quadrático médio. Os Diagramas de Taylor para as duas regiões foram repetidos para $1000 \mathrm{~m}$ e $1700 \mathrm{~m}$, profundidades relativas a AIA e APAN, porém nenhum modelo apresentou bons resultados nessas profundidades, apresentando correlações abaixo de $20 \%$.

As séries temporais foram comparadas também através de mapas de erros quadráticos médios (Figuras 45 a 52 .

Observamos que a temperatura de superfície do GFDL apresentou maiores erros no domínio da Corrente das Malvinas, ultrapassando os $4^{\circ} \mathrm{C}$ de erro quadrático médio - Figura 45. Por outro lado, o MIROC, obteve menores erros (praticamente nunca ultrapassando os $2.5^{\circ} \mathrm{C}$ ), porém distribuído por boa parte da região. O CCSM3, embora obtenha a menor média, possui valores muito intensos superando os $6^{\circ} \mathrm{C}$. Além disso tais erros estão concentrados justamente na região da Confluência Brasil-Malvinas (de extrema importância para esse trabalho). 
(a)

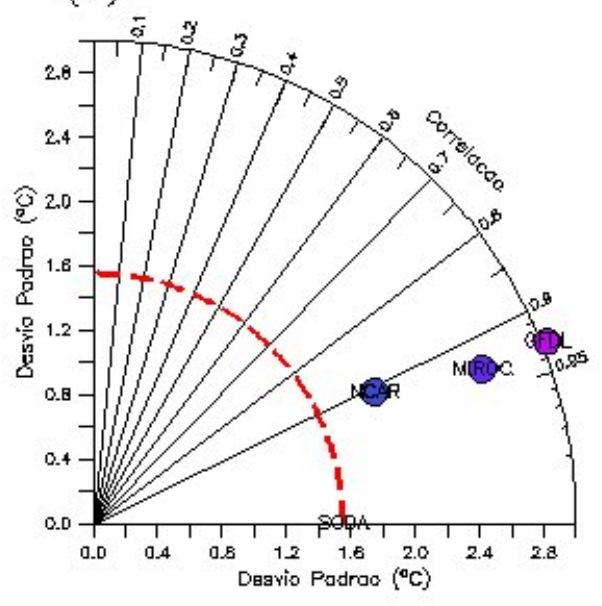

(c).

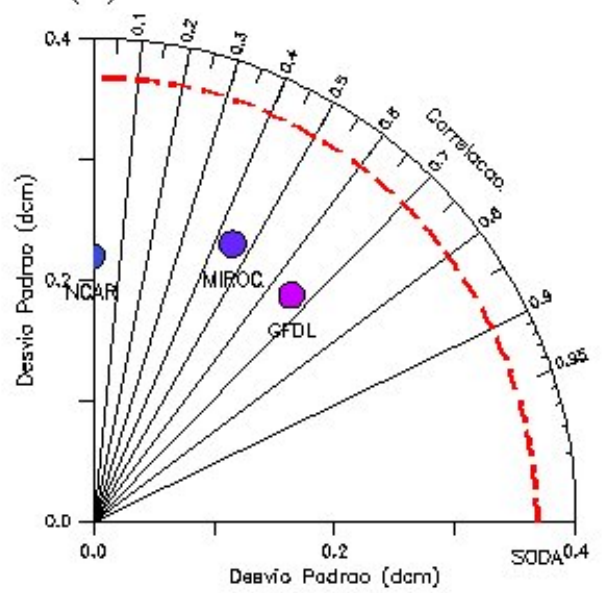

(b)

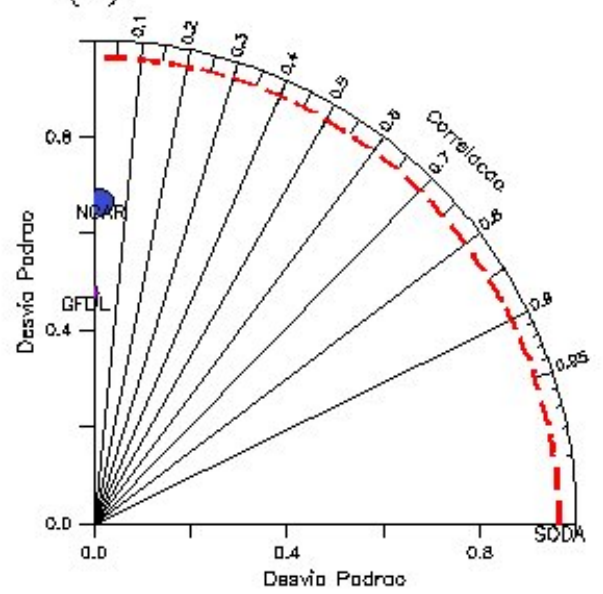

(d)

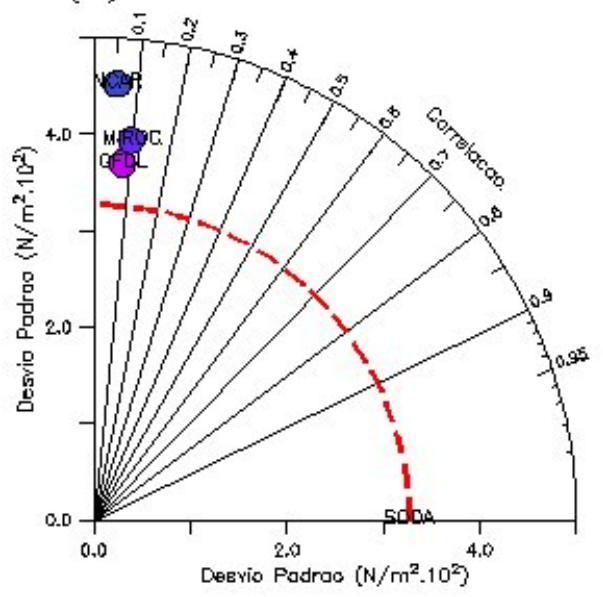

Figura 44: Diagramas de Taylor comparando os dados de superfície de reanálise do SODA (linha vermelha) e os três modelos numéricos do $4^{\circ}$ Relatório do IPCC na Região 2 (30$55^{\circ} \mathrm{W} ; 45-55^{\circ} \mathrm{S}$ ) para (a) temperatura; (b) salinidade; (c) altura do nível do mar; (d) tensão de cisalhamento do vento sobre a superfície. 
(a)

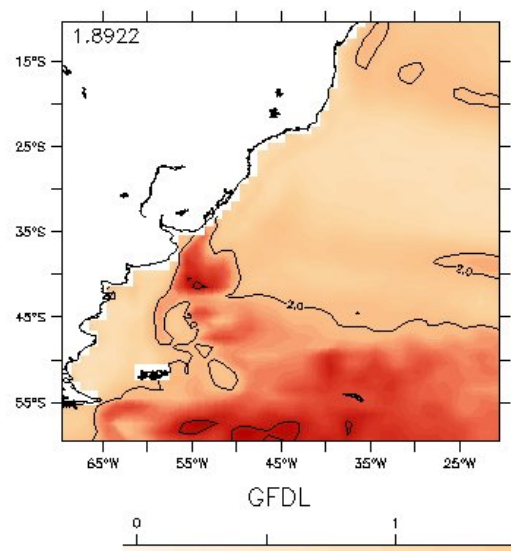

(b)

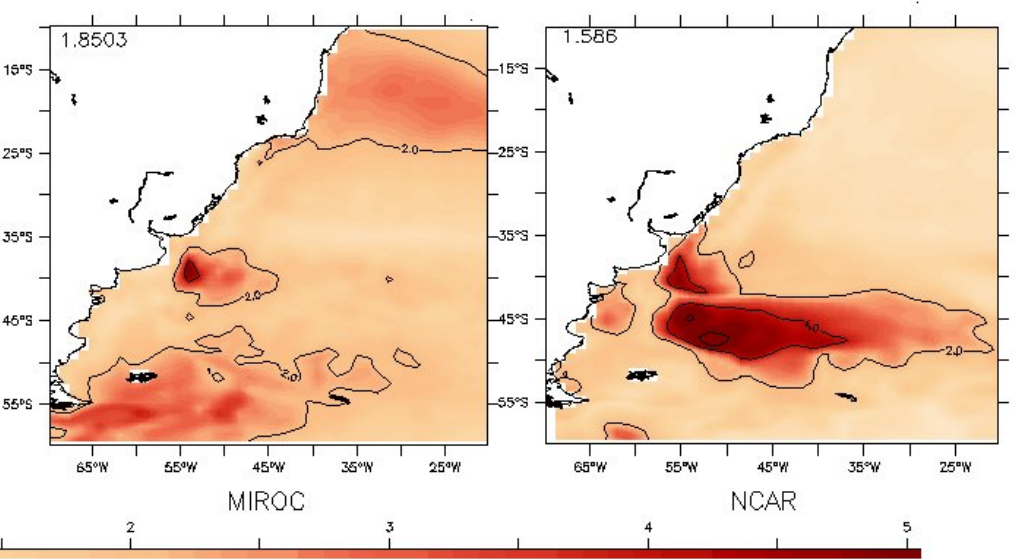

Figura 45: Erro quadrático médio das séries temporais de temperatura de superfície $\left({ }^{\circ} \mathrm{C}\right)$ : (a) GFDL, (b) MIROC, (c) CCSM3 e os dados de Reanálise do SODA.

O mesmo acontece com a salinidade de superfície (Figura 46). Observamos que embora a média de erro quadrático médio do MIROC seja a mais elevada, esse modelo é o que apresenta erros menores, nunca ultrapassando 1. Todos os modelos apresentaram os maiores erros relacionados à descarga do Rio da Prata, sobretudo o CCSM3. O MIROC apresentou a menor média nessa região.

O MIROC obteve um bom resultado também na tensão de cisalhamento do vento. O GFDL e o CCSM3 obtiveram valores altos de erro quadrático médio, sobretudo na região da Corrente das Malvinas. Nesse caso, o MIROC obteve não só a menor média, como também não concentrou grandes erros em nenhuma parte da região (Figura 47). O erro relacionado à elevação do nível do mar (Figura 48), no MIROC e no CCSM3 são mais intensos na região próxima a Confluência Brasil-Malvinas enquanto que no GFDL na região dominada pela Corrente das Malvinas (podem estar relacionados aos erros da tensão de cisalhamento do vento observado na Figura 47). Essa análise pode demonstrar erros acumulados tanto na dinâmica oceânica (em toda a coluna d'água) quanto da tensão de cisalhamento do vento.

As seções de erro quadrático médio das Figuras 49 e 50 mostram que os maiores erros associados à temperatura nos modelos são observados nos primeiros 400m (provavelmente relativos à AT) na região da Confluência Brasil-Malvinas (entre $38^{\circ} \mathrm{S}$ e $40^{\circ} \mathrm{S}$ ), sobretudo nas proximidades da costa (de 52 a $54^{\circ} \mathrm{W}$ ). Observamos que no MIROC e no CCSM3, se 
(a)

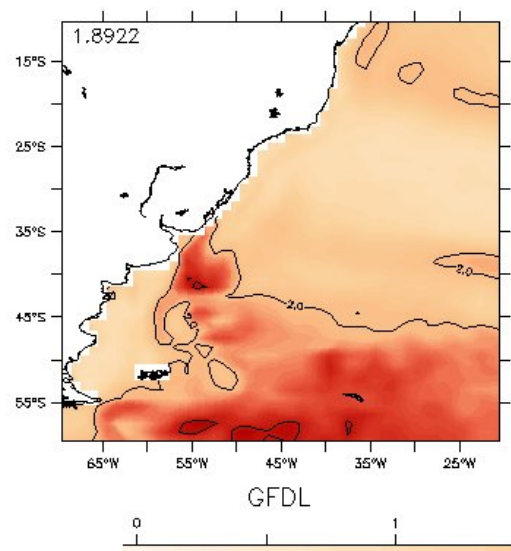

(b)

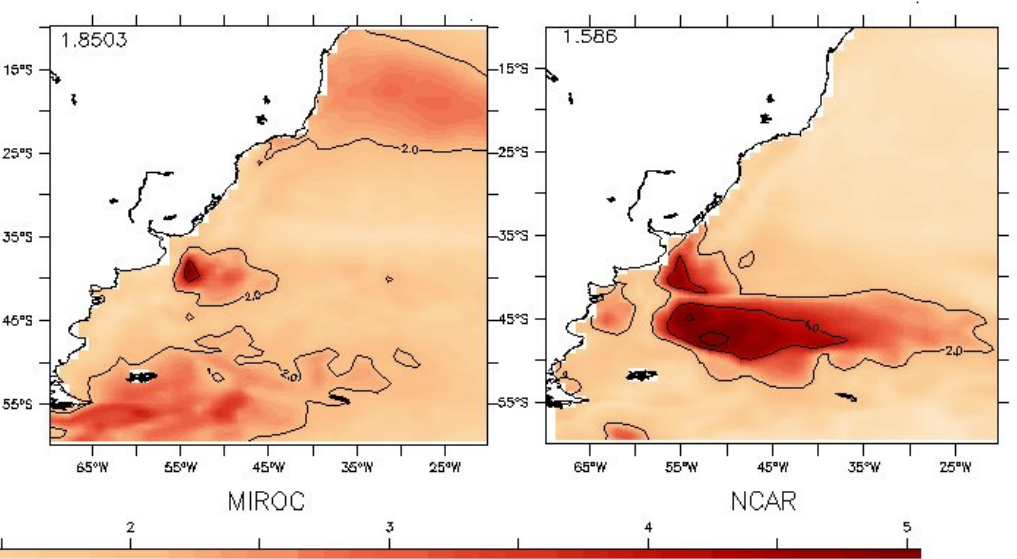

Figura 46: Erro quadrático médio das séries temporais de salinidade de superfície: (a) GFDL, (b) MIROC, (c) CCSM3 e os dados de Reanálise do SODA.

concentram nos primeiros $1000 \mathrm{~m}$ enquanto que no GFDL até os 2000m (provavelmente associados a APAN).

No CCSM3, observamos erros mais intensos (acima de $4^{\circ} \mathrm{C}$ ) em altas latitudes (de 40 a $48^{\circ}$ S). Da região da CBM para o Sul, esse modelo apresentou os maiores erros dos transectos nos primeiros $400 \mathrm{~m}$. O MIROC apresentou erros de até $2.5^{\circ} \mathrm{C}$ por volta dos $1000 \mathrm{~m}$ provavelmente relacionados a AIA e foi o único que excedeu $1^{\circ} \mathrm{C}$ abaixo dos $4000 \mathrm{~m}$.

Ao contrário dos transectos de erro quadrático médio de temperatura, a salinidade apresentou os maiores valores em latitudes menores, relacionados ao domínio da Corrente do Brasil, principalmente o CCSM3 - Figuras 51 e 52. Novamente os principais desvios estão associados aos primeiros 400m. No GFDL e no MIROC os mais significativos foram observados acima de $35^{\circ} \mathrm{W}$, enquanto que o CCSM3 apresentou em quase todo o domínio do Transecto 2 (latitudinal em $50^{\circ} \mathrm{W}$ ). Novamente, observamos uma faixa de maior erro quadrático médio por volta dos 2000m no GFDL possivelmente associado à AIA. O MIROC foi o modelo que apresentou menor média nas duas seções e menor erro máximo. Ao contrário, o CCSM3 apresentou erros de quase 1 unidade, sobretudo em latitudes mais baixas.

Na comparação da série temporal do modelo com os dados do SODA, observamos que o CCSM3 é o que apresenta os maiores erros. Por outro lado, o MIROC, embora não se sobressaia em todas as análises é o que apresenta menores desvios e menos erros extremos. 
(a)

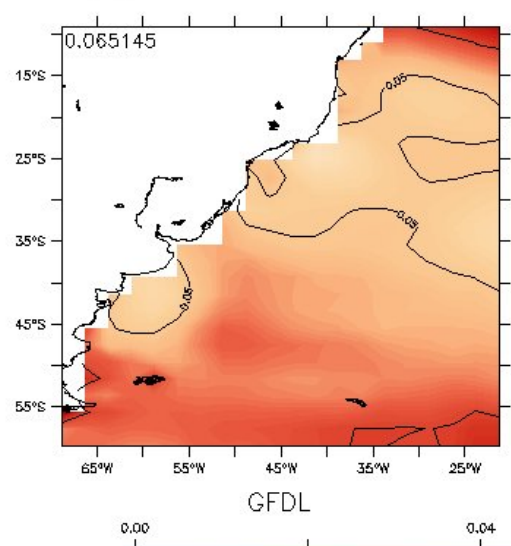

(b)

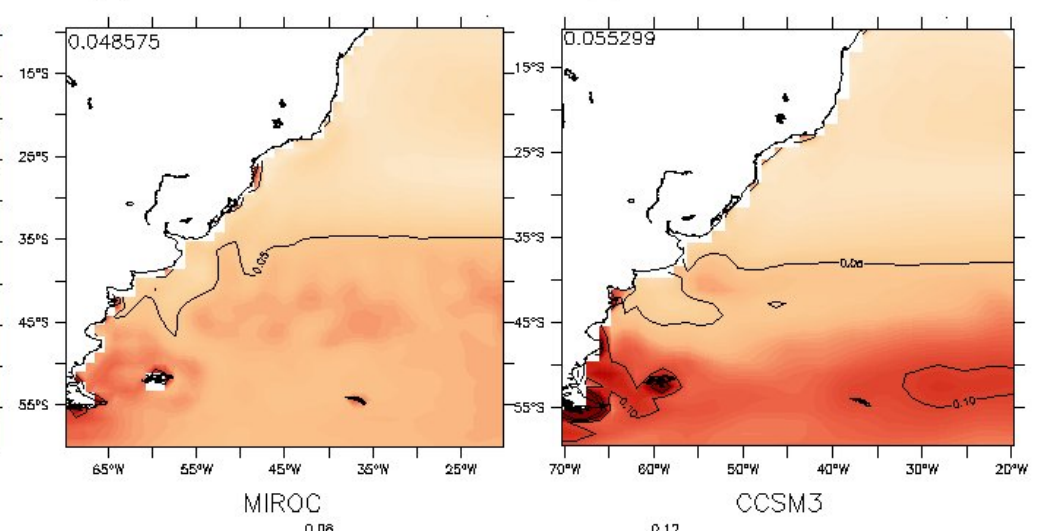

Figura 47: Erro quadrático médio das séries temporais da tensão de cisalhamento do vento sobre a superfície $\left(\mathrm{N} / \mathrm{m}^{2}\right)$ : (a) GFDL, (b) MIROC, (c) CCSM3 e os dados de Reanálise do SODA.

(a)

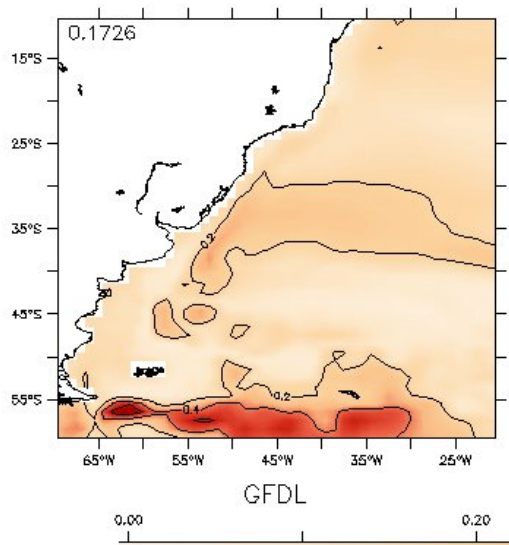

(b)

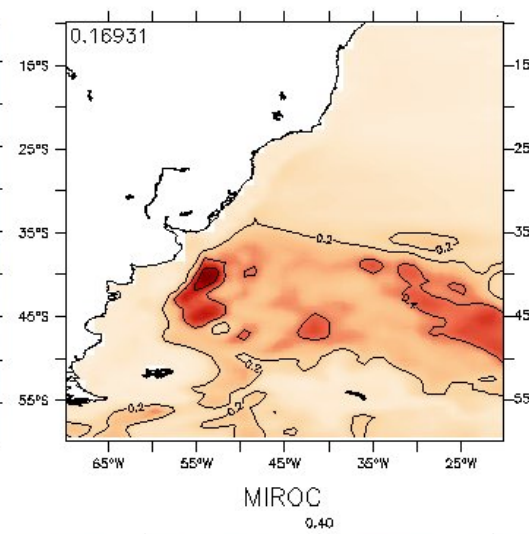

(c)

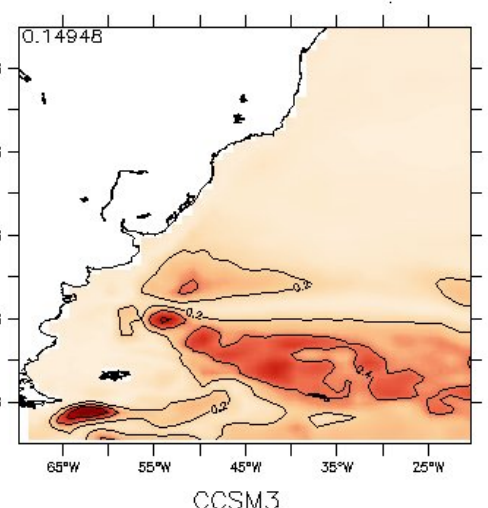

0.60

Figura 48: Erro quadrático médio das séries temporais da elevação do nível do mar $\left(10^{-1} \mathrm{~m}\right)$ : (a) GFDL, (b) MIROC, (c) CCSM3 e os dados de Reanálise do SODA e média do erro acima e à esquerda. 
(a)
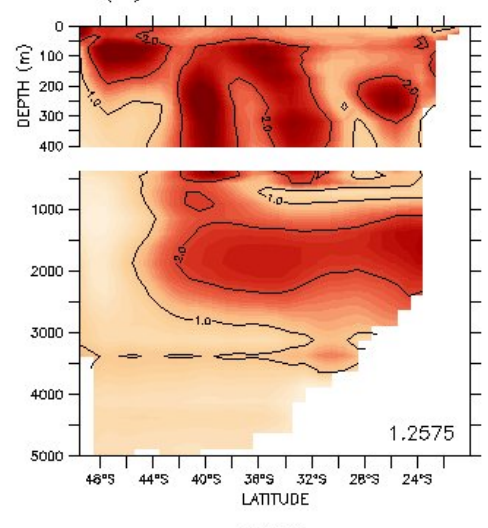

GFDL (b)
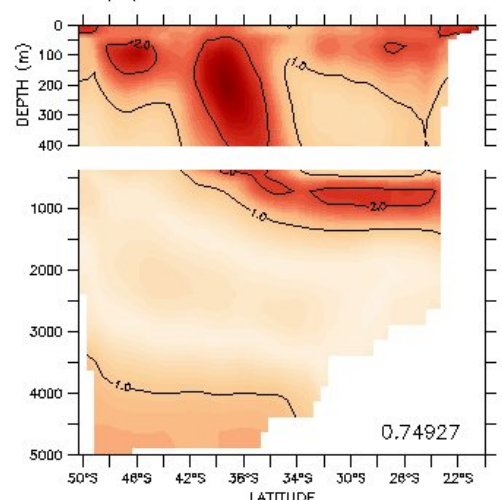

MIROC (c)
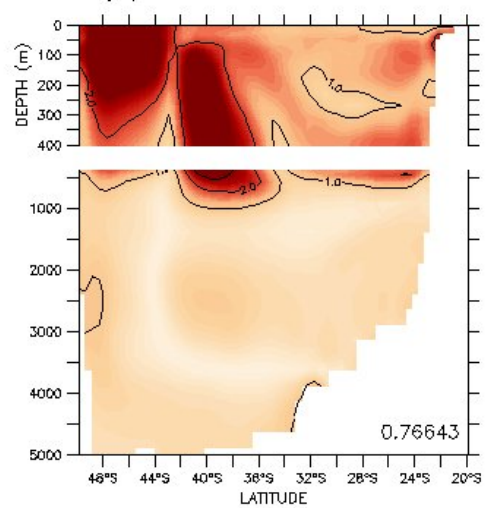

CCSM3

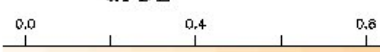

$\stackrel{0 . \widehat{8}}{1}$

1.2 1,8

Figura 49: Transecto latitudinal em $50^{\circ} \mathrm{W}$ (Transecto 1) do erro quadrático médio entre a temperatura $\left({ }^{\circ} \mathrm{C}\right)$ dos 3 modelos numéricos do IPCC ( (a) GFDL, (b) MIROC, (c) CCSM3) e os dados de Reanálise do SODA e média do erro abaixo e à direita.

(a)
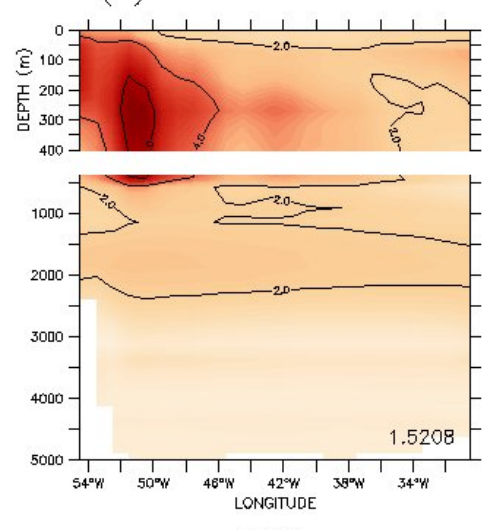

$\frac{0,0}{1}$ (b)
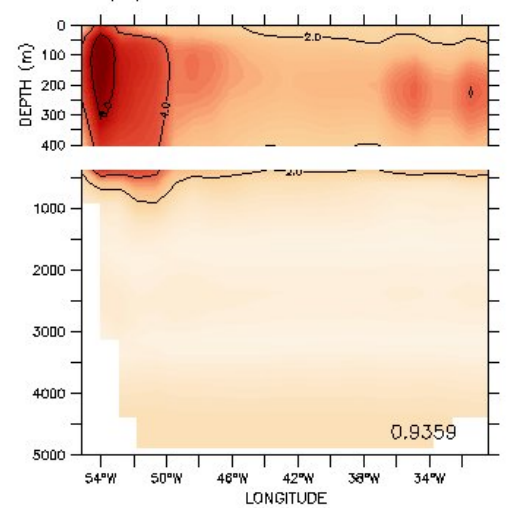

MIROC (c)
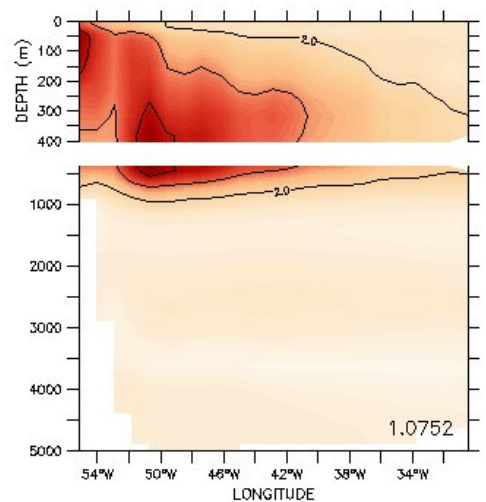

CCSM3

Figura 50: Transecto longitudinal em $40^{\circ} \mathrm{S}$ (Transecto 2) do erro quadrático médio entre a temperatura $\left({ }^{\circ} \mathrm{C}\right)$ dos 3 modelos numéricos do IPCC ( (a) GFDL, (b) MIROC, (c) CCSM3) e os dados de Reanálise do SODA e média do erro abaixo e à direita. 
(a)

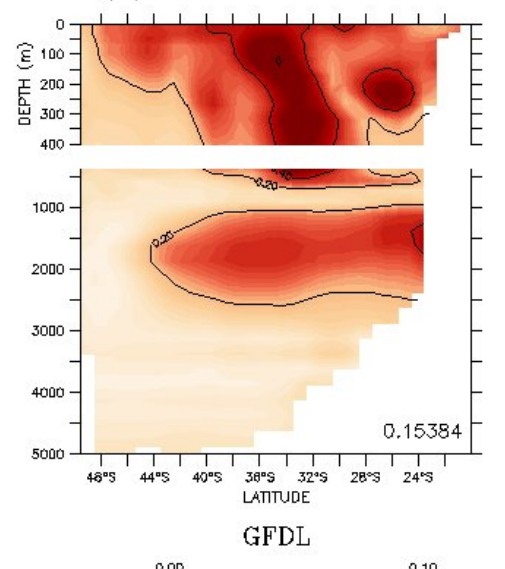

(b)

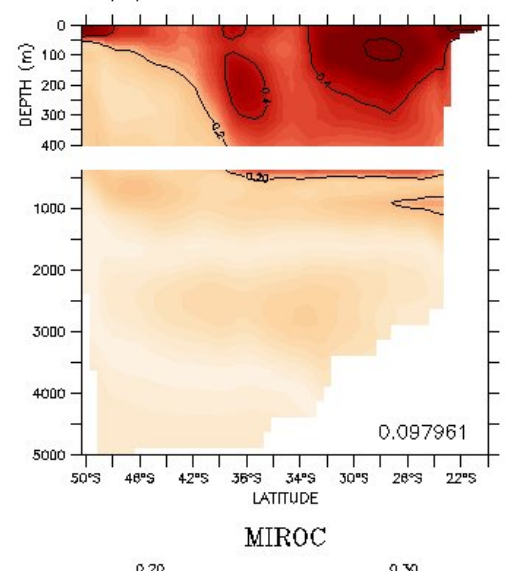

(c)

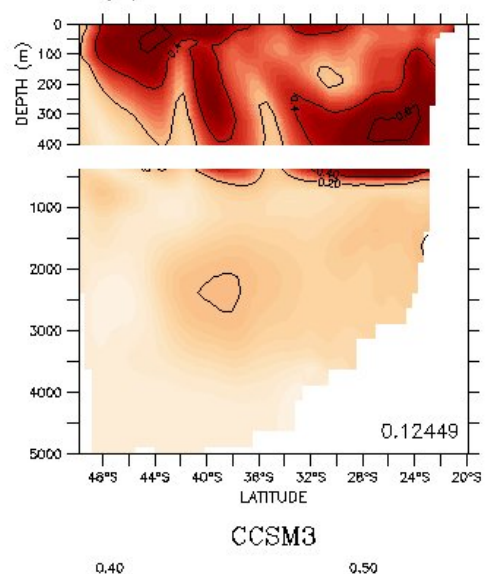

Figura 51: Transecto latitudinal em $50^{\circ} \mathrm{W}$ (Transecto 1) do erro quadrático médio entre a salinidade dos 3 modelos numéricos do IPCC ( (a) GFDL, (b) MIROC, (c) CCSM3) e os dados de Reanálise do SODA e média do erro abaixo e à direita.

(a)
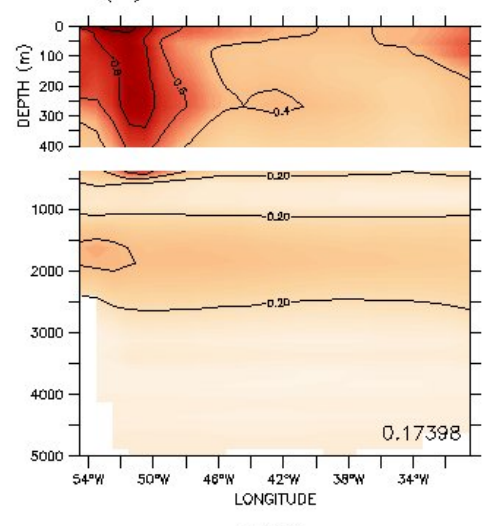

GFDL (b)
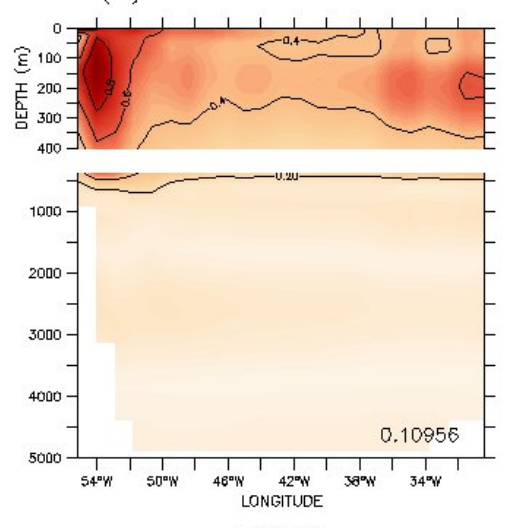

MIROC (c)
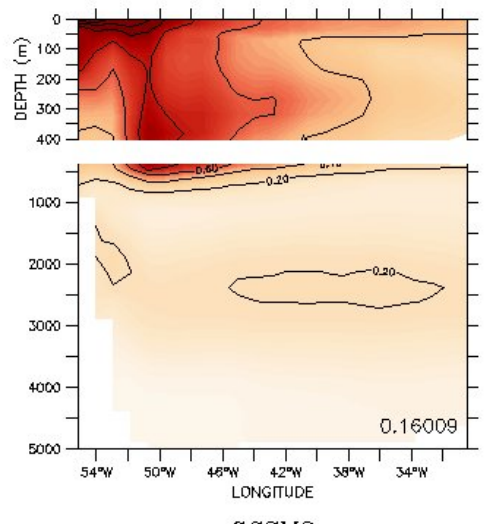

CCSM3

Figura 52: Transecto longitudinal em $40^{\circ} \mathrm{S}$ (Transecto 2) do erro quadrático médio entre a salinidade dos 3 modelos numéricos do IPCC ( (a) GFDL, (b) MIROC, (c) CCSM3) e os dados de Reanálise do SODA e média do erro abaixo e à direita. 


\subsubsection{Síntese da escolha do modelo}

As análises acima citadas forneceram base para a escolha do modelo a ser utilizado na região. Dessa forma, as principais observações foram sintetizadas a seguir:

\section{Padrão Médio}

- O Padrão médio de temperatura de superfície foi bem representado em todos os modelos (principalmente no MIROC).

- O Padrão geral de salinidade foi descrito em todos os modelos, embora não tão precisamente quanto a temperatura.

- MIROC é o que mais subestima a temperatura do núcleo da CB e não representa as baixas temperaturas abaixo de 4000m.

- MIROC e CCSM3 subestimam velocidade de corrente em superfície (sobretudo no domínio da CB).

- Nenhum modelo representou bem todos os índices termohalinos.

- O MIROC foi o modelo que melhor representou as profundidades dos núcleos e interfaces das massas d'água (exceto o núcleo da AT).

- O GFDL obteve o pior resultado na determinação da posição da CBM, sendo que os outros dois modelos chegaram a um valor próximo.

\section{Diferença da Média}

- Maiores erros de temperatura e salinidade de superfície na região da Corrente do Brasil do que na Corrente das Malvinas.

- MIROC e GFDL superestimam a temperatura, ao contrário do CCSM3.

- Todos os modelos superestimam salinidade na região do Rio da Prata e na região da Corrente do Brasil.

- Todos os modelos superestimam a tensão de cisalhamento do vento, tendo o MIROC o melhor desempenho.

- A altura do nível do mar foi subestimada em todos os modelos e o MIROC apresentou a pior diferença da média. 
- Nos perfis verticais de temperatura e salinidade os maiores erros concentraram-se nos primeiros $400 \mathrm{~m}$.

- O GFDL foi o único modelo a apresentar grandes erros associados à profundidade de $2000 \mathrm{~m}$.

- Nenhum modelo se destacou nos perfis de diferença da média.

\section{Variabilidade Sazonal}

- A amplitude de temperatura do ciclo sazonal de superfície foi exagerada pelo GFDL.

- Embora o GFDL obtenha a melhor média da amplitude do ciclo sazonal de temperatura de superfície, o MIROC apresentou a melhor distribuição horizontal.

- O MIROC e GFDL reapresentaram bem a variabilidade sazonal de salinidade.

- As correlações em todos os modelos foram negativas nas climatologias de temperatura e salinidade em $2000 \mathrm{~m}$.

- O MIROC obteve a melhor correlação com o SODA da posição da CBM (92\%).

\section{Tendências}

- Todos os modelos subestimaram as tendências.

- O MIROC foi o que melhor representou as tendências de superfície de temperatura, salinidade e altura do nível do mar.

- O deslocamento para o sul da CBM foi subestimada pelo GFDL e CCSM3 e levemente superestimada pelo MIROC.

- Nenhum modelo representou a tendência positiva do transporte da Corrente do Brasil.

- Apenas o MIROC representou (mesmo subestimada) o deslocamento da Corrente das Malvinas.

\section{Anomalias}

- Todos os modelos subestimaram a variabilidade extra-climatológica. 
- Na superfície nenhum modelo se destacou na representação da variabilidade da anomalia, porém em 1000 e 1700 metros, o MIROC obteve os melhores resultados.

\section{Séries temporais}

- Os melhores resultados de superfície concentram-se na região 1 (relacionada à Corrente do Brasil e à temperatura).

- O MIROC apresentou os melhores resultados de salinidade de superfície.

- As correlações de tensão de cisalhamento do vento e de salinidade e temperatura em 1000 e 1700m apresentaram correlações baixíssimas.

- No mapas de erro quadráticos médios, de forma geral o CCSM3 apresentou os valores mais extremos (embora obtenha a melhor média em alguns casos) ao contrário do MIROC apresentou erros mais homogêneos na região, embora sem apresentar valores extremos.

- O MIROC e o CCSM3 apresentam seus erros concentrados nos primeiros 400m, ao contrário do GFDL que apresenta valores altos de erro quadrático médio até os $2000 \mathrm{~m}$.

A Tabela 15 resume os produtos das análises.

No geral, o MIROC apresentou o melhor padrão médio. O GFDL e o CCSM3 não representaram as intrusões das Correntes do Brasil e das Malvinas com tanta clareza quanto no SODA. Embora nenhum modelo descreva todos os índices termohalinos com precisão, o MIROC foi o que melhor estimou a profundidade média dos núcleos e interfaces das massas d'água.

O CCSM3, embora não apresente médias da diferença em relação ao SODA, esse apresenta grandes valores pontuais. O GFDL, por outro lado, não apresentam grandes diferenças da média em relação ao SODA mas estende seus erros de forma intensa até os 2000m. Em contraponto, o MIROC apresenta uma distribuição do erro mais homogênea sem grandes valores e concentra essas diferenças nos primeiros $400 \mathrm{~m}$.

As análises de tendências e anomalias, mostram que todos os modelos subestimam as variabilidades fora do ciclo sazonal. Embora nenhum modelo descreva as anomalias de forma similar ao SODA (correlação baixíssima) o MIROC é o modelo que possui maior liberdade em relação à climatologia. 
O erro quadrático médio mostrou maiores valores máximos no CCSM3. O GFDL e o MIROC, embora nem sempre apresentem as menores médias, apresentaram menos valores elevados.

Quando analisamos de forma geral, o MIROC não se sobressaiu em todas as análises, mas foi o modelo que melhor representou o padrão médio e climatológico, os menores valores de erro máximo, apesar de apresentar a maior variabilidade extra-climatológica. Além disso, esse modelo foi o que melhor representou a posição da CBM em relação ao SODA. Como os objetivos principais desse trabalho incluem a descrição da evolução do padrão espacial e das tendências em cenários de aquecimento diferentes, o MIROC mostrou-se o modelo mais adequado ao estudo nessa região.

O melhor desempenho do MIROC está associado não só à física do modelo, mas principalmente a maior resolução horizontal e a inclusão do modelo fluvial, já que o Rio da Prata desempenha um importante papel regional. 


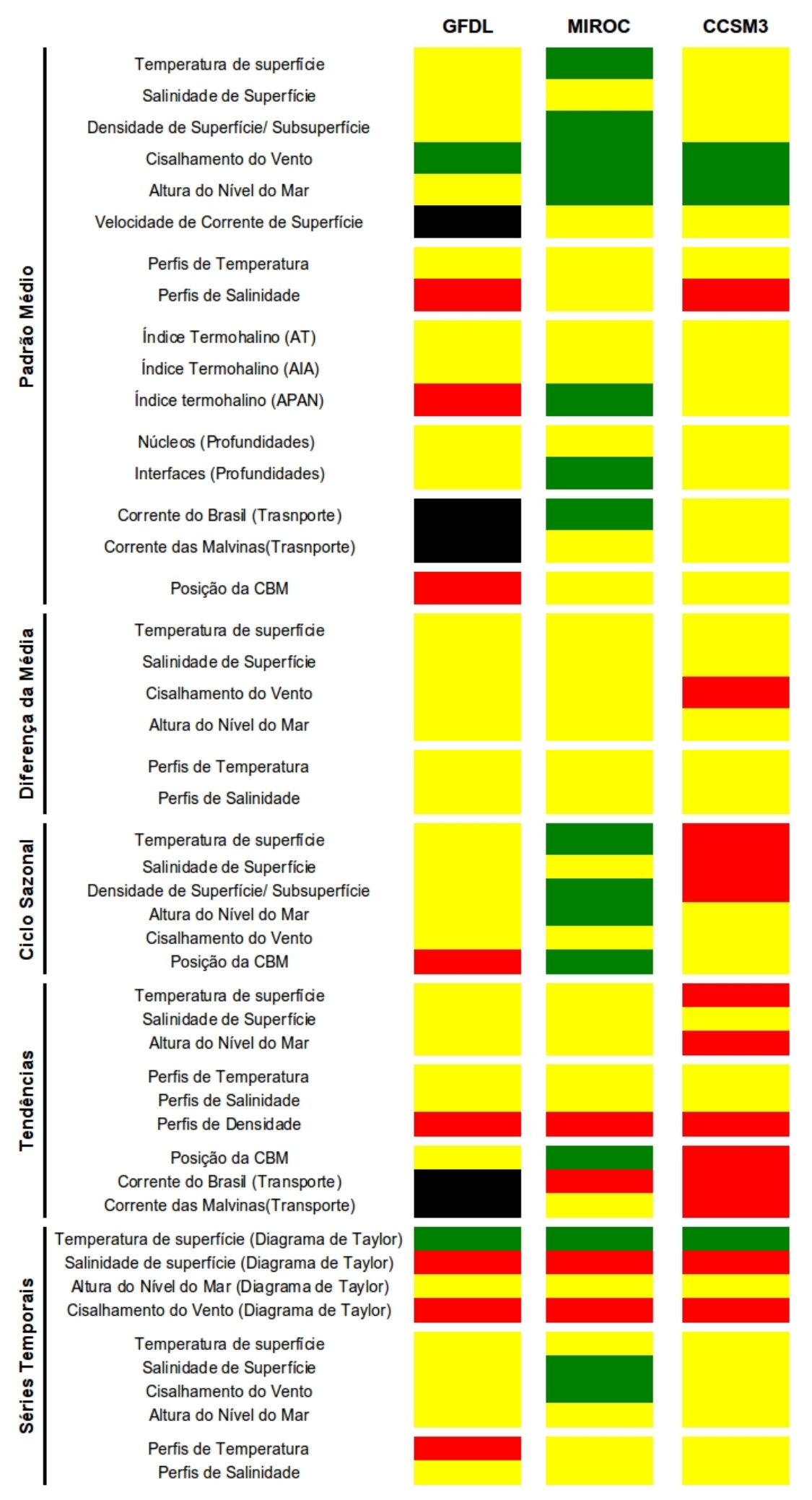

Tabela 15: Síntese dos critérios de escolha do modelo numérico adequado para a região. As opções grifadas em verde, representam os resultados mais satisfatórios. Enquanto os amarelos e vermelhos representam regular e insatisfatório respectivamente. As análises não realizadas encontram-se em preto. 


\subsection{Comparação entre as saídas do MIROC para dois cenários climáticos de aquecimento global}

Nesta seção dos resultados, as saídas dos cenários climáticos A1b e B2 do MIROC serão analisadas e discutidas. Aqui pretende-se discutir as mudanças no ciclo sazonal, nas tendências, nas variabilidades inter anuais, na composição das massas d'água e no padrão médio tridecadal durante o século XXI a partir do modelo escolhido - MIROC - high resolution.

Embora as massas d'água variem de profundidade ao longo do Atlântico Sudoeste, foram escolhidas 2 profundidades para representar a AIA (1000m) e APAN (1700), onde estas são dominantes em quase toda região (embora eventualmente ocupadas por outras massas d'água). A comparação entre os cenários de profundidades distintas poderia ser errônea.

\subsubsection{O Padrão espacial médio}

As principais diferenças médias entre os cenários e a média do século XX segundo o mesmo modelo, estão representadas nas Tabelas 16 a 18 .

\section{Superfície}

\begin{tabular}{|c|c|c|c|c|c|}
\hline & & Séc XX & A1b-SécXX & B2 - SécXX & Desvio Padrão \\
\hline Temperatura $\left({ }^{\circ} \mathrm{C}\right)$ & \multirow{4}{*}{ 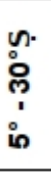 } & 22.99 & 2.3 & 1.85 & 1.64 \\
\hline Salinidade & & 35.76 & 0.35 & 0.31 & 0.06 \\
\hline Densidade (kg/m3) & & 24.51 & -0.42 & -0.32 & 0.48 \\
\hline Cisalhamento (N/m2) & & 0.69 & -0.05 & -0.07 & 0.05 \\
\hline Temperatura $\left({ }^{\circ} \mathrm{C}\right)$ & \multirow{4}{*}{ 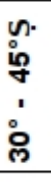 } & 15.27 & 2.34 & 2.07 & 2.53 \\
\hline Salinidade & & 34.55 & 0.19 & 0.18 & 0.06 \\
\hline Densidade (kg/m3) & & 25.41 & -0.36 & -0.3 & 0.57 \\
\hline Cisalhamento (N/m2) & & 0.69 & -0.02 & 0 & 0.05 \\
\hline Temperatura & \multirow{4}{*}{$\begin{array}{l}0 \\
\circ \\
0 \\
0 \\
1 \\
\text { in }\end{array}$} & 3.45 & 2.04 & 1.68 & 2.29 \\
\hline Salinidade & & 33.52 & -0.04 & -0.03 & 0.12 \\
\hline Densidade (kg/m3) & & 26.31 & -0.26 & -0.21 & 0.36 \\
\hline Cisalhamento (N/m2) & & 0.71 & -0.01 & 0.01 & 0.06 \\
\hline
\end{tabular}

Tabela 16: Média das variáveis de superfície (temperatura, salinidade, densidade e tensão de cisalhamento do vento) em três regiões durante o século XX, diferença da média entre 2000 e 2100 e o século XX (nos cenários A1b e B2) e o desvio padrão do século XX. 
Na Tabela 16 observamos que as maiores diferenças entre as variáveis nos cenários A1b e B2 e o século XX, referem-se à região que comporta a Confluência (entre 30 e $45^{\circ} \mathrm{S}$ ). Nessa região, a temperatura média de $15.3^{\circ} \mathrm{C}$ no Século XX eleva-se a $17.6^{\circ} \mathrm{C}$ no cenário A1b e a $15.4^{\circ} \mathrm{C}$ no B2. Por outro lado, a região que apresentou maior diferença entre as médias dos cenários foi a de menores latitudes (entre 5 e $30^{\circ} \mathrm{S}$ ).

A temperatura média nos dois cenários foi sensivelmente maior que o experimento do Século XX, superando o desvio padrão de $1.64^{\circ} \mathrm{C}$ na região entre 5 e $30^{\circ} \mathrm{S}$. Em toda a região a temperatura elevou-se em mais de $1.5^{\circ} \mathrm{C}$, sendo o principal fator responsável pelo decréscimo da densidade. Apesar do acentuado aumento da salinidade, a região intertropical da área de estudo apresentou forte redução da densidade de superfície, sendo a média nessa região $0.42 \mathrm{~kg} / \mathrm{m}^{3}$ menor no cenário A1b em relação ao século XX. Essa diminuição de densidade persiste até em regiões de latitudes mais altas chegando a $0.26 \mathrm{~kg} / \mathrm{m}^{3}$ entre 45 e $60^{\circ} \mathrm{S}$. Esse fenômeno pode dificultar a formação de massas d'água profunda, bem como alterar o padrão vertical das estruturas termohalinas.

Enquanto a temperatura de superfície sofre intensas alterações na média em todas as regiões, a salinidade decresce ligeiramente nas altas latitudes. Possivelmente por conta da alteração do regime pluviométrico, as baixas latitudes sofrem intenso aumento da salinidade de superfície (0.35 no A1b e 0.31 no B2). Por outro lado, a tensão de cisalhamento do vento manteve-se pouco alterado, sobretudo em altas latitudes.

Na Tabela 17, observamos as médias das regiões no Século XX e a diferença em relação aos cenários climáticos em 1000m. Mesmo em regiões mais profundas, a região intertropical sofre intenso aquecimento (em média $0.71^{\circ} \mathrm{C}$ no cenário $\mathrm{A} 1 \mathrm{~b}$ e $0.66^{\circ} \mathrm{C}$ no B2), mas ainda foi superada pela região intermediária. Essa profundidade, dominada principalmente pela AIA, possui salinidade semelhante e as médias comportarem-se de forma semelhante sem grandes diferenças de salinidade. Observamos uma redução da salinidade no setor mais austral e aumento nas regiões intermediárias e baixas latitudes.

Em 1700m, os dois cenários obtiveram médias muito semelhantes em todas as regiões para todas as variáveis (Tabela 18). Essa profundidade, dominada pela APAN, mostrouse menos sensível nessa região. A salinidade não apresentou reduções maiores que 0.2 e a temperatura foi aumentada em até $0.37^{\circ} \mathrm{C}$ no cenário B2 na região entre 30 e $45^{\circ} \mathrm{S}$. Por tratar-se de uma massa d'água cuja região de formação é muito distante, essa profundidade pode demorar mais a responder às alterações dos cenários. 
$1000 \mathrm{~m}$

\begin{tabular}{|c|c|c|c|c|c|}
\hline & & Séc XX & $A 1 b-S e ́ c X X$ & B2 - SécXX & Desvio Padrão \\
\hline \multirow{3}{*}{$\begin{array}{c}\text { Temperatura }\left({ }^{\circ} \mathrm{C}\right) \\
\text { Salinidade } \\
\text { Densidade }(\mathrm{kg} / \mathrm{m} 3)\end{array}$} & \multirow{2}{*}{$\begin{array}{l}\text { n. } \\
\text { :्లे }\end{array}$} & 5.22 & 0.71 & 0.66 & 0.14 \\
\hline & & 34.66 & 0.02 & 0.02 & 0.004 \\
\hline & in & 31.96 & -0.09 & -0.08 & 0.02 \\
\hline \multirow{3}{*}{$\begin{array}{c}\text { Temperatura }\left({ }^{\circ} \mathrm{C}\right) \\
\text { Salinidade } \\
\text { Densidade }(\mathrm{kg} / \mathrm{m} 3) \\
\end{array}$} & \multirow{2}{*}{$\begin{array}{l}\text { n. } \\
\stackrel{n}{y}\end{array}$} & 4.13 & 1.18 & 1.07 & 0.19 \\
\hline & & 34.47 & 0.02 & 0.01 & 0.002 \\
\hline & $\stackrel{्}{\circ}$ & 31.95 & -0.15 & -0.13 & 0.03 \\
\hline \multirow{3}{*}{$\begin{array}{c}\text { Temperatura } \\
\text { Salinidade } \\
\text { Densidade }(\mathrm{kg} / \mathrm{m} 3)\end{array}$} & \multirow{2}{*}{$\begin{array}{l}\text { ñ } \\
\stackrel{0}{0}\end{array}$} & 1.98 & 0.37 & 0.35 & 0.07 \\
\hline & & 34.63 & -0.01 & -0.01 & 0.01 \\
\hline & 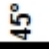 & 32.33 & 0.35 & -0.04 & 0.01 \\
\hline
\end{tabular}

Tabela 17: Média das variáveis de 1000m (temperatura, salinidade e densidade) em três regiões durante o século XX, diferença da média entre 2000 e 2100 e o século XX (nos cenários A1b e B2) e o desvio padrão do século XX.

As diferenças entre os resultados do modelo nos dois cenários climáticos aumenta com o tempo de experimento. Para melhor descrevê-la, o período de 100 anos foi dividido em três de aproximadamente 33 anos. Na Figura 53 observamos que a região da CBM é a mais sensível ao aquecimento superficial da água do mar. Na região, no cenário A1b, as médias de temperatura chegaram a a superar $5^{\circ} \mathrm{C}$ e $3^{\circ} \mathrm{C}$ no B2. A diferença entre os dois cenários é bem sensível nas últimas 3 décadas. Observamos que o setor mais austral da região de estudo aquece mais de $2^{\circ} \mathrm{C}$ sendo responsável pela formação de massas d'águas mais quentes (AIA). Nas últimas 3 décadas de experimento, a temperatura de superfície média no Atlântico Sudoeste foi $0.5^{\circ} \mathrm{C}$ maior no cenário A1b do que no $\mathrm{B} 2$ e quase $3^{\circ} \mathrm{C}$ a mais do que em relação ao experimento do século XX. Os primeiros 1000m do oceano sofreram um aquecimento médio de aproximadamente $1.8^{\circ} \mathrm{C}$ (calor suficiente para aquecer os $11 \mathrm{~km}$ de atmosfera em mais de $0.7^{\circ} \mathrm{C}$ ). Wainer et al. (2004), em um estudo numérico calculou o aquecimento de $0.64^{\circ} \mathrm{C}$ em para o século XX em relação ao período pré-industrial.

A forte tendência positiva de temperatura também é observada em maiores profundidades. Em 1000m, onde prevalece a AIA na região, observamos na Figura 54 que a temperatura no último período dos experimentos supera em mais do que $2^{\circ} \mathrm{C}$ a temperatura do século XX nessa mesma região e média em mais de $1^{\circ} \mathrm{C}$ para a região. Embora a diferença de temperatura seja inferior à metade da encontrada em superfície, devemos notar que esse impacto na temperatura é no mínimo 2 vezes maior do que variabilidade 


\begin{tabular}{|c|c|c|c|c|c|}
\hline & & Séc XX & A1b-SécXX & B2 - SécXX & Desvio Padrão \\
\hline \multirow{2}{*}{$\begin{array}{c}\text { Temperatura }\left({ }^{\circ} \mathrm{C}\right) \\
\text { Salinidade }\end{array}$} & \multirow{2}{*}{$\begin{array}{l}n \cdot \\
\stackrel{\text { ñ }}{1}\end{array}$} & 3.23 & 0.28 & 0.26 & 0.05 \\
\hline & & 34.8 & -0.02 & -0.02 & 0.01 \\
\hline Densidade (kg/m3) & in & 35.74 & -0.06 & -0.05 & 0.01 \\
\hline \multirow{2}{*}{$\begin{array}{c}\text { Temperatura }\left({ }^{\circ} \mathrm{C}\right) \\
\text { Salinidade }\end{array}$} & \multirow{2}{*}{$\begin{array}{l}\text { n. } \\
\stackrel{\circ}{9} \\
\stackrel{5}{7}\end{array}$} & 2.45 & 0.37 & 0.35 & 0.67 \\
\hline & & 34.64 & 0 & -0.01 & 0.01 \\
\hline Densidade (kg/m3) & 을 & 35.72 & -0.06 & -0.05 & 0.01 \\
\hline \multirow{3}{*}{$\begin{array}{c}\text { Temperatura } \\
\text { Salinidade } \\
\text { Densidade }(\mathrm{kg} / \mathrm{m} 3)\end{array}$} & \multirow{3}{*}{$\begin{array}{l}n \\
\vdots \\
\dot{0} \\
\dot{0} \\
\dot{10}\end{array}$} & 1.46 & 0.15 & 0.15 & 0.03 \\
\hline & & 34.7 & -0.01 & -0.01 & 0.003 \\
\hline & & 35.88 & -0.02 & -0.02 & 0.01 \\
\hline
\end{tabular}

Tabela 18: Média das variáveis de 1700m (temperatura, salinidade e densidade) em três regiões durante o século XX, diferença da média entre 2000 e 2100 e o século XX (nos cenários A1b e B2) e o desvio padrão do século XX.

anual típica para profundidade que dificilmente ultrapassa os $0.5^{\circ} \mathrm{C}$ em comparação com os $5^{\circ} \mathrm{C}$ da superfície. Novamente, a região mais sensível foi a da Confluência. Tal aumento da temperatura na região pode estar relacionado tanto ao aquecimento dessa água em sua região de formação quanto ao deslocamento da posição da confluência para o Sul, trazendo águas mais quentes do norte da região. A região ao norte da Confluência sofreu maior elevação da temperatura.

Até regiões mais profundas do oceano responderam aos cenários de aquecimento. Em $1700 \mathrm{~m}$ de profundidade, nos dois cenários a média das temperaturas nas entre 2066 e 2100 aumentaram mais de $0.3^{\circ} \mathrm{C}$, sendo que a amplitude anual média nessa profundidade não ultrapassa os $0.2^{\circ} \mathrm{C}$ (Figura 55). Novamente a região da Confluência mostrou-se a mais sensível da área estudada. Essa profundidade apresentou a menor diferença de temperatura entre os cenários.

Todos os mapas de temperatura em todas as profundidades demonstram feições espaciais semelhantes nos períodos, com exceção do deslocamento do limite da Corrente do Brasil para sul.

O aumento de temperatura média nos três períodos em toda a região não é seguido pela salinidade. Embora a média da salinidade de superfície para região aumente nas últimas 3 décadas de experimento (por volta de 0.177 no A1b e 0.15 no B2), observamos um decréscimo de salinidade no domínio da Corrente das Malvinas e um acréscimo em 


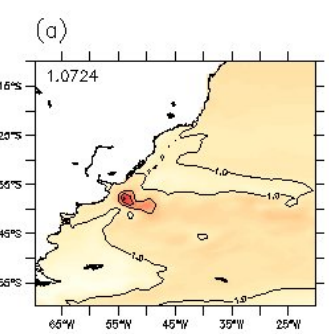

(b)

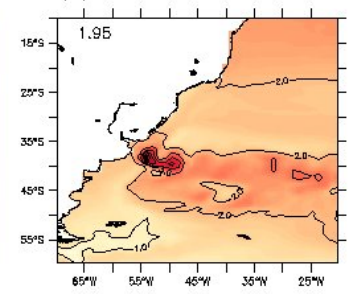

(d)

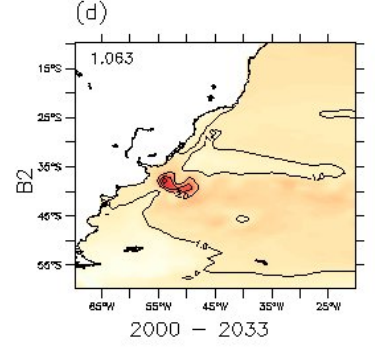

(e)

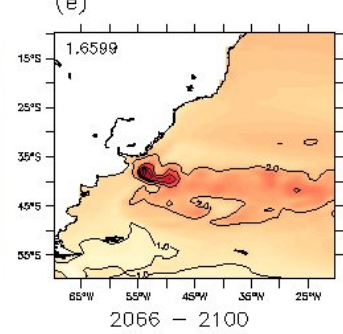

(c)

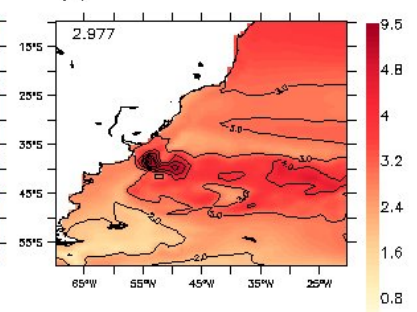

( $\mathrm{f})$

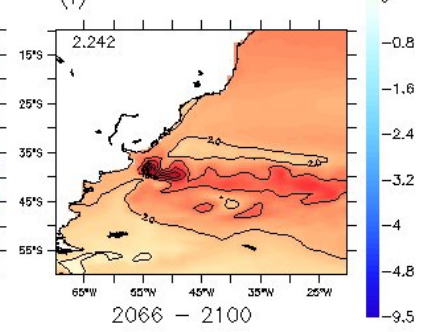

Figura 53: Diferença de TSM $\left({ }^{\circ} \mathrm{C}\right)$ entre três períodos dos experimentos para o século XXI e a média do século XX- cenários A1b: (a), (b) e (c) e B2 (c), (d) e (e).

menores latitudes - Figura 56. Essas alterações diferenciadas aumentam ainda mais o contraste das característica termohalinas da região tornando-a ainda mais complexa. A região mais sensível a alterações halinas localiza-se próxima à desembocadura do Rio da Prata e as baixas latitudes, onde o cenário A1b mostrou-se até 2 vezes mais impactado que o B2 no último período chegando a uma elevação média superior a 0.5 em boa parte da região provavelmente devido ao aumento da evaporação das águas de superfície. $\mathrm{Na}$ porção mais austral, o derretimento de gelo provavelmente desempenha importante papel no decréscimo de salinidade.

Em 1000m metros, observamos na Figura 57 que a salinidade média além da superfície também é fortemente impactada no Atlântico Sul. Essa profundidade, de baixa oscilação anual de salinidade (sempre inferior a 0.05), apresentou acréscimos de mais de 0.4 na região do domínio da Corrente do Brasil. Por outro lado, na região da CBM e um pouco mais ao Sul, encontramos regiões de forte decréscimo. A diferença entre os cenários, por outro lado não ultrapassou 0.05 em nenhum dos três períodos e mostrou-se muito menor que em relação a superfície e a regiões mais profundas. A redução da salinidade em altas latitudes do Atlântico Sul deve estar relacionada à alterações na região de formação da AIA, como o derretimento de gelo antártico e a intensificação dos ventos polares que podem estar acelerando esse processo de formação. Russel et al. (2006) discutiu a possibilidade da 

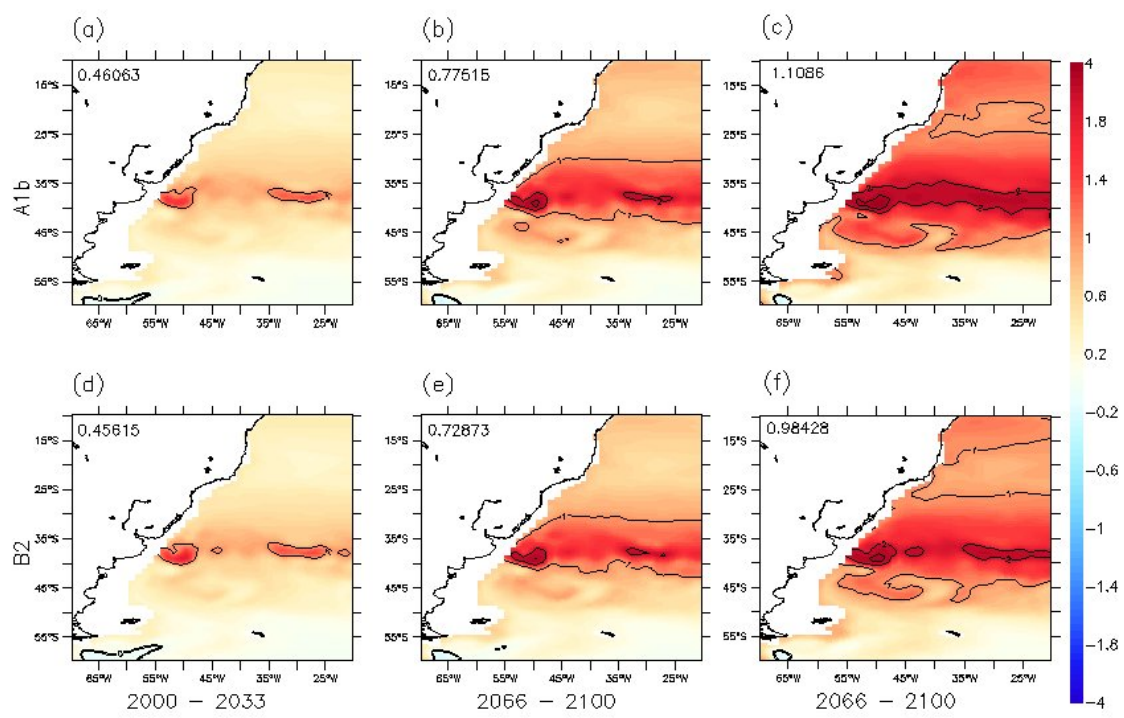

$(\mathrm{f})$

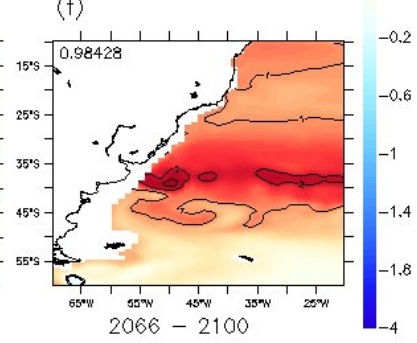

Figura 54: Diferença de temperatura em $1000\left({ }^{\circ} \mathrm{C}\right)$ entre três períodos dos experimentos para o século XXI e a média do século XX- cenários A1b: (a), (b) e (c) e B2 (c), (d) e (e).

aceleração da formação de massas d'águas transportar calor e carbono para as camadas mais profundas, reduzindo o efeito do aquecimento global.

A evolução da salinidade em 1700m, por estar associada a APAN (massa d'água de região de formação no Atlântico Norte) possui um padrão mais complexo. Na Figura 58 , observamos que nessa profundidade, a massa d'água adquire características consequentes não só da troca inter-hemisférica de água profunda, como também da água recirculante do giro subtropical. Nessa profundidade, praticamente toda a região sofreu um decréscimo de salinidade, com exceção de uma estreita faixa longitudinal entre 25 e $35^{\circ} \mathrm{S}$. Os dois cenários possuem comportamento semelhantes, com exceção dessa faixa, onde o cenário A1b possui uma diferença até 2 vezes maior do que o B2. Embora a amplitude média do ciclo anual seja tipicamente metade nessa profundidade em relação aos 1000m, bem como o desvio padrão médio (0.012 e 0.0068 para o século XX respectivamente) a diferença entre a média do terceiro período nos experimentos é muito maior. Assim, das três profundidades analisadas, a profundidade de 1000m (onde predomina a AIA), mostrou-se mais suscetível a mudanças (se comparada a variabilidade típica).

O sensível aumento da temperatura, bem como a redução da salinidade em boa parte da região gerou uma redução do peso específico da água do mar em todas as profundi- 


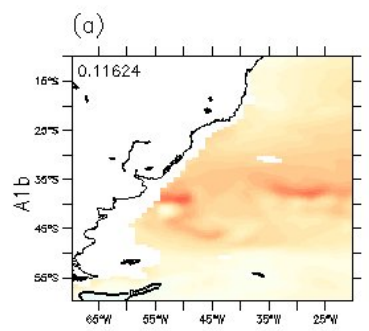

(b)

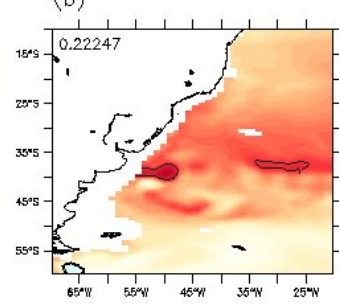

(c)
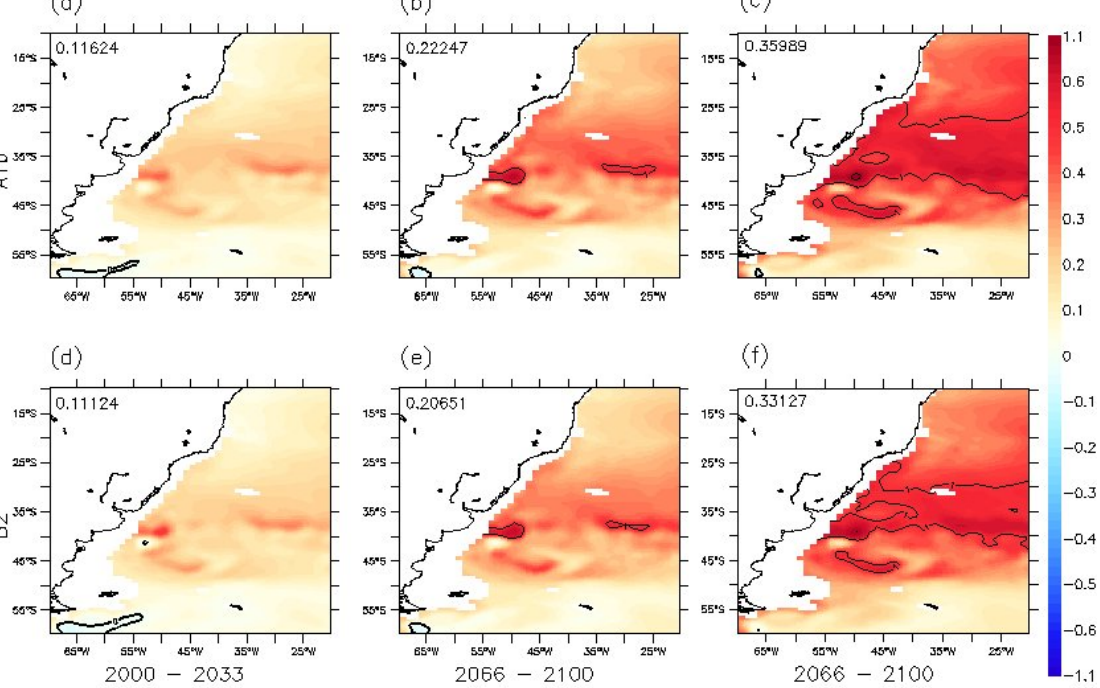

$(\mathrm{f})$

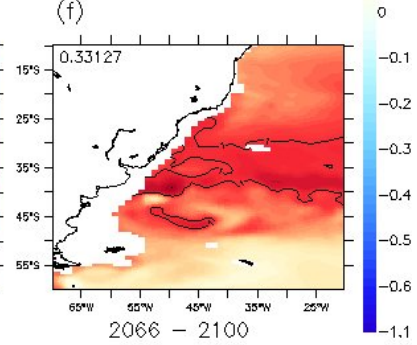

Figura 55: Diferença de de temperatura em $1700\left({ }^{\circ} \mathrm{C}\right)$ entre três períodos dos experimentos para o século XXI e a média do século XX- cenários A1b: (a), (b) e (c) e B2 (c), (d) e (e).

dades e regiões (com exceção de pontos específicos relacionados à desembocadura do Rio da Prata). As baixas latitudes foram mais afetadas, mesmo com o aumento de salinidade como podemos observar na Figura 59. Os resultados do cenário A1b apresentaram densidades até $0.4 \mathrm{~kg} / \mathrm{m}^{3}$ maiores que o B2 o que representa mais da metade do desvio padrão médio da região durante o século XX $\left(0.58 \mathrm{~kg} / \mathrm{m}^{3}\right)$. O contraste entre as regiões de baixas e altas latitudes não foi tão intensa no cenário B2 quanto no A1b. Novamente, na superfície o contraste entre as águas muito densas provindas do oceano austral com águas leves de baixas latitudes é intensificado. A redução da densidade é evidenciada pelo deslocamento da isopicnal de $25 \mathrm{~kg} / \mathrm{m}^{3}$ de 40 para $45^{\circ} \mathrm{S}$. As diferenças entre os cenários (sobretudo em baixas latitudes) reflete na média da diferença de densidade de superfície na região no terceiro período $\left(-0.64 \mathrm{~kg} / \mathrm{m}^{3}\right.$ para o A1b e $-0.48 \mathrm{~kg} / \mathrm{m}^{3}$ para o B2).

A redução de densidade em 1000 e 1700 metros acompanharam a distribuição espacial do aumento de temperatura concentrando grande parte da redução de densidade na região da CBM. Observamos nas Figuras 60 61 que a AIA mostrou-se mais sensível a alterações de densidade e que os cenários não apresentam grandes diferenças nessa variável, sendo bem maior o decréscimo em relação ao Século XX.

A tensão de cisalhamento do vento, não apresentou grandes diferenças na média. A 
(a)

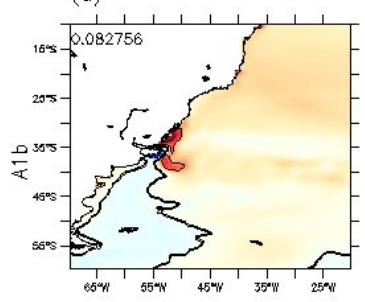

(d)

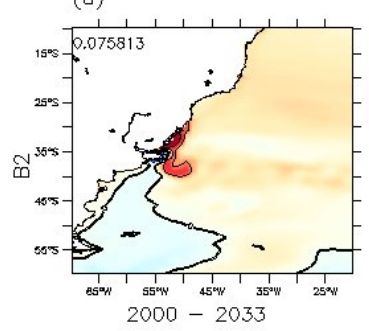

(b)

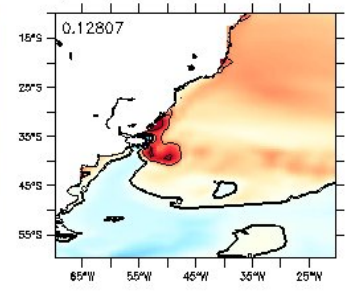

(e)

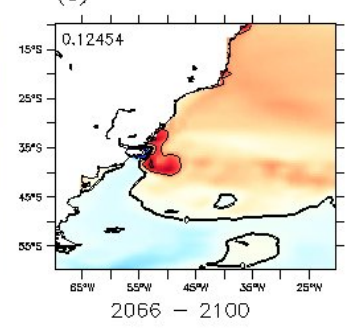

(c)

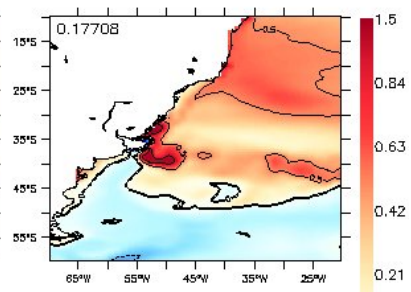

(f)

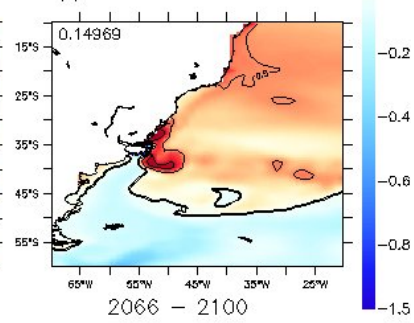

Figura 56: Diferença de SSM entre três períodos dos experimentos para o século XXI e a média do século XX- cenários A1b: (a), (b) e (c) e B2 (c), (d) e (e).

(a)

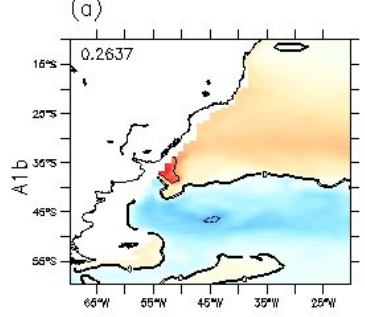

(d)

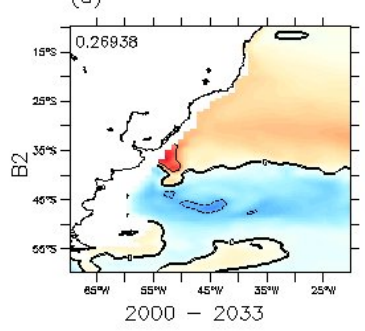

(b)

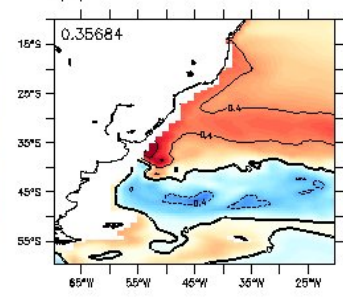

(e)

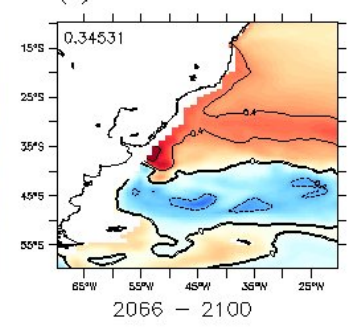

(c)

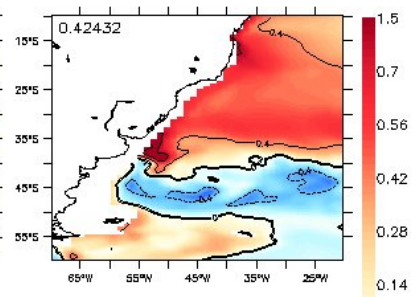

(f)

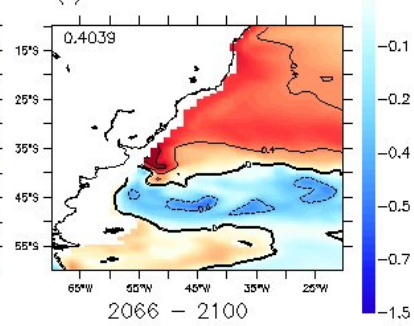

Figura 57: Diferença de salinidade em $1000 \mathrm{~m}$ entre três períodos dos experimentos para o século XXI e a média do século XX- cenários A1b: (a), (b) e (c) e B2 (c), (d) e (e). 
(a)

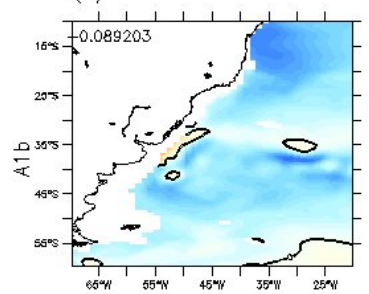

(d)

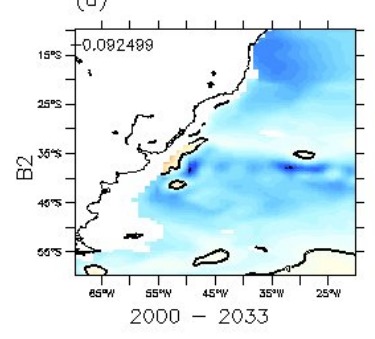

(b)

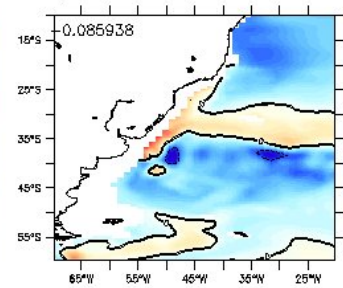

(e)

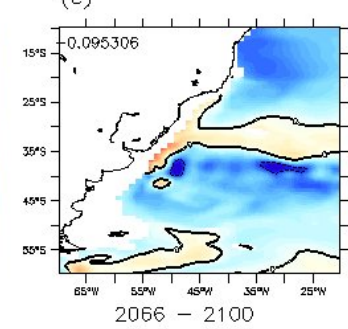

(c)

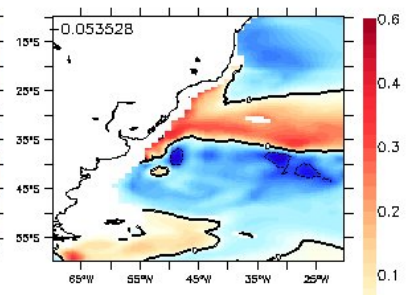

(f)

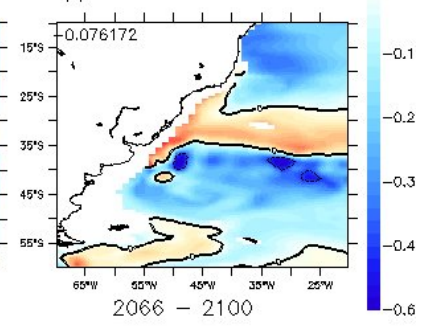

Figura 58: Diferença de salinidade em 1700m entre três períodos dos experimentos para o século XXI e a média do século XX- cenários A1b: (a), (b) e (c) e B2 (c), (d) e (e).

(a)

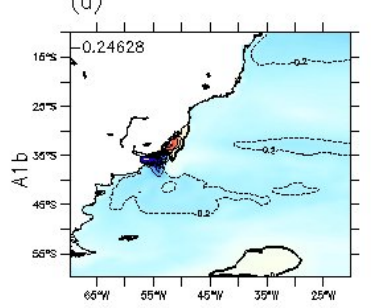

(b)

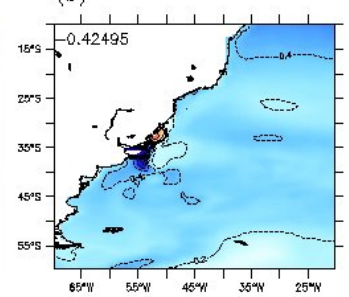

(d)

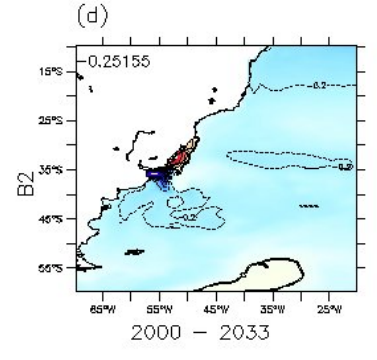

(e)

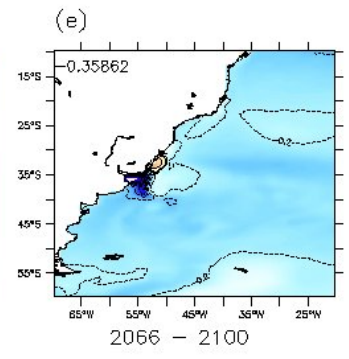

(c)

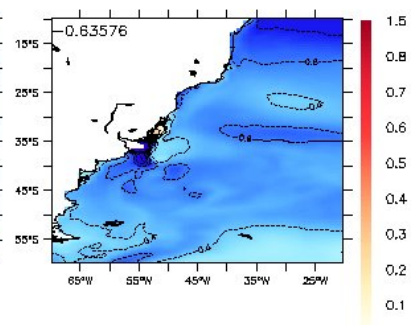

(f)

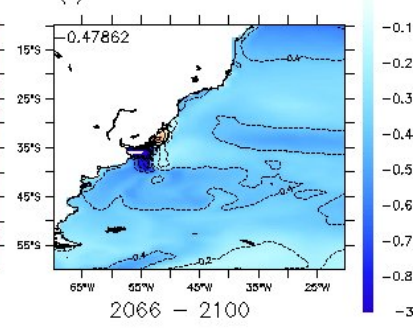

Figura 59: Diferença de densidade de superfície $\left(\mathrm{kg} / \mathrm{m}^{3}\right)$ entre três períodos dos experimentos para o século XXI e a média do século XX- cenários A1b: (a), (b) e (c) e B2 (c), (d) e (e). 
(a)

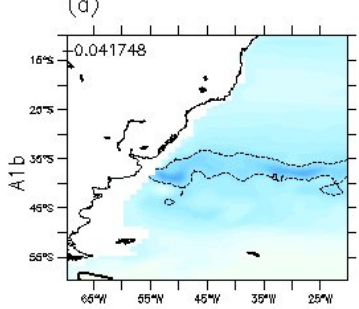

(b)

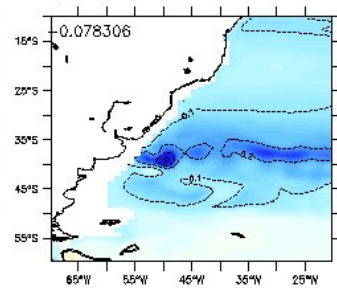

(e)

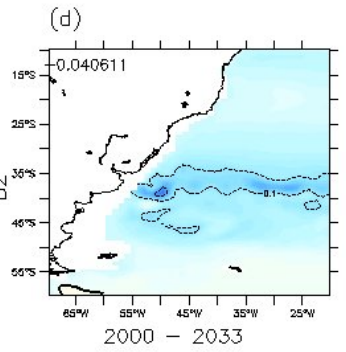

(c)

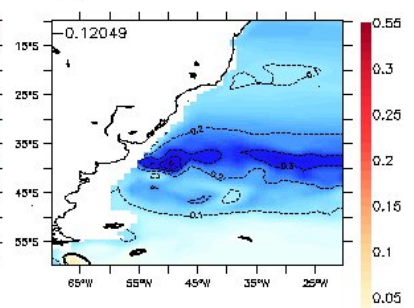

(f)

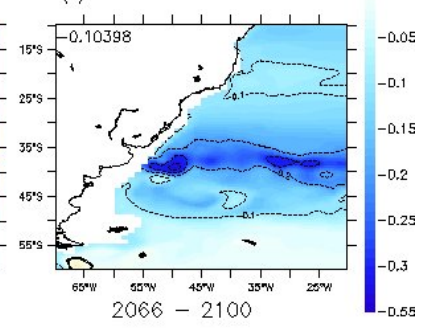

Figura 60: Diferença de densidade em 1000m $\left(\mathrm{kg} / \mathrm{m}^{3}\right)$ entre três períodos dos experimentos para o século XXI e a média do século XX- cenários A1b: (a), (b) e (c) e B2 (c), (d) e (e).

(a)

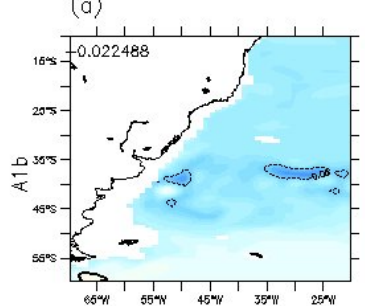

(d)

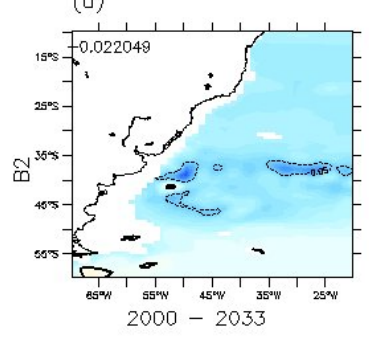

(b)

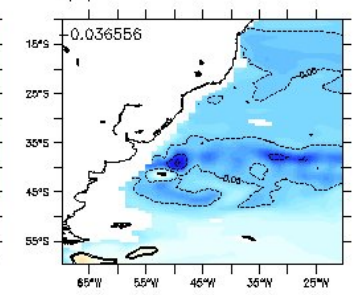

(e)

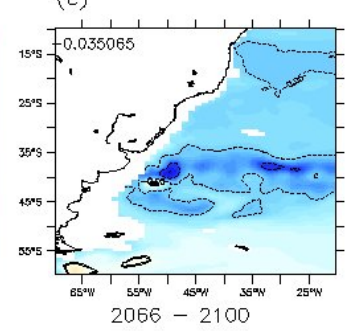

(c)

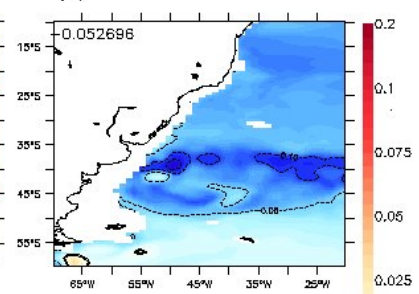

$(\mathrm{f})$

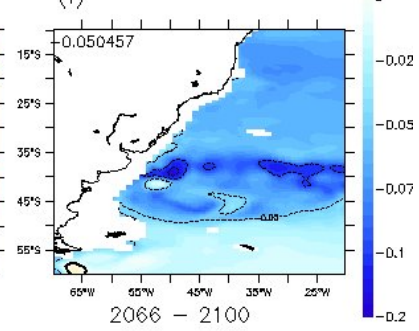

Figura 61: Diferença de densidade em 1700m $\left(\mathrm{kg} / \mathrm{m}^{3}\right)$ entre três períodos dos experimentos para o século XXI e a média do século XX- cenários A1b: (a), (b) e (c) e B2 (c), (d) e (e). 
(a)

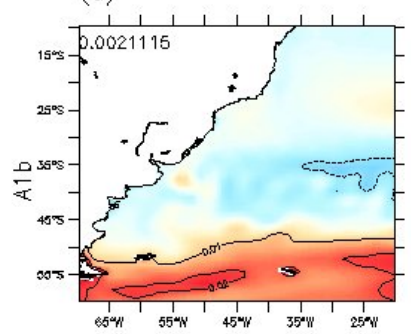

(d)

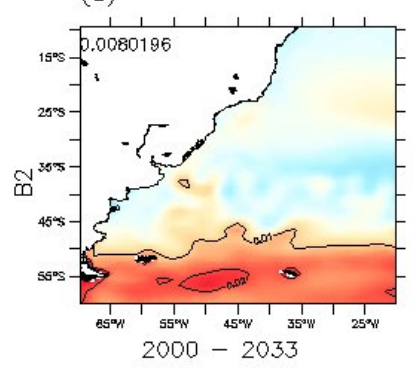

(b)

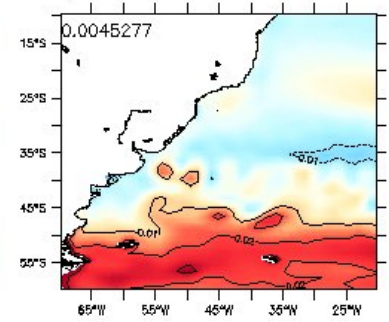

(e)

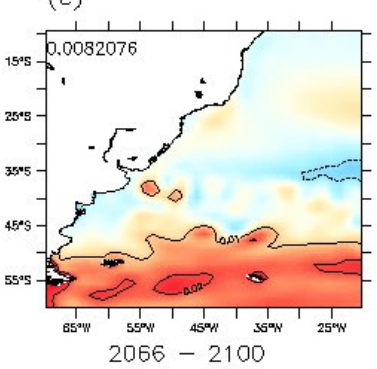

(c)

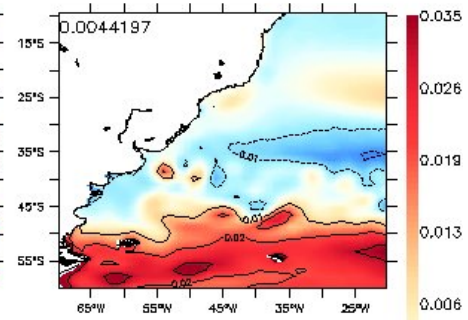

(f)

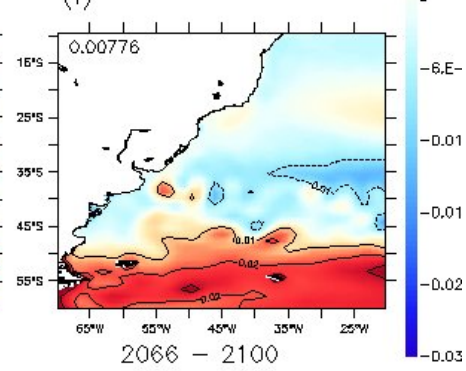

Figura 62: Diferença média de tensão de cisalhamento do vento sobre o mar $\left(\mathrm{N} / \mathrm{m}^{2}\right)$ entre três períodos dos experimentos para o século XXI e a média do século XX- cenários A1b: (a), (b) e (c) e B2 (c), (d) e (e).

diferença máxima encontrada na média do período entre 2066 e 2100 foi de $0.032 \mathrm{~N} / \mathrm{m}^{2}$, sendo que o desvio padrão médio da tensão de cisalhamento do vento na região é de 0.05 $\mathrm{N} / \mathrm{m}^{2}$ no século XX - Figura 62. Em altas latitudes, o aumento da tensão de cisalhamento do vento foi o mais intenso da região. Russell et al. (2006) destaca a importância do aumento da tensão de cisalhamento dos ventos de oeste circumpolares que intensifica a formação de massas d'águas ao redor do continente Antártico e assim sequestram calor e carbono da superfície. Embora a diferença entre a média da região seja quase o dobro no cenário A1b, em relação ao B2. observamos que a diferença o padrão espacial é bem pequeno.

Os perfis verticais indicam que o aumento de temperatura nos períodos é presente em toda a coluna d'água. Nota-se, abaixo dos $2500 \mathrm{~m}$ um resfriamento (embora muito ameno) das águas no ponto 1 (40W, 30S)- Figura 63. Embora esse resfriamento médio no último período não ultrapasse $0.1^{\circ} \mathrm{C}$, chega a 2 desvios padrões dessa profundidade para o século XX no cenário A1b e a 1 no B2. Esse resfriamento ocorre nas profundidades correspondentes à densidade da ACP e pode estar relacionada ao derretimento do gelo 
que isolava termicamente a massa d'água em seu local de formação. Essa hipótese é reforçada pela diminuição da salinidade em até 8 desvios padrões (0.08). O cenário A1b embora mais quente possui em média $5 \%$ menos concentração de gelo marinho na região de formação dessa água facilitando o resfriamento dessa massa d'água. Por outro lado, as regiões mais rasas tendem a tornar-se mais salina e quentes. Sobretudo por volta do núcleo da APAN que chega a elevar sua temperatura em até 10 desvios padrões $\left(0.6^{\circ} \mathrm{C}\right)$ e 2 na salinidade (0.04). Essa região, o núcleo da AIA (por volta dos 1000m) esquentou, no último período médio (2066-2100), 6 desvios padrões $\left(1.5^{\circ} \mathrm{C}\right)$ em relação ao século XX e o primeiro (2000-2033) apenas $2\left(0.5^{\circ} \mathrm{C}\right)$. A média da densidade só diminuiu ao longo dos períodos obtendo seu mínimo em 400m. Nessa profundidade, a diferença entre os cenários é a mais marcante e chega a quase 4 desvios padrões. A velocidade da corrente apresenta maior acréscimo próximo ao núcleo da corrente do Brasil de até 0.8 desvios padrões $(0.012 \mathrm{~m} / \mathrm{s})$ nos dois cenários. Em pontos mais próximos a costa, esse aumento foi mais intenso chegando a $0.026 \mathrm{~m} / \mathrm{s}$ em $45^{\circ} \mathrm{W}$.

Observamos na Figura 64 que no ponto $2\left(55^{\circ} \mathrm{W}, 45^{\circ} \mathrm{S}\right)$, situado no domínio da Corrente das Malvinas, a temperatura aumenta em toda a coluna d'água sobretudo em torno dos $500 \mathrm{~m}$ chegando a 7.3 desvios padrões no cenário A1b $\left(2.5^{\circ} \mathrm{C}\right)$ e quase 6 no B2 $\left(2^{\circ} \mathrm{C}\right)$. As águas de subsuperfície tornam-se mais doces ao longo dos períodos (possivelmente por conta do derretimento de gelo) e a maior redução ocorre por volta de $3500 \mathrm{~m}$ atingindo quase 6 desvios padrões. A densidade diminui em toda a coluna d'água nesse ponto sendo a maior redução em 240m. A média da velocidade não apresenta variações superiores a 0.5 desvios padrões e é atenuada nas camadas intermediárias, embora só aumente em regiões próximas a costa.

A elevação da média de temperatura no último período, sobretudo na região da CBM (por volta dos $39^{\circ}$ Ṣ) também é observada nas seções de temperatura. Nessa região, a temperatura média entre 2066 e 2100 até os $1000 \mathrm{~m}$ supera os $3^{\circ} \mathrm{C}$, sendo que chega a $5^{\circ} \mathrm{C}$ em subsuperfície (por volta de $100 \mathrm{~m}$ ). Os primeiros $800 \mathrm{~m}$ aumentam sua temperatura média em mais de $1^{\circ} \mathrm{C}$ em todo o transecto nos dois cenários climáticos globais. As maiores diferenças de temperatura, referem-se aos primeiros $1000 \mathrm{~m}$ de coluna d'água. A Figura 65 representa a diferença entre a média de temperatura em cada período e a média do Século XX ao longo do transecto latitudinal em $40^{\circ} \mathrm{W}$. Nesse caso, observamos um núcleo de maiores diferenças próximo a costa em baixas latitudes $\left(22^{\circ} \mathrm{S}\right)$ por volta 


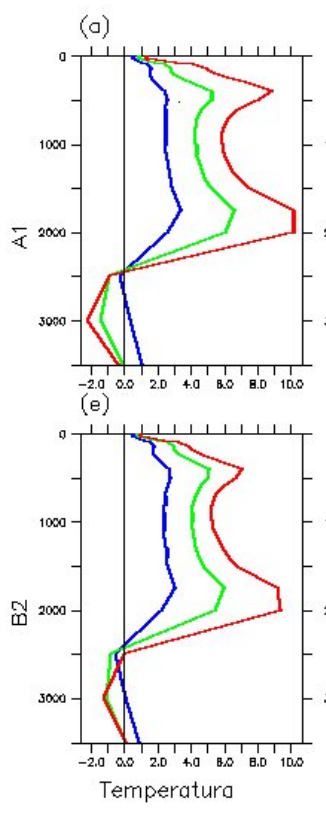

2000-2033 (b)
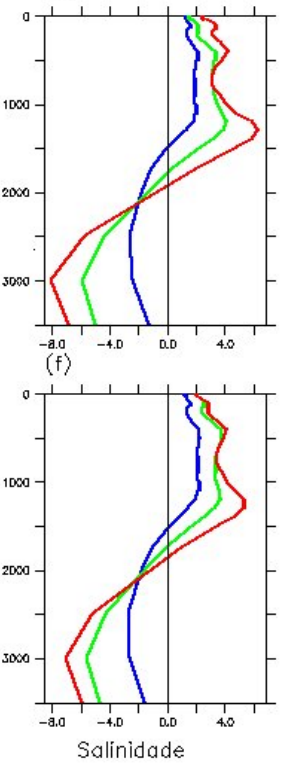

(c)

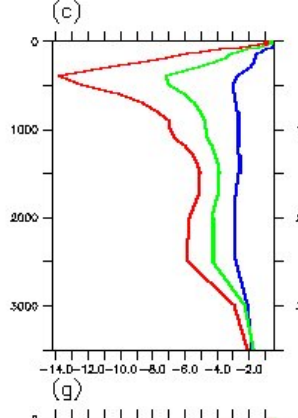

(d)

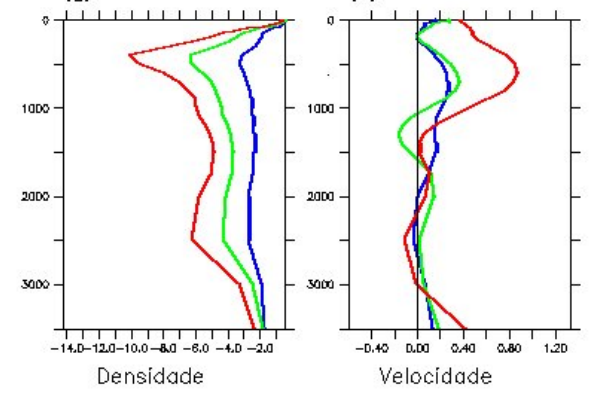

Figura 63: Perfis verticais no ponto $1\left(40^{\circ} \mathrm{W}, 30^{\circ} \mathrm{S}\right)$ da diferença entre as variáveis (temperatura -(a) e (e), salinidade - (b) e (f), densidade - (c) e (g) e velocidade - (d) e (h), segundo dois cenários climáticos A1b (a,b e c) e B2 (d, e, e f) normalizados pelos desvio padrão das variáveis durante o Século XX. As linhas azuis representam o primeiro período (2000-2033), as verdes o segundo (2033-2066) e as vermelhas o terceiro (2066-2100). 


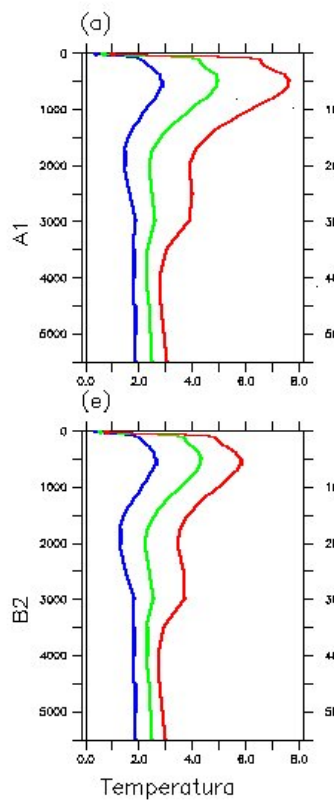

(b)

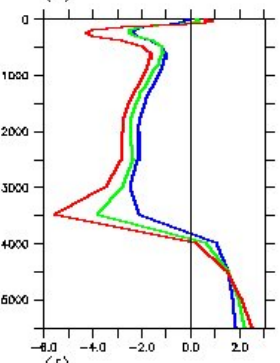

(f)

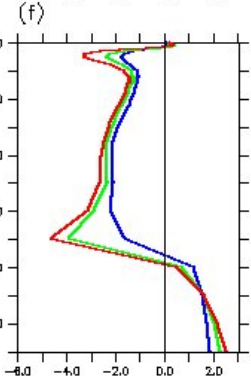

(c)
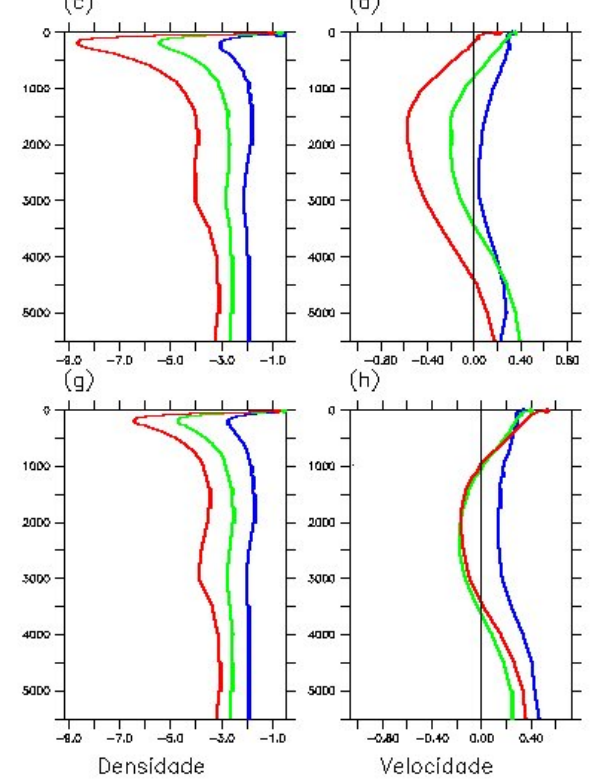

2000-2033

Figura 64: Perfis verticais no Ponto $2\left(55^{\circ} \mathrm{W}, 45^{\circ} \mathrm{S}\right)$ da diferença entre as variáveis (temperatura -(a) e (e), salinidade - (b) e (f), densidade - (c) e (g) e velocidade - (d) e (h), segundo dois cenários climáticos A1b (a,b e c) e B2 (d, e, e f) normalizados pelos desvio padrão das variáveis durante o Século XX. As linhas azuis representam o primeiro período (2000-2033), as verdes o segundo (2033-2066) e as vermelhas o terceiro (2066-2100). 

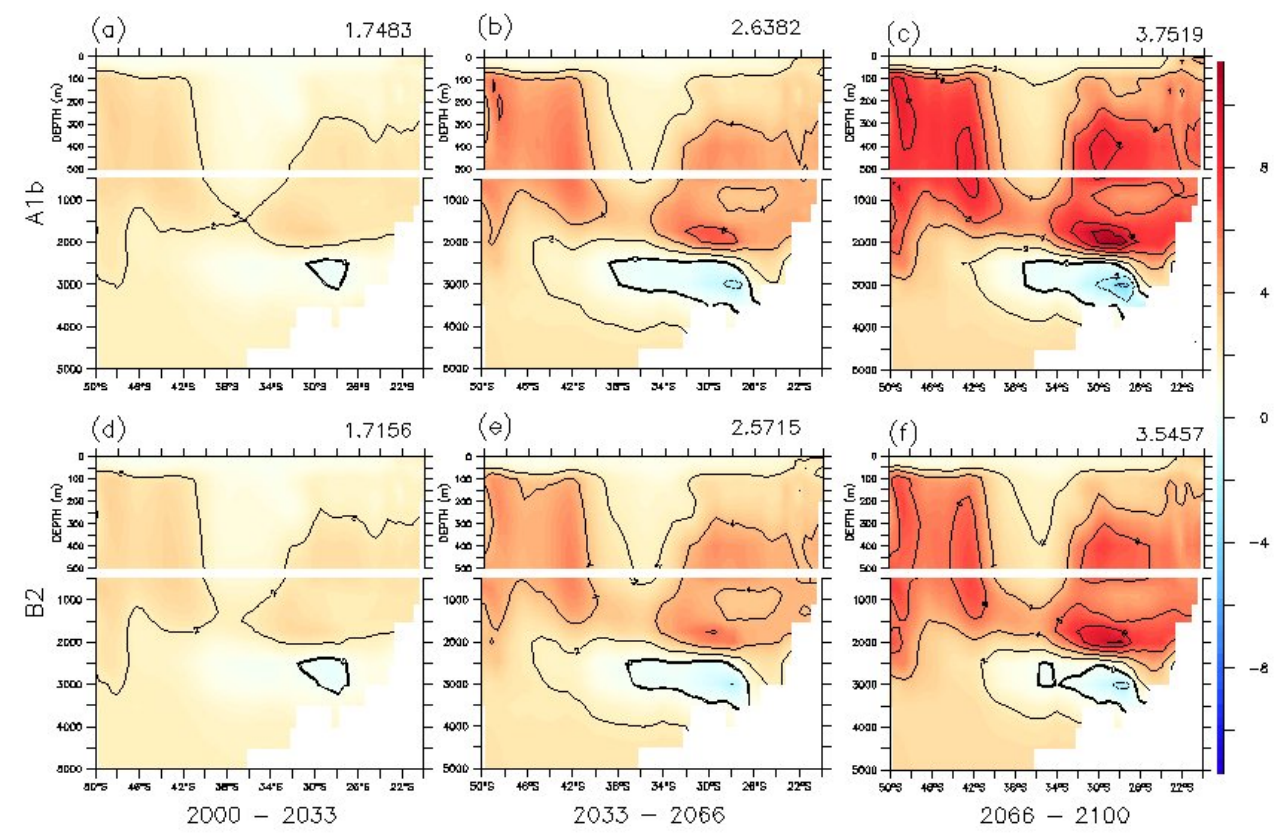

Figura 65: Seção latitudinal em $40^{\circ} \mathrm{W}$ de diferença de temperatura $\left({ }^{\circ} \mathrm{C}\right)$ entre três períodos dos experimentos para o século XXI e a média do século XX-cenários A1b: (a), (b) e (c) e B2 (c), (d) e (e).

de $1700 \mathrm{~m}$ chegando a 10 desvios padrões no cenário $\mathrm{A} 1 \mathrm{~b}\left(1^{\circ} \mathrm{C}\right)$ e 8 no $\mathrm{B} 2\left(0.8^{\circ} \mathrm{C}\right)$. Junto a costa, por volta de $30^{\circ} \mathrm{S}$ e $3000 \mathrm{~m}$ de profundidade, observamos uma das poucas regiões onde a temperatura média decresceu no último período, principalmente no cenário A1b que chega a 4 desvios padrões $\left(0.16^{\circ} \mathrm{C}\right)$. A densidade desse corpo d'água possui densidade convencional de $42 \mathrm{~kg} / \mathrm{m}^{3}$, temperatura potencial de $2^{\circ} \mathrm{C}$ e salinidade de 34.77 e possivelmente encontra-se no domínio da ACP.

No transecto 2 da Figura 66, observamos a seção longitudinal ao longo de $40{ }^{\circ} \mathrm{S}$ da diferença de temperatura também normalizada pelo desvio padrão. Observamos poucas diferenças entre os resultados dos cenários. O maior valor encontrado foi de $6.2^{\circ} \mathrm{C}$ próximo a costa, em subsuperfície, possivelmente relacionado a desembocadura do Rio da Prata. Nos dois primeiros períodos o comportamento dos dois cenários foi praticamente igual sendo que a diferença média entre eles não ultrapassou $0.1^{\circ} \mathrm{C}$. Toda a região obteve uma diferença da média entre 2066 e 2100 acima de 2 desvios padrões com exceção da faixa entre 2200 e $3500 \mathrm{~m}$, onde as alterações da média não ultrapassou $0.1^{\circ} \mathrm{C}$.

Os transectos de diferença de salinidade, mostram que nos cenários de aquecimento, 

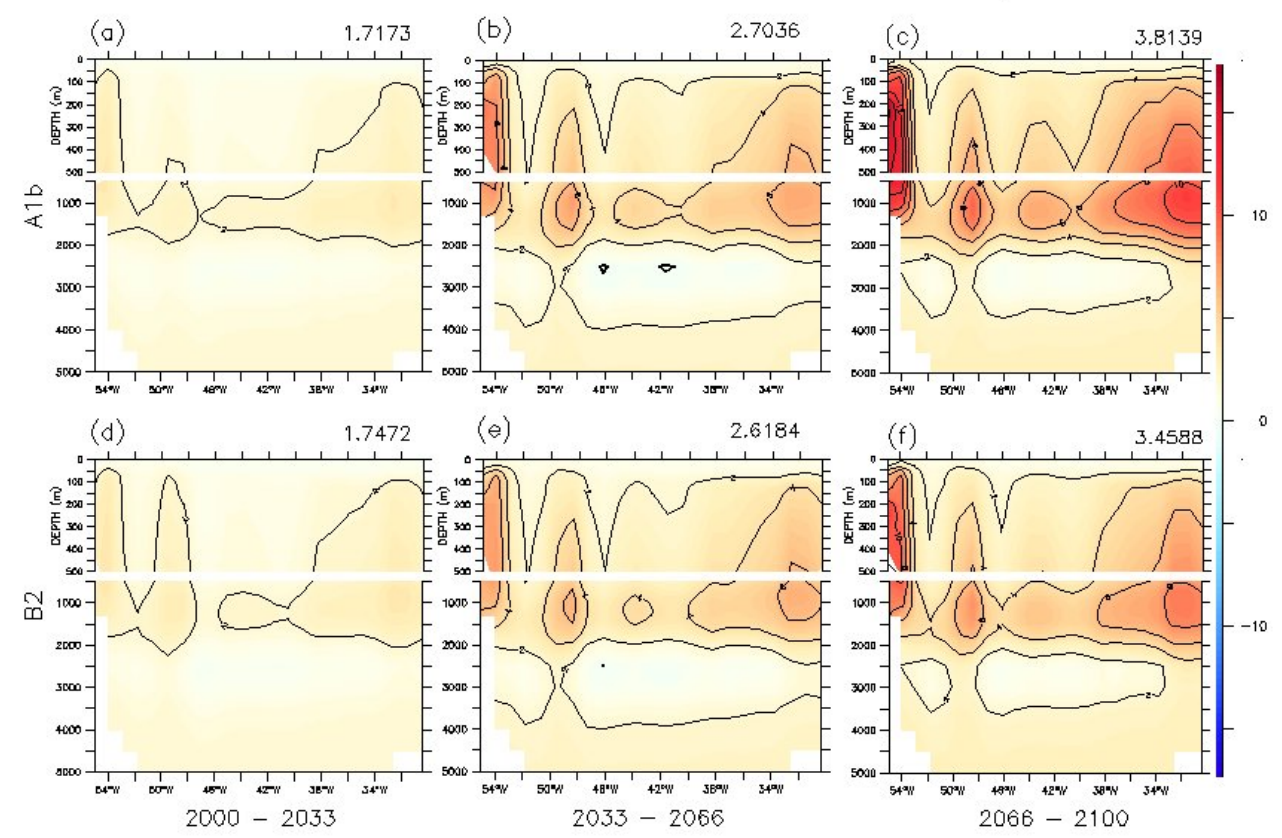

Figura 66: Seção longitudinal em $40^{\circ} \mathrm{S}$ de diferença de temperatura $\left({ }^{\circ} \mathrm{C}\right)$ entre três períodos dos experimentos para o século XXI e a média do século XX- cenários A1b: (a), (b) e (c) e B2 (c), (d) e (e).

a estratificação vertical de salinidade se intensifica tornando a haloclina ainda mais pronunciada. Até a latitude de $40^{\circ} \mathrm{S}$, a água de superfície até os $1000 \mathrm{~m}$ torna-se mais salina enquanto que as águas entre 1500 e 4000m tornam-se mais doces (Figura 68). Os dois cenários comportam-se de maneira bem semelhante e a diferença entre eles nunca supera 0.1 em nenhum período. A profundidade de 3000m é a que mais sofre o decréscimo de salinidade chegando a 9 desvios padrões em $26^{\circ} \mathrm{S}$. Essa redução, novamente deve estar associada à ACP.

Na seção longitudinal (Figura 68) observamos que o maior aumento de salinidade no último período concentra-se nas proximidades da costa, ainda sob o efeito do Rio da Prata. Nessa região, o aumento de salinidade superou 1. Nas regiões mais afastadas da costa, permaneceu enter 0.3 e 0.1 até $1000 \mathrm{~m}$ de profundidade. A partir daí a salinidade média entre 2066 e 2100 decaiu em menos 0.1. As diferença entre os cenários foi ainda menor nesse transecto e basicamente se restringiu aos primeiros $1000 \mathrm{~m}$. Por volta dos $3000 \mathrm{~m}$ a salinidade chegou a ser reduzida em até 6 desvios padrões.

Assim, as variações de densidades mais relevantes estão restritas aos primeiros $1000 \mathrm{~m}$ 

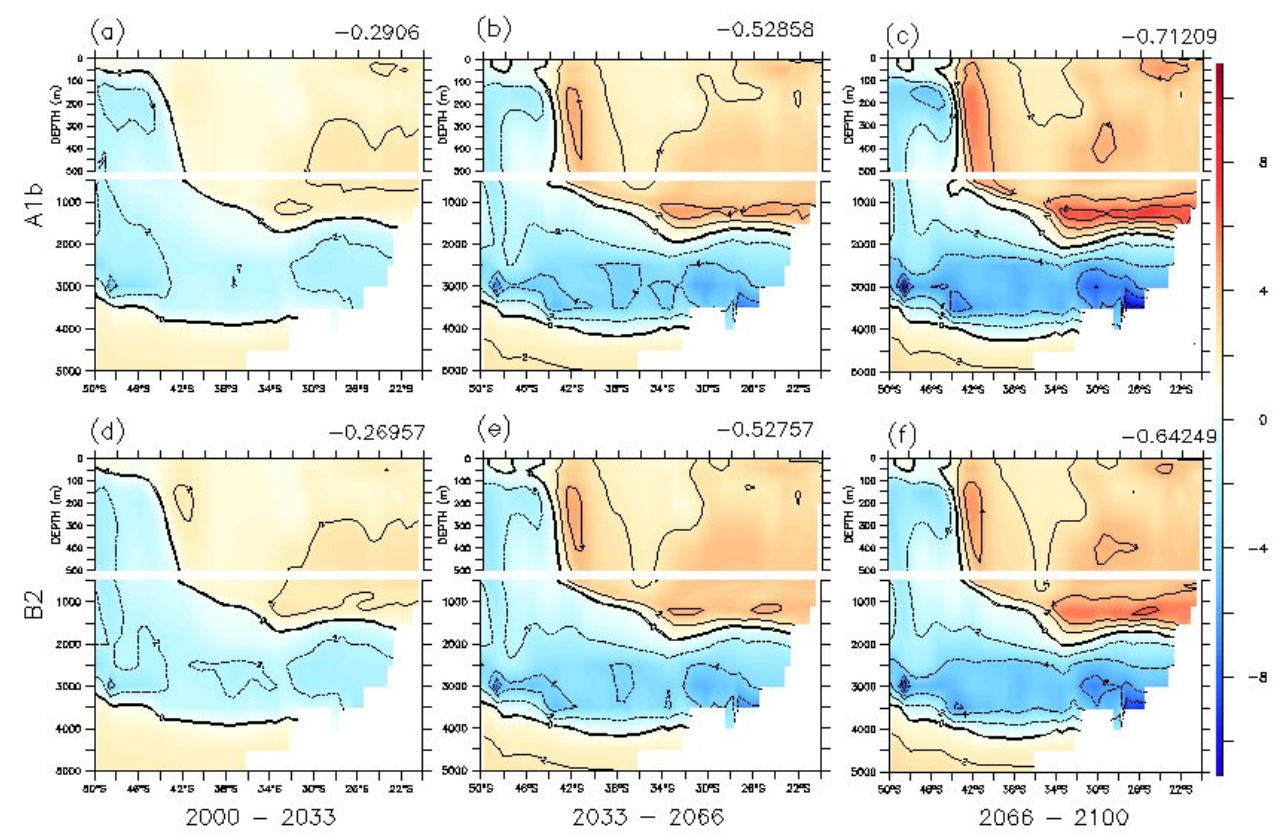

Figura 67: Seção latitudinal em $40^{\circ} \mathrm{W}$ de diferença de salinidade entre três períodos dos experimentos para o século XXI e a média do século XX-cenários A1b: (a), (b) e (c) e B2 (c), (d) e (e).

(Figuras 69 e 70). Em toda a região a densidade diminui, como consequência principalmente da elevação da temperatura.

Na Tabela 19 observamos a evolução da posição da Confluência Brasil Malvinas e dos transportes das correntes do Brasil e da Malvinas. Observamos que, devido ao leve enfraquecimento da Corrente das Malvinas e, principalmente, a intensificação da Corrente do Brasil a CBM desloca-se para o sul.

A média do transporte da corrente do Brasil calculado em $30^{\circ} \mathrm{S}$ aumentou de $12.2 \mathrm{~Sv}$ (média do século XX) para 16.21Sv entre 2066 e 2100 no cenário A1b e 15.08 Sv no B2. Esse aumento de 33 e 24\% superou a variabilidade anual típica de 3.21 Sv no cenário A1b e foi bem próxima no cenário B2. Por outro lado a Corrente das Malvinas sofreu uma leve redução de $82.5 \mathrm{~Sv}$ para 80.5 e Sv no cenário A1b e até aumentou no último período do cenário B2 ( $83 \mathrm{~Sv})$. Essa redução de menos de $0.3 \%$ do transporte médio da Corrente das Malvinas é irrisório se comparada com a variabilidade anual típica no século XX de $7 \mathrm{~Sv}$.

A posição da CBM, fortemente associada à Corrente do Brasil, desloca-se para o sul 

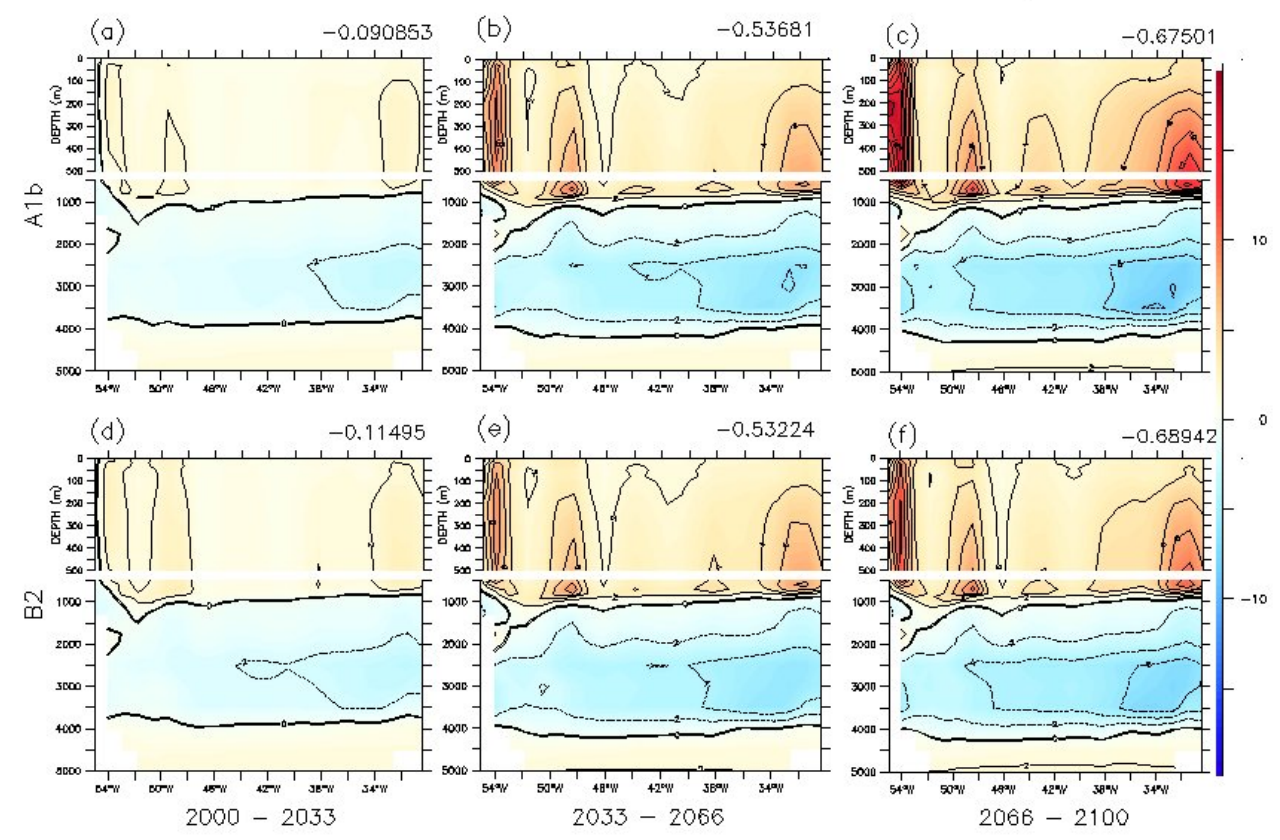

Figura 68: Seção longitudinal em $40^{\circ} \mathrm{S}$ de salinidade entre três períodos dos experimentos para o século XXI e a média do século XX- cenários A1b: (a), (b) e (c) e B2 (c), (d) e (e).

em mais de $1^{\circ}$ nos dois cenários. No século XX, a posição média calculada através do MIROC foi $39.7^{\circ} \mathrm{S}$, enquanto que a encontrada para os cenários A1b e B2 entre 2066 e 2100 foram de 41 e $40.7^{\circ} \mathrm{S}$ respectivamente. Enquanto a média da posição da CBM nos três períodos só deslocou-se para sul no cenário A1b, ela retrocede levemente no terceiro período do cenário B2.

As diferenças entre os períodos foi evidenciada em todas as profundidades. As características das massas d'água foram modificadas, bem como as profundidades do núcleo. Observamos nos diagramas de estado da Figura 71 a evolução das características termoha-

\begin{tabular}{ccccccc} 
& \multicolumn{2}{c}{ Transporte CB (Sv) } & \multicolumn{2}{c}{ Transporte CM (Sv) } & \multicolumn{2}{c}{ Posicão CBM ( } \\
\hline & A1b & B2 & A1b & B2 & B2 \\
\hline $\mathbf{2 0 0 0 - 2 0 3 3}$ & 12.8 & 12.81 & 82.9 & 83.27 & 40.27 & 40.48 \\
$\mathbf{2 0 3 3 - 2 0 6 6}$ & 14.21 & 13.71 & 82.64 & 82.49 & 40.82 \\
$\mathbf{2 0 6 6 - 2 1 0 0}$ & 16.21 & 15.08 & 80.47 & 82.97 & 41.08 \\
\hline
\end{tabular}

Tabela 19: Média dos módulos dos transportes das correntes do Brasil e das Malvinas (Sv) segundo o modelo MIROC em dois cenários de aquecimento global (A1b e B2) e a posição média da confluência das duas correntes $\left({ }^{\circ} \mathrm{S}\right)$. 

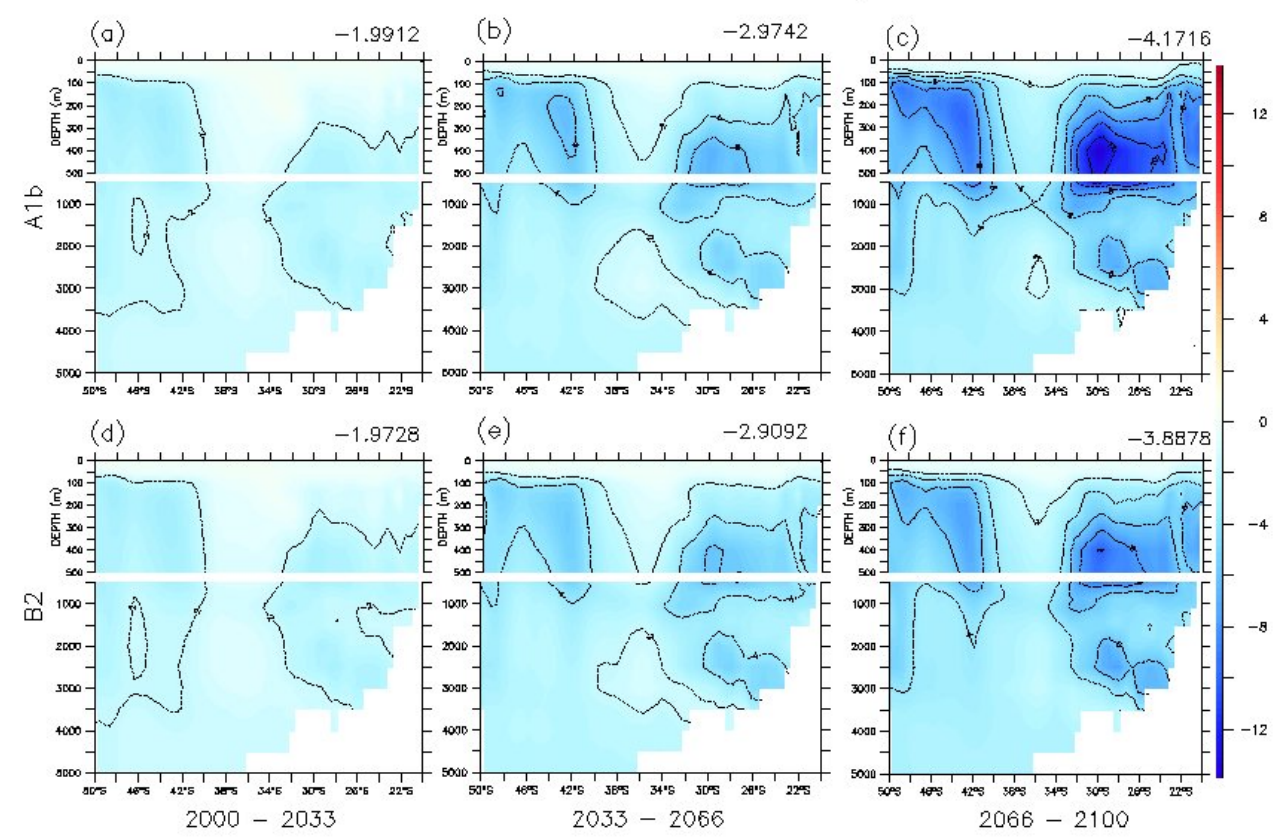

Figura 69: Seção latitudinal em $40^{\circ} \mathrm{W}$ de diferença de densidade $\left(\mathrm{kg} / \mathrm{m}^{3}\right)$ entre três períodos dos experimentos para o século XXI e a média do século XX- cenários A1b: (a), (b) e (c) e B2 (c), (d) e (e).

linas médias nos três períodos.

A partir dos diagramas de estado, foram encontrados os índices termohalinos da Tabela 20 .

A AT foi a massa d'água que mais foi alterada no período. Para o século XX, encontramos os índices dessa massa d'água de $17.7^{\circ} \mathrm{C}$ e 36 . Já no primeiro período, entre 2000 e 2033, observamos um aumento considerável, sobretudo de salinidade. A temperatura aumentou para 18.5 no cenário $\mathrm{A} 1 \mathrm{~b}$ e para $18^{\circ} \mathrm{C}$ no $\mathrm{B} 2$. No terceiro período, a temperatura estimada para o índice supera os $20^{\circ} \mathrm{C}$ no cenário $\mathrm{B} 2$ e a salinidade a 35.75 . As diferenças entre os cenários é grande para essa massa d'água, ao contrário da APAN.

A temperatura da AIA mostrou-se muito vulnerável nos experimentos do século XXI. A temperatura encontrada para a AIA, já apresentou sensível diferença no primeiro período, elevando-se de $4.3^{\circ} \mathrm{C}$ do século $\mathrm{XX}$ para $5^{\circ} \mathrm{C}$ nos dois cenários. No último período, esse índice subiu para $7^{\circ} \mathrm{C}$ no cenário $\mathrm{A} 1 \mathrm{~b}$ e para $6^{\circ} \mathrm{C}$ no $\mathrm{B} 2$. caracterizando a maior diferença de temperatura entre os cenários de aquecimento global (A1b e B2). Por se tratar de uma água intermediária, o aquecimento de quase $3{ }^{\circ} \mathrm{C}$ é bastante intenso. 

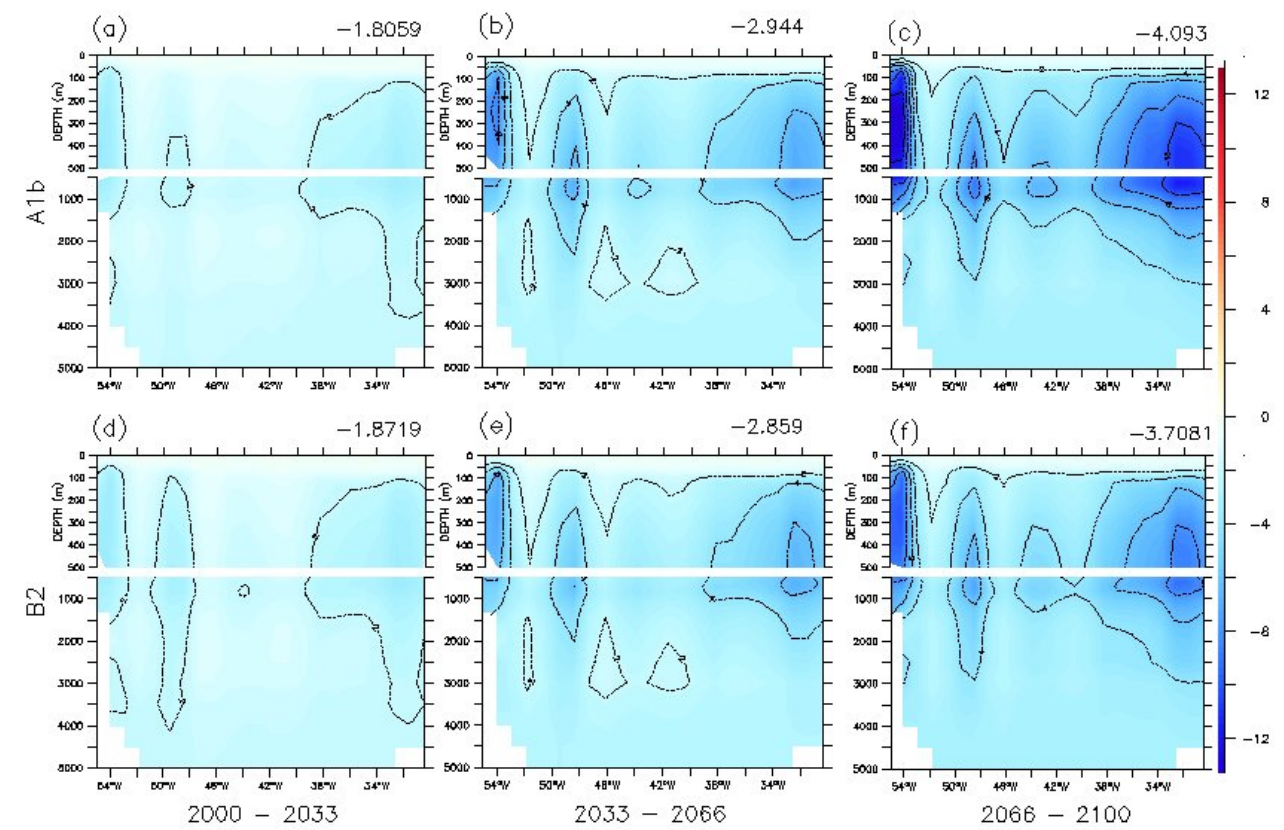

Figura 70: Seção longitudinal em $40^{\circ} \mathrm{S}$ de densidade $\left(\mathrm{kg} / \mathrm{m}^{3}\right)$ entre três períodos dos experimentos para o século XXI e a média do século XX-cenários A1b: (a), (b) e (c) e B2 (c), (d) e (e).

(a)

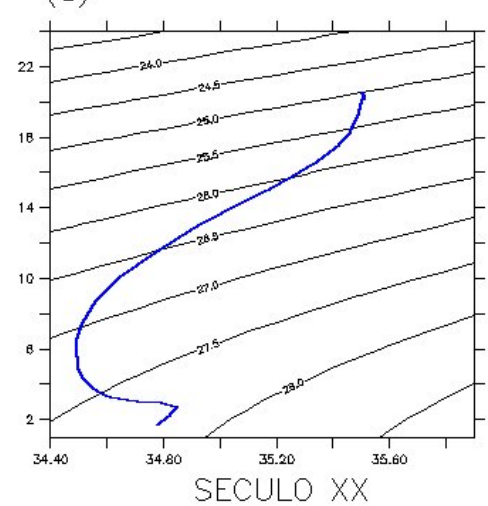

$2000-2033$ (b)

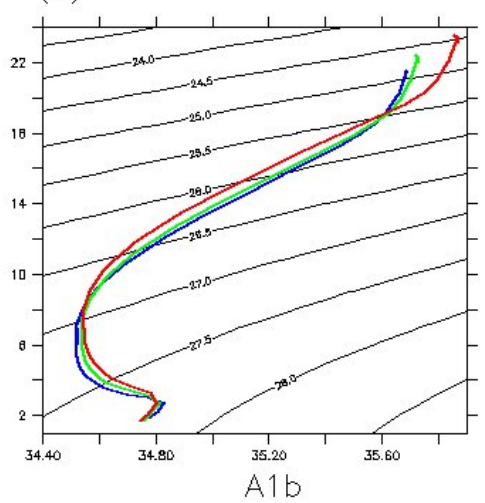

2033-2066 (c)

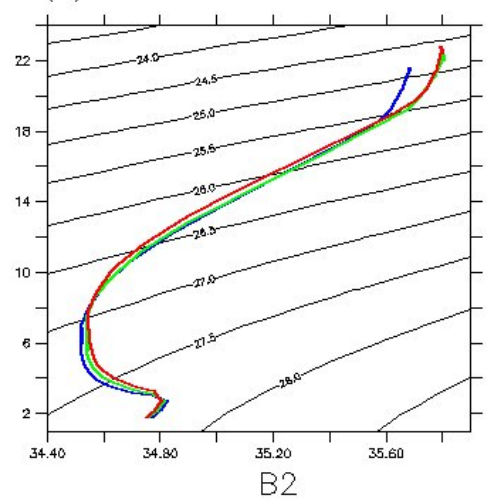

2066-2100

Figura 71: Diagramas de estado (médio) em $30^{\circ} \mathrm{S}, 40^{\circ} \mathrm{W}$ : (a) século XX, (b) cenários A1b e (c) B2. As linhas azuis representam o período entre 2000 e 2033, as verdes entre 2033 e 2066 e as vermelhas entre 2066 e 2100. 


\begin{tabular}{|c|c|c|c|c|c|c|c|}
\hline \multirow{5}{*}{ 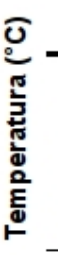 } & & \multicolumn{2}{|c|}{ AT } & \multicolumn{2}{|c|}{ AIA } & \multicolumn{2}{|c|}{ APAN } \\
\hline & & A1b & B2 & A1b & B2 & A1b & B2 \\
\hline & $2000-2033$ & 18.5 & 18 & 5 & 5 & 2.9 & 2.6 \\
\hline & 2033-2066 & 19.2 & 19.3 & 5.6 & 5.3 & 3 & 3 \\
\hline & $2066-2100$ & 20.1 & 19.8 & 7 & 6 & 3 & 3 \\
\hline & $2000-2033$ & 35.6 & 35.55 & 34.05 & 34.1 & 34.9 & 34.85 \\
\hline & 2033-2066 & 35.62 & 35.68 & 34.05 & 34.05 & 34.85 & 34.83 \\
\hline & $2066-2100$ & 35.75 & 35.7 & 34 & 34.05 & 34.82 & 34.85 \\
\hline
\end{tabular}

Tabela 20: Índices termohalinos de 3 massas d'águas em três períodos do século XXI segundo o MIROC.

\begin{tabular}{|c|c|c|c|c|c|c|c|c|c|}
\hline \multirow{3}{*}{ 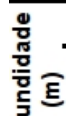 } & & \multicolumn{2}{|c|}{ AT } & \multicolumn{2}{|c|}{ AIA } & \multicolumn{2}{|c|}{ AT $\times$ AIA } & \multicolumn{2}{|c|}{ AIA $\times$ APAN } \\
\hline & & A1b & B2 & A1b & B2 & $\overline{\text { A1b }}$ & B2 & $\overline{A 1 b}$ & B2 \\
\hline & $2000-2033$ & 100 & 120 & 875 & 880 & 510 & 520 & 1311 & 1232 \\
\hline 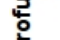 & 2033-2066 & 105 & 100 & 870 & 885 & 500 & 525 & 1400 & 1234 \\
\hline & 2066-2100 & 97 & 98 & 860 & 870 & 470 & 515 & 1157 & 1180 \\
\hline
\end{tabular}

Tabela 21: Profundidades $(\mathrm{m})$ dos núcleos e interfaces de 3 massas d'águas em três períodos do século XXI segundo o MIROC.

Por outro lado, a salinidade da AIA sofreu uma ligeira redução de salinidade no cenário A1b e manteve-se no cenário B2 (com exceção do período entre 2033 e 2066 onde ela reduziu). Esse leve adoçamento da AIA, bem como o intenso aumento de temperatura, pode estar relacionado com o derretimento de gelo na região de formação dessa massa d'água. A cobertura de gelo no oceano austral, segundo o experimento do MIROC, reduziu de 68.5\% para 63.9\% no cenário A1b e de 68.28 para 65.27 no B2.

Por outro lado, a APAN quase não sofreu alteração no seu índice termohalino, sobretudo na temperatura que chegou ao máximo de $3^{\circ} \mathrm{C}$ ante aos $2.8^{\circ} \mathrm{C}$ no século XXI. A salinidade oscilou e sofreu uma pequena redução. Essa massa d'água demonstrou menor sensibilidade possivelmente por estar muito longe de sua região de formação no Hemisfério Norte.

A profundidade das massas d'água também foi sutilmente alterada nos cenários de aquecimento, como demonstrado na Tabela 21.

Praticamente todos os núcleos e interfaces tornaram-se mais rasos nos cenários de aquecimento, sobretudo no A1b. As interfaces apresentam maiores diferenças, sendo que a a interface AIA x APAN deslocou-se quase 400 metros no último período. 


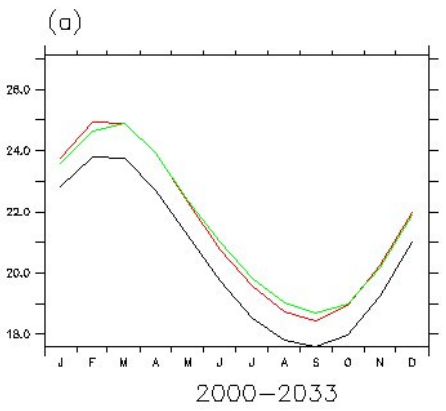

Século XX (b)

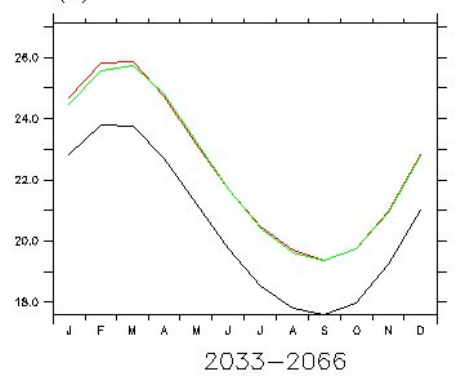

$\mathrm{A} 1 \mathrm{~b}$

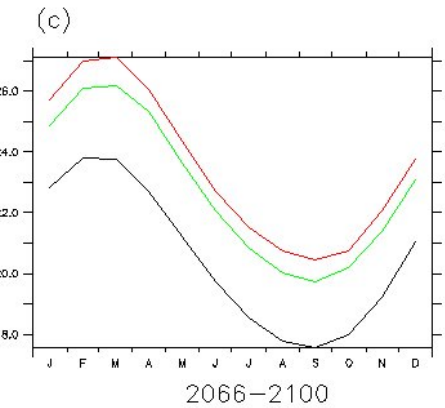

B2

Figura 72: Padrão climatológico de temperatura $\left({ }^{\circ} \mathrm{C}\right)$ em superfície em três períodos distintos (entre 2000 e 2033 (a), entre 2033 e 2066 (b) e e entre 2066 e 2100 (c)). Média do Século XX em preto, cenários A1b em vermelho e B2 em verde. Ponto $1-\left(40^{\circ} \mathrm{W}, 30^{\circ} \mathrm{S}\right)$.

\subsubsection{O padrão climatológico e os cenários climáticos}

Essa seção pretende discutir a evolução da variabilidade sazonal ao longo dos períodos em cada cenário de aquecimento global.

Embora a temperatura média do oceano aumente tanto no verão quanto no inverno nos dois cenários climáticos dos experimentos, o verão mostrou-se mais sensível a esse aumento. Em praticamente toda região, o aumento de TSM foi mais de $1^{\circ} \mathrm{C}$ maior no verão em relação ao inverno, com exceção do ponto próximo à posição da frente da CBM $\left(5^{\circ} \mathrm{W}, 38^{\circ} \mathrm{S}\right)$, onde a temperatura de inverno subiu mais de $8^{\circ} \mathrm{C}$ e a de verão $6^{\circ} \mathrm{C}$. Tal diferença relaciona-se com o deslocamento da frente da CBM para o sul. Dessa forma, não só a TSM média foi alterada, como também a amplitude do ciclo sazonal. A diferença entre a média de verão e inverno na região cresceu de $4.8^{\circ} \mathrm{C}$ no século XX para $5.4^{\circ} \mathrm{C}$ entre 2066 e 2100 no cenário A1b e para $5.3^{\circ} \mathrm{C}$ no B2 sendo o maior aumento da amplitude da temperatura na região da Confluência.

A Figura 72 mostra a climatologia anual em 3 profundidades em 3 períodos nos dois cenários e no século XX em $40^{\circ} \mathrm{W}, 30^{\circ} \mathrm{S}$ - domínio da Corrente do Brasil.

Em superfície, o maior aumento na média climatológica ocorre em março para o cenário A1b $\left(3.3^{\circ} \mathrm{C}\right)$ e em abril para o $\mathrm{B} 2\left(2.7^{\circ} \mathrm{C}\right)$. A amplitude do ciclo anual aumentou aproximadamente $0.002^{\circ} \mathrm{C} /$ ano nos dois cenários.

No Ponto $2\left(55^{\circ} \mathrm{W}, 45^{\circ} \mathrm{S}\right)$, a amplitude da temperatura de superfície foi reduzida nos 


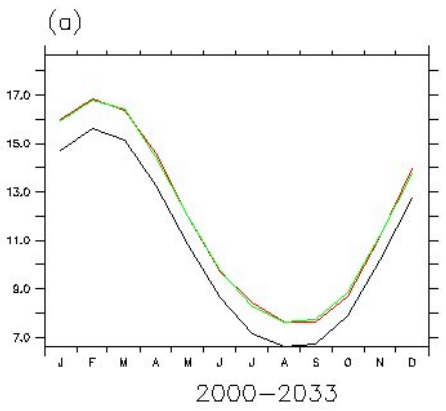

Século XX (b)

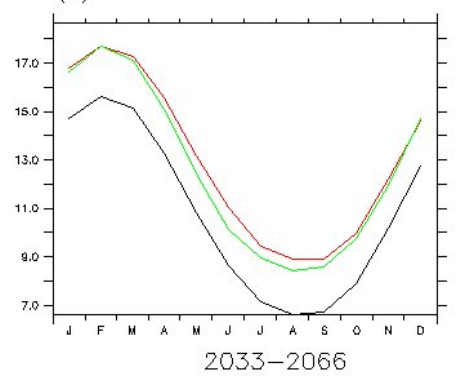

$\mathrm{A} 1 \mathrm{~b}$ (c)

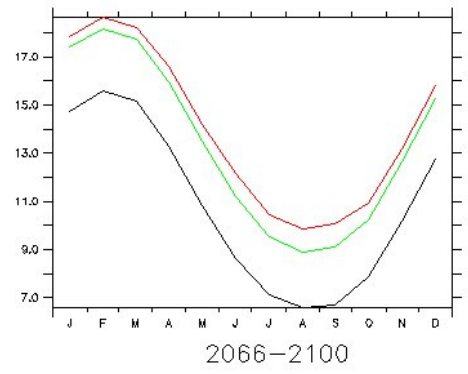

B2

Figura 73: Padrão climatológico de temperatura $\left({ }^{\circ} \mathrm{C}\right)$ em superfície em três períodos distintos (entre 2000 e 2033 (a), entre 2033 e 2066 (b) e e entre 2066 e 2100 (c)). Média do Século XX em preto, cenários A1b em vermelho e B2 em verde. Ponto 2 - $\left(55^{\circ} \mathrm{W}, 45^{\circ} \mathrm{S}\right)$.

dois cenários aproximadamente $0.01^{\circ} \mathrm{C} /$ ano (Figura 73). O inverno apresentou uma taxa de aumento 15\% maior do que no verão, no caso do cenário A1b. O mês de maior aumento de temperatura média no último período foi agosto no caso do A1b e maio no caso do B2.

Observamos na Figura 73 que durante o período entre 2033 e 2066 a média da TSM de verão era maior no cenário B2 do que no cenário A1b.

Por não obedecer uma climatologia bem definida, o padrão anual de salinidade é mais complicado de ser analisado. Observamos que a padrão anual é intensamente alterado em todas as profundidades. Na superfície, em quase toda a região, o inverno sofre maior aumento da salinidade do que o verão. A amplitude do ciclo sazonal permanece semelhante em todos os períodos, apesar da padrão anual ser alterado. A salinidade de superfície altera seu padrão de forma complexa.

A Figura 75 representa a diferença média entre verão e inverno na região no século XX e em 3 períodos dos cenários A1b e B2. Podemos observar que ambas, basicamente, o domínio da corrente do Brasil sofreu um aumento do ciclo sazonal ou um leve decréscimo. No setor mais austral, onde a amplitude era negativa (verão menos salino que inverno), a salinidade torna-se ainda mais negativa. Assim, de forma geral, a amplitude do ciclo anual tende a aumentar em toda a região. Na Figura 75, observamos as alterações do ciclo anual nos três períodos dos cenários A1b e B2 no ponto $1\left(40^{\circ} \mathrm{W}, 30^{\circ} \mathrm{S}\right)$.

O ciclo anual de superfície foi pouco alterado. A maior média de manteve-se em abril, 
apesar de maior. No ponto $2\left(55^{\circ} \mathrm{W}, 45^{\circ} \mathrm{S}\right)$ o padrão anual de salinidade foi intensamente alterado (Figura 76). O claro padrão de superfície de maior salinidade na primavera e um mínimo no outono, não é percebido em nenhum dos dois cenários. Essa alteração pode estar relacionada com o aumento da tensão de cisalhamento do vento que aumenta nas altas latitudes e com o derretimento de gelo antártico.

A climatologia da tensão de cisalhamento do vento foi marcada por uma redução da média de inverno mais acentuada no ponto 1 e em regiões até os $40^{\circ} \mathrm{S}$ e um aumento nas regiões de altas latitudes.

Observamos, na Figura 77 as alterações do ciclo anual médio ao longo dos cenários A1b e B2 da posição da frente da CBM e dos transportes da Corrente do Brasil e das Malvinas. A média climatológica do século XX, demonstra uma tendência clara da CBM, e um deslocamento máximo para o norte em julho e agosto chegando a latitude mínima de $39.2^{\circ} \mathrm{S}$. Durante o mês de março, a $\mathrm{CBM}$ desloca-se para $40.2^{\circ} \mathrm{S}$. Esse padrão, já é bem alterado nos primeiros 33 anos de experimento do MIROC, para ambos os cenários. A amplitude de variação dessa frente é reduzida de 1 para $0.6^{\circ}$ de latitude no cenário A1b e para $0.4^{\circ}$ no B2. Entre 2066 e 2100. observamos que o mês de menor latitude da posição média agora é setembro no cenário A1b e outubro no B2. A amplitude da posição reduz-se a $0.5^{\circ}$ de latitude no cenário $\mathrm{B} 2$ e $0.4^{\circ}$ no $\mathrm{A} 1 \mathrm{~b}$.

A climatologia da posição da CBM foi completamente alterada, bem como a do transporte da Corrente das Malvinas. Embora a média dessa corrente tenha sofrido pouca alteração, observamos que o padrão anual foi completamente desfeito. Por outro lado, a Corrente do Brasil, embora tenha alterado a média em mais de $30 \%$ nos dois cenários, manteve um ciclo sazonal semelhante. Entre 2000 e 2033. notamos pouca diferença entre a climatologia do transporte da corrente do Brasil nos cenários e no século XX. A diferença média foi de aproximadamente 0.6Sv nos dois cenários. Já no período 2066-2100. essa média aumenta para 4Sv no cenário A1b e 3Sv no B2. Os mês de transporte máximo (fevereiro) foi mantido nos cenários, porém o de mínimo (julho no século XX) não se manteve sendo no cenário A1b, sendo precedido por maio (14.3Sv).

O deslocamento para on Sul da CBM, possivelmente relaciona-se mais com aumento da Corrente do Brasil, já que a corrente das Malvinas também aumentou, embora em menor intensidade. 
(b)

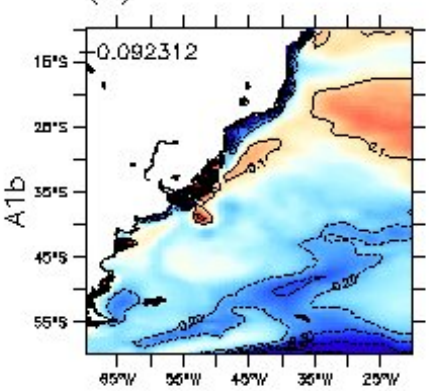

(e)

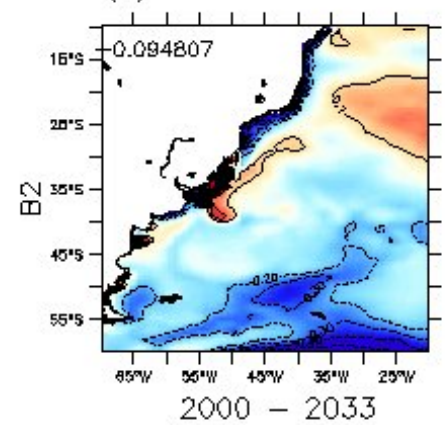

(a)

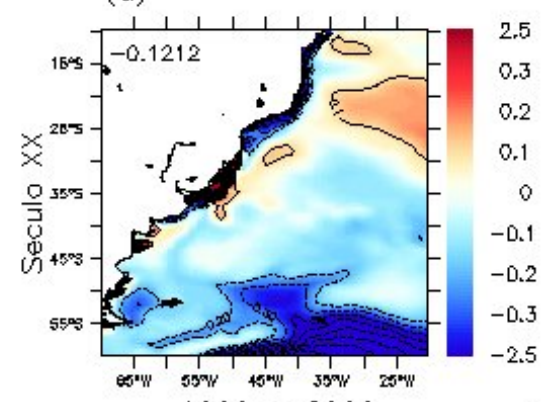

(c)

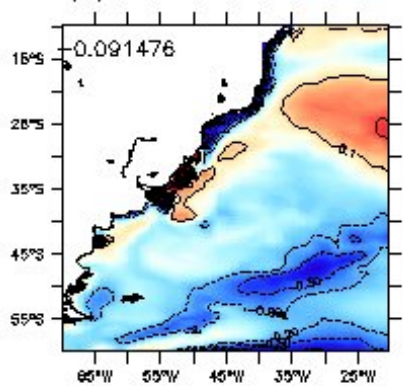

$(\mathrm{f})$

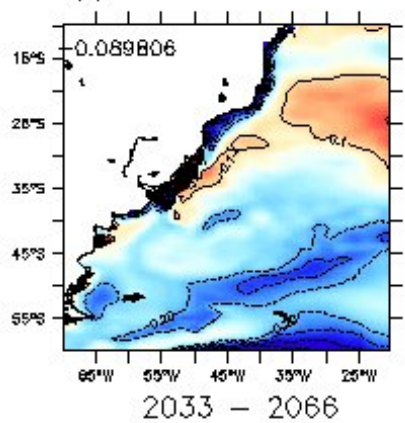

(d)

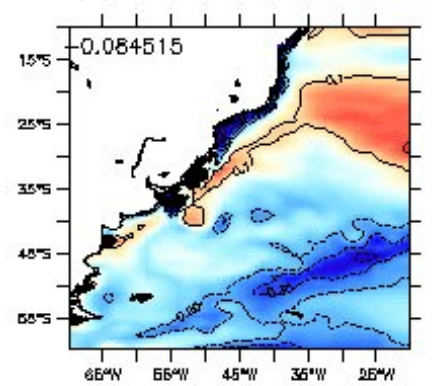

(g)

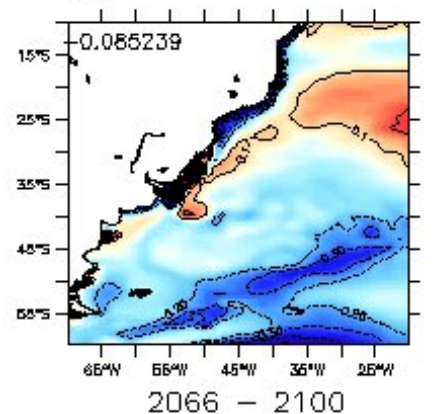

Figura 74: Diferença entre a média de salinidade em superfície de janeiro e julho: (a) século XX, (b) entre 2000 e 2033. (c) entre 2033 e 2066, (d) entre 2066 e 2100 no cenário A1b e (e) entre 2000 e 2033. (f) entre 2033 e 2066, (g) entre 2066 e 2100 no cenário B2. 
(a)

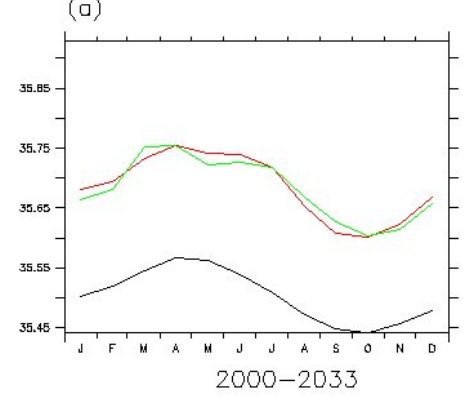

(b)

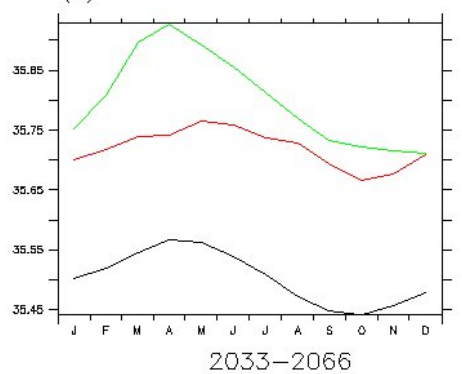

$\mathrm{A} 1 \mathrm{~b}$

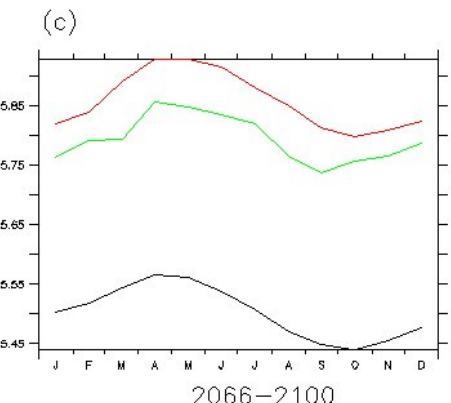

B2

Figura 75: Padrão climatológico de salinidade $\left({ }^{\circ} \mathrm{C}\right)$ em superfície em três períodos distintos (entre 2000 e 2033 (a), entre 2033 e 2066 (b) e e entre 2066 e 2100 (c)). Média do Século XX em preto, cenários A1b em vermelho e B2 em verde. Ponto $1-\left(40^{\circ} \mathrm{W}, 30^{\circ} \mathrm{S}\right)$.

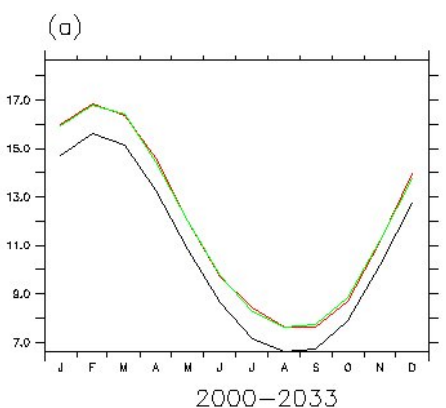

Século XX

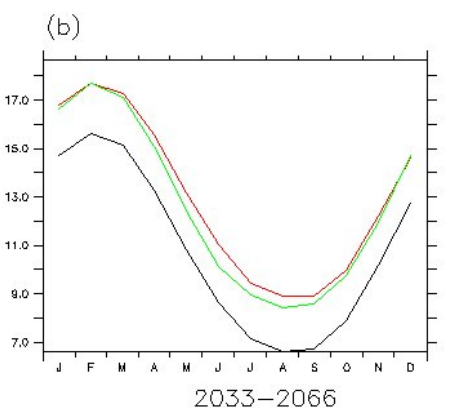

$\mathrm{A} 1 \mathrm{~b}$

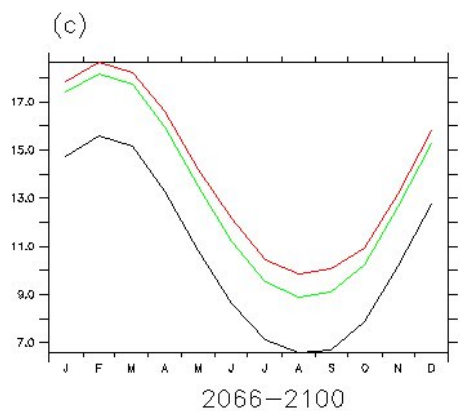

B2

Figura 76: Padrão climatológico de salinidade $\left({ }^{\circ} \mathrm{C}\right)$ em superfície em três períodos distintos (entre 2000 e 2033 (a), entre 2033 e 2066 (b) e e entre 2066 e 2100 (c)). Média do Século XX em preto, cenários A1b em vermelho e B2 em verde. Ponto $2-\left(55^{\circ} \mathrm{W}, 45^{\circ} \mathrm{S}\right)$. 
(a)

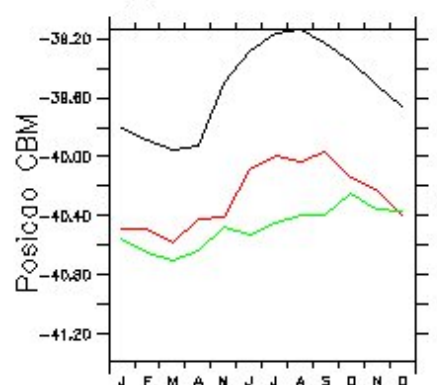

(d)

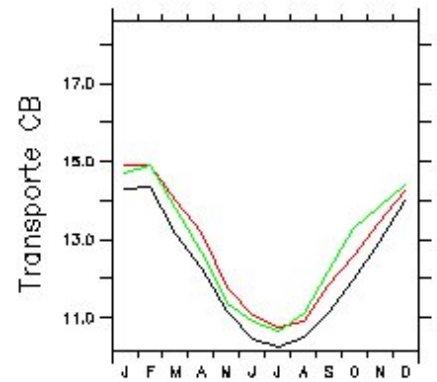

(g)

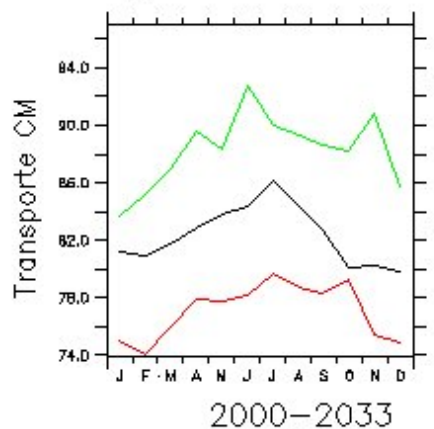

2000-2033 (b)

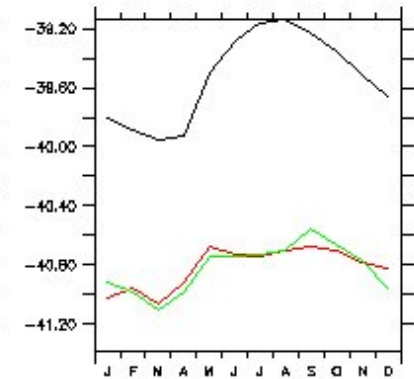

(e)

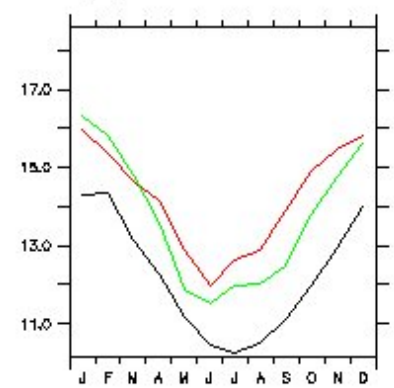

(h)

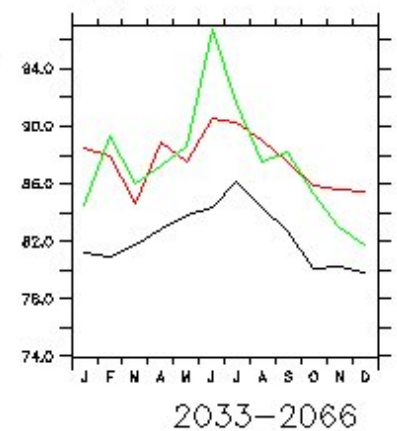

A1b (c)

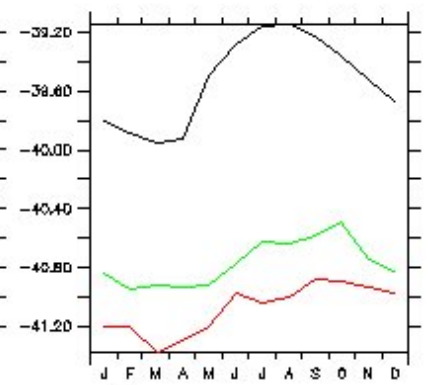

(f)

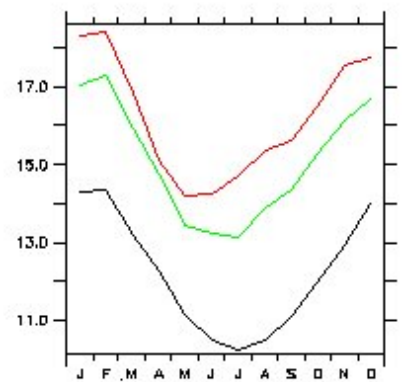

(i)

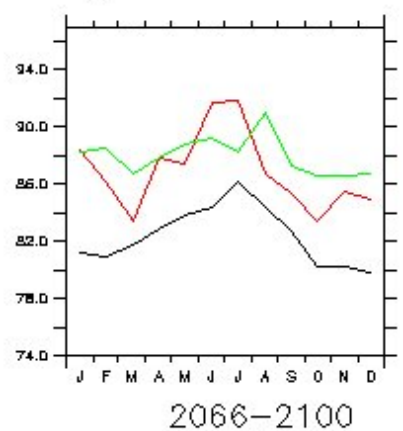

Século XX

Figura 77: Padrão climatológico da posição da frente da Confluência Brasil-Malvinas em - de latitude (a, b e c), do módulo do transporte da Corrente do Brasil (d, e e f) e da Corrente das Malvinas (g, h e i) em Sv, durante três períodos distintos (entre 2000 e 2033. entre 2033 e 2066 e entre 2066 e 2100). A linha preta refere-se à média de todo o Século XX em todos os gráficos, a vermelha ao cenário A1b e a verde ao B2. 


\subsubsection{Os cenários climáticos e as tendências}

Na Figura 78 observamos a tendência positiva de temperatura em todas as profundidades observadas, sobretudo entre 35 e $45^{\circ} \mathrm{S}$, região que abriga a Confluência Brasil-Malvinas. Nessa região a tendência de TSM chega a $0.03^{\circ} \mathrm{C} /$ ano entre 2000 e 2100 no cenário A1b e a $0.02^{\circ} \mathrm{C} /$ ano no $\mathrm{B} 2$. A diferença entre os cenários é grande, sendo a média da tendência do cenário A1b (0.028) 56\% maior que no cenário B2 (0.018). Novamente observamos que as baixas latitudes são mais sensíveis a essas alterações que as altas latitudes. A média da tendência entre 5 e $30^{\circ}$ no cenário $\mathrm{A} 1 \mathrm{~b}$ é de $0.027^{\circ} \mathrm{C} /$ ano enquanto que acima dos $50^{\circ} \mathrm{S}$ essa média cai para $0.018^{\circ} \mathrm{C} /$ ano. Novamente, a região da $\mathrm{CBM}$ mostrou-se a mais sensível do Atlântico Sudoeste em todas as profundidades.

Nas demais profundidades, a diferença entre os cenários é notavelmente menor, mas as tendências de temperatura ainda se concentram na região que comporta a Confluência Brasil-Malvinas. Em 1000m de profundidade, a tendência de aquecimento da região é somente 19\% maior no cenário A1b em relação ao B2 e 18\% em 1700m. A tendência até os $30^{\circ} \mathrm{S}$ manteve-se entre 0.005 e $0.012^{\circ} \mathrm{C}$ /ano enquanto que em altas latitudes chegou a próxima de zero. Tais tendências indicam uma maior vulnerabilidade da AIA recirculada em relação àquela transportada diretamente de altas latitudes.

Em $1700 \mathrm{~m}$, não obtemos tendências superiores a $0.01^{\circ} \mathrm{C} /$ ano e com exceção da região da $\mathrm{CBM}$, manteve-se abaixo dos $0.004^{\circ} \mathrm{C} /$ ano. Essa profundidade apresentou o menor contraste entre as tendências de baixa e alta latitude.

As tendências de salinidade estão representadas na Figura 79, O claro contraste entre as tendências de salinidade de superfície ao norte e ao sul da CBM fica claro nos mapas (a) e (b). Enquanto as águas mais doces do sul sofrem com a redução da salinidade de até $0.006 \mathrm{ano}^{-1}$ no cenário A1b e 0.004 ano $^{-1}$ no cenário B2, as águas carregadas pela corrente do Brasil aumenta sua salinidade em taxas semelhantes. A região da CBM tende, assim, a aumentar seus fortes gradientes termohalinos tornado sua dinâmica ainda mais complexa. O aumento da incidência de eventos de meso-escala, como instabilidades baroclínica e ondas de Rossby, é um possível efeito disso (Polito \& Sato 2008).

Em 1000m a tendência de temperatura é mais complexa. Possivelmente por conta da mudança de profundidade das massas d'água, observamos uma faixa de tendência negativa de salinidade ao sul da CBM que prevalece até os 1700 metros. Nessa profundidade, quase todo o setor ao sul da CBM é dominado pelo decréscimo da salinidade, mesmo 
(a)

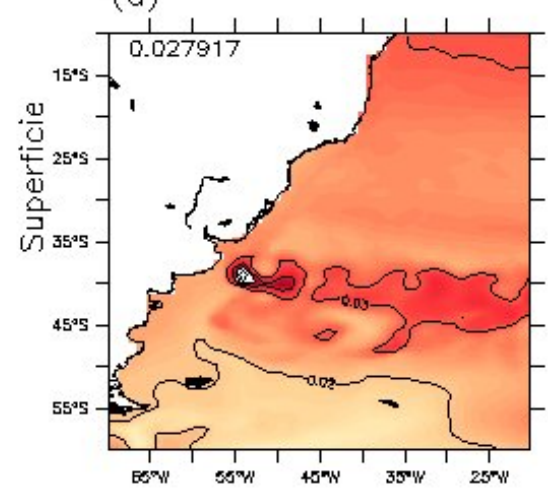

(c)

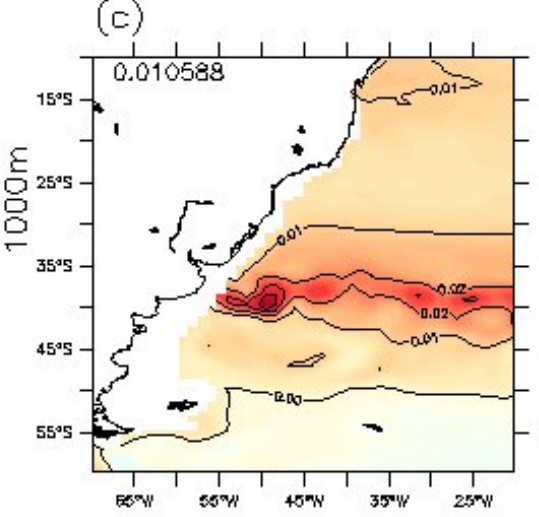

(e) (b)

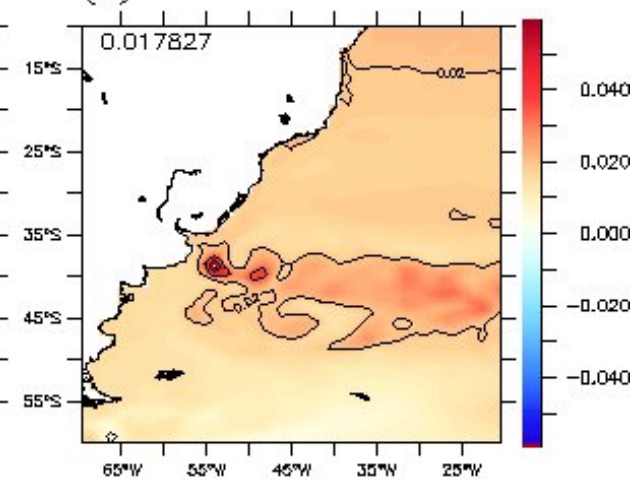

(d)

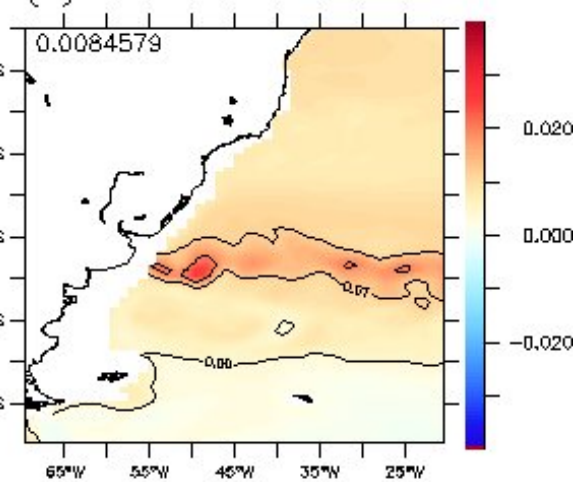

(f)
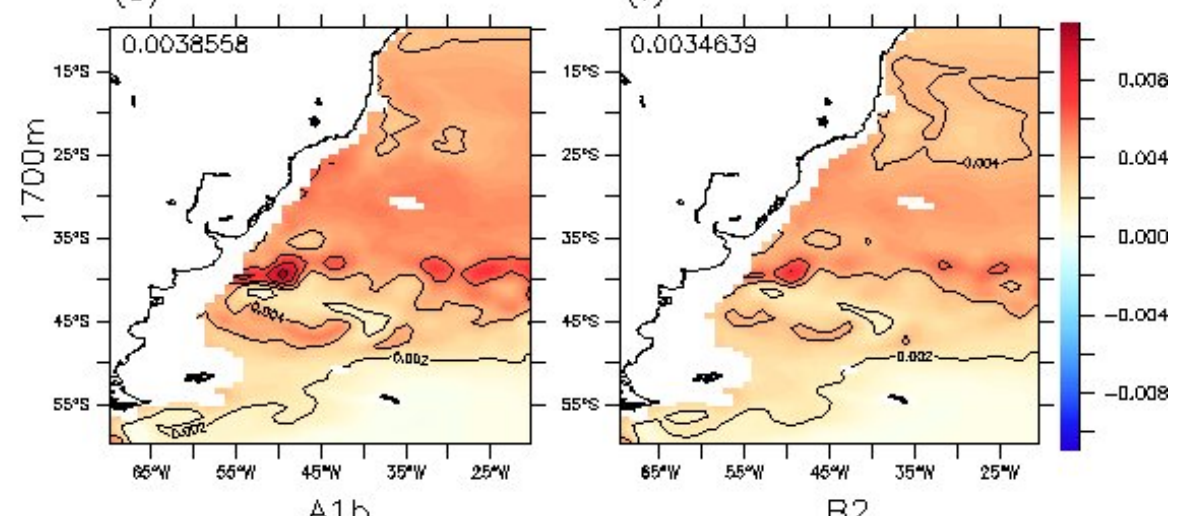

B2

Figura 78: Tendência de temperatura $\left({ }^{\circ} \mathrm{C} /\right.$ ano $)$ entre 2000 e 2100 nos cenários climáticos A1b (a- superfície, c- em 1000m e e- em 1700) e B2 (b- superfície, d- em 1000m e f- em 1700). 
(a)

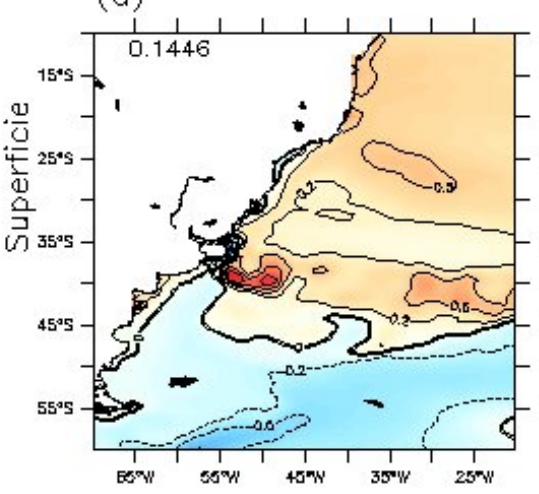

(c) (b)

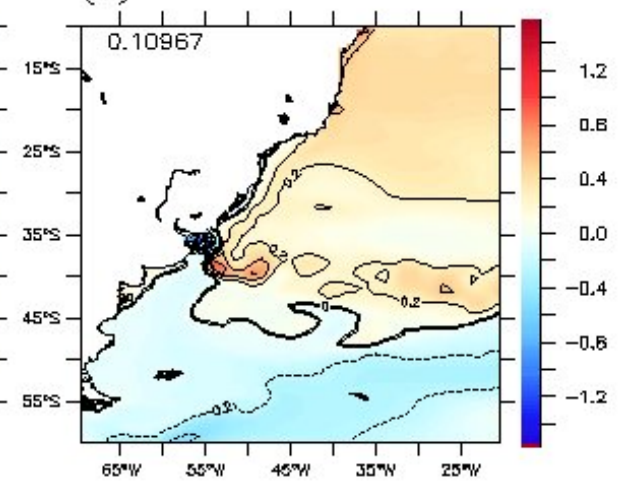

(d)

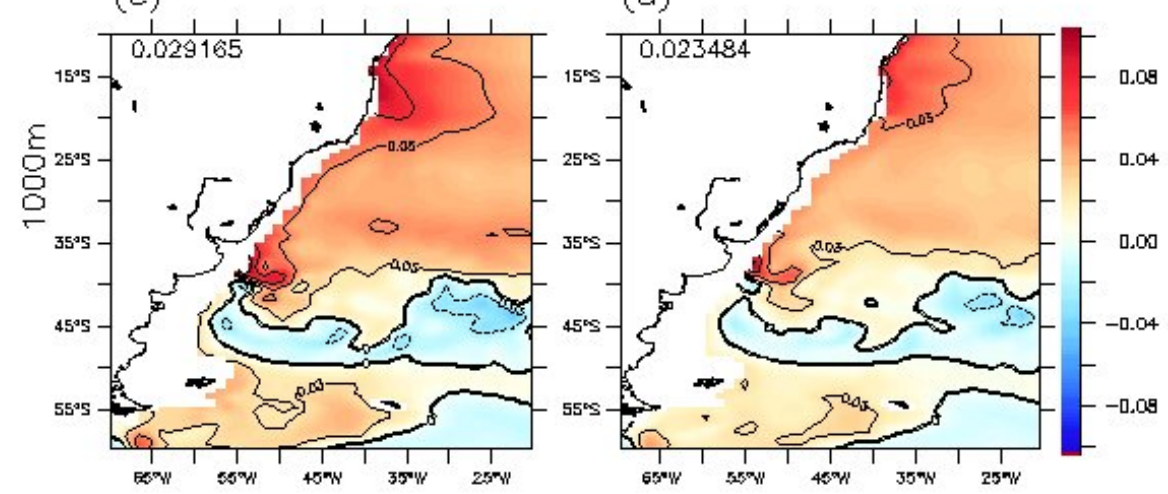

(e)

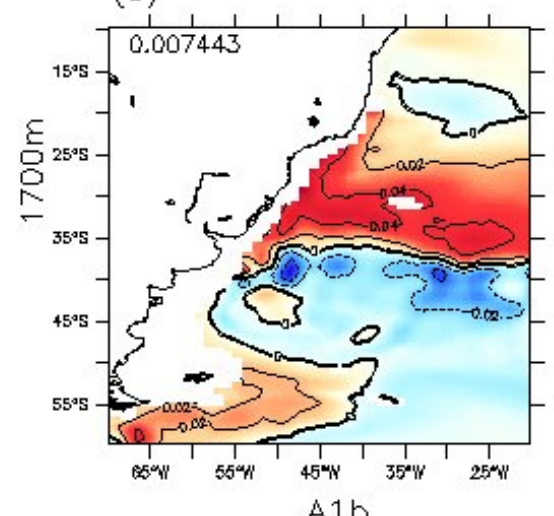

(f)

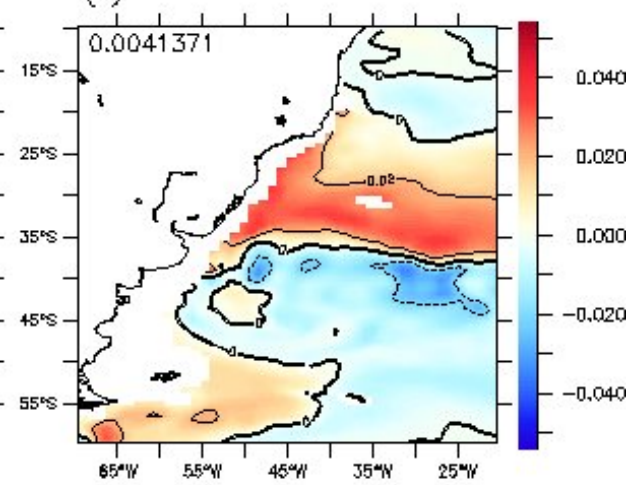

B2

Figura 79: Tendência de salinidade $\left(10^{-2} \mathrm{ano}^{-1}\right)$ entre 2000 e 2100 nos cenários climáticos A1b (a- superfície, c- em 1000m e e- em 1700) e B2 (b- superfície, d- em 1000m e f- em 1700). 


\begin{tabular}{cccc}
\hline & Posição da CBM (\%)ano) & Transporte da CB (Sv/ano) & Transporte da CM (Sv/ano) \\
\hline A1b & -0.0125 & 0.0520 & -0.0350 \\
B2 & -0.0055 & 0.0320 & -0.0116 \\
SéculoXX & -0.0010 & 0.0028 & -0.0710 \\
\hline
\end{tabular}

Tabela 22: Tendências da Posição da CBM (\%/ano) e dos transportes da CB e da CM $(\mathrm{Sv} / \mathrm{ano})$.

que sutil (não ultrapassa $0.00025 \mathrm{ano}^{-1}$ ) em quase toda a região, enquanto que entre 25 e $35^{\circ} \mathrm{S}$ observamos a maior tendência positiva nessa profundidade. A diferença entre as tendências de salinidade em 1000 e 1700m é bem mais marcante que entre as de temperatura.

A Tabela 22 apresenta as tendências de deslocamento da posição da CBM, bem como de transporte da Corrente das Malvinas e do Brasil.

A taxa de $0.0125^{\circ}$ de latitude por ano (aproximadamente 1,4km/ano) do cenário A1b, supera em mais de 10 vezes a encontrada no século XX e em duas vezes a do cenário B2 de $-0.0055^{\circ}$ /ano (612 m/ano). O aumento da corrente do Brasil no cenário A1b é mais de $60 \%$ maior que no B2, enquanto que o encontrado no século XX é quase nulo. Por outro lado, a tendência do transporte da Corrente das Malvinas é o dobro no século XX em relação ao cenário A1b e 6 vezes maior em relação ao cenário B2. A tendência anual é praticamente nula se considerada o total de mais de 80Sv transportados por essa corrente. Possivelmente o rápido deslocamento da posição média da CBM está mais associado ao aumento do transporte da Corrente do Brasil. 


\begin{tabular}{crc}
\hline & Corrente do Brasil & Corrente das Malvinas \\
\hline A1b & $-39 \%$ & $11 \%$ \\
B2 & $-36 \%$ & $12 \%$ \\
Século XX & $-29 \%$ & $18 \%$ \\
\hline
\end{tabular}

Tabela 23: Correlação entre a posição da CBM, o transporte da CB e da CM.

\subsubsection{A Corrente do Brasil e a Posição da Confluência Brasil Malvinas}

A Corrente do Brasil, mostrou-se estar mais relacionada ao deslocamento da frente da CBM. A Tabela 23 lista as correlações entre a posição da CBM e os transportes das correntes em cada cenário.

Observamos que a correlação entre a posição da CBM e o transporte da CB cresce nos cenários do século XXI. Por outro lado, a correlação com o transporte da CM reduz em ambos os cenários. A grande semelhança entre o transporte da CM e a posição da CBM pode ser vista na Figura 77, o que não ocorre nos cenários A1b e B2. O sinal negativo das correlações com a CB, deve-se ao fato de que quando o transporte dessa corrente aumenta, a latitude (negativa) da CBM aumenta.

Além disso, observamos que o espectro da corrente do Brasil é bem mais semelhante ao da posição da CBM que o da corrente das Malvinas. A posição da CBM no experimento do século XX, demonstrou um forte sinal sazonal como descrito na literatura. Um sinal intra anual de alta frequência, embora ameno também é observado - Figura 80.

No espectro global, o maior pico de variabilidade, encontra-se no período de 4 anos, sobretudo nas últimas décadas. Observamos um pico de energia associada à década de 1980. A variabilidade semi-anual também é significativa no espectro global. Os padrões espectrais referentes à posição da CBM na Figura 80 descritos, também são encontrados na Figura 81. Além disso, observamos que as incidências de eventos estatisticamente significantes nos dois casos são bastante coincidentes.

A Corrente das Malvinas possui um padrão bem diferente. O ciclo sazonal é bem mais sutil, embora ainda marcado, e a variabilidade prevalece sobre todos os períodos do espectro, sobretudo em 2 e 6 anos - Figura 82. Embora o padrão anual dessa corrente seja bem marcado, a grande variabilidade intra anual dificulta sua identificação. Embora o ciclo anual, seja o único estatisticamente significativo, encontramos picos ainda maiores de variabilidade associados aos 2 e 6 anos, mais intenso em meados da década de 50. Esse 

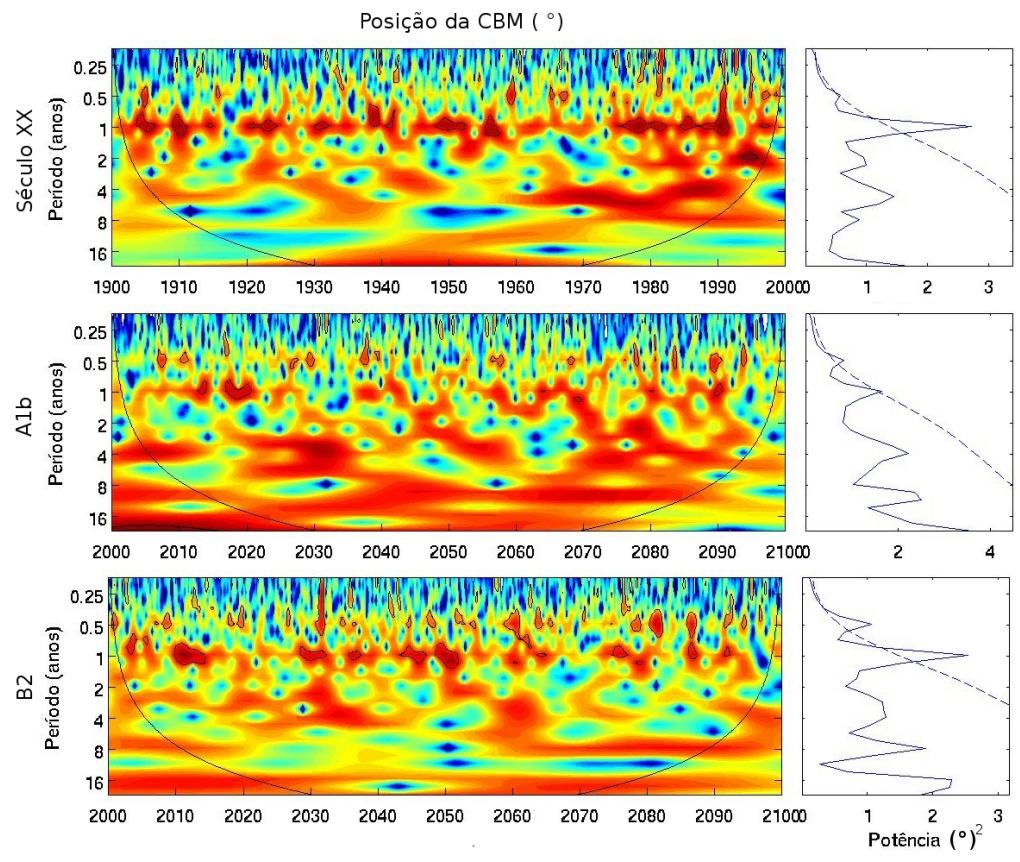

Figura 80: Espectro de Potência de Ondaletas da posição da CBM $\left({ }^{\circ 2}\right)$ : (a) Século XX, (b) Cenário A1b e (c) Cenário B2.
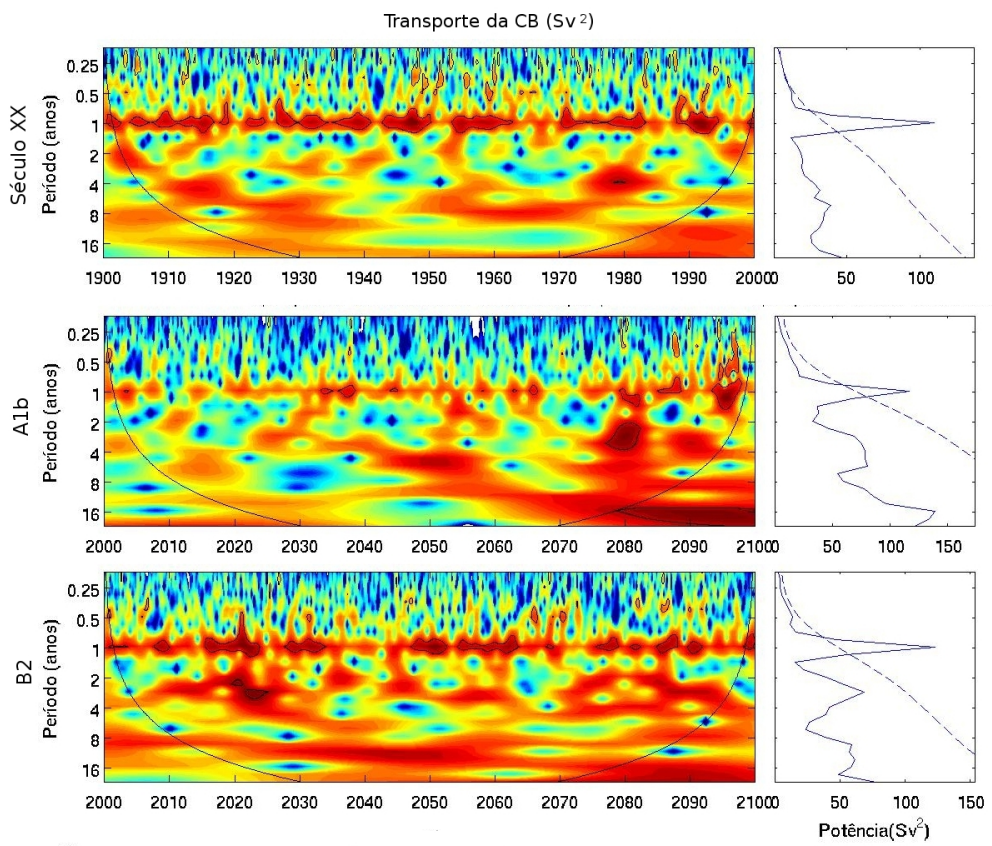

Figura 81: Espectro de Potência de Ondaletas do transporte da $\mathrm{CB}\left(\mathrm{Sv}^{2}\right)$ : (a) Século XX, (b) Cenário A1b e (c) Cenário B2. 


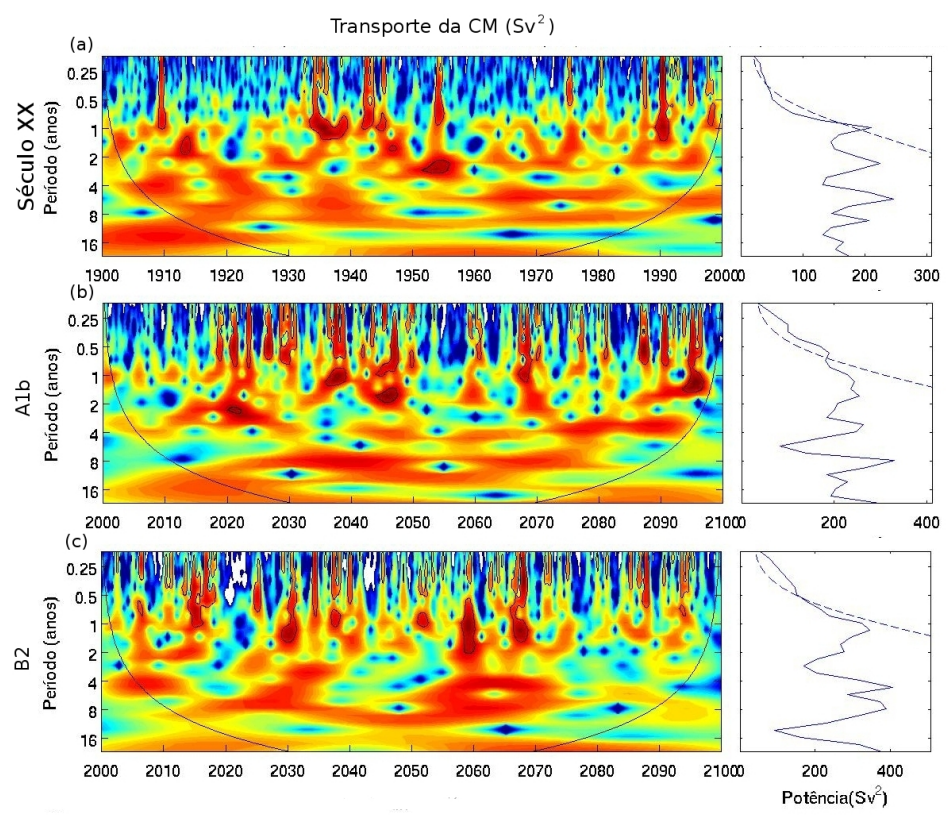

Figura 82: Espectro de Potência de Ondaletas do transporte da CM $\left(\mathrm{Sv}^{2}\right)$ : (a) Século XX, (b) Cenário A1b e (c) Cenário B2.

pico não apareceu nem no espectro de Potência da Posição da CBM, nem no do transporte da CB.

Dessa forma, enquanto a CB e a posição da CBM possuem grande parte da energia do espectro concentrados no ciclo anual, a CM está sujeita a grande variabilidade interanual, responsável por mais de $60 \%$ da energia do espectro. É notável a semelhança entre o espectro da CB e da posição da CBM no século XX, porém nos cenários de mudanças climáticas A1b e B2, os padrões dessa variáveis são fortemente alterados.

Nos cenários A1b e B2 (sobretudo no A1b), observamos que a energia do espectro da posição da CBM e do transporte da CB, basicamente concentrada no ciclo anual, é dissipada em variabilidades inter e intranual. Embora a variância média aumente, o espectro global não atinge máximos tão claros nos cenários do século XXI.

No cenário A1b, o ciclo anual que no século XX era de quase $3^{\circ 2}$, é reduzido para menos 2, aumentando a intra anual do ciclo semi-anual e das variabilidades inter anuais (Figura 80). Nesse cenário, há maior número de ocorrências extremos na variabilidade semianual do que na anual. De forma geral, a análise espectral desse período não demonstrou nenhum período de variabilidade claramente dominante e menor variância média $\left(0.63^{\circ 2}\right)$ em relação ao século XX $\left(0.74^{\circ 2}\right)$, apesar da variância da CB e da CM terem aumentado. 
Nota-se a presença de uma grande energia concentrada no período de 8 anos não observada no século XX, sobretudo no último período da série.

Embora também atenuado no cenário A1b, o ciclo anual da CB permanece o mais importante. Os eventos mais notáveis associados a essa variabilidade ocorrem nas duas últimas décadas. Observamos nos padrões espectrais de diversas variáveis (incluindo) o aumento da variabilidade associada aos 4 anos, possivelmente por conta da intensificação do El Niño.

A CM mostra um padrão espectral ainda mais difuso no cenário A1b. A variabilidade anual torna-se ainda menos clara e as fenômenos de potências estatisticamente relevantes estão dispersos e associados a fenômenos de alta frequência (até 2 anos). A redução da periodicidade bem marcada dessas duas correntes, pode ser a responsável pela redução da variabilidade da posição da CBM, apesar do aumento da variância de seus transportes.

O cenário B2 é caracterizado pelo mesmo fenômeno de difusão da energia espectral a partir do ciclo anual para maiores e menores frequências. A posição da CBM continua com um forte sinal anual e o sinal semi-anual ganha importância. Por outro lado, a energia associada a maiores períodos aumenta, embora não concentrada em nenhuma frequência específica.

O ciclo anual da CB foi intensificado, bem como a variabilidade inter anual. A variância nesse período foi quase o dobro do que no século XX. Ao contrário do que houve no cenário A1b, no cenário B2 os eventos mais extremos estaticamente significantes ocorreram no início do período e não no final.

A análise espectral da CM nesse período também foi bem difuso, apresentando variabilidade em todas as frequências sem destacar-se nenhuma específica.

Na Figura 83 observamos a análise de coerência de ondaletas entre a posição da CBM e o transporte da CB. Observamos grande correlação espectral na variabilidade anual. Nessa faixa do espectro, a correlação supera 0.8 em quase todo o período e a fase reduz sutilmente ao longo do tempo. No começo da série temporal, a defasagem era de aproximadamente $200^{\circ}$ ( 7 meses) e no final de $180^{\circ}$ (6 meses). Por um lado, essa coerência entre a defasagem aponta para as relações físicas importantes entre as duas séries temporais, mas a mudança entre a fase das séries pode significar uma alteração na forma de interação entre elas. Também observamos regiões de forte correlação nos períodos de 0.5 e 2 anos.

Nos cenários A1b e B2, a correlação entre a periodicidade das séries torna-se ainda 
(a)

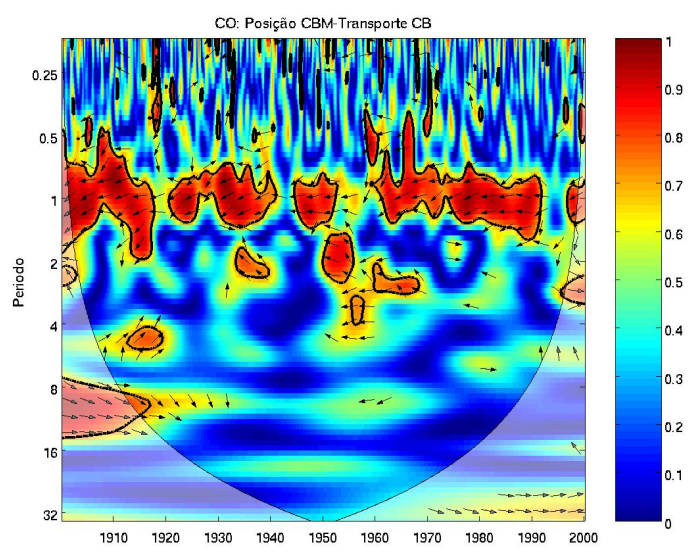

(b)

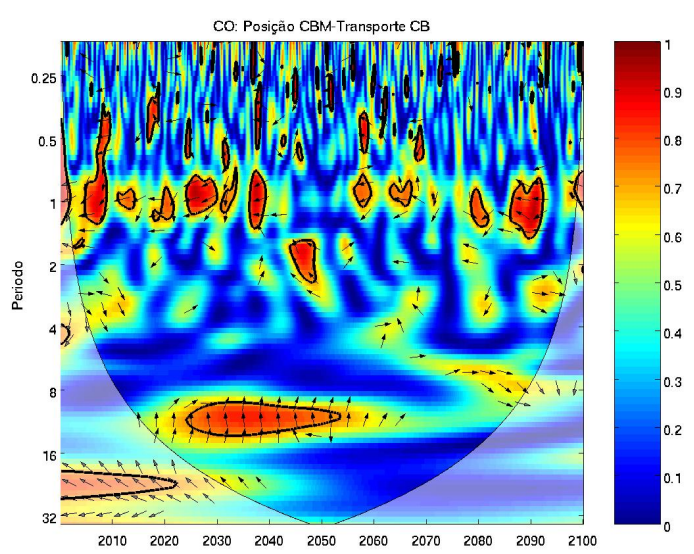

(c)

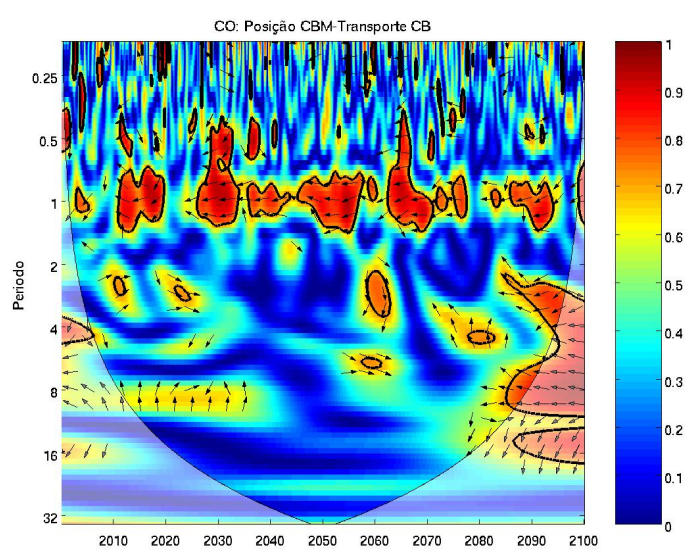

Figura 83: Coerência de ondaletas cruzadas entre a posição da CBM e o transporte da CB: (a) Século XX, (b) A1b e (c) B2. 
menor. No cenário A1b, a coerência das séries em 1 ano reduz-se principalmente aos primeiros 40 anos de série. Por outro lado, existe uma região de periodicidade de correlação maior do que 0.8 por volta dos 9 anos de fase constante $\left(90^{\circ}\right)$.

Essa alta correlação nesse período não ocorre no cenário B2. As correlações nesse cenários assemelham-se muito das encontradas no século XX. A correlação no ciclo sazonal é reduzida, mas ainda prevalece nesse caso mantendo as fases do período anterior. Em 2 anos, a correlação forte apresentada no século XX praticamente desaparece.

Por outro lado, observamos que o ciclo sazonal da posição da CBM está bem menos correlacionado com a Corrente das Malvinas (Figura 84). Existe uma forte correlação entre a variabilidade de alta frequência da posição da CBM e do transporte da CM que diminui nos dois cenários. A baixa correlação em maior parte da região no século XX é ainda menor nos dois cenários de aquecimento. O padrão espectral da CBM está correlacionado com o padrão da CM, sobretudo nos cenários do século XXI. 
(a)

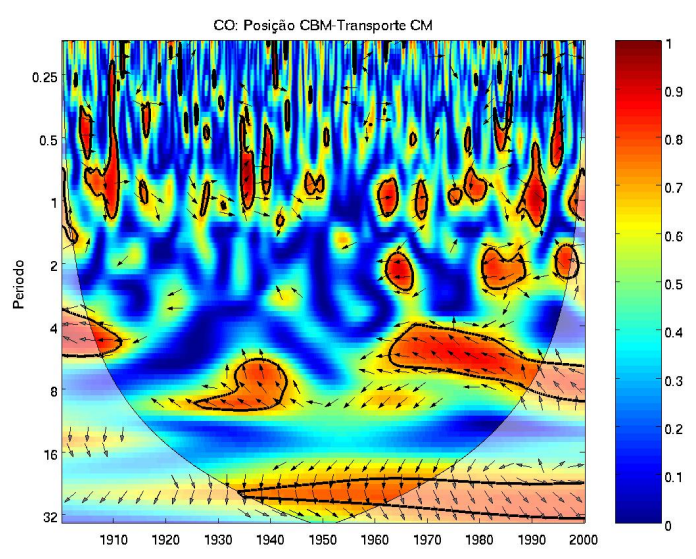

(b)

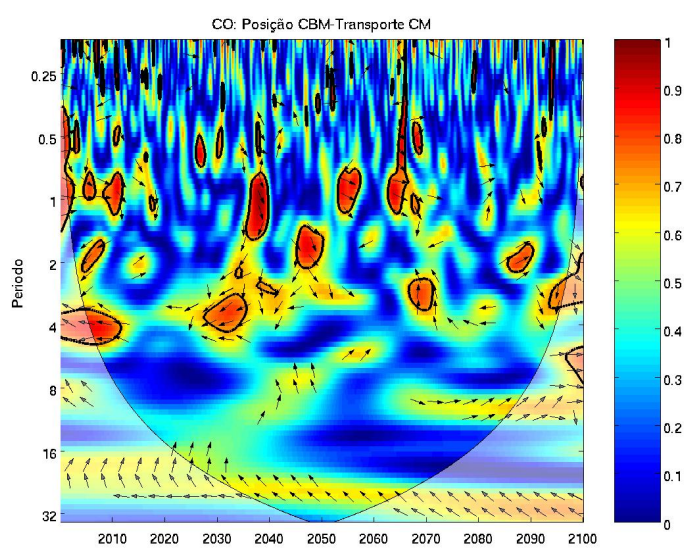

(c)

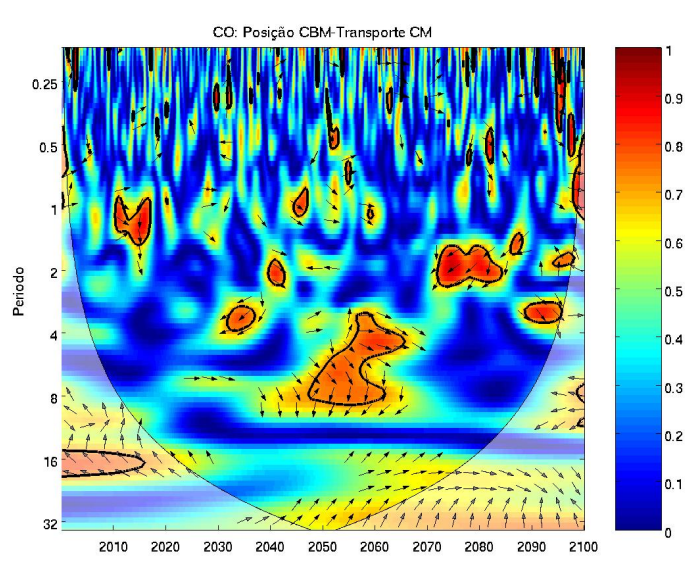

Figura 84: Coerência de ondaletas cruzadas entre a posição da CBM e o transporte da CM: (a) Século XX, (b) A1b e (c) B2. 

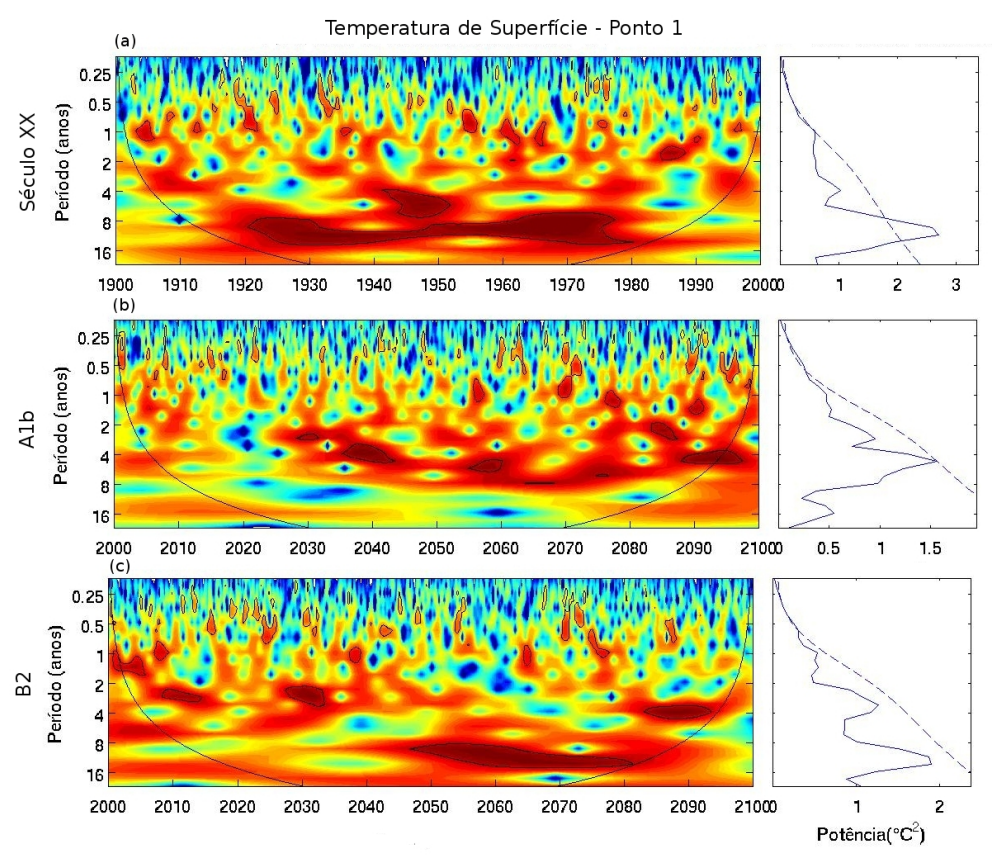

Figura 85: Espectro de Potência de Ondaletas de TSM $\left({ }^{\circ} \mathrm{C}\right)^{2}$ no ponto $1\left(40^{\circ} \mathrm{W}, 30^{\circ} \mathrm{S}\right)$ :

(a) Século XX, (b) Cenário A1b e (c) Cenário B2.

\subsubsection{Padrões de Variabilidade no Atlântico Sudoeste}

O padrão anual de salinidade e temperatura do Atlântico Sudoeste foram previamente analisados. Nessa seção serão utilizados dados de anomalias em relação à climatologia anual, descontadas suas respectivas tendências.

No ponto $1\left(40^{\circ} \mathrm{W}, 30^{\circ} \mathrm{S}\right)$, observamos que a variabilidade inter anual de TSM no século XX está fortemente atrelada à variabilidade de 8 a 10 anos, possivelmente relacionada ao Dipolo do Atlântico (Moura \& Shukla 1981) e apenas uma região de variância significativa associada ao período de 4 anos, como observamos na Figura 85.

Embora enfraquecida, essa variabilidade ainda ocorre no cenário B2 de forma significativa entre 2050 e 2080 o que não ocorre no cenário A1b onde a maior variabilidade está associada ao período de 4 anos. A TSM pode apontar para a intensificação do impacto do El Niño nos cenários de mudanças climáticas A1b e B2, sendo que este sinal quase ausente no século XX, torna-se o mais relevante no cenário A1b e o segundo maior no cenário B2.

Na Figura 86, observamos que o comportamento espectral no ponto $2\left(55^{\circ} \mathrm{W}, 45^{\circ} \mathrm{S}\right)$ é bem mais difuso. O período de variabilidade mais marcado do século XX é o de 2 

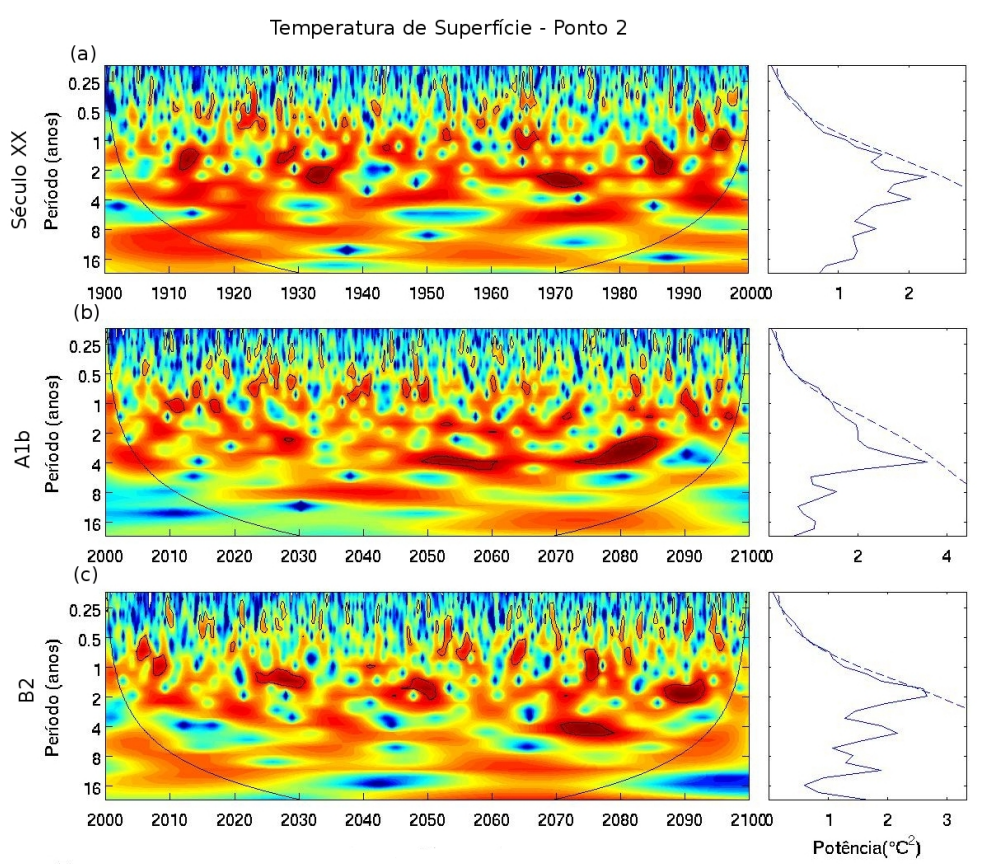

Figura 86: Espectro de Potência de Ondaletas de TSM $\left({ }^{\circ} \mathrm{C}\right)^{2}$ no ponto $2\left(55^{\circ} \mathrm{W}, 45^{\circ} \mathrm{S}\right)$ :

(a) Século XX, (b) Cenário A1b e (c) Cenário B2.
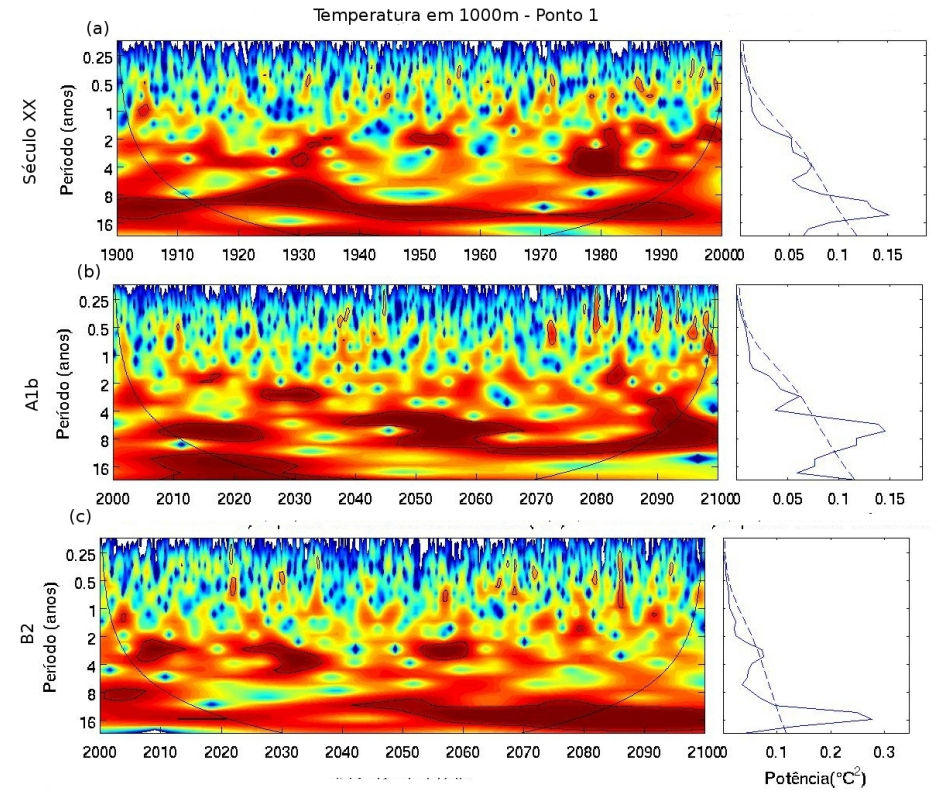

Figura 87: Espectro de Potência de Ondaletas de temperatura em $1000 \mathrm{~m}\left({ }^{\circ} \mathrm{C}\right)^{2}$ no ponto $1\left(40^{\circ} \mathrm{W}, 30^{\circ} \mathrm{S}\right)$ : (a) Século XX, (b) Cenário A1b e (c) Cenário B2. 

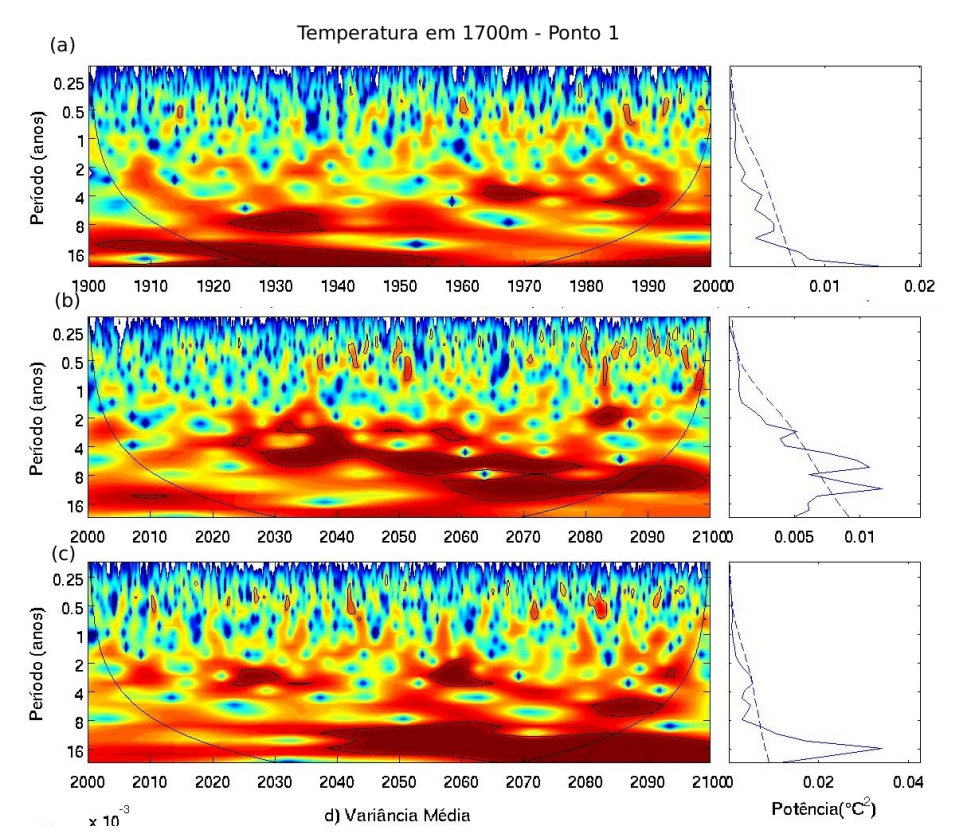

Figura 88: Espectro de Potência de Ondaletas de temperatura em $1700 \mathrm{~m}\left({ }^{\circ} \mathrm{C}\right)^{2}$ no ponto $1\left(40^{\circ} \mathrm{W}, 30^{\circ} \mathrm{S}\right)$ : (a) Século XX, (b) Cenário A1b e (c) Cenário B2.

anos, apresentando apenas 5 regiões de variabilidade significativa. No espectro global de ondaletas, observamos um segundo pico por volta dos 4 anos que não ultrapassa $2^{\circ} C^{2}$.

Ao longo do século XXI, sobretudo no cenário A1b, a variância de temperatura associada ao período reduz-se a medida que aumenta a importância do sinal de 4 anos de periodicidade, assim como no ponto 1. Em ambos os cenários observamos um evento extremo de grande energia no começo da década de 2080.

No cenário A1b grande parte da variância de TSM do Ponto 2 concentra-se no período de 4 anos, sendo maior que o dobro do que no século XX. No cenário B2 a variabilidade de período de 2 anos ainda é a maior do espectro, porém em 4 anos, observamos um aumento de potência.

A variabilidade de 2 anos também é encontrada na séries de salinidade de superfície (Figuras 89 e 90). Ao contrário do que acontece com a TSM, a variabilidade associada a esse período durante o século XX é maior que nos cenários prognósticos. No cenário A1b, o sinal de 4 anos de período é significativo espectro global de ondaletas.

No século XX, a variabilidade de SSM, no ponto 1 (domínio da CB) é marcada por uma variabilidade de baixa frequência, por volta dos 8 anos, além de um pico em 16 anos. A variabilidade de baixa frequência (além do ciclo anual já removido) é menos relevante. 
A variabilidade de 16 anos é intensamente reduzida na série do cenário B2 e desaparece do espectro global no A1b. Enquanto o cenário B2 passa a possuir um padrão espectral ainda mais difuso, sendo o único período de variabilidade relevante próximo aos 2 anos contando com apenas 3 eventos de significativa energia, o cenário A1b possui grande variabilidade nos períodos de 4 e 8 anos. Novamente, no cenário A1b, a periodicidade de 4 anos ganha relevância, bem como o período de 8 anos.

A salinidade no ponto 2, possui um padrão espectral ainda menos marcado - Figura 90. No século XX a maior variabilidade concentra-se entre 8 e 16 anos e a variabilidade nos períodos curtos é muito baixa. No cenário A1b, as variabilidades em 4 e 8 anos ganham energia, mas mesmo assim não chegam a ser estatisticamente significativas no espectro global.

No ponto 2, o cenário B2 é o que apresenta um padrão espectral mais bem definido para salinidade de superfície. As variabilidade associadas a períodos próximos a 2, 4 e 16 anos são estatisticamente relevantes e estão associadas a diversas variabilidades significativas ao longo da série temporal. O período entre 2030 e 2066 todo apresenta um padrão fortemente marcado pela variabilidade de 16 anos. A Figura 87 e 91 representam as variabilidades de temperatura e salinidade associadas a profundidade de 1000m no Ponto 1, onde prevalece a AIA.

Observamos que a variabilidade de baixa frequência domina a energia do sistema tanto no século XX quanto nos cenários A1b e B2. A variabilidade entre 8 e 16 anos é a mais intensa no século XX e possui variabilidades significativas ao longo de toda a série temporal. No cenário B2, a variabilidade associada a esse mesmo período é praticamente duplicada no espectro global. O aumento dessa variabilidade concentra-se principalmente nas últimas décadas da série temporal.

No cenário A1b, esse pico de variabilidade é deslocado para o período de 6 anos. Dessa forma, enquanto o padrão espectral da temperatura da AIA nesse ponto é intensificado no cenário B2, ele é alterado no cenário A1b, gerando variabilidades significativas que antes eram desconhecidas.

Em todas as séries, observamos também uma variabilidade relevante entre 2 e 4 anos.

Observamos também eventos extremos em 1980, presente nas outras análises de temperatura. O padrão espectral de salinidade nessa mesma profundidade está representado na Figura 91. No século XX, a variabilidade não estocástica do século XX não possui 


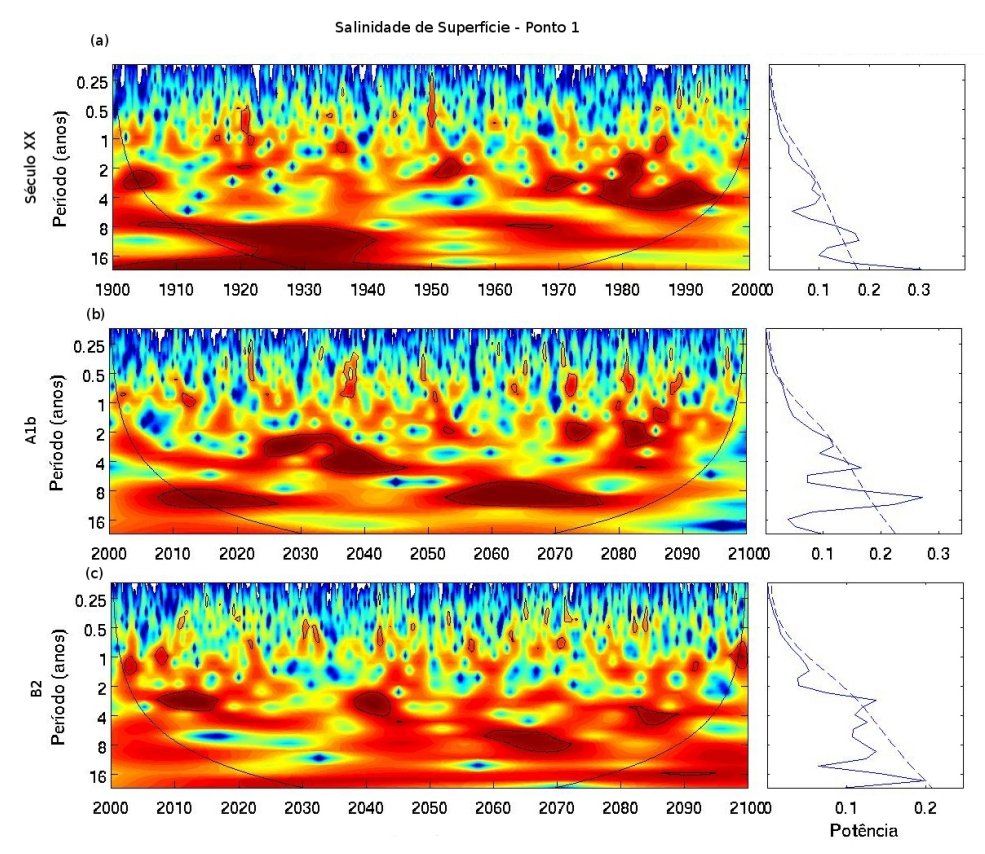

Figura 89: Espectro de Potência de Ondaletas de SSM no ponto $1\left(40^{\circ} \mathrm{W}, 30^{\circ} \mathrm{S}\right)$ : (a) Século XX, (b) Cenário A1b e (c) Cenário B2.

uma frequência dominante específica. Nesse século, a variabilidade é dividida em várias frequências, sobretudos nas mais baixas. Destacam-se os fenômenos associados ao ciclo de 16 e 4 anos.

Nos cenários de aquecimento, o padrão espectral é fortemente alterado e um padrão forte aparece entre 8 e 16 anos, concentrando grande parte da energia do sistema.

A variabilidade dominante no cenário A1b está por volta de 12 anos, enquanto que no B2, por volta dos 15 anos. Nesse último cenário, uma variabilidade por volta dos 5 anos é encontrada no espectro.

A AIA no século XXI, mostrou grande variabilidade interdecadal tanto no que se refere a salinidade quanto a temperatura.

No mesmo ponto, na profundidade de 1700m (domínio da APAN) observamos a concentração de variabilidade em baixa frequência.

No século XX, observamos um forte sinal nas menores frequências do espectro (acima de 16 anos) e um espectro bem difuso no resto dos períodos. Observamos também dois fenômenos estatisticamente significativos em 1970 e 1990 referentes ao período de 4 anos embora não seja notável essa variabilidade no espectro global de ondaletas.

No cenário A1b, a variabilidade próxima a 4 anos aparece mais pronunciada no espec- 

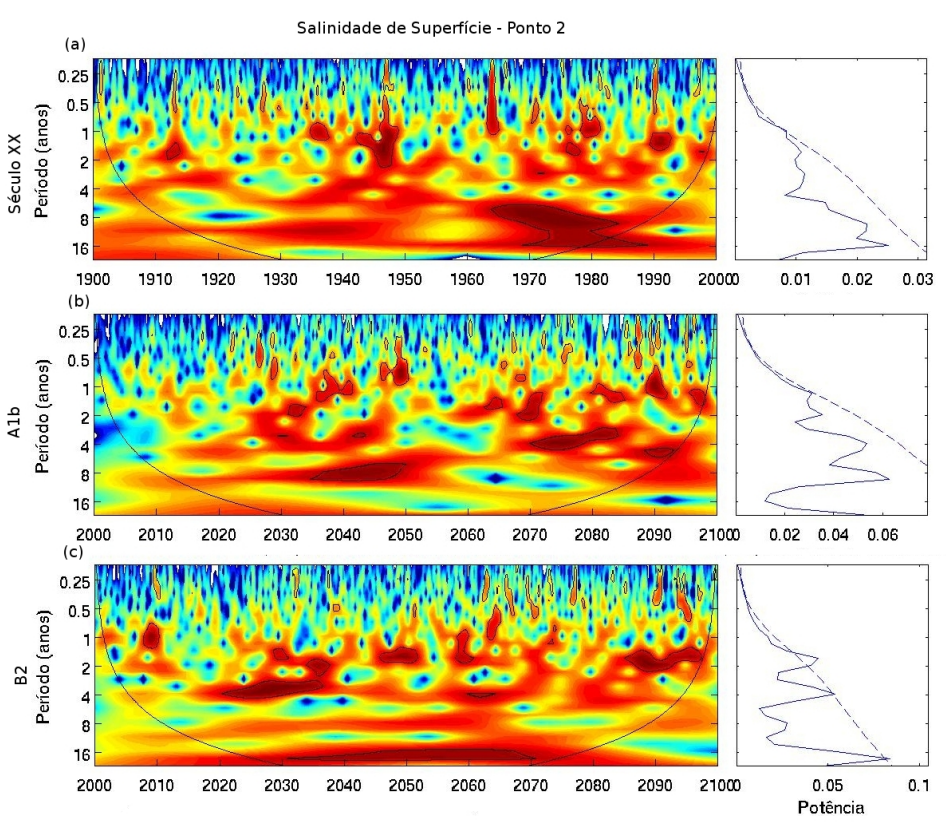

Figura 90: Análise de Ondaletas de SSM no século XX e em 2 cenários de aquecimento Global e seu respectivo espectro Global de Ondaletas no ponto $2\left(55^{\circ} \mathrm{W}, 45^{\circ} \mathrm{S}\right)$.
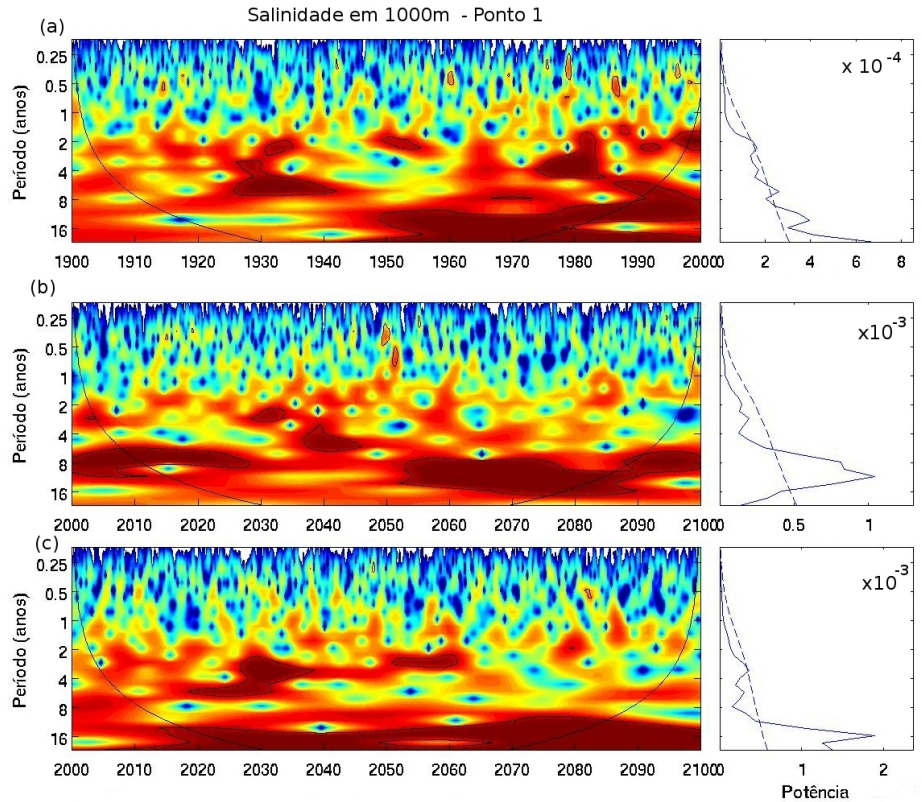

Figura 91: Espectro de Potência de Ondaletas de salinidade em 1000m no ponto 1 $\left(40^{\circ} \mathrm{W}, 30^{\circ} \mathrm{S}\right)$ : (a) Século XX, (b) Cenário A1b e (c) Cenário B2. 

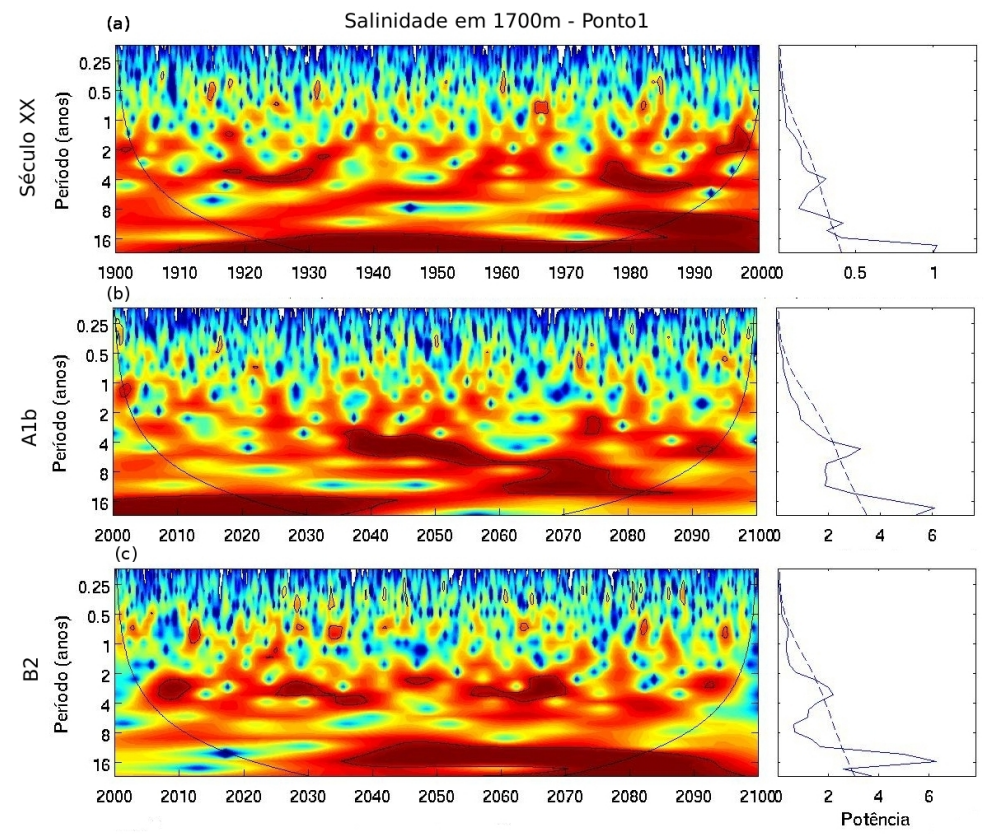

Figura 92: Espectro de Potência de Ondaletas de salinidade em 1700m no ponto 1 (40W,30S): (a) Século XX, (b) Cenário A1b e (c) Cenário B2.

tro global e outros pontos de variabilidade destacam-se no espectro: por volta de 6 e 12 anos. Ao longo do século XXI, nessa variabilidade foi intensificada.

O sinal de baixa frequência do século XX torna-se mais claro no cenário B2. A variabilidade no espectro global em 16 anos é a mais intensa entre as três séries. Observamos que a partir de 2040 esse período domina o espectro.

Por fim, a salinidade nessa profundidade não sofreu grandes alterações no seu espectro. As oscilações de baixa frequência acompanham todos os espectros, bem como uma variabilidade secundária associada ao período de 4 anos. No cenário B2, observamos a transferência de energia durante o século XXI de energia de menores períodos ( 4 anos) para mais baixas frequências. 


\section{Discussão}

Dentre os 3 modelos escolhidos (GFDL, MIROC e CCSM3), o que melhor representou a região de estudo foi o modelo japonês MIROC hires. Além de apresentar os menores erros associados ao padrão médio (sobretudo em profundidade) das variáveis hidrológicas. Em superfície, esse modelo foi o que melhor representou o padrão espacial, bem como o ciclo sazonal.

Uma forte limitação dos modelos numéricos climáticos, é sua capacidade de representar padrões além do ciclo anual. O modelo MIROC, dentre os 3 investigados, foi o que apresentou desvio padrão das anomalias relativas ao ciclo anual mais próximo ao do SODA. A tendência observada durante o Século XX nos resultados do MIROC também apresentam maior grau de consistência com relação a reanálise.

O erro quadrático médio do MIROC foi o menor para a região de estudo, com exceção da salinidade e temperatura de superfície, onde a média da região foi menor no GFDL. Esse último, apesar de obter as menores médias de erro quadrático médio em superfície, obteve os maiores valores absolutos concentrados na região da CBM.

Nas análises de massa d'água, o MIROC apresentou os índices termohalinos mais próximos do SODA, bem como suas profundidades de interface e núcleo. No entanto, nenhum resultado dos modelos analisados apresentou bons resultados no Diagrama de Taylor para nenhuma variável.

Portanto, o MIROC foi o escolhido para a análise de cenários climáticos futuros considerando que sua representação da CBM para o século 20 foi a mais realista.

Em todas as profundidades, a região da CBM mostrou-se a mais sensível ao aquecimento global do Atlântico Sudoeste nos dois cenários. O cenário A1b mostrou aumento de temperatura na CBM de até $8.5^{\circ} \mathrm{C}$ entre 2066 e 2100 enquanto que o cenário B2 observamos um aumento de até $7^{\circ} \mathrm{C}$. Esse aumento pode estar associado não só ao aumento da média da temperatura de superfície, mas também ao deslocamento da posição média da frente da CBM para Sul, como sugerido por Zavialov et al. (1999). A tendência da temperatura de superfície chega a $0.05^{\circ} \mathrm{C} /$ ano no cenário A1b na região da $\mathrm{CBM}$. Essa tendência supera em 5 vezes a tendência encontrada entre 1854 e 1999 por Zavialov et al. (1999) através de observações.

A salinidade aumentou do Equador até $45^{\circ} \mathrm{S}$. No cenário A1b, a salinidade chega a aumentar 1.2 na região da CBM e mais de 1 no cenário B2. A posição média da CBM 
quase $1^{\circ}$ mais ao sul consistentes com os aumentos locais de temperatura e salinidade. A salinidade aumentou desde o Equador até a CBM possivelmente pelo déficit de pluviosidade em relação à (eg. Nuñez et al., 2009). As águas menos salinas em altas latitudes estão associadas ao degelo e são consistentes com resultados de Pereira (2007).

Diversos estudos descrevem a diminuição da temperatura e salinidade da AIA (Wong et al. 1999) enquanto outros discutem o processo contrário (Arbic \& Owens 2001). Nesse modelo, sobretudo a temperatura dessa massa d'água aumenta sensivelmente durante o século XXI, nos dois cenários de aquecimento (A1b e B2). Em 1000m de profundidade, onde domina a presença dessa massa d'água em toda a região, observamos um aumento médio de $1.1^{\circ} \mathrm{C}$ entre 2066 e 2100 no cenário A1b e pouco menos de $1^{\circ} \mathrm{C}$ no cenário $\mathrm{B} 2$. Essa massa d'água, ao entrar no giro subtropical e retornar pela corrente do Brasil, pode apresentar ainda maior alteração, devido à contribuições do vazamento das Agulhas Lee et al. 2011). Esse efeito pode justificar a diferença entre a salinidade ao norte e ao sul da CBM. Os índices termohalinos apontam para uma grande sensibilidade da AIA em cenários de aquecimento global no que se refere à temperatura, porém a mudança de salinidade não é significativa.

Em 1700 metros, as diferenças de temperatura foram cerca de três vezes menores que em 1000m. Nessa profundidade, em boa parte da região predomina a APAN. Essa massa d'água mostrou-se menos sensível às mudanças no clima que a AIA. Embora o índice termohalino da APAN (calculado para $40^{\circ} \mathrm{W}, 30^{\circ} \mathrm{S}$ ) apresente maior salinidade no século XXI (nos dois cenários) que no século XX, grande parte da região sofre uma redução da salinidade em $1700 \mathrm{~m}$.

Os padrões diferenciados entre as propriedades físicas das águas ao sul e ao norte da CBM podem aumentar a complexa atividade de meso-escala da região (Seo \& Xie 2011) e aumentar os gradientes horizontais já intensos das propriedades físicas (sobretudo salinidade e temperatura).

Enquanto que a CM sofre pouca alteração (se comparada com seu transporte total), a CB intensifica-se consideravelmente nos cenários de aquecimento global do século XXI (0.05Sv/ano no cenário A1b e 0.03Sv/ano no cenário B2). Esse resultado contrapõe-se à tendência negativa de -0.014Sv/ano encontrada por Goni et al (2011) entre 1992 e 2009. Como resultado, a posição média da CBM desloca-se $1.3^{\circ}$ para o sul no cenário A1b e $1^{\circ}$ no cenário B2. Esse deslocamento para sul já foi documentado por outros autores 
(Zavialov et al. 1999). As tendências dos cenários A1b e B2 (-0.0125\%/ano e 0.0055\%/ano, respectivamente) da posição da CBM são comparáveis com àquela encontrada para o inverno por Zavialov et al. (1999) de 0.009\%/ano entre 1854 e 1998. Nesse estudo, a posição da CBM é determinada pela isoterma de $17^{\circ} \mathrm{C}$ em superfície que pode deslocar-se devido ao efeito do aquecimento e não somente do deslocamento da frente.

O confronto dos dados sugere que o rápido deslocamento da frente da CBM para sul está mais relacionado com o aumento do transporte da $\mathrm{CB}$, do que com outros fatores como o transporte da CM ou a variabilidade da tensão do cisalhamento do vento. Essas últimas forçantes apresentam baixa correlação com a posição da CBM (em todos os experimentos), bem como pouca correlação no espectro de ondaletas cruzadas. Esse resultado não está de acordo o estudo de Garzoli \& Giulivi(1993) que sugere que essa oscilação está relacionada com a anomalias do padrão de vento ao sul da Confluência, bem como Wainer et al. (2000). Matano et al. (1993) discutem a variabilidade gerada pelas flutuações de padrões da CB.

Nos dois cenários de aquecimento a variabilidade anual da posição da CBM é modificada, além de seu deslocamento para o sul. O padrão senoidal foi alterado e a amplitude reduzida. As análises espectrais revelaram uma forte perda de energia da variabilidade anual para outras frequências do espectro. Em ambos os cenários tanto a variabilidade intra como inter anual ganharam energia em detrimento do ciclo anual, assim como no caso nos transportes da CB e CM o que explica o padrão temporal mais difuso da posição da CBM nos cenários A1b e B2.

Os padrões espectrais de TSM, sugerem um aumento da influência do El Niño na região, sobretudo no cenário A1b. O aumento da importância da variabilidade de temperatura por volta dos 4 anos também é observado em 1000 e 1700m de profundidade, bem como nos espectros de salinidade. Nessa variável, a intensificação das variabilidades interdecadal é marcante nas profundidades analisadas. 


\section{Conclusões}

A Corrente do Brasil determina o limite oeste do giro subtropical do Atlântico Sul e estende-se desde as proximidades do Equador (por volta de $8^{\circ} \mathrm{S}$ ) até a região em que se encontra com Corrente das Malvinas chamada de Confluência Brasil-Malvinas. Essa região comporta massas d'água de propriedades físicas muito distintas e consequentemente uma dinâmica de meso e grande escala muito complexa sendo uma das mais energéticas entre todos os oceanos. Apesar de representar uma região de particular sensibilidade às mudanças climáticas atuais o comportamento futuro dessa região em cenários de aquecimento global ainda é completamente desconhecido. A descrição das mudanças no Atlântico Sudoeste em cenários futuros, bem como o comportamento da CBM é o objetivo desse trabalho.

A hipótese científica desse trabalho é que a emissão de gases estufa e as mudanças climáticas podem impactar nos parâmetros físicos no Atlântico Sudoeste. Tais impactos incluem aumento de temperatura e salinidade não só de superfície, alteração dos padrões temporais das correntes do Brasil e das Malvinas, deslocamento para o Sul da frente da CBM bem como a alteração do ciclo anual.

Para isso, foram analisadas saídas de um modelo numérico do IPCC para estimar o comportamento dessa região. Baseado em análises prévias, bem como a revisão bibliográfica foram escolhidos três resultados de modelos numéricos acoplados do $4^{\circ}$ Relatório do IPCC para as análises de cenários futuros: o GFDL, o MIROC e o CCSM3.

Comparando os modelos numéricos com os dados de reanálise global do SODA, constatamos que o padrão médio e climatológico do Atlântico Sudoeste foi representado nos três modelos. A variabilidade da tensaõ do cisalhamento do vento foi subestimada em todos os modelos, bem como a salinidade de superfície. O GFDL apresentou menor semelhança com o SODA com relação a salinidade e não foi capaz de representar a posição da CBM através da altura do nível do mar - Tabela 15. O CCSM3 apresentou diversos problemas em relação aos dados do SODA (sobretudo relacionado ao ciclo sazonal e as tendências das variáveis). O MIROC, embora tenha subestimado a variabilidade extra climatológica (tanto tendência quanto os desvios padrões), apresentou o melhor resultado em relação ao SODA tanto no padrão espacial quanto a variabilidade temporal.

O melhor desempenho do MIROC está associado não só à física do modelo, mas principalmente a maior resolução horizontal e a inclusão da descarga fluvial, já que o Rio 
da Prata desempenha um importante papel regional.

Escolhido o modelo que melhor representa a região de estudo, foram comparados os dados do Século XX com os cenários de aquecimento global A1b e B2.

O cenário A1b contempla um dos cenários mais extremos em termos de emissão de gases estufas, enquanto que o cenário B2 apresenta uma das menores emissões de carbono do relatório do IPCC. Na Tabela 5 observamos que a emissão de óxidos de carbono no cenário A1b é 120\% maior que no cenário B2. De forma geral, os dois cenários responderam da mesma forma às mudanças do clima, sendo os valores associados ao cenário A1b mais intensos.

Como esperado, a superfície mostrou-se mais sensível às mudanças climáticas observadas nos cenários A1b e B2, sobretudo na região da CBM. Em superfície, o aumento de temperatura média foi $25 \%$ maior no cenário A1b até os $30^{\circ} \mathrm{S}$ e $13 \%$ entre 30 e $45^{\circ} \mathrm{S}$ e de $21 \%$ entre 45 e $60^{\circ} \mathrm{S}$. Assim, a região da CBM foi a que apresentou maiores alterações da temperatura média, mas a menor diferença percentual entre os cenários. Na salinidade essa diferença não foi tão clara, já que observamos fortes contrastes de aumento e decréscimo de salinidade na região, mas as alterações mais notáveis em superfície (com exceção de extremos pontuais próximos a costa na região da CBM) foram encontradas em baixas latitudes onde a salinidade aumentou em mais de 0.5.

Em 1000m, a temperatura novamente se destacou pela maior aumento em ambos os cenários. Tanto no A1b quanto B2. a média da temperatura superou $1^{\circ} \mathrm{C}$. A diferença média da salinidade não ultrapassou 0.01 em toda a região. A profundidade de $1700 \mathrm{~m}$ apresentou menor suscetibilidade em relação a 1000m. Como boa parte dessa região é dominada pela APAN, essa região pode demorar mais para responder a mudanças climáticas, já que a região de formação dessa massa d'água é mais distante.

Como consequência, os índices termohalinos das três massas d'água analisadas (AT, AIA e APAN) foram alterados. Na AT, o índice termohalino sofreu grande alteração, sobretudo de temperatura. Na média do século XX, o índice encontrado para essa massa d'água era de $17.7^{\circ} \mathrm{C}$ e 35.5. Entre 2066 e 2100 esse índice sobre para $20.1^{\circ} \mathrm{C}$ e 35.75 no cenário A1b e para $19.8^{\circ} \mathrm{C}$ e 35.7 no cenário B2 - Tabelas 8 e 20. O índice da AIA, mostrou-se muito sensível às mudanças climáticas nos cenários A1b e B2, elevando-se de $4.3^{\circ} \mathrm{C}$ no século XX para $7^{\circ} \mathrm{C}$ e $6^{\circ} \mathrm{C}$ nos cenários A1b e B2. respectivamente. A salinidade, sofreu pouca alteração (34.05 e 34.1 entre 2066 e 2100 nos cenários A1b e B2 ante a 34.1 no 
século XX). A manutenção da salinidade do índice termohalino (em $40^{\circ} \mathrm{W}, 30^{\circ} \mathrm{S}$ ) apesar da redução da salinidade na região de formação dessa massa d'água pode estar associado à porção recirculante da AIA que entra no giro subtropical e recebe contribuição de sal do vazamento das Agulhas. A APAN sofreu menores alterações nos índices termohalinos (de $2.8^{\circ} \mathrm{C}$ no século XX para $3^{\circ} \mathrm{C}$ em ambos os cenários e de 34.9 para 34.82 no cenário A1b e 34.85 no cenário B2).

O padrão de TSM em ambos nos pontos $1\left(40^{\circ} \mathrm{W}, 30^{\circ} \mathrm{S}\right)$ e $2\left(45^{\circ} \mathrm{W}, 45^{\circ} \mathrm{S}\right)$, observamos uma intensificação da importância da variabilidade em 4 anos. No cenário A1b, a potência associada a essa variabilidade (pouco significativa no século XX) praticamente dobra e aumenta por volta de 30\% no cenário B2. A salinidade também teve seu padrão espectral alterado, concentrando energia principalmente em baixa frequência.

A posição média da CBM foi deslocada para Sul em ambos os cenários (sendo deslocada em aproximadamente $1.1^{\circ}$ de latitude no cenário A1b e 0.9 no cenário B2 entre 2066 e 2100). A tendência dessa posição foi $70 \%$ no cenário A1b em relação ao século XX e 38\% maior no cenário B2. A energia do espectro de potencia associada à variabilidade anual foi reduzida pela metade no cenário A1b e praticamente mantida no B2. A variabilidade de baixa frequência ganhou importância nesses cenários, sobretudo por volta dos 4, 8 e 16 anos.

A tendência de deslocamento para o sul da CBM, condiz com o aumento do transporte da CB. A correlação entre essas duas variáveis foi de 36\% no cenário B2 e de 39\% no cenário A1b, ante a 29\% no século XX. Assim, o deslocamento da posição média da CBM deve estar associado à intensificação da CB, hipótese também sugerida pela similaridade entre os espectros de potências dessas duas variáveis, bem como a forte correlação (sobretudo na variabilidade anual) no espectro cruzado de ondaletas (Figura 83) que não acontece com a CM. Assim, a variabilidade anual da CBM passa a não ser o mais importante no cenário A1b, e o ciclo sazonal não é tão claro. A amplitude da média climatológica da posição da CBM é reduzida em ambos os cenários e a variabilidade inter anual (que representa aproximadamente $50 \%$ do espectro) passa a dominar mais de $70 \%$ do espectro de potência global no cenário A1b e $60 \%$ no B2.

Assim, a hipótese científica é verdadeira já que os padrões temporais e espaciais, bem como as médias na região foram alteradas nos cenários de aquecimento global. A posição média da CBM foi deslocada para sul e sua média climatológica alterada. O 
comportamento do Atlântico Sudoeste responde de forma sensível e complexa às alterações no clima.

Portanto, de fato a estrutura espaço-temporal da CBM foi modificada. Os impactos que isso possa ter no clima regional será alvo de investigações futuras. 


\section{Referências}

Acevedo, O. C., L. P. Pezzi, R. B. Souza, \& V. Anabor, 2010:. Atmospheric boundary layer adjustment to the synoptic cycle at the Brazil-Malvinas Confluence, South Atlantic Ocean. J. Geophys. Res. 115(D22107), 1-12.

Arbic, B. \& W. Owens, 2001: Climatic warming of Atlantic intermediate waters. J. Clim., 14, 1081-1095.

Bakun, A., 1990:. Global climate change and intensification of coastal ocean upwelling. Science, 247, 198-201.

Bianchi, A. A., C. F. Giulivi, \& A. R. Piola, 1993: Mixing in the Brazil Malvinas Confluence. Deep Sea Res. 40(7), 1345-1358.

Bianchi, A. A., D. R. Pino, H. G. I. Perlender, A. P. Osiroff, V. Segura, V. Lutz, M. L. Clara, C. F. Balestrini, \& A. R. Piola, 2009:. Annual balance and seasonal variability of sea-air $\mathrm{CO}_{2}$ fluxes in the Patagonia Sea: Their relationship with fronts and chlorophyll distribution. J. Geophys. Res. 114(C03018).

Bigg, G. R., T. D. Jickells, P. S. Liss, \& T. J. Osborn, 2003:. The role of the oceans in climate. Int. J. Climatol., 23, 1127-1159.

Broecker, W. C. \& T. F. Stocker, 2006:. The holocene $\mathrm{CO}_{2}$ rise: anthropogenic or natural? EOS 87(3), 27-29.

Broecker, W. S., 1997:. Thermohaline circulation, the Achilles heel of our climate system: Will man-made $\mathrm{CO}_{2}$ upset the the current balance? Science, 278, 1582-1588.

Bryan, F. O., G. Danabasoglu, N. Nakashiki, D. H. Kim, J. Tsutsui, \& S. C. Doney, 2006: Response of the North Atlantic thermohaline circulation and ventilation to increasing carbon dioxide in CCSM3. J. Clim., 19, 2382-2397.

Bryden, H. L., H. R. Longworth, \& S. A. Cunninghan, 2005:. Slowing of the Atlantic Meridional Overtuning Circulation at $25^{\circ}$ N. Nature, 438, 655-657.

Cane, M., A. Clement, A. Kaplan, Y. Kushnir, D. Podynyakov, R. Seager, S. Zebiak, \& R. Murtuguddenatuer, 1997: Twentieth-century sea surface temperature trends. Science 275(5302), 957-960.

Carton, J., G. Chepruin, X. Cao, \& B. Giese, 2000:. A Simple Ocean Data Assimilation Analysis of the global upper ocean 1950-95. Part 1: Methology. J. Phys. 
Oceanogr., 30, 294-309.

Carton, J., G. Chepurin, X. Cao, \& B. Giese, 2000b:. A Simple Ocean Data Assimilation Analysis of the global upper ocean 1950-95. Part 2: Results. J. Phys. Oceanogr., 30, $311-326$.

Carton, J. \& B. Giese, 2007:. A reanalysis of ocean climate using SODA. Mon. Weather Rev., 13, 1664-1673.

Chelton, D. B., M. G. Schlax, D. L. Witter, \& J. G. Richman, 1990:. Geosat altimeter observations of the surface circulation of the southern ocean. J. Geophys. Res., 95, $17877-17903$.

Ciotti, C. M., C. Odebrecht, \& G. Fillmann, 1995:. Freshwater outflow and Subtropical Convergence influence on phytoplankton biomass in the southern Brazilian continental shelf. Cont. Shelf Res. 15(14), 1737-1756.

Crowley, T., 2000: Causes of climate change over the past 1000 years. Science 289(5477), 270-277.

Crueger, T., E. Roeckner, T. Raddatz, R. Schnur, \& P. Wetzel, 2008:. Ocean dynamics determine the response of oceanic $\mathrm{CO}_{2}$ uptake to climate change. Clim. Dyn., $\mathbf{3 1}$, $151-168$.

da Silveira, I. C. A. \& W. S. Brown, 2000:. Dynamics of the North Brazil Current retroflection region from the WESTRAX observations. Journal of Geophysical Research, 12, 28559-28584.

da Silveira, I. C. A., L. Calado, B. M. Castro, M. Criano, J. A. M. Lima, \& A. S. Mascarenhas, 2004:. On the baroclinic structure of the Brazil Current-Intermediate Western Boundary Current at $22^{\circ}-23^{\circ}$ S. Geophysical Research Letters 31(LI), 4308. da Silveira, I. C. A., G. R. Fierl, \& W. S. Brown, 1999:. Dynamics of separating Western Boundary Currents. J. Phys. Oceanogr., 29, 129-144.

da Silveira, I. C. A., A. C. K. Schmidt, E. J. D. Campos, S. S. Godoi, \& Y. Ikeda, 2000:. A Corrente do Brasil da Costa Leste Brasileira. Rev. bras. oceanogr. 48(2), $171-183$.

De Ruijter, W., P. van Leeuwen, W. Weijer, A. Biastoch, J. R. E. Lutjeharms, R. Matano, \& T. Pichevins, 1999:. Indian-Atlantic interocean exchange - dynamics, esti- 
mation and impact. J. Geophys. Res. 104(C9), 20-885.

Delworth, T. L. \& T. R. Knutson, 2000:. Simulation of early 20th century global warming. Science, 287, 2246-2250.

Depetris, P. J. \& J. E. Paolini, 1991:. Biogeochemistry of Major World Rivers, Chapter Biogeochemical aspects of south American rivers: The Paraná and the Orinoco., pp. 105-122. Scope42.

Dixon, K. W., T. L. Delworth, M. J. Spelman, \& R. J. Stouffer, 1999:. The influence of transient surface fluxes on North Atlantic overtuning in a coupled dcm climate change experiment. Geophys. Res, Lett., 26, 2749-2752.

Etheridge, D. M., L. P. Steele, R. L. Langenfelds, \& R. J. Francey, 1996:. Natural and anthropogenic changes in atmospheric $\mathrm{CO}_{2}$ over the last 1000 years from air in Antartic ice and firn. J. Geophys. Res. 101(D2), 4115-4128.

Ferreira, M. B., 2010:. Observação da variação espectral e posicional da Frente BrasilMalvinas por sensoriamento remoto. Tese de Doutorado, Instituto Oceanográfico da Universidade de São Paulo.

Ferrero, B., 2009:. Estudo comparativo da estrutura e variabilidade das massas de água a partir das simulações numéricas do 4AR/IPCC. Tese de Mestrado, Instituto Oceanográfico da Universidade de São Paulo.

Fisher, A., 1964:. The circulation and stratification of the Brazil Current. Tese de Mestrado, New York University., New York.

Garfield, N., 1988:. Surface characteristics of the Brazil Current. EOS 69(44), 1237.

Garfield, N., 1990:. The Brazil Current at subtropical latitudes. Tese de Doutorado, University of Rhode Island.

Garzoli, S. \& C. Giulini, 1994:. What forces the variability of the Southwestern Atlantic boundary currents. Deep Sea Res., 41, 1527-1550.

Garzoli, S. L., 1993:. Geostrophic velocity and transport variability in the BrazilMalvinas Confluence. Deep Sea Res. 40(7), 1379-1403.

Garzoli, S. L. \& A. Bianchi, 1987:. Time-space variability of the local dynamics of the Malvinas-Brazil Confluence as revealed by inverted echo sounders. J. Geophys. Res., 92, 1914-1922. 
Gates, P., 1993:. Climate change and its biological consequences. Massachusetts: Sinauer Associates.

Giarolla, E., 1999:. Investigação numérica da variabilidade de mesoescala na Confluência Brasil-Malvinas induzida pela atmosfera. Tese de Mestrado, Instituto Oceanográfico da Universidade de São Paulo.

Gille, S. T., 2002:. Warming of the Southern Ocean since the 1950s. Science 295(1275), $1275-1277$.

Goni, G. \& I. Wainer, 2001:. Investigation of the Brazil Current front variability from altimeter data. J. Geophys. Res. $106(31), 128$.

Gordon, A. L., 1986:. Inter-ocean exchange of Thermocline Water. J. Geophys. Res., 91, $5037-5046$.

Gordon, A. L., 1989:. Brazil-Malvinas Confluence - 1984. Deep Sea Res. 36(3), 359-384.

Gordon, A. L. \& C. L. Greengrove, 1986: Geostrophic circulation of the Brazil-Falkland Confluence. Deep Sea Res., 33, 573-585.

Gregory, J. M., 2005: A model intercomparison of changes in the Atlantic Termohaline Circulation in response to increasing atmospheric $\mathrm{CO}_{2}$ concentration. Geophys. Res, Lett., 32, 12703-12710.

Guemas, V. \& D. Salas-Mélia, 2007:. Simulation of the Atlantic Meridional Overtuning Circulation in an atmosphere-ocean global coupled model. Part I: a mechanism governing the variability of the ocean convection in a preindustrial experiment. Clim. Dyn, 10, 525-531.

Hansen, B., W. R. Turrell, \& S. Osterhus, 2001:. Decreasing overflow from the Nordic Seas into the Atlantic Ocean through the Faroe Bank channel since 1950. Nature, 21, 927-930.

Hasumi, H. \& S. Emori, 2004:. K-1 coupled model (MIROC) description. Tech. rep., 1, 34.

Houghton, J. T., 1995:. Climate Change - The science of climatic change. Cambridge Univ. Press.

IPCC, 2001:. IPCC special reports on climate change - complete online versions. 
IPCC, 2007, June). 4th Assesment Report from Intergovernmental Panel on Climate Change.

Latif, M., E. Roeckner, U. Mikolajewics, \& R. Voss, 2000:. Tropical stabilization of the Thermohaline Circulation in a greenhouse warming simulation. J. Clim., 13, $1808-1813$.

Lee, S., W. Park, E. [van Sebille], M. O. Baringer, C. Wang, D. B. Enfield, S. G. Yeager, \& M. P. Kirtman, 2011:. What caused the significant increase in Atlantic Ocean heat content since the mid 20th century? Geophys. Res. Let., 38, 17607.

Legeckis, R. \& A. L. Gordon, 1982:. Satellite observations of the Brazil and Falkland currents - 1975 to 1976 and 1978. Deep Sea Res. 29(3A), 375-401.

Lentini, C. A. D., D. B. Olson, \& G. Podestá, 2002:. Statistics form the Brazil Current rings observed in the confluence region observed from AVHRR: 1993 to 1998. J. Geophys. Res. 29(16), 1-17.

Levitus, S., 1984:. Annual cycle of temperature and heat storage in the World Ocean. J. Phys. Oceanogr., 14, 727-746.

Levitus, S., J. I. Antonov, T. P. Boyer, \& C. Stephens, 2000:. Warming of the world ocean. Science 287(5461), 2225-2229.

Maamaatuaiahutapu, K., V. C. Garcon, C. Provost, M. Boulahdid, \& A. P. A. P. Osiroff, 1992:. Brazil-Malvinas Confluence - water mass composition. J. Geophys. Res., 97, 9493-9505.

Mamayev, O. I., 1975:. Temperature-Salinity analisys of world ocean waters. Elsevier Scientific Publishing Company.

Manabe, S. R. \& R. Stouffer, 1994:. Multiple-century response of a coupled oceanatmosphere model to an increase of atmospheric carbon-dioxide. J. Clim., 7, 5-23.

Matano, R. P., M. G. Schilax, \& D. B. Chelton, 1993:. Seasonal variability in the Southwestern Atlantic. J. Geophys. Res. 98(C10), 18,027-18,035.

McCabe, G. J., M. Clark, \& M. Serreze, 2001:. Trends in Northern Hemisphere surface cyclone frequency and intensity. J. Clim. 14(12), 2763-2768.

Miranda, L. B. \& B. M. Castro Filho, 1982:. Geostrophic flow conditions of the Brazil Current at $19^{\circ} \mathrm{S}$. Cien. Interam., 22, 44-48. 
Moura, A. \& J. Shukla, 1981:. On the dynamics of droughts in Northeast Brazil: observations,theory and numerical Experiments with a General Circulation Model. J. Atmos. Sci. 38(12), 2653-2675.

Nuñez, M. N., S. A. Solman, \& M. F. Cabré, 2009:. Regional climate change experiments over southern South America. II: Climate change scenarios in the late twenty first century. Clim. Dyn., 32, 1081-1095.

Olson, D. B., G. P. Podesta, R. H. Evans, \& O. B. Brown, 1988:. Temporal variations in teh separation of Brazil and Malvinas currents. Deep Sea Res. 35 (12), 1971-1990.

Peltier, W. R. \& A. M. Tushingham, 1989:. Global sea level rise and the greenhouse effect: might they be connected? Science, 244, 806-810.

Pereira, J., 2007:. Influência do Gelo Marinho Antártico no Setor Austral e Sudoeste do Atlântico Sul. Tese de Doutorado, Instituto Oceanográfico da Universidade de São Paulo.

Peterson, R. G., 1992:. The boundary currents in the western Argentine Basin. Deep Sea Res., 39, 623-644.

Peterson, R. G. \& L. Stramma, 1991: Upper-level circulation in the South Atlantic Ocean. Prog. Oceanog., 26, 1-73.

Pezzi, L. P. \& I. F. A. Cavalcanti, 2001:. The relative importance of ENSO and tropical Atlantic sea surface temperature anomalies for seasonal precipitation over South America: a numerical study. Clim. Dyn., 17, 205-212.

Pezzi, L. P., R. B. Souza, M. S. Dourado, C. A. E. Garcia, M. M. Mata, \& M. A. F. Silva-Dias, 2005:. Ocean-atmosphere in situ observations at the Brazil-Malvinas Confluence region. Geophys. Res. Let., 32, 1-4.

Piola, A. R., E. J. D. Campos, O. O. Möller-Jr, M. C. Charo, \& C. Martinez, 2000:. Subtropical Shelf Front off eastern South America. J. Geophys. Res., 105, 6565-6578.

Piola, A. R. \& A. L. Gordon, 1989:. Intermediate waters in the Southwest-Atlantic. Deep Sea Res. 36(1), 1-16.

Polito, P. S. \& O. T. Sato, 2008:. Global inter annual trends and amplitude modulations of the sea surface height anomaly form the TOPEX/Jason-1 altimeters. J. Clim., 21, $2824-2834$. 
Provost, C., V. Garçon, \& L. M. Falcon, 1996:. Hydrographic conditions in the surface layers over the slope-open ocean transition area near the Brazil-Malvinas Confluence during austral summer 1990. Cont. Shel. Res. 16(2), 215-235.

Provost, C., O. Garcia, \& V. Gargon, 1992:. Analysis of sea surface temperature time series in the Brazil-Malvinas currents confluence region: dominance of annual and semiannual periods. J. Geophys. Res., 97, 17841-17858.

Provost, C. \& P. Traon, 1993: Spatial and temporal scales in altimetric variability in teh Brazil-Malvinas Current confluence region: Dominance of the semiannual period and large spatial scales. J. Geophys. Res. 98(C10), 18,037-18,051.

Reid, J. L., W. D. Nowln, \& W. C. Patzert, 1977:. On the characteristics and circulation of the Southwestern Atlantic Ocean. J. Phys. Oceanogr., 7, 62-91.

Roemmich, D., 1983:. The balance of geostrophic and Ekman transport in the tropical Atlantic Ocean. J. Phys. Oceanogr., 13, 1534-1539.

Russell, J. L., K. W. Dixon, G. J. Stouffer, \& J. R. Toggweiler, 2006:. The Southern Hemisphere Westerlies in a warming world: Propping open the door to the deep ocean. J. Clim., 19, 6382.

Russell, J. L., R. J. Stouffer, \& K. W. Dixon, 2007:. Intercomparison of the Southern Ocean circulations in IPCC coupled model control simulations. J. Clim. 19(16), 4287.

Sarmiento, J. L. \& N. Gruber, 2002:. Sinks of anthropogenic carbon. Phys. Today, 55, $30-36$.

Schmittner, A., M. Latiff, \& B. Schneider, 2005:. Model projections of the North Atlantic Termohaline Circulation for the 21st century assessed by observations. Geophys. Res. Lett., 32, 564-572.

Seo, H. \& S. Xie, 2011:. Response and impact of equatorial ocean dynamics and tropical instability waves in the tropical Atlantic under global warming: A regional coupled downscaling study. J. Geophys. Res., 116, C03026.

Smith, L., E. Chassignet, \& D. Olson, 1994:. Wind-force variations in the BrazilMalvinas Confluence region as simulated in a course resolution numerical model of the South Atlantic. J. Geophys. Res., 99, 5095-5117. 
Spadone, A., N. Barre, F. Stoehr, \& C. Provost, 1992:. Variability of the Brazil-Malvinas Current transport. Geophys. Res. Abs., 8, 02947.

Steffen, W., P. J. Crutzen, \& J. R. McNeil, 2007:. The Anthropocene: Are humans now overwhelming the great foces of nature? AMBIO 36(8), 614-621.

Stommel, H., 1948:. The westward intensification of wind-driven ocean currents. Trans. Amer. Geophys., 29, 202-206.

Stommel, H., 1957:. A survey of ocean current theory. Deep Sea Res., 4, 149-184.

Stommel, H., 1965:. The Gulf Stream: A physical and dynamical description. Univ. Calif. Press.

Stramma, L., 1989:. The Brazil Current transport south of $23^{\circ}$ S. Deep Sea Res., 36, $639-646$.

Stramma, L., Y. Ikeda, \& R. G. Peterson, 1991:. Geostrophic transport in the Brazil Current region north of $20^{\circ}$ S. Deep Sea Res. 37(12), 1875-1886.

Stramma, L. \& R. G. Peterson, 1990:. The South Atlantic Current. J. Phys. Oceanogr., 20, 846-859.

Sverdrup, H., M. W. Johnson, \& R. H. Fleming, 1942:. The Oceans: their physics, chemistry and general biology. (1 ed.). Prentice-Hall, Inc.

Takahashi, T., S. C. Sutherland, \& R. Wanninkhof, 2009:. Climatological mean and decadal change in surface ocean $\mathrm{pCO}(2)$, and net sea-air $\mathrm{CO}(2)$ flux over the global oceans. Deep Sea Res., 56, 554-557.

Taylor, K., 2001:. Summarizing multiple aspects of model performance in a single diagram. J. Geophys. Res, 106, 7183-7192.

Thorpe, R. B., J. M. Gregory, T. C. Johns, R. A. Wood, \& J. F. B. Mitchell, 2001: Mechanism determining the Atlantic Thermohaline Circulation rensponse to greenhouse gas forcing in a non-flux adjusted coupled climate model. J. Clim., 14, $3102-3116$.

Vellinga, M. \& R. Wood, 2002:. Global climatic impacts of a colapse of the Atlantic Thermohaline Circulation. Clim. Change, 54, 251-267.

Vivier, F. \& C. Provost, 1999:. Direct velocity measurements in the Malvinas Current. J. Geophys. Res., 104, 21083-21103. 
Wagner, R. G., 1996:. Mechanisms controlling variability of the interhemispheric sea surface temperature gradient in the tropical Atlantic. J. Clim. 9(7), 2010-219.

Wainer, I., P. Gent, \& G. Goni, 2000:. Annual cycle of the Brazil-Malvinas confluence region in the National Center for Atmospheric Research Climate System Model. J. Geophys. Res. 105 (C11), 26,167-16,177.

Wainer, I., A. Taschetto, B. Otto-Bliesner, \& E. Brady, 2004:. A numerical study of greenhouse gases on the South Atlantic ocean climatology. Clim. Change, 31, 151168.

Wigley, T. M. \& S. Raper, 1987:. Thermal expansion of sea water associated with global warming. Nature, 247, 127-131.

Wong, A. P. S., N. L. B. NL, \& J. A. Church, 1999:. Large-scale freshening of intermediate waters in the Pacific and Indian oceans. Nature, 400, 440-443.

Wüst, G., 1935:. Schichtung und zirukation des Atlantischen Ozeans. Die stratosphare des Atlantischen Ozeans. Wiss. Ergebn. Deutsch.Atlant. Exp., 6, 109-228.

Zavialov, P. O., I. Wainer, \& J. M. Absy, 1999:. Sea surface temperature variability off southern Brazil and Uruguay as revealed from historical data since 1854. J. Geophys. Res., 104, 21021-21032.

Zyryanov, V. N. \& D. N. Severov, 1979:. Water circulation in the Falkland-Patagonia region and its seasonal variation. Oceanology, 19, 518-522. 